\title{
WestVirginiaUniversity
}

THE RESEARCH REPOSITORY @ WVU

Graduate Theses, Dissertations, and Problem Reports

2012

\section{Comparison of LTPP-Bind V3.1 and MEPDG for the Selection of Binder Grades}

Jennifer Bustos Rios

West Virginia University

Follow this and additional works at: https://researchrepository.wvu.edu/etd

\section{Recommended Citation}

Bustos Rios, Jennifer, "Comparison of LTPP-Bind V3.1 and MEPDG for the Selection of Binder Grades" (2012). Graduate Theses, Dissertations, and Problem Reports. 159.

https://researchrepository.wvu.edu/etd/159

This Thesis is protected by copyright and/or related rights. It has been brought to you by the The Research Repository @ WVU with permission from the rights-holder(s). You are free to use this Thesis in any way that is permitted by the copyright and related rights legislation that applies to your use. For other uses you must obtain permission from the rights-holder(s) directly, unless additional rights are indicated by a Creative Commons license in the record and/ or on the work itself. This Thesis has been accepted for inclusion in WVU Graduate Theses, Dissertations, and Problem Reports collection by an authorized administrator of The Research Repository @ WVU. For more information, please contact researchrepository@mail.wvu.edu. 


\title{
Comparison of LTPP-Bind V3.1 and MEPDG for the Selection of Binder Grades
}

\author{
Jennifer Bustos Rios \\ Thesis submitted to the \\ Benjamin M. Statler College of Engineering and Mineral Resources \\ at West Virginia University \\ in partial fulfillment of the requirements for the degree of \\ Master of Science \\ in Civil Engineering
}

Dr. John P. Zaniewski, Committee Chairperson

Dr. John Quaranta, P.E.

Dr. Avinash Unnikrishnan,

Morgantown, West Virginia

2012

Keywords: Flexible Pavement, Pavement Structure Design, Asphalt Binder, MEPDG 


\begin{abstract}
Comparison of LTPP-Bind V3.1 and MEPDG for the Selection of Binder Grades

Jennifer Bustos Rios

Binders for five analysis locations and two pavement designs were selected using the LTPPBind V3.1 software. The recommended binders were then refined to meet realistic constraints of pavement construction in West Virginia. The performance of pavements with the selected binders, pavement structures and analysis locations was predicted using MEPDG. For the range of conditions evaluated in this study, the performance predictions of MEPDG were not sensitive to the binder selection. The materials models used in MEPDG for a Level 3 analysis were examined to assess why the predicted pavement performance was not sensitive to binder selection.
\end{abstract}




\section{ACKNOWLEDGEMENTS}

I would like to thank my advisor, Dr. John P. Zaniewski. I thank for his unconditional help and guidance in the whole process of my graduate studies, by always keeping the motivation to continue and succeed.

I would like to thank my Advisory and committee members Dr. John P. Zaniewski, Dr. John Quaranta and Thomas Medvick, PE. for their support in the evaluation.

Lastly, I want to thank my daughter, husband, mother, siblings and friends for their unconditional support and encouragement during my years of life and study in USA. 


\section{TABLE OF CONTENTS}

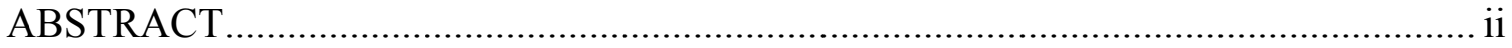

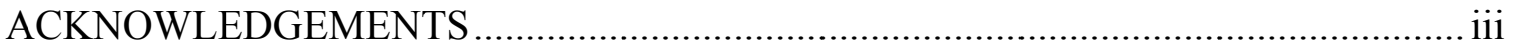

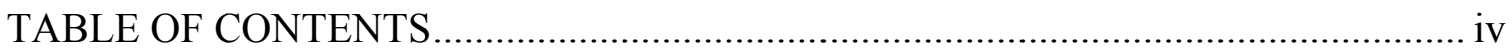

LIST OF FIGURES …….................................................................................... vii

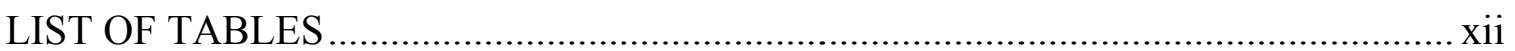

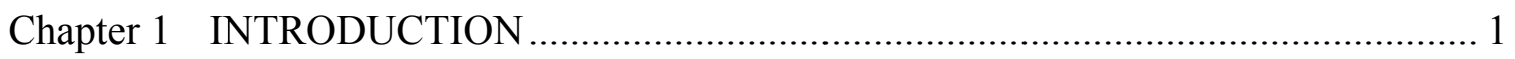

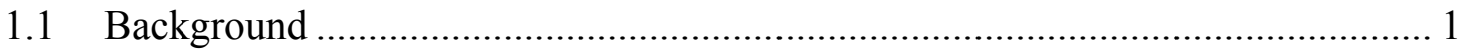

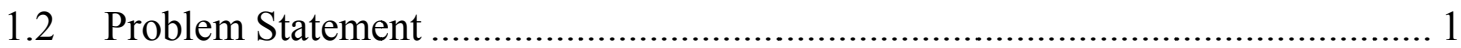

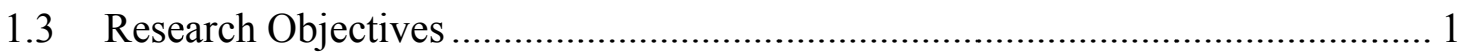

1.4 Scope and Limitations ................................................................................. 1

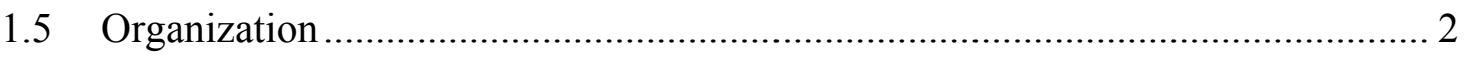

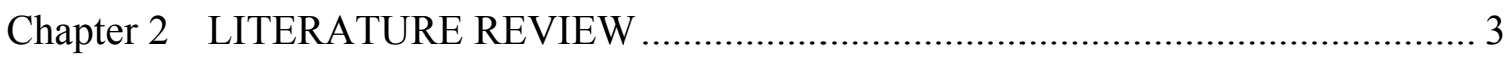

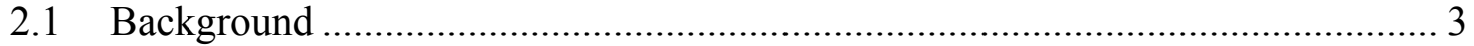

2.2 Studies for Selecting Asphalt Binders............................................................. 3

2.2.1 University of Wisconsin Madison 3

2.2.2 The Virginia Transportation Research Council 4

2.2.3 Georgia Department of Transportation 4

2.2.4 Minnesota Department of Transportation 4

2.2.5 Other Studies 5

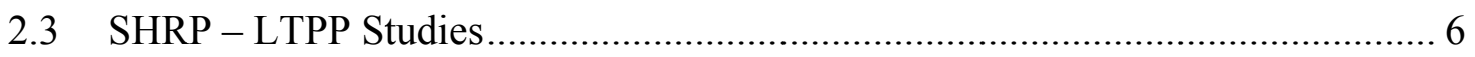

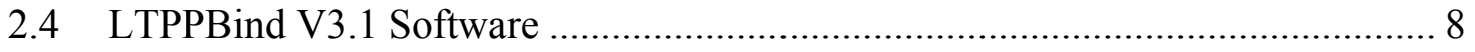

2.4.1 Weather Stations 9

2.4.2 Pavement Temperature Analysis 9

2.4.3 Traffic Adjustment 11

2.4.4 Depth Adjustment 12

$\begin{array}{lll}2.4 .5 & \text { Reliability } & 13\end{array}$

2.4.6 Comparison to previous version of LTPPBind 13

2.5 Mechanistic-Empirical Pavement Design Guide MEPDG ……......................... 13

2.5.1 Principles of the Mechanistic Procedure 15

2.5.2 Hierarchical Design Input in MEPDG 15 
$\begin{array}{lll}\text { 2.5.3 Traffic } & 16\end{array}$

$\begin{array}{lll}\text { 2.5.4 Climate } & 18\end{array}$

2.5.5 Response Model in the Design of Flexible Pavements 19

2.5.6 Pavement Performance 19

2.5.7 Distress Prediction Equations for Design of Flexible Pavements 20

2.5.8 Material Properties 26

2.5.9 Viscosity of Asphalt Binder 28

2.5.10 Developing of the Master Curve for Asphalt Concrete 30

Chapter 3 RESEARCH METHODOLOGY ……………………………………....... 34

3.1 Selection of the Pavement Structures................................................................ 34

3.2 Selection of climatic zones in West Virginia ..................................................... 34

3.3 Determination of asphalt binder with LTPP Bind V3.1 ….................................. 36

3.4 Selection of the traffic parameters for MEPDG analysis ...................................... 36

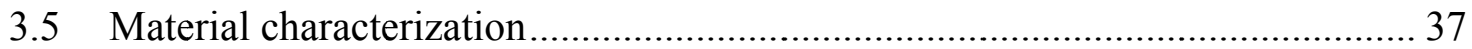

3.6 Analysis Parameter and Performance Criteria …………………………......... 37

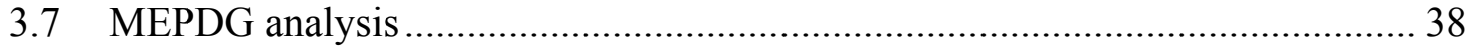

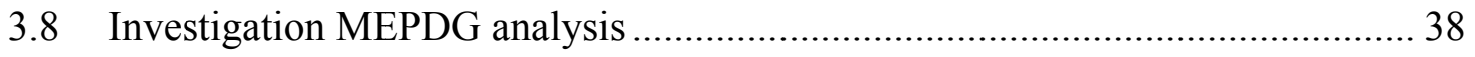

3.8.1 Analysis of Viscosity 38

3.8.2 Dynamic modulus master curve for asphalt concrete 38

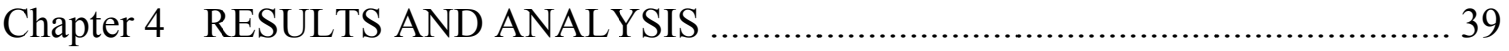

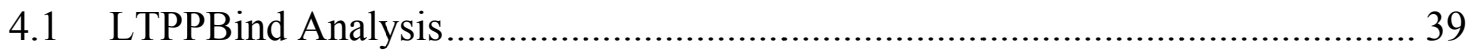

4.1.1 LTPPBind recommended Performance Grade 43

4.1.2 Selection of Performance Grade 45

4.1.3 Binders for MEPDG analysis 51

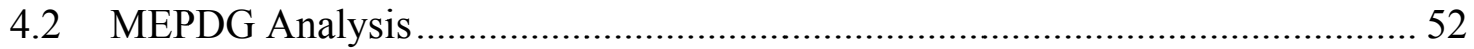

4.2.1 Analysis based on LTPPBind V3.1 recommendations 53

4.2.2 Analysis based on a single binder type 57

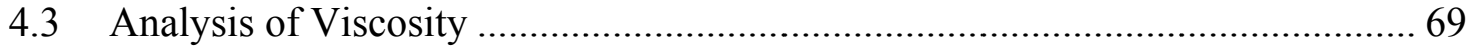

4.4 Master curve for Asphalt Concrete Mix........................................................ 71

Chapter 5 CONCLUSIONS AND RECOMMENDATIONS ……………………....... 74

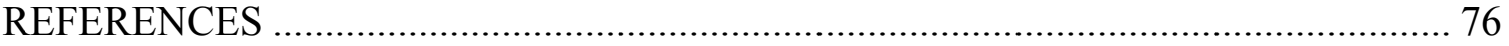




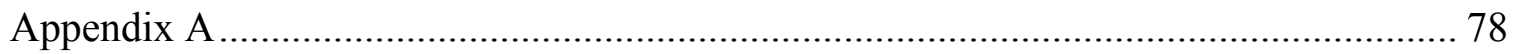

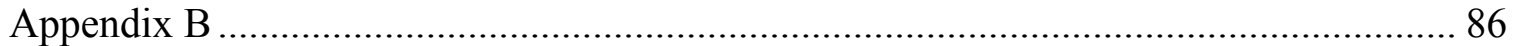




\section{LIST OF FIGURES}

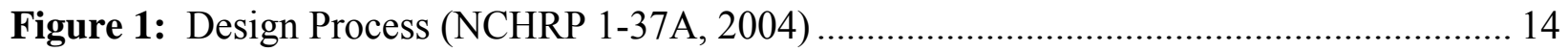

Figure 2: Multilayer Elastic System (Yoder et al., 1975) ...................................................... 16

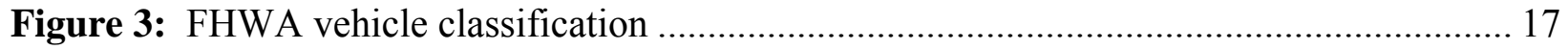

Figure 4: Pavement Performance trends and IRI values.( NCHRP 1-37A, 2004) ……............. 20

Figure 5: Interaction between materials with other component in MEPDG (NCHRP 1-37A,

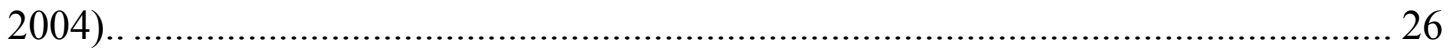

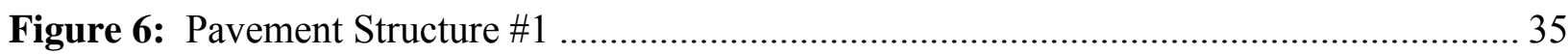

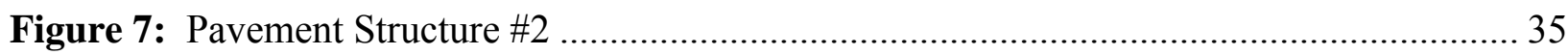

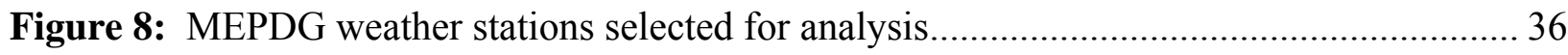

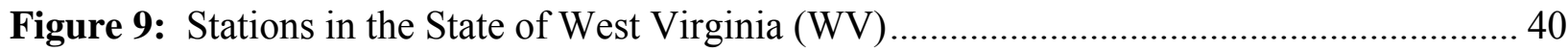

Figure 10: Climatic Condition in West Virginia ………….................................................... 41

Figure 11: Low Temperature PG distribution....................................................................... 40

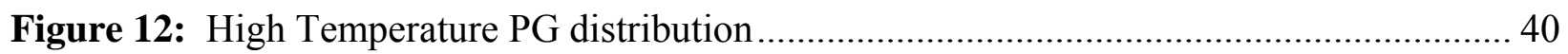

Figure 13: Distribution of Performance Grade Binder in West Virginia 98\% Reliability ......... 42

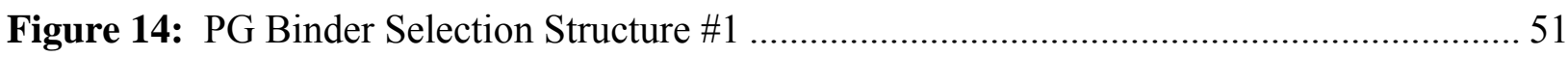

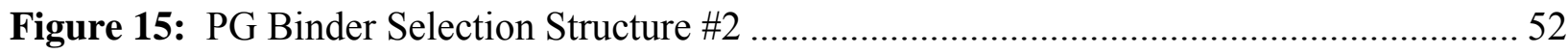

Figure 16: Effect of PG Asphalt Binder on AC Rutting Structure \#1 ………………............. 54

Figure 17: Effect of PG Asphalt Binder on Longitudinal Structure \#1 ..................................... 54

Figure 18: Effect of PG Asphalt Binder on Total Rutting Structure \#1 ……........................... 54

Figure 19: Effect of PG Asphalt Binder on IRI Structure \#1 …………………...................... 54

Figure 20: Effect of PG Asphalt Binder on Alligator Structure \#1 …………......................... 54

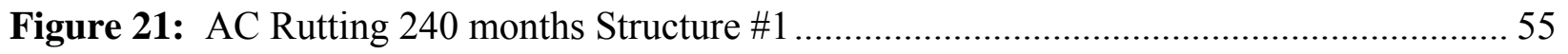

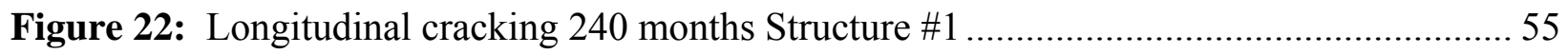

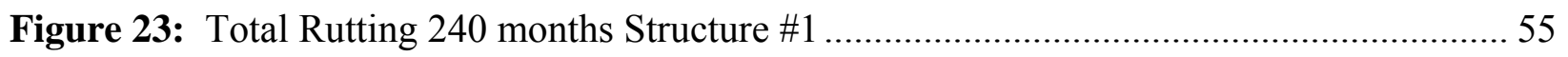

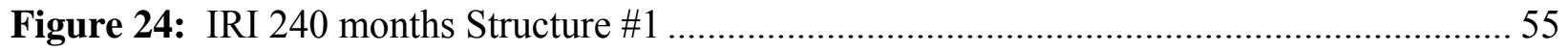

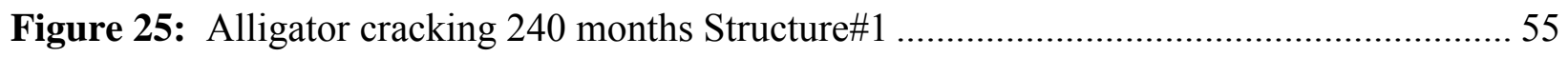

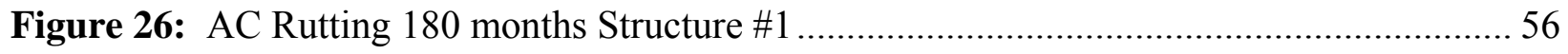

Figure 27: Longitudinal cracking 180 months Structure \#1 ………….................................... 56

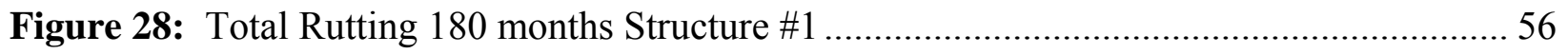

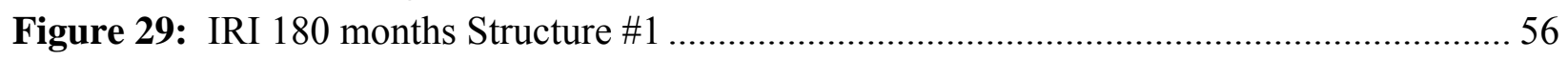

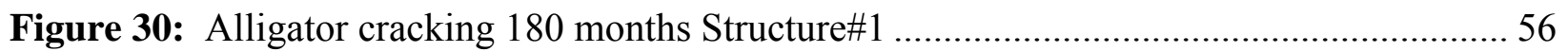

Figure 31: Effect of PG Asphalt Binder on AC Rutting Structure \#2 .....................................58

Figure 32: Effect of $P G$ Asphalt Binder on Longitudinal Structure \#2 …................................ 58

Figure 33: Effect of PG Asphalt Binder on Total Rutting Structure \#2 ………........................ 58

Figure 34: Effect of PG Asphalt Binder on IRI Structure \#2 ………………...................... 58

Figure 35: Effect of PG Asphalt Binder on Alligator Structure \#2 ………………................ 58

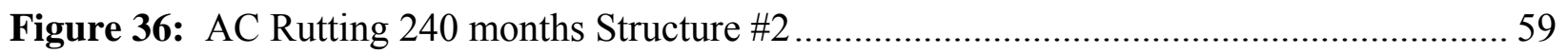

Figure 37: Longitudinal cracking 240 months Structure \#2 ………….................................. 59

Figure 38: Total Rutting 240 months Structure \#2 ………………….................................. 59 
Figure 39: IRI 240 months Structure $\# 2$......................................................................... 59

Figure 40: Alligator cracking 240months Structure ${ }^{\circ} \# 2$........................................................ 59

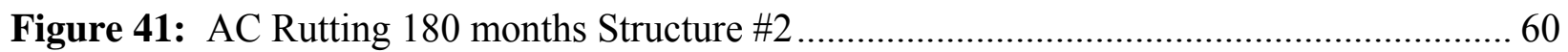

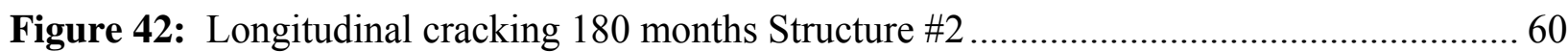

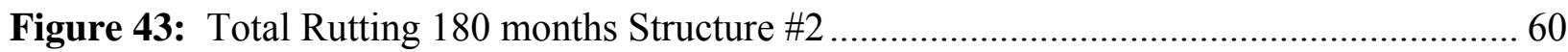

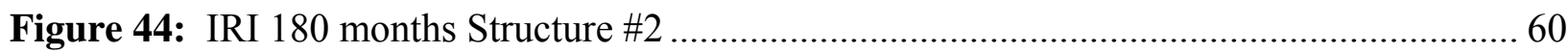

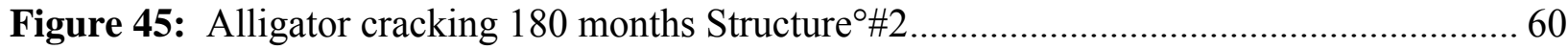

Figure 46: AC Rutting as a function of PG Binder type Structure \#1 .................................. 61

Figure 47: Longitudinal cracking as a function of PG Binder type Structure \#1 ................... 61

Figure 48: Total Rutting as a function of PG Binder type Structure \#1 ................................ 61

Figure 49: IRI as a function of PG Binder type Structure \#1 ............................................ 61

Figure 50: Alligator cracking as a function of $\mathrm{PG}$ Binder type Structure \#1 ......................... 61

Figure 51: AC Rutting as a function of PG Binder type 240 months Structure \#1 ................. 63

Figure 52: Longitudinal cracking as a function of PG Binder type 240 months Structure \#1 ... 63

Figure 53: Total Rutting as a function of PG Binder type 240 months Structure \#1 ............... 63

Figure 54: IRI as a function of PG Binder type 240 months Structure \#1 ............................. 63

Figure 55: Alligator cracking as a function of PG Binder type 240 months Structure \#1......... 63

Figure 56: AC Rutting as a function of PG Binder type Structure \#2 ................................... 64

Figure 57: Longitudinal cracking as a function of PG Binder type Structure \#2 ................... 64

Figure 58: Total Rutting as a function of PG Binder type Structure \#2 ................................. 64

Figure 59: IRI as a function of PG Binder type Structure \#2 ............................................ 64

Figure 60: Alligator cracking as a function of PG Binder type Structure \#2 ......................... 64

Figure 61: AC Rutting as a function of PG Binder type 240 months Structure \#2 .................. 65

Figure 62: Longitudinal cracking as a function of PG Binder type 240 months Structure \#2 ... 65

Figure 63: Total Rutting as a function of PG Binder type 240 months Structure \#2 ............... 65

Figure 64: IRI as a function of PG Binder type 240 months Structure \#2 .............................. 65

Figure 65: Alligator cracking as a function of PG Binder type 240 months Structure \#2 ........ 65

Figure 66: AC Rutting as a function of AC thickness Structure \#2 ...................................... 67

Figure 67: Longitudinal cracking as a function of AC thickness Structure \#2........................ 67

Figure 68: Total Rutting as a function of AC thickness Structure \#2 ..................................... 67

Figure 69: IRI as a function of AC thickness Structure \#2 ............................................. 67

Figure 70: Alligator cracking as a function of AC thickness Structure \#2 ............................ 67

Figure 71: AC Rutting as a function of AC thickness 180 months Structure \#2 .................... 68

Figure 72: Longitudinal cracking as a function of AC thickness 180 months Structure \#2 ...... 68

Figure 73: Total Rutting as a function of AC thickness 180 months Structure \#2 ................... 68

Figure 74: IRI as a function of AC thickness 180 months Structure \#2 ................................ 68

Figure 75: Alligator cracking as a function of AC thickness 180 months Structure \#2 ........... 68

Figure 76: Viscosity for short term after RTFO Condition ................................................. 70

Figure 77: Variation in temperature with depth for Bluefield........................................... 70

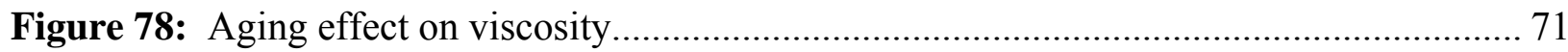


Figure 79: Master Curves for PG58-28, PG64-22, PG70-22 and PG76-22 for $9.5 \mathrm{~mm}$ surface $\operatorname{mix}$ 72

Figure 80: Shift Factors for PG58-28, PG64-22, PG70-22 and PG76-22 _............................ 72

Figure 81: Dynamic Modulus - Bluefield .................................................................... 73

Figure 82: Effect of PG Asphalt Binder on AC Rutting Structure \#1 ................................... 87

Figure 83: Effect of PG Asphalt Binder on Longitudinal cracking Structure \#1 .................... 87

Figure 84: Effect of PG Asphalt Binder on Total Rutting Structure \#1 ............................... 87

Figure 85: Effect of PG Asphalt Binder on IRI Structure \#1 ............................................ 87

Figure 86: Effect of PG Asphalt Binder on Alligator cracking Structure \#1 ........................ 87

Figure 87: Effect of PG Asphalt Binder on AC Rutting Structure \#1 ................................... 88

Figure 88: Effect of PG Asphalt Binder on Longitudinal cracking Structure \#1 .................... 88

Figure 89: Effect of PG Asphalt Binder on Total Rutting Structure \#1 ................................ 88

Figure 90: Effect of PG Asphalt Binder on IRI Structure \#1 ............................................. 88

Figure 91: Effect of PG Asphalt Binder on Alligator cracking Structure \#1 ......................... 88

Figure 92: Effect of PG Asphalt Binder on AC Rutting Structure \#1 ................................... 89

Figure 93: Effect of PG Asphalt Binder on Longitudinal cracking Structure \#1 .................... 89

Figure 94: Effect of PG Asphalt Binder on Total Rutting Structure \#1 .................................. 89

Figure 95: Effect of PG Asphalt Binder on Longitudinal Structure \#1 ................................... 89

Figure 96: Effect of PG Asphalt Binder on Alligator cracking Structure \#1 …..................... 89

Figure 97: Effect of PG Asphalt Binder on AC Rutting Structure \#1 ................................... 90

Figure 98: Effect of PG Asphalt Binder on Longitudinal Structure \#1 ................................. 90

Figure 99: Effect of PG Asphalt Binder on Total Rutting Structure \#1 ................................. 90

Figure 100: Effect of $P G$ Asphalt Binder on Longitudinal Structure \#1 ................................ 90

Figure 101: Effect of PG Asphalt Binder on Alligator Structure \#1 ....................................... 90

Figure 102: Effect of $P G$ Ashalt Binder on AC Rutting Structure \#2 ................................... 91

Figure 103: Effect of $P G$ Asphalt Binder on Longitudinal Structure \#2 ................................ 91

Figure 104: Effect of PG Asphalt Binder on Total Rutting Structure \#2 .............................. 91

Figure 105: Effect of $P G$ Asphalt Binder on Longitudinal Structure \#2 .............................. 91

Figure 106: Effect of PG Asphalt Binder on Alligator Structure \#2 .................................... 91

Figure 107: Effect of PG Asphalt Binder on AC Rutting Structure \#2 .................................. 92

Figure 108: Effect of $P G$ Asphalt Binder on Longitudinal Structure \#2 ............................... 92

Figure 109: Effect of PG Asphalt Binder on Total Rutting Structure \#2 …........................... 92

Figure 110: Effect of PG Asphalt Binder on Longitudinal Structure \#2 ............................... 92

Figure 111: Effect of PG Asphalt Binder on Alligator Structure \#2 .................................... 92

Figure 112: Effect of $P G$ Asphalt Binder on AC Rutting Structure \#2 ................................. 93

Figure 113: Effect of PG Asphalt Binder on Longitudinal Structure \#2 .............................. 93

Figure 114: Effect of PG Asphalt Binder on Total Rutting Structure \#2 ............................... 93

Figure 115: Effect of $P G$ Asphalt Binder on Longitudinal Structure \#2 ............................... 93

Figure 116: Effect of PG Asphalt Binder on Alligator Structure \#2 _................................... 93

Figure 117: Effect of PG Asphalt Binder on AC Rutting Structure \#2 ................................. 94 
Figure 118: Effect of $P G$ Asphalt Binder on Longitudinal Structure \#2 …........................... 94

Figure 119: Effect of PG Asphalt Binder on Total Rutting Structure \#2 ............................... 94

Figure 120: Effect of $P G$ Asphalt Binder on Longitudinal Structure \#2 ................................. 94

Figure 121: Effect of PG Asphalt Binder on Alligator Structure \#2 ..................................... 94

Figure 122: AC Rutting as a function of $P G$ Binder type Structure \#1 .................................. 95

Figure 123: Longitudinal cracking as a function of $P G$ Binder type Structure \#1 .................. 95

Figure 124: Total Rutting as a function of PG Binder type Structure \#1 .............................. 95

Figure 125: IRI as a function of PG Binder type Structure \#1 ........................................... 95

Figure 126: Alligator cracking as a function of $P G$ Binder type Structure \#1 ....................... 95

Figure 127: AC Rutting as a function of PG Binder type Structure \#1 ................................. 96

Figure 128: Longitudinal cracking as a function of $P G$ Binder type Structure \#1 ................... 96

Figure 129: Total Rutting as a function of $P G$ Binder type Structure \#1 ............................... 96

Figure 130: IRI as a function of PG Binder type Structure \#1 ............................................ 96

Figure 131: Alligator cracking as a function of PG Binder type Structure \#1 ....................... 96

Figure 132: AC Rutting as a function of PG Binder type Structure \#1 ................................. 97

Figure 133: Longitudinal cracking as a function of PG Binder type Structure \#1 ................... 97

Figure 134: Total Rutting as a function of PG Binder type Structure \#1 ................................ 97

Figure 135: IRI as a function of PG Binder type Structure \#1 .............................................. 97

Figure 136: Alligator cracking as a function of $P G$ Binder type Structure \#1 ...................... 97

Figure 137: AC Rutting as a function of PG Binder type Structure \#1 ................................. 98

Figure 138: Longitudinal cracking as a function of $P G$ Binder type Structure \#1 .................. 98

Figure 139: Total Rutting as a function of $\mathrm{PG}$ Binder type Structure \#1 ................................ 98

Figure 140: IRI as a function of PG Binder type Structure \#1 ........................................... 98

Figure 141: Alligator cracking as a function of $P G$ Binder type Structure \#1 ....................... 98

Figure 142: AC Rutting as a function of PG Binder type Structure \#2 ................................. 99

Figure 143: Longitudinal cracking as a function of PG Binder type Structure \#2 ................... 99

Figure 144: Total Rutting as a function of PG Binder type Structure \#2 ............................... 99

Figure 145: IRI as a function of PG Binder type Structure \#2 ............................................ 99

Figure 146: Alligator cracking as a function of $P G$ Binder type Structure \#2 ....................... 99

Figure 147: AC Rutting as a function of PG Binder type Structure \#2 .............................. 100

Figure 148: Longitudinal cracking as a function of PG Binder type Structure \#2 ................. 100

Figure 149: Total Rutting as a function of $\mathrm{PG}$ Binder type Structure \#2 ............................. 100

Figure 150: IRI as a function of PG Binder type Structure \#2 …...................................... 100

Figure 151: Alligator cracking as a function of PG Binder type Structure \#2 ....................... 100

Figure 152: AC Rutting as a function of PG Binder type Structure \#2 ................................ 101

Figure 153: Longitudinal cracking as a function of PG Binder type Structure \#2 ................. 101

Figure 154: Total Rutting as a function of PG Binder type Structure \#2 ............................ 101

Figure 155: IRI as a function of PG Binder type Structure \#2 .......................................... 101

Figure 156: Alligator cracking as a function of $P G$ Binder type Structure \#2 ..................... 101

Figure 157: AC Rutting as a function of PG Binder type Structure \#2 .............................. 102 
Figure 158: Longitudinal cracking as a function of PG Binder type Structure \#2 …............. 102

Figure 159: Total Rutting as a function of $P G$ Binder type Structure \#2 ............................. 102

Figure 160: IRI as a function of PG Binder type Structure \#2 ......................................... 102

Figure 161: Alligator cracking as a function of PG Binder type Structure \#2 ...................... 102

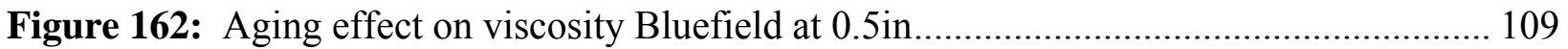

Figure 163: Aging effect on viscosity Bluefield at 1.0in.................................................. 109

Figure 164: Aging effect on viscosity Bluefield at 3.0in................................................ 109

Figure 165: Aging effect on viscosity Bluefield at 5.0in................................................... 109

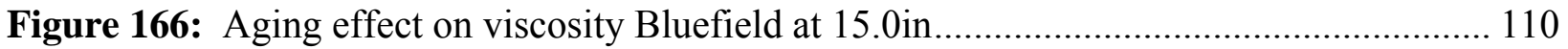

Figure 167: Aging effect on viscosity Bluefield at 18.0in.............................................. 110

Figure 168: Aging effect on viscosity Morgantown at $0.5 \mathrm{in} \mathrm{.............................................} 110$

Figure 169: Aging effect on viscosity Morgantown at 1.0in ............................................ 110

Figure 170: Aging effect on viscosity Morgantown at 3.0in........................................... 111

Figure 171: Aging effect on viscosity Morgantown at 5.0in ......................................... 111

Figure 172: Aging effect on viscosity Morgantown at 15.0in ......................................... 111

Figure 173: Aging effect on viscosity Morgantown at 18.0in ............................................. 111

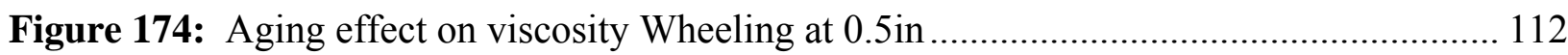

Figure 175: Aging effect on viscosity Wheeling at 1.0in ............................................... 112

Figure 176: Aging effect on viscosity Wheeling at 3.0in ............................................. 112

Figure 177: Aging effect on viscosity Wheeling at 5.0in .............................................. 112

Figure 178: Aging effect on viscosity Wheeling at 15.0in ............................................. 113

Figure 179: Aging effect on viscosity Wheeling at 18.0in ............................................... 113

Figure 180: Aging effect on viscosity Elkins at $0.5 \mathrm{in}$...................................................... 113

Figure 181: Aging effect on viscosity Elkins at 1.0in ..................................................... 113

Figure 182: Aging effect on viscosity Elkins at 3.0in ..................................................... 114

Figure 183: Aging effect on viscosity Elkins at 5.0in ...................................................... 114

Figure 184: Aging effect on viscosity Elkins at 15.0in ................................................. 114

Figure 185: Aging effect on viscosity Elkins at 18.0in ................................................... 114

Figure 186: Aging effect on viscosity Charleston at $0.5 \mathrm{in}$........................................... 115

Figure 187: Aging effect on viscosity Charleston at 1.0in ............................................. 115

Figure 188: Aging effect on viscosity Charleston at 3.0in .......................................... 115

Figure 189: Aging effect on viscosity Charleston at 5.0in ............................................ 115

Figure 190: Aging effect on viscosity Charleston at 15.0in ............................................. 116

Figure 191: Aging effect on viscosity Charleston at 18.0in ........................................... 116 


\section{LIST OF TABLES}

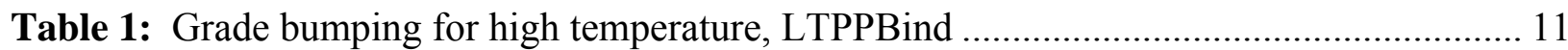

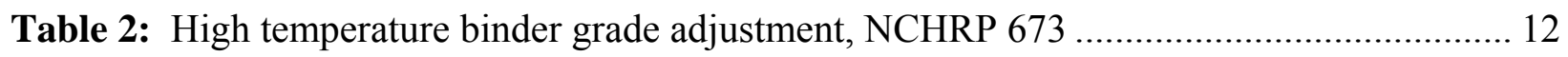

Table 3: Material Input Considerations by material group (NCHRP 1-37A, 2004).................. 27

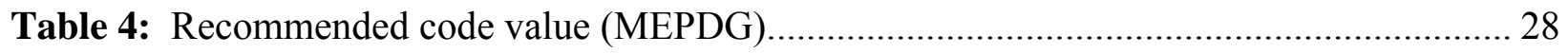

Table 5: Asphalt Dynamic Modulus ( $\left.E^{*}\right)$ estimation at various hierarchical input levels for new

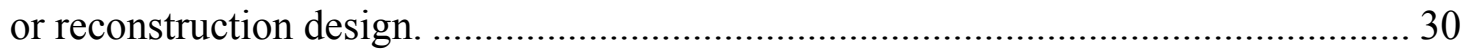

Table 6: Recommended RTFO A and VTS parameters based on asphalt PG grade .................. 33

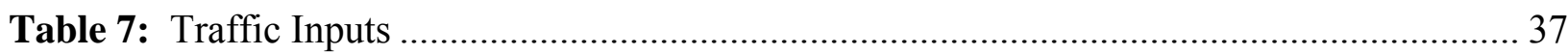

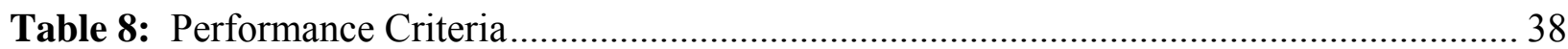

Table 9: LTPPBind V3.1 temperature and location parameters for analysis areas .................. 43

Table 10: LTPPBind V3.1 base Performance Grade at the surface........................................... 44

Table 11: Comparison of LTPPBind documentation and program correction factors for

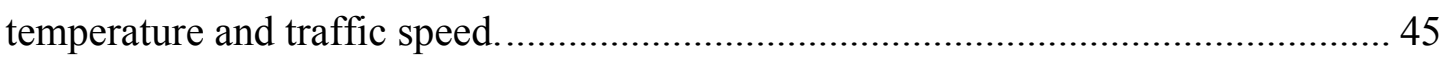

Table 12: Performance Grade from LTPPBind V3.1 Structure \#1 adjusted for depth and traffic $>30 \times 10^{6}$ ESALs

Table 13: Performance Grade from LTPPBind V3.1 Structure \#2 adjusted for depth and traffic

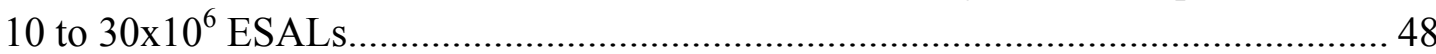

Table 14: Performance Grade adjusted Structure \#1 compared to typical WVDOH grades...... 49

Table 15: Performance Grade adjusted Structure \#2 compared to typical WVDOH grades...... 50

Table 16: Performance Grade for Snowshoe weather station...................................................5 50

Table 17: Climatic Characteristics of the selected stations ………….................................... 53

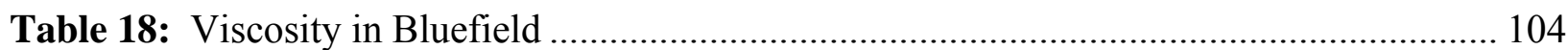

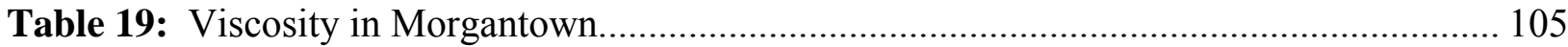

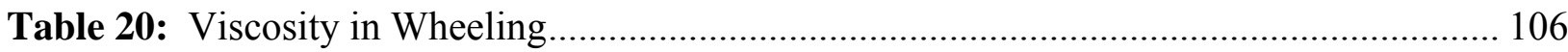

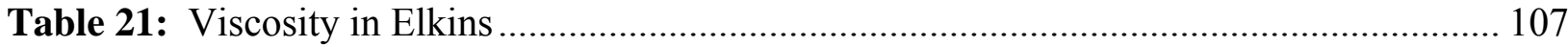

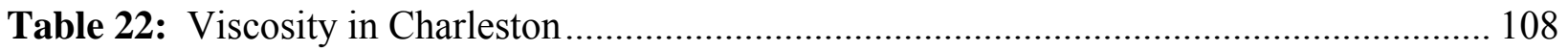




\section{Chapter 1 INTRODUCTION}

\subsection{Background}

Historically the pavement material selection process was not coupled with the pavement design process. In the 1993 AASHTO pavement design guide a material's contribution to the pavement performance was represented as structural coefficients. There was no basis for selecting these coefficients as a function of the binder type and mix design properties. Through research efforts during the Strategic Highway Research Program, and follow on studies, and studies for the development of a mechanistic based pavement design method, there is a technological path for coupling the material selection and design process with the pavement design process.

The LTPPBind V3.1 software helps to identify the most suitable binder for a specific area under different conditions of traffic, speed and climate. The MEPDG software for pavement design uses material characteristics to predict structural pavement performance. This potentially links material selection and pavement design.

\subsection{Problem Statement}

The potential to couple the selection and design of materials with the pavement design process can lead to pavements that are more cost effective and have longer service lives. The purpose of this research is to investigate the extent to which the selection of binders affects the predicted pavement performance.

\subsection{Research Objectives}

The main objectives of this research are:

1. To analyze the Performance Grade from the Department of Transportation of West Virginia within different areas of the state.

2. To determine which asphalt binders are obtained when the Long Term Pavement Performance Asphalt binder software, LTPPBind, is used.

3. To analyze the response of two typical pavement structures using four of the asphalt binders recommended by the Department of Transportation of West Virginia by use of MEPDG and determine which asphalt binders minimize Permanent Deformation, Fatigue Cracking, Thermal Cracking and Terminal IRI.

\subsection{Scope and Limitations}

This research is concerned with the selection of the most suitable asphalt binders that can be used in the State of West Virginia for two specific flexible pavement structures, full-depth asphalt pavement and conventional flexible pavement. The MEPDG is the software used for calculating the response of the pavement structures under different asphalt binders. Permanent Deformation, Fatigue Cracking, Thermal Cracking and Terminal IRI are analyzed with the 
models provided in MEPDG. When this research was started, the DARWIN ME software was not available so this research was completed with the MEPDG software that was accessible to the public. A comparison with the asphalt binders recommended by LTPPBind V3.1 according to climatic, traffic, and speed was also considered. The LTPPBind V3.1 beta version software from 2005 was used for this analysis. This is the current version of the software available from the FHWA.

This study was not based on an evaluation of materials in the laboratory or the field. All calculations were based on a theoretical analysis for flexible asphalt pavement structures. In the study the use of default values defined in the methodological guide within Level 3 (NCHRP 137A, 2004) were taken for all the calculations.

Throughout the analysis the "nationally calibrated" models were used; there were no resources in this work to consider calibrating the models for West Virginia.

\subsection{Organization}

This thesis contains five chapters. Chapter 1 gives an introduction to this research. Chapter 2 presents the literature review outlining describes the LTPPBind V3.1 product; also introduces the classification of performance grade, pavement temperature analysis, and grade bumping for high temperature and previous studies focusing on the selection of asphalt binders. The MEPDG, principles of the mechanistic procedure, hierarchical design input in MEPDG, response models, pavement performance, and distress prediction equations for the design of flexible pavements, traffic, climate, material properties Chapter 3 contains the methodology used for this research. Chapter 4 discusses the results, analysis and discussion from LTPP and MEPDG outputs, asphalt binder viscosity and dynamic modulus of the asphalt concrete mix. Chapter 5 contains conclusions and recommendations. 


\section{Chapter 2 LITERATURE REVIEW}

The first part of this chapter presents procedures for selecting a Performance Grade binder. Several researchers have addressed this topic and their work is reviewed as background information. The state of the art for binder selection is embodied in the LTPPBind V3.1 software. The concepts of reliability for selecting asphalt binders are detailed, and the applications of LTPPBind V3.1 are described.

The second part of this chapter describes the methodology of the MEPDG. The main concepts that MEPDG implements to determine the distresses in flexible pavement structures are discussed.

\subsection{Background}

The Strategic Highway Research Program (SHRP) was a comprehensive research program in the 1990's with the goal of providing research products that could be implemented to improve the highway infrastructure in the US. The two main products developed for asphalt materials were the Performance Grade specifications for asphalt binders and the Superpave mix design method (WSDOT 2011). Since these research products were developed simultaneously, it is common practice to refer to Performance Grade binders as Superpave binders. However, Performance Grade binders can be, and are, used with other mix design methods. In the Performance Grade method, the binder classification is based on the rated low and high temperatures of the binder, e.g. $\mathrm{PG} 64-22$ has a rated temperature range of $-22^{\circ} \mathrm{C}$ to $64^{\circ} \mathrm{C}$. In general the binders are specified in $6^{\circ} \mathrm{C}$ increments, but some agencies use increments of $3^{\circ} \mathrm{C}$.

\subsection{Studies for Selecting Asphalt Binders}

\subsubsection{University of Wisconsin Madison}

Studies on the selection of asphalt binders have had a laboratory testing component. Nam Kitae, and Bahia U Hussain from The University of Wisconsin Madison (Bahia et al., 2004) have developed a detailed research for the Wisconsin Department of Transportation in order to determine the behavior of some asphalt binders and their relation to observed distresses in the pavement structure. Distresses considered are: rutting, fatigue, and thermal cracking. The main focus of that investigation was on the development of several tests following NCHRP-10 protocols (Characterization of modified asphalt binders in Superpave Mix Design) to find the best binder under various traffic, climate and pavement conditions. The result of that study led to the derivation of specification limits for the selection of binders when the climate meets certain criteria, along with traffic and pavement conditions. The final asphalt binder selection is not corrected by bumping; this means that it is not necessary to shift the high temperature grade for the asphalt binder (Bahia et al., 2004). 
The Wisconsin study allows the use of neat asphalt and modified binders. The research was developed in three stages; in the first stage, traffic, climate, air temperature, and pavement temperature data were collected, and studies of previous binder selection were reviewed. The second stage consisted of laboratory test program. The tests performed were: Dynamic Shear Rheometer test (DSR), Bending Beam Rheometer test (BBR), Direct Tension Test (DTT), Glass Transition Test (GTT), and an evaluation of the workability of the asphalt concrete mix. In the last stage the Specification System for different conditions was successfully developed.

The main analyses were related with fatigue, rutting, and thermal cracking and workability of the concrete asphalt mix. Asphalt binders are classified by rutting and fatigue. For rutting, traffic speed and traffic volumes are considered. For fatigue evaluation, pavement structure, traffic speed, and traffic volume are considered. Two seasons, a normal season and a thaw season, are considered within the specification. The inclusion of two seasons allows direct evaluation of the influence of the temperature and the loss of support during the thaw season. A set of binder selection guidelines were developed, based on traffic and pavement response. The guidelines include pavement temperatures, traffic conditions and pavement structures (Bahia et al., 2004).

\subsubsection{The Virginia Transportation Research Council}

Prowell has researched the determination of the performance grade asphalt binders for Virginia (Prowell, 1999). That research included laboratory studies to aid in the correct selection of the binder according to its performance under different conditions. The use of the Georgia loaded-wheel tester and the Asphalt Pavement Analyzer (APA) were used to evaluate mixes in the laboratory. The study also included construction of different pavement sections in the field. PG64-22 was recommended as the base asphalt for Virginia. PG70-22 is specified only for surfaces and PG76-22 for extreme traffic loading.

\subsubsection{Georgia Department of Transportation}

The Georgia Department of Transportation (GDOT) has created a guideline for selecting binders (GDOT 2006). One of the important aspects gained with that research is the knowledge of traffic levels and traffic classification. GDOT has made a great effort to determine and report all traffic data that is collected across the state on a continuous basis. This information is key for selecting asphalt binders in a given zone within the state.

\subsubsection{Minnesota Department of Transportation}

A comprehensive guide developed by the Department of Transportation of Minnesota focused on the selection of binders. The base of that work was the study of air temperature and algorithms given by Superpave. Studies performed in Canada were used in that research because it was considered that low temperature requires more investigation. Regression equations were created in order to determine the climatic variations (MAPA 2008). 


\subsubsection{Other Studies}

In addition to these investigations, the departments of Transportation of Florida, California, Michigan, Colorado, Mississippi and Texas among others have developed guidelines that provide guidance on the selection of asphalt and modifiers that can be used in each of those states.

McMillan from Engineering Consultants Ltd had worked in a research made in 1999 (McMillan et al., 1999). The evaluation of low and high pavement temperature was considered the first interest in this research. Second the interest in knowing how the loads to which the pavement structure is subjected are responding through the life time selected for design.

A detailed analysis in the laboratory was done with the binders utilized so far within the region, concluding that the quality of binders was satisfactory. The implementation of the temperature algorithms and reliability was validated through sections constructed to monitor pavement behavior for a long period of time. A comparison was performed with specific binders and as a result, (McMillan et al., 1999).

"Canadian airport pavement designers will be able to select the most economical PG grades for the expected aircraft loading at a given site. The algorithm for estimating the low pavement temperature should be used to determine the low pavement design temperature using a reliability of $98 \%$. Long term monitoring of airport PG binder test sections will be used to validate the binder selection methodology and the long term performance of PG binders under typical airport operations"

It is observed that built sections for experimental tests are very effective research approaches to study the behavior of materials and the significance of reliability when exposed to different weather conditions and loading rate.

Finally, it is important to mention the research performed by Ayesha Shah from Purdue University (Shah, 2004). This study-site research was made to validate the concepts from Superpave. The main idea was validating the theory and studies about the influence of asphalt binder in the performance of the pavement structure.

The construction involves the use of the Marshall and Superpave asphalt mix design. The sections were continuously checked and the pavement conditions documented. In addition, sampling was done for a direct analysis of the layers built. The result showed a good correlation between laboratory and field tests.

The results agreed with all Superpave binder classifications, and field calibration was found to be key to the good correlation between the theory and tests performed. As a conclusion, the effect of decreasing the low temperature binder grade leads to increased transverse crack 
length. Regarding the increment of high grade, there was no evidence of changes in rutting (Shah, 2004).

The studies mentioned above provide information on the equations and implementation of Superpave System. The review about asphalt binder selection is related with site-field constructions and laboratory testing, where researchers were seeking how to generate specifications and guidelines for each site under study.

\subsection{SHRP - LTPP Studies}

Chunchua Han (Lukanen et al., 1998), Mohseni (Mohseni, 1997) and Robertson (Robertson, 1997) have found different models to predict the maximum and minimum surface temperature from air temperatures; some authors include the latitude within the model. The equations proposed by Chunchua Han (Lukanen et al., 1998), relate the 7-day average high (maximum) air temperatures to the 7-day average high (maximum) temperature within the asphalt concrete and the coldest (minimum) air temperature to the coldest temperature within the asphalt concrete pavement.

The temperatures predicted by Mohseni (Mohseni, 1997) and Han (Lukanen et al., 1998), result in essentially the same PG. Han's equations is as follows:

\section{- High Temperature Model}

$$
T d_{(\max )}=0.52+6.225 \phi-0.15 \phi^{2}+0.0011 \phi^{3}+0.28 T a_{(\max )}-8.37 L N(d+40)
$$

Where,

$\operatorname{Td}_{(\max )}=$ high pavement design temperature, ${ }^{\circ} \mathrm{C}$

$\mathrm{Ta} a_{(\max )} \quad=\quad$ high air temperature, ${ }^{\circ} \mathrm{C}$

$\mathrm{d}=\quad$ Depth in pavement in $\mathrm{mm}(20 \mathrm{~mm})$

$\phi \quad=\quad$ Latitude (degrees)

\section{- Low Temperature Model}

$$
T d_{(\min )}=-0.14-1.7 \phi+0.06 \phi^{2}-0.0007 \phi^{3}+0.69 * T a_{(\min )}+4.12 L N(d+100)
$$

Where,

$\begin{array}{lll}\mathrm{Td}_{(\max )} & = & \text { low pavement design temperature, }{ }^{\circ} \mathrm{C} \\ \mathrm{Ta}_{(\max )} & = & \text { low air temperature, }{ }^{\circ} \mathrm{C} \\ \mathrm{d} & = & \text { Depth in pavement in } \mathrm{mm}(20 \mathrm{~mm}) \\ \phi & = & \text { Latitude (degrees) }\end{array}$

Mohseni's equations are as follows: 


\section{- High Temperature Model}

$T d(\max )=54.32+0.77585 \operatorname{Ta}(\max )-0.002468 \phi^{2}-15.137 \log (d+25)$

Where,

$\operatorname{Td}(\max )=$ high pavement design temperature, ${ }^{\circ} \mathrm{C}$

$\mathrm{Ta}(\max )=$ high air temperature, ${ }^{\circ} \mathrm{C}$

$\mathrm{d} \quad=\quad$ Depth in pavement in $\mathrm{mm}(20 \mathrm{~mm})$

$\phi \quad=\quad$ Latitude (degrees)

- Low Temperature Model

$T d(\min )=-1.56+0.71819 T a(\mathrm{~min})-0.003966 \phi^{2}+6.264 \log (d+25)$

where,

$\operatorname{Td}(\max )=$ low pavement design temperature, ${ }^{\circ} \mathrm{C}$

$\mathrm{Ta}(\max )=$ low air temperature, ${ }^{\circ} \mathrm{C}$

$\mathrm{d} \quad=\quad$ Depth in pavement in $\mathrm{mm}(20 \mathrm{~mm})$

The relationship between pavement temperature and weather is addressed in an equation by Bosscher, Bahia, Thomas and Russell (Bosscher et al.,1998). The model defines the minimum pavement temperature measured at $6.4 \mathrm{~mm}$ below the pavement surface:

- For air temperature below $0^{\circ} \mathrm{C}$,

$T_{P A V @(6.4 m m)}=6.83+1.014 T_{A I R(M I N)}$

- For air temperature below $-5^{\circ} \mathrm{C}$,

$T_{P A V @(6.4 m m)}=0.3768+0.687 T_{A I R(M I N)}$

For air temperature above $0^{\circ} \mathrm{C}$ and above $-5^{\circ} \mathrm{C}$, the temperature of the pavement can also be calculated at specified depth, following this model:

- For minimum pavement temperature:

$T_{d(M I N)}=T_{P A V @ 6.4 m m(M I N)}-\left(0.00123 T_{P A V @ 6.4 m m(M I N)}(d-6.4)\right)+0.0146(d-6.4)$

where,

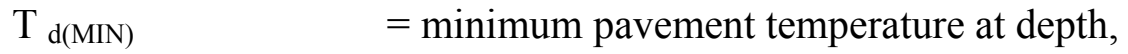

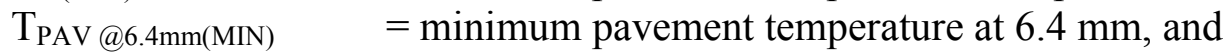

$\mathrm{d}=$ depth from surface, $\mathrm{mm}$ 


\section{- For maximum pavement temperature:}

For air temperature higher than $10^{\circ} \mathrm{C}$,

$T_{\text {PAV @ 6.4mm(MAX) }}=-0.519+0.820 T_{A I R(M A X)}+0.00335$ Solar

For air temperature below $10^{\circ} \mathrm{C}$,

$$
T_{P A V @ 6.4 m m(M A X)}=2.811+1.087 T_{A I R(M A X)}+0.00246 \text { Solar }
$$

where,

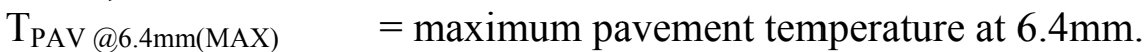

$\mathrm{T}_{\text {AIR(MAX) }}=$ maximum air temperature, and

Solar $=$ daily total solar radiation intensity, $\mathrm{W}^{*} \mathrm{hr} / \mathrm{m}^{2}$

\section{- Maximum pavement temperature at specified depth}

$$
\begin{array}{ll}
T_{d(M A X)}=T_{P A V @ 6.4 m m(M A X)}-2.68 \times 10^{-3}(d-6.4) & T_{P A V @ 6.4 m m(M A X)}+4.25 \times 10-4(d-6.4)^{2} \\
\text { where }, & =\text { maximum pavement temperature at depth } \mathrm{d} \\
\mathrm{T}_{\mathrm{d}(\mathrm{MAX})} & =\text { maximum pavement temperature at } 6.4 \mathrm{~mm} \text { and } \\
\mathrm{T}_{\mathrm{PAV} @ 6.4 \mathrm{~mm}(\mathrm{MAX})} & =\text { depth from surface, } \mathrm{mm}
\end{array}
$$

Solar radiation plays an important role in determining the maximum pavement temperature and it is strongly recommended that solar radiation intensity be measured in addition to air temperature (Bosscher et al.,1998).

\subsection{LTPPBind V3.1 Software}

The selection of a Performance Grade binder for a specific project depends on the traffic speed; traffic quantity expected over the life of the project, the estimated high and low temperatures, and the project location. Models are used to estimate the pavement temperature. The estimated high and low pavement temperatures are used for the initial selection of the binder grade. Since temperatures vary across time the developers of the Performance Grade method developed a reliability concept to limit the anticipated percent time the pavement temperatures will be outside of the rated range of the binder. The initial binder grade is adjusted for the selected reliability. Reliability is defined as the probability in a single year that the actual temperature (seven-day-average highest or one-day lowest) will not exceed the binder grade temperatures (WSDOT, 2011). The binder grade may then be adjusted for traffic quantity and speed. For the selection of the binder for a surface layer the temperatures are computed for 20 $\mathrm{mm}$ below the surface. When selecting a binder for a binder or base course, the depth of the lift in the pavement structure is used for the analysis (Brown et al., 2009). Software has been developed to assist the pavement technologist with the selection of a binder grade for a project; 
the latest version is LTPPBind V3.1. As the name indicates, this is the third generation of the program. The following review is based on the current edition of the software.

LTPPBind V3.1, was developed in 2005 by Pavement Systems, LLC for the Federal Highway Administration (FHWA) (Mohnesni, 2005). This is a binder selection program that guides in the selection of a Performance Grade Binder for a given location using different traffic data and operational speed. This software is based on the latest low and high temperature Performance Grade (PG) algorithms and uses a database of 7,439 weather stations within the US and Canada. The climatic databases used for LTPPBind V3.1 software within U.S and Canada are Surface Land Daily (Cooperative Summary of the Day) and Canadian Daily Climatic Data. For every weather station the software provides an ID name, geographical information (longitude, latitude, elevation) and climatic-meteorological information (low air temperature, high air temperature, precipitation, snowfall, snow depth, evaporation, 24-hour wind movement, maximum and minimum soil temperature).

\subsubsection{Weather Stations}

When analyzing the binder grade for a specific location, LTPPBind V3.1 identifies the five weather stations closest to the site to determine the environmental conditions. The recommendation of a binder grade is based on the average of the environmental variables for the five stations.

\subsubsection{Pavement Temperature Analysis}

The meteorological information used by LTPPBIND V3.1 considers maximum and minimum daily air temperatures (Mohnesni, 2005). The low temperature model was developed by regression analysis of the LTPP's Seasonal Monitoring Program (SMP) which relates the air temperature to a pavement temperature through latitude and depth (Mohseni, 1998). The high temperature model uses a combination of a mechanistic based analysis for rutting (Mohseni et al., 2005) to estimate the "base temperature" with a modification using the high temperature equation (Mohseni, 1998) to estimate the temperature as a function of depth.

\section{Low Temperature Evaluation}

The regression equation developed for low pavement temperature is:

$$
\text { Tpav }=-1.56+0.72 \text { Tair }-0.004 * \operatorname{Lat}^{2}+6.26 \log _{10}(H+25)-z\left(4.4+0.52 \sigma_{\text {air }}{ }^{2}\right)^{1 / 2}
$$

Where:

Tpav $=$ Low AC pavement temperature below surface, ${ }^{\circ} \mathrm{C}$

Tair $=$ Low air temperature, ${ }^{\circ} \mathrm{C}$

Lat $=$ Latitude of the section, degrees

$H=$ Depth from surface, $\mathrm{mm}$

$\sigma_{\text {air }}=$ Standard deviation of the mean low air temperature, ${ }^{\circ} \mathrm{C}$

$z=$ Standard normal distribution value selected based on reliability level. 
The effect of depth in the pavement structure is captured directly in Equation 2.11. There is no correction for speed and number of ESAL repetitions.

\section{High Temperature Evaluation}

Selection of the high temperature grade involves several steps:

- Determine the base temperature for grade selection

- Estimate the coefficient of variation of the temperature based on the degree days and rut depth

- Use the coefficient of variation and the $\mathrm{z}$ value for the selected reliability level

- Adjust the base temperature for the reliability

- "Bump" the temperature for slow speed and number of ESAL applications.

- Modify the adjusted base temperature for depth

- Select the performance grade in 6 degree increments.

Estimating the temperature for the selection of the high temperature binder grade is more complex. The model developed for this purpose was established on rutting damage model; a study performed Mohseni et al. (Mohseni et al., 2005). Their study included 187 sites throughout the United States. It takes degrees-days and rut depth with 50\% reliability as inputs, and yields a damage-based PG. This is followed by a PG-variability with respect to altitude and an adjustment for reliability greater than $50 \%$. The models are:

$P G d=48.2+14 D D-0.96 D D^{2}-2 R D$

Where, the variables as defined by the authors are:

$\mathrm{PGd}=$ Estimated damage-based performance grade, ${ }^{\circ} \mathrm{C}$

$\mathrm{DD}=$ Average Yearly Degree-Days air temperature over $10^{\circ} \mathrm{C}\left(\mathrm{x} 1000^{\circ} \mathrm{C}\right.$-Days)

$R D=$ Target Rut Depth $(5-13 \mathrm{~mm})$,

The degree-day parameter is the sum of the high daily air temperatures for a year when the temperature is above $10^{\circ} \mathrm{C}$, averaged over an observation period.

PGd is the base high temperature for the pavement. The corresponding binder grade, in 6 degree increments is the "base grade". PGd is the estimate of the high temperature pavement parameter for a reliability of 50 percent, a "fast" traffic speed, traffic loads of less than $0.3 \times 10^{6}$ ESALs, and at the surface of the pavement.

The base temperature is adjusted for reliability by considering the coefficient of variation of the base temperature. The coefficient of variation of the pavement base high temperature is estimated as:

CVPG $=0.000034(\text { Lat }-20)^{2} R D^{2}$ 
Where,

CVPG $=\quad$ Yearly PG Coefficient of Variation, \%

Lat $=$ Latitude of Site, Degrees

$R D=$ Target Rut Depth, $\mathrm{mm}$

The coefficient of variation is used to modify the base temperature using for the selected reliability level as:

PGrel $=P G d+z P G d *((C V P G) / 100)$

Where,

$\mathrm{PGd}=\mathrm{PG}$ at a Reliability level, ${ }^{\circ} \mathrm{C}$

$\mathrm{Z}=$ From Standard Probability Table

CVPG $=\quad$ Yearly PG Coefficient of Variation, $\%$

PGrel is the upper temperature for the selected reliability.

\subsubsection{Traffic Adjustment}

The adjustment for traffic speed and number of ESALs is termed "grade bumping".

Grade bumping uses the base grade of the asphalt, traffic speed (slow or fast) and the number of ESAL repetitions as shown in Table 1. The values in the table are added to PGrel to obtain the adjusted high pavement temperature.

Table 1: Grade bumping for high temperature, LTPPBind

\begin{tabular}{||c||c||c|c|c|c||}
\cline { 3 - 6 } \multicolumn{2}{c||}{} & \multicolumn{4}{c||}{ Traffic Loading ESAL, Millions } \\
\hline \hline \multirow{3}{*}{ Speed } & $\begin{array}{c}\text { Base } \\
\text { Grade }\end{array}$ & $<3$ & $3-10$ & $10-30$ & $>30$ \\
\hline \hline \multirow{3}{*}{ Fast } & 52 & 0 & 10.3 & 16.8 & 19.3 \\
\cline { 2 - 6 } & 58 & 0 & 8.7 & 14.5 & 16.8 \\
\cline { 2 - 6 } & 64 & 0 & 7.4 & 12.7 & 14.9 \\
\cline { 2 - 6 } & 70 & 0 & 6.1 & 10.8 & 12.9 \\
\hline \hline \multirow{3}{*}{ Slow } & 52 & 3.1 & 13 & 19.2 & 21.6 \\
\cline { 2 - 6 } & 58 & 2.9 & 11.2 & 16.8 & 19 \\
\cline { 2 - 6 } & 64 & 2.7 & 9.8 & 14.9 & 17 \\
\cline { 2 - 6 } & 70 & 2.5 & 8.4 & 12.9 & 14.9 \\
\hline \hline
\end{tabular}

One criticism of LTTBind V3.1 is the threshold associated with fast and slow traffic in not well defined (Advanced Asphalt Technologies, 2011):

One limitation to the current LTPPBind, Version 3.1, is that only fast and slow traffic speeds are addressed, and the specific speeds in kph corresponding to these categroies are not given, although it appears that fast traffic corresponds to an average speed of about $70 \mathrm{kph}$, and slow traffic to a speed of about $35 \mathrm{kph}$. Performance grade adjustments for very slow traffic are not addressed. 
The following table is recommended for high temperature binder grade adjustments, including very slow traffic speeds (Advanced Asphalt Technologies, 2011).

Table 2: High temperature binder grade adjustment, NCHRP 673

\begin{tabular}{|l|c|c|c|}
\hline \multirow{4}{*}{$\begin{array}{l}\text { Design } \\
\text { traffic } \\
\text { (MESALs) }\end{array}$} & \multicolumn{3}{|c|}{ Grade Adjustment for Average Vehicle } \\
\cline { 2 - 4 } & very slow & slow & fast \\
\cline { 2 - 4 } & $<25$ & 25 to $<70$ & $\geq 70$ \\
$(<15)$ & -15 to $<45)$ & $(\geq 45)$ \\
\hline$<0.3$ & 12 & - & - \\
\hline 0.3 to $<3$ & $18^{*}$ & 6 & 6 \\
\hline 3 to $<10$ & $22^{*}$ & 13 & 10 \\
\hline 10 to $<30$ & - & $26^{*}$ & $15^{*}$ \\
\hline$\geq 30$ & -4 & - \\
\hline$*$ & Consider use of polymer modified binder. If a polymer \\
modified binder is used, high temperature grade may be \\
reduced one grade $\left(6^{\circ} \mathrm{C}\right)$, provided rut resistance is \\
verified using suitable performance testing.
\end{tabular}

\subsubsection{Depth Adjustment}

For the selection of an asphalt binder for a lift below the surface the following equation is used (Monhseni, 2005) to compute the temperature at the surface and the temperature at the desired depth. The difference between these temperatures is the temperature correction factor for depth. This value is added to PGrel, as adjusted for traffic speed and repetitions, to estimate the high pavement temperature for selecting the binder grade, before the traffic correction.

Tpav $=54.32+0.78$ Tair $-0.0025 \operatorname{Lat}^{2}-15.14 \log _{10}(H+25)+z\left(9+0.61{\sigma_{\text {air }}}^{2}\right)^{1 / 2}$

Where:

Tpav $=$ High $\mathrm{AC}$ pavement temperature below surface, Deg. ${ }^{\circ} \mathrm{C}$

Tair $=$ High air temperature, ${ }^{\circ} \mathrm{C}$

Lat $=$ Latitude of the section, degrees

$H \quad=\quad$ Depth to surface, $\mathrm{mm}$

$\sigma_{\text {air }}=$ Standard deviation of the high 7 day means air temperature, ${ }^{\circ} \mathrm{C}$

$z \quad=\quad$ Standard normal distribution value selected based on reliability level.

The low pavement temperature, adjusted for reliability, is used for the low temperature grade selection subject to the six degree increments of performance grade binder availability, e.g. if Tpav from Equation 2.1 is $-19^{\circ} \mathrm{C}$, the low temperature grade is $-22^{\circ} \mathrm{C}$. The high pavement temperature with all adjustments is used for the high temperature grade selection, e.g. if the adjusted pavement temperature is $61.5 \mathrm{C}$, the high temperature grade is $64^{\circ} \mathrm{C}$. Hence, for the example, the selected binder grade is PG 64-22. 


\subsubsection{Reliability}

Reliability for binder grade selection has been defined as "the percent probability in a single year that the actual temperature (one-day low or seven-day average high) will not exceed the corresponding design temperatures" (Brown, et. al, 2009). LTPPBind allows the user to either determine the binder grade required for a selected level of reliability or determine the reliability of a selected binder grade.

\subsubsection{Comparison to previous version of LTPPBind}

The current version of LTPPBind is an update of the V2.1. The models used for the selection of the high temperature of the binder grade in V2.1 were considered to be inadequate. The researchers compared the results of the old and new LTPPBind programs and found reasonable agreement when the upper temperature was about 52 degrees however at higher temperatures there was disagreement (Mohseni et al, 2005):

At SHRP PG 58, however, 566 sites (20\%) were one grade higher. At SHRP PG 64, 701 sites (30\%) were one grade higher and at SHRP PG 70, 67 sites (38\%) were one grade higher.

\subsection{Mechanistic-Empirical Pavement Design Guide MEPDG}

The MEPDG is a software product developed by the National Cooperative Highway Research Program (NCHRP) Project 1-37A for the design of new and rehabilitated pavement structures using mechanistic-empirical basis (NCHRP 1-37A, 2004).

The MEPDG incorporates the impact of climate, discriminated traffic loads in the form of load spectra, and a complete material characterization that considers aging of the materials throughout the life of the pavement structure. The basis of the design is the incremental damage approach generated for different types of distresses.

The MEPDG has been calibrated for a national field database. However, the implementation guide recommends local calibration and validation of the models.

One of the main components of MEPDG is the Enhanced Integrated Climatic Model (EICM). This package contains several models that provide information used in the analysis of the pavement structure. The information processed by EICM is used as inputs by different algorithms within MEPDG. EICM provides moisture and temperature data. For example, it takes air temperature and yields temperatures across the pavement structure through the analysis period. The seasonal variation and temporal variations in the material properties due to environment are serve as input to the MEPDG algorithms.

MEPDG predicts the mechanical behavior of the pavement structure, in terms of stresses and strains, and estimates incremental distress due to traffic. The incremental distresses are accumulated over the analysis period. 
Pavement design is performed on a trial-and-error basis by selecting the appropriate inputs that are consistent with predetermined design criteria. The designer determines the conditions and inputs that will result in an acceptable amount/magnitude of distress in the life of the pavement.

Figure 1 is the overall analysis process of MEPDG. This figure does not highlight the components of the analysis that are performed by the EICM.

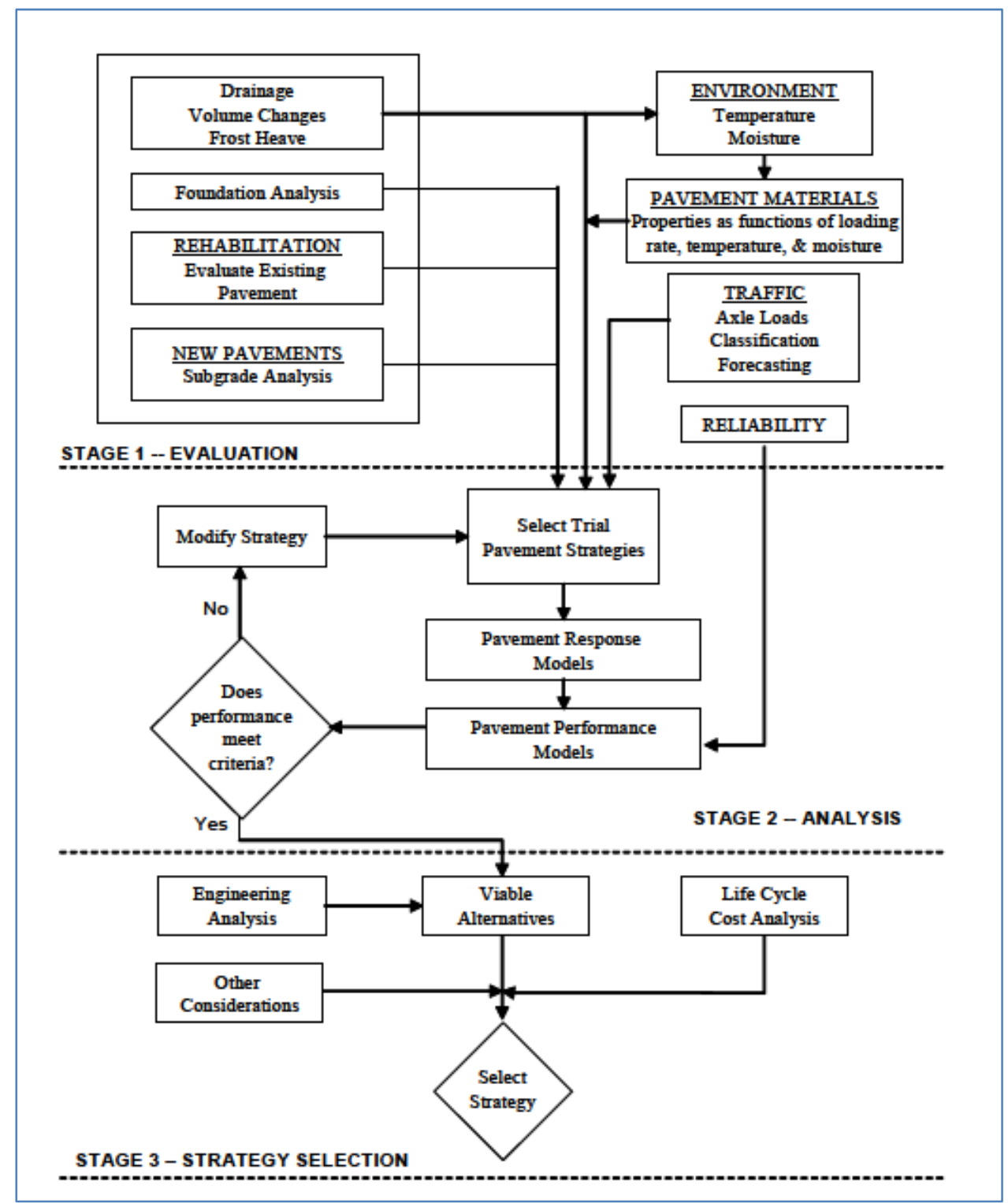

Figure 1: Design Process (NCHRP 1-37A, 2004)

The process can be summarized in three stages:

- Stage one: Definition of inputs, comprising the definition of the material characterization, traffic data, axle load spectra, and climate. 
- Stage two: Process of design, comprising trial designs, calculation through the equation models and checking against performance criteria.

- Stage three: Trials are analyzed in order to select the best option that is consistent with life cycle cost analysis.

\subsubsection{Principles of the Mechanistic Procedure}

Behind the prediction of pavement damage is the calculation of stresses, strains and deflections developed in the pavement structure. This mechanical response is a function of traffic loading, environmental conditions and material properties.

To calculate the state of stresses, strains and deflections of the pavement structure, different theories have been used. These are: The Multilayer Elastic Theory, the Viscoelastic theory, the dynamic analysis (inertial effects), Thermal Models (variability in temperature), and Finite Element methods.

The Elastic Layered Theory was developed by Burmister (1945). Yoder and Witczak (Yoder et al., 1975) defined the concept of multi-layer elastic in Figure 2. According to the theory, the calculation of stresses, strains and deflections can be obtained at any point within the pavement structure (Huang, 2004). For that, it is necessary to follow some assumptions:

- The thickness of the layer at the bottom of the pavement structure is infinite.

- The different layers of the pavement structure are infinite in the horizontal direction.

- Every layer has a finite thickness, $h_{i}$.

- Every layer is linearly elastic, isotropic, continuous, and homogeneous.

- Every layer is defined with a value for the elastic modulus $E_{\mathrm{i}}$ and a Poisson's ratio $v_{\mathrm{i}}$.

- The material within the fully bonded layers is weightless.

- The shear stress and the radial displacement between the layers is zero.

- Loads are applied vertically on the pavement surface over a circular area (radius a) uniformly distributed. There is a full friction between the structure layers as a result of the application of loads. There is not shear forces developed when the load is applied.

The calculation of stresses and deformation is done with JULEA, a computer program that uses the linear elastic theory implemented within MEPDG. The JULEA program needs few inputs data, such as: the elastic modulus for unbound layers, dynamic modulus for HMA layers, layer thicknesses, Poisson's ratio, pressure, spacing and contact area of the tire.

\subsubsection{Hierarchical Design Input in MEPDG}

The guide uses three hierarchical levels. They are designated as: Level 1, Level 2 and Level 3. . These levels represent the different possible approaches and efforts employed in determining input properties, and give the designer the flexibility in selecting the inputs for performing the design. According to MEPDG (NCHRP 1-37A, 2004): 
Level 1: Contains the highest precision in the selection of inputs. For this level, it is necessary to perform tests in the laboratory. This is the level that takes more time for obtaining information for design.

Level 2: $\quad$ Contains a medium level of precision in the selection of inputs; the use of predictive correlation equations is incorporated in lieu of laboratory tests.

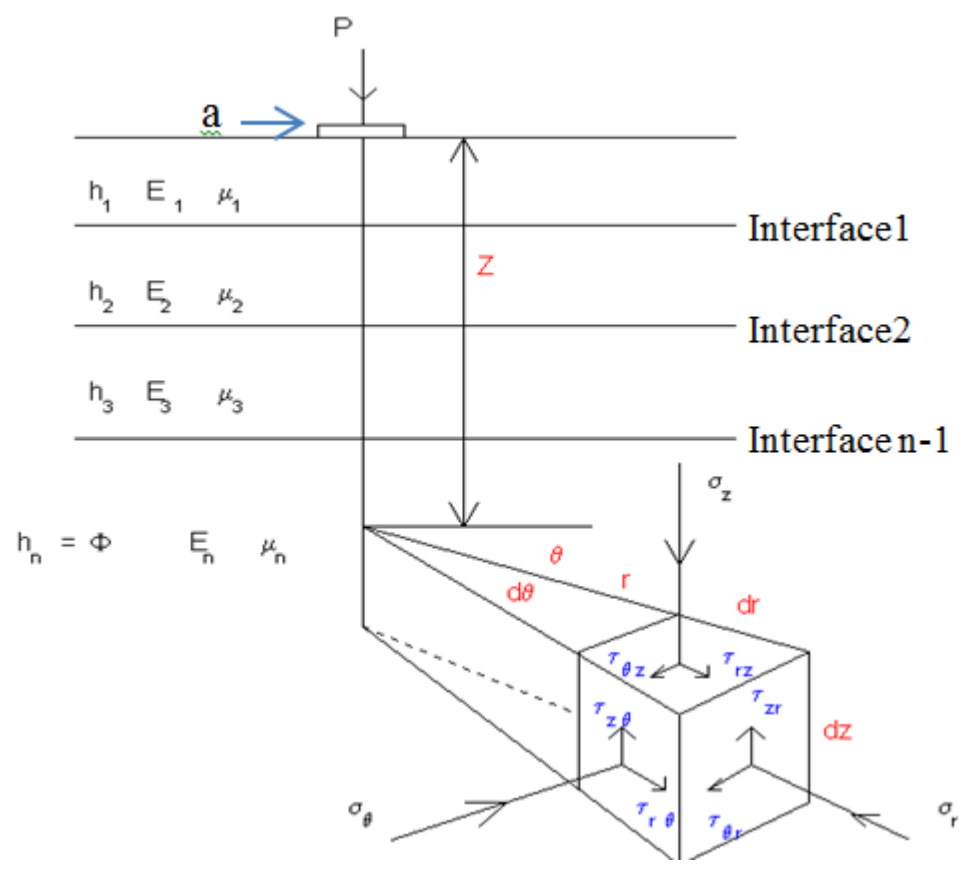

Figure 2: Multilayer Elastic System (Yoder et al., 1975)

Level 3: Contains a low level of precision in the selection of inputs; inputs are taken from existing information, correlations, or typical values. There is no laboratory tests involved.

A combination of Levels 1, 2 and 3 can be used in a design. Once the inputs are defined, the calculations are the same for every level.

\subsubsection{Traffic}

MEPDG uses full axle load spectrum in traffic analysis. The vehicle classification is compound for thirteen classes, shown in the figure 3. 


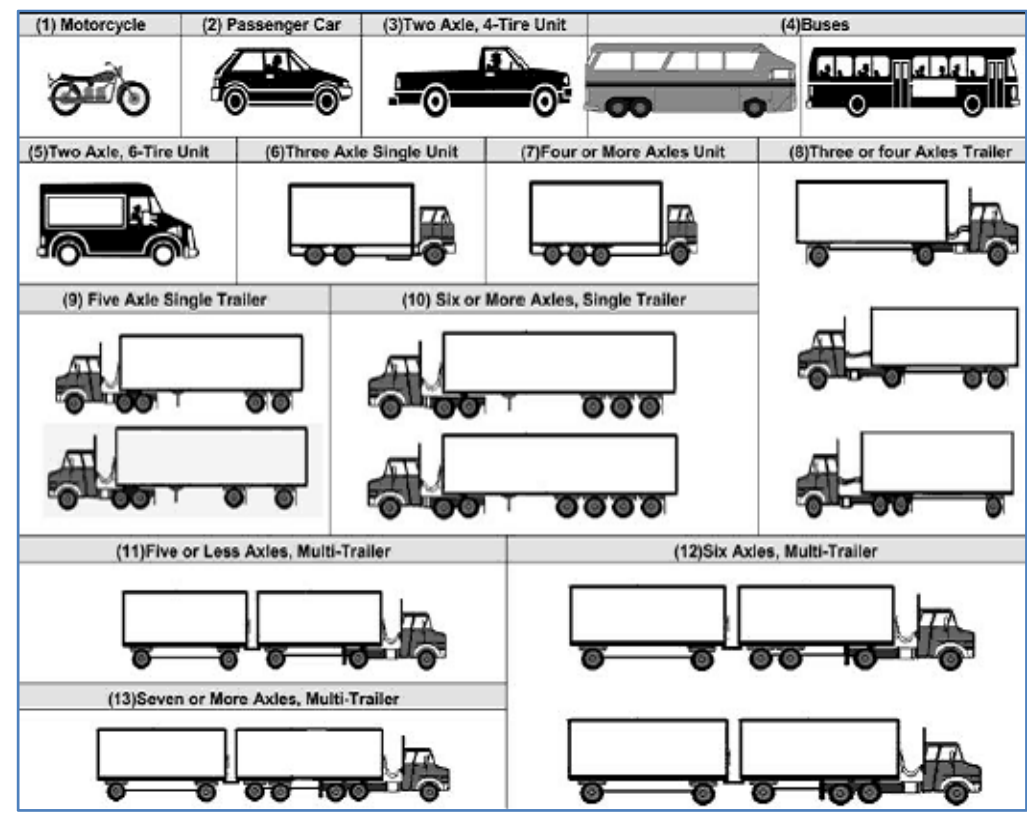

Figure 3: FHWA vehicle classification

(http://support.diamondtraffic.com/knowledgemanager/questions/46/FHWA+Vehicle+Classification+Scheme+F+Report)

In MEPDG the Annual Average Daily Truck traffic (AADTT) distribution consider classes 4 through Class 13. The data sources used are Weight in Motion (WIM), used to describe the traffic as an axle load distribution for every truck class and for each axle type, and Automatic Vehicle Classification (AVC) used for class distribution and vehicle counts for traffic characterization (NCHRP 1-37A, 2004).

\section{Inputs required for traffic characterization}

According to MEPDG, there is a list of inputs required for traffic calculation, as follows:

- Traffic Volume (Base year information). This is the first year the project is opened to traffic. . This is a function of:

- The two-way annual average daily truck traffic (AADTT).

- Numbers of lanes in the design direction

- The percent of trucks in design direction and design lane

- The vehicle operational speed.

- Traffic Volume adjustment factors

- Monthly adjustment

- Vehicle class distribution

- Hourly truck distribution

- Traffic growth factors

- Axle load distribution factors

- Number axles per truck

- Axle configuration

- Wheel base 


\section{Prediction of Total Traffic}

According to MEPDG Equation 2.16 is used for the calculation of Total Traffic (NCHRP 1-37A, 2004):

$$
T T_{1, j, i}=\left(A A D T T_{1}\right)\left(M D F_{j}\right)\left(H D F_{i}\right)(D D F)(L D F)(\text { number of days })
$$

where,

$T T_{1, j, i}=$ Total Number of trucks for a time increment $\mathrm{i}$, month $\mathrm{j}$ and year 1

AADTT $_{1}=$ Annual number of trucks per day for year 1

$M D F_{j} \quad=\quad$ Monthly distribution factor of month $\mathrm{j}$

$H D F_{i} \quad=\quad$ Hourly distribution factor of time increment $\mathrm{i}$

$D D F \quad=\quad$ Directional distribution factor

$L D F \quad=\quad$ Lane distribution factor

number of days $=$ number of days within the period design

$T_{1, j, i, k}=\left(T T_{1, j, i}\right)\left(N T P_{k}\right)$

$\mathrm{T}_{1, \mathrm{j}, \mathrm{i}, \mathrm{k}} \quad=\quad$ Total number of trucks for each truck class

$\mathrm{NTP}_{\mathrm{k}} \quad=\quad$ Truck class distribution percentage for truck class $\mathrm{k}$

$N A_{1, j, i, k, a}=\left(T_{1, j, i, k}\right)\left(N A T_{k, a}\right)$

$\mathrm{NA}_{1, \mathrm{j}, \mathrm{i}, \mathrm{k}, \mathrm{a}}=$ Total number of axles for each axle type for that truck class

$\mathrm{NAT}_{\mathrm{k}, \mathrm{a}}=$ Average number of axles by axle type for each truck class

$A L_{l, j, i, k, a, w}=\left(N W P_{a, w}\right)\left(N A_{1, j, i, k, a}\right)$

$\mathrm{AL}_{1, \mathrm{j}, \mathrm{i}, \mathrm{k}, \mathrm{a}, \mathrm{w}}=$ Number of axles within each load group for a specific axle type

$\mathrm{NWP}_{\mathrm{a}, \mathrm{w}} \quad=\quad$ Normalized axle load distribution (\%) for a specific load group.

In doing so, the total number of axles for every class under every load group is the number used for determining the number of repetitions in the time increment.

\subsubsection{Climate}

Climate is incorporated into the pavement structure analysis through the Enhanced Integrated Climatic Model (EICM). The initial version was developed by the Federal Highway Administration followed by a research made by the University of Illinois, United States Army Cold Regions Research and Engineering Laboratory and Texas A\&M University. The model exists as a computer program that is merged into the MEPDG, performing calculations that lead to the following tasks:

Provide the resilient modulus to the user; analyze the change in moisture within the materials throughout time and depth, evaluate the effect of freezing, thawing and soil moisture 
conditions, analyze how resilient modulus changes in the computation of the response of the pavement structure (NCHRP 1-37A, 2004).

MEPDG, the latitude, longitude, elevation, and the depth of water table in feet are the inputs required for selecting the station in order to generate the climatic file for the project.

\subsubsection{Response Model in the Design of Flexible Pavements}

The mechanical response of a pavement structure is a function of traffic loading, weather conditions, and material properties. These factors are considered in the analysis performed by the response models of the pavement structure. The output of the analysis includes permanent deformation in asphaltic layers, permanent deformation in the total structure, fatigue, thermal cracking, and terminal International Roughness Index, IRI. These are the distresses in a flexible pavement that can be developed through the life of the structure.

The design process is based on a comparison between predicted distresses and performance criteria, which determines whether a trial set of inputs (trial design) will be accepted or rejected. For each distress evaluated, there is a group of models that correlate the mechanical response (given by stresses and strains) with accumulated damage through the design period for which the pavement structure is designed.

\subsubsection{Pavement Performance}

The concept of pavement performance considers functional performance, structural performance and safety. According to the MEPDG, the most important concern is functional and structural performance. In structural performance includes the analysis of fatigue cracking and permanent deformation for flexible pavements. The functional performance is related to the service of the highway to the user; the most important functionality condition is serviceability, which is an indicator of comfort or ride quality. The serviceability concept is expressed in terms of the Present Serviceability Index (PSI). This term is obtained through the measurement of roughness due to distresses such as fatigue cracking, and rutting, under traffic and environmental conditions. Roughness is the indicator selected by MEPDG, through IRI. Equation 2.20 shows the general model for roughness (NCHRP 1-37A, 2004):

$$
S(t)=S_{0}+\left(a_{1} S_{D(t) 1}+a_{2} S_{D(t) 2}+\ldots \ldots \ldots \ldots+a_{n} S_{D}(t) n\right)+b_{j} S_{j}+c_{j} M_{j}
$$

Where,

$\mathrm{S}_{(\mathrm{t})}=$ pavement roughness at a specific time, $\mathrm{t}(\mathrm{IRI}, \mathrm{in} / \mathrm{mi})$.

$\mathrm{S}_{0}=$ initial roughness immediately after construction (IRI, in $/ \mathrm{mi}$ ).

$\mathrm{S}_{\mathrm{D}(\mathrm{t})(\mathrm{i}=1 \text { to } \mathrm{n})}=\quad$ change of roughness due to its distress at a given time $\mathrm{t}$ in the analysis period.

$a_{(i=1 \ldots n)}, b_{j}, c_{j}=\quad$ regression constants.

$\mathrm{S}_{\mathrm{j}}=$ change in roughness due to site factors (subgrade and age)

$\mathrm{M}_{\mathrm{j}} \quad=\quad$ change in roughness due to maintenance activities. 
Figure 4 gives a schematic time history of pavement structure performance expressed as a function of roughness and serviceability (NCHRP 1-37A, 2004).

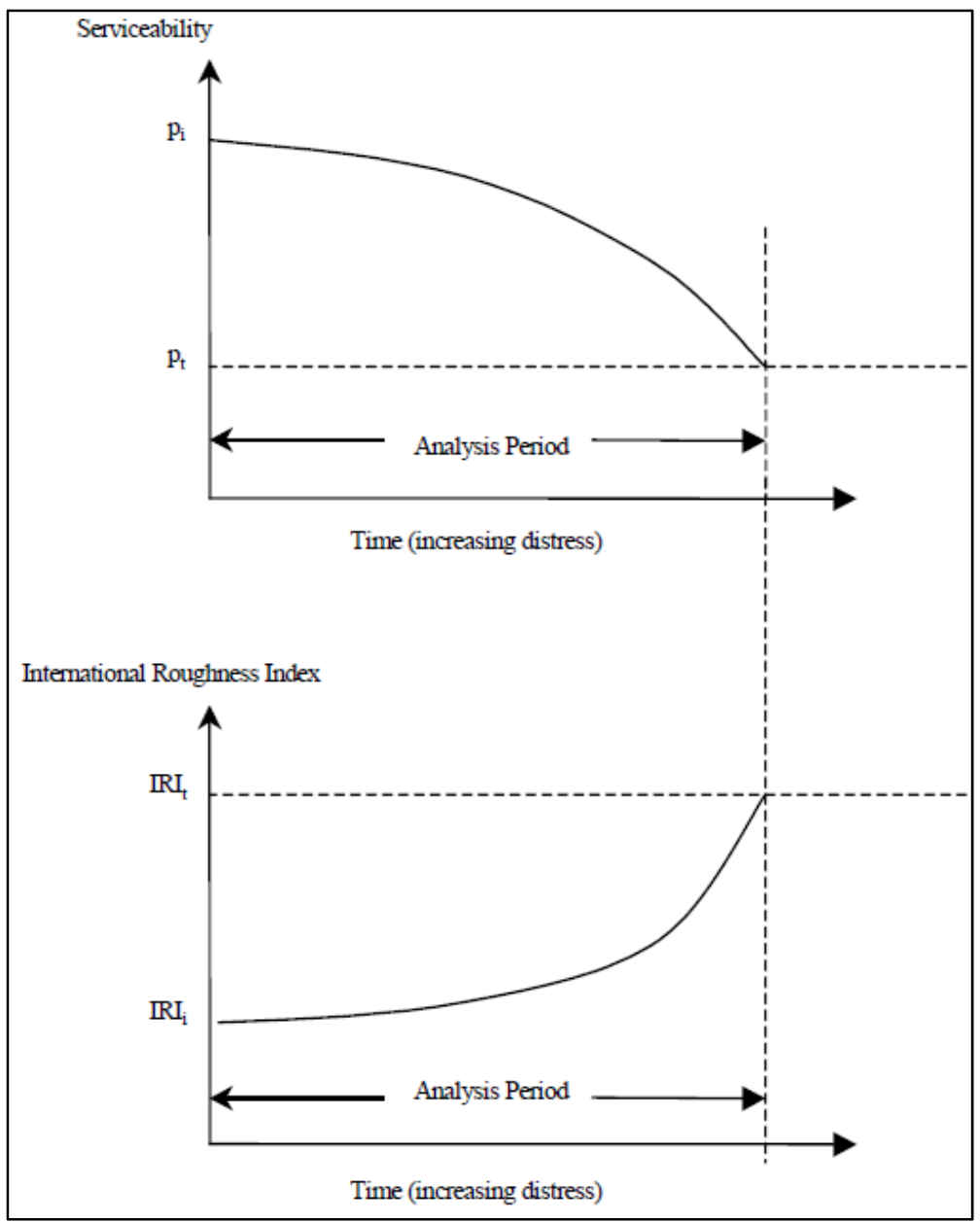

Figure 4: Pavement Performance trends and IRI values.( NCHRP 1-37A, 2004)

\subsubsection{Distress Prediction Equations for Design of Flexible Pavements}

The use of Transfer Functions and predictive equations is implemented in MEPDG. The distress indicators are: smoothness, asphaltic layers and total permanent deformation, fatigue cracking (longitudinal and alligator cracking) and thermal cracking. These distress indicators are described below:

\section{Smoothness Prediction}

Smoothness is defined as the measurement of the irregularities in the surface of the pavement that can affect the quality of ride. Smoothness also impacts the operational speed of the road, fuel consumption, and maintenance of vehicles (WSDOT,2011). 
In MEPDG the increment of roughness is related to deformations in the surface of the pavement, a site factor and maintenance. A model of roughness for new hot mix asphalt pavement and overlays of flexible pavements over time is given in Equation 2.21 (AASHTO, 2005).

$$
I R I=I R I o+0.0150(S F)+0.400\left(F C_{\text {total }}\right)+0.0080(T C)+40.0(R D)
$$

Where:

IRI $=$ International roughness index

IRIo $=$ Initial IRI after construction, in $/ \mathrm{mi}$.

$\mathrm{FC}_{\text {total }}=$ Area of fatigue cracking (combined alligator and longitudinal cracking in the wheel path), percent of total lane area

$\mathrm{TC}=$ Length of transverse cracking, $\mathrm{ft} / \mathrm{mi}$

$\mathrm{RD} \quad=$ Average rut depth, in

$\mathrm{SF}=$ Site factor

$$
S F=\operatorname{Age}(0.02003(P I+1)+0.007947(\text { Rain }+1)+0.000636(F I+1))
$$

Where:

$\begin{array}{ll}\text { Age } & =\text { Pavement age, years } \\ \text { PI } & =\text { Percent plasticity index of the soil } \\ \text { Rain } & =\text { Average annual rainfall, in } \\ \text { FI } & =\text { Average annual freezing index, }{ }^{\circ} \mathrm{F} \text { days }\end{array}$

$F I=\sum_{i=1}^{n}(0-T i)$

Where:

FI $=$ freezing index, degrees Celsius $\left({ }^{\circ} \mathrm{C}\right)$

$\mathrm{T}_{\mathrm{i}} \quad=$ average daily air temperature on day I when the temperature is below freezing, ${ }^{\circ} \mathrm{C}$

$\mathrm{n}=$ days in the specified period when average daily temperature is below freezing

$\mathrm{i}=$ number of days below freezing

The number of days for which the average daily temperature is below freezing is used in Equation 2.23. Hence, the freezing index is the negative of the sum of all daily average temperature below $0^{\circ} \mathrm{C}$ in a given period.

\section{Permanent Deformation Prediction}

Permanent deformation is estimated as the sum of an incremental rutting depth computed for sublayers of the pavement structure. MEPDG subdivides every layer of the pavement structure into sub-layers. Time is discretized such that one month of analysis is subdivided in five sub-seasons. For each sub-season, permanent deformation is calculated at mid-depth for every sub-layer of the pavement structure. The permanent deformation at one point in time is the sum of permanent deformations for each sublayer. MEPDG uses load spectra. For every load, 
there is a permanent deformation that contributes to the total permanent deformation (AASHTO, 2005). The calculation is described below:

$\Delta_{p}=\sum_{i=1}^{n} \varepsilon_{p}^{i} \times h^{i}$

Where,

$\Delta_{\mathrm{p}} \quad=\quad$ Permanent or plastic vertical deformation of a layer, inches.

$\mathrm{n}=$ Number of sublayers.

$\varepsilon_{\mathrm{p}}^{\mathrm{i}} \quad=\quad$ Total plastic axial strain in sublayer $\mathrm{i}$.

$\mathrm{h}^{\mathrm{i}} \quad=$ Thickness of sublayer $\mathrm{i}$.

The permanent deformation is computed in asphaltic, unbound layers and subgrade. There are different models for the calculation, accordingly. A model for asphaltic layers after a national calibration is given in Equation 2.25:

$\frac{\varepsilon_{p}}{\varepsilon_{r}}=k_{1} * 10^{-3.4488} T^{1.5606} N^{0.479244}$

Where,

$\varepsilon_{p} \quad=\quad$ Accumulated permanent deformation in the HMA layer or sub-layer (in/in).

$\varepsilon_{r} \quad=\quad$ Resilient or elastic strain from structural response model at the mid-depth of each HMA sublayer (in/in).

$\mathrm{N}=$ Number of axle Load repetitions. (For every period and load type)

$\mathrm{T}=$ Mix or pavement temperature, ${ }^{\circ} \mathrm{F}$.

$K_{1}=\left(C_{1}+C_{2} *\right.$ depth $) * 0.328196^{\text {depth }}$

$C_{1}=-0.1039 * h_{a c}^{2}+2.4868 * h_{a c}-17.342$

$C_{2}=0.0172 * h_{a c}^{2}-1.7331 * h_{a c}+27.428$

Where,

depth $\quad=\quad$ Depth below the surface (in)

$h_{a c} \quad=\quad$ Total HMA thickness (in)

The permanent deformation model for unbound layers is (AASHTO, 2005):

$\Delta_{p(\text { soil })}=\beta_{s 1} K_{s 1} \varepsilon_{v} h_{\text {soil }}\left(\frac{\varepsilon_{0}}{\varepsilon_{r}}\right) e^{-\left(\frac{\rho}{N}\right)^{\beta}}$

Where, $\Delta_{\mathrm{p}(\text { soil) }}=$ Permanent or plastic deformation for the granular layer/sublayer (in).

$\mathrm{N}=$ Number of axle load application.

$\varepsilon_{0}=$ Intercep determined from laboratory repeated load permanent deformation test, in/in.

$\varepsilon_{r} \quad=$ Resilient strain imposed in laboratory test to obtain $\varepsilon_{\mathrm{o}}$ and $\rho$, in/in 
$\varepsilon_{v} \quad=$ Average vertical resilient strain in the layer/sublayer calculated by structural response model

$h_{\text {soil }}=$ Thickness of the layer/sublayer (in).

$K_{s 1}=$ Global calibration coefficient; $K_{s 1}=1.673$ for granular and 1.35 for fine-grained material.

$\beta_{\text {s1 }}=$ Local calibration constant for the rutting in the unbound granular and subgrade materials layers; it is 1.0 for the global calibration effort.

$$
\begin{aligned}
& \log \beta=-0.61119-0.017638\left(\omega_{c}\right) \\
& \rho=10^{9}\left(\frac{c_{o}}{\left(1-\left(10^{9}\right)^{\beta}\right.}\right)^{\frac{1}{\beta}} \\
& c_{o}=\ln \left(\frac{a_{1} M r^{b_{1}}}{a_{9} M r^{b_{9}}}\right)=0.0075
\end{aligned}
$$

Where,

$\begin{array}{lll}\omega_{c}= & \text { water content } \% \\ M r= & \text { Resilient Modulus of the unbound layer or sublayer, psi } \\ a_{1,9}= & \text { Regression constant } a_{1}=0.15 a_{9}=20 \\ \mathrm{~b}_{1,9}= & \text { Regression constant } \mathrm{b}_{1}=0.0 \quad \mathrm{~b}_{9}=0.0\end{array}$

\section{Fatigue Cracking Prediction}

MEPDG models both top-down and bottom-up fatigue cracking. The approach is "based on calculating the fatigue damage at the surface for the top-down cracking and at the bottom of each asphalt layer for the bottom up cracking" (AASHTO, 2005).

The damage is calculated upon Miner's Law as follows. The damage is the summation of the incremental damage index over time (AASHTO, 2005).

$D=\sum_{i=1}^{T} \frac{n_{i}}{N_{f-H M A}}$

Where,

$\mathrm{D}=$ Cumulative damage

$\mathrm{T}=$ Total number of periods

$n_{i} \quad=$ number of axle load applications in the time period

$N_{f-H M A}=$ allowable number of axle load applications

The calculation of fatigue damage depends on the tensile strain and the dynamic modulus of the concrete asphalt mix. Equation 2.34 calculates the allowable number of axle load applications to predict cracking (AASHTO, 2005):

$N_{f-H M A}=K_{f 1} \beta_{f 1}(C)(C H)\left(\varepsilon_{t}\right)^{K_{f 2} \beta_{f 2}}\left(E_{H M A}\right)^{K_{f 3} \beta_{f 3}}$ 
Where,

$$
\begin{aligned}
& N_{f-H M A}=\text { allowable number of axle load applications } \\
& \varepsilon_{\mathrm{t}} \quad=\quad \text { tensile strain at the critical location, in/in } \\
& \mathrm{E}_{\text {HMA }}=\text { stiffness of the HMA, psi } \\
& K_{f 1}, K_{f 2}, K_{f 3}=\quad \text { Global field calibration parameters, } \\
& K_{f 1},=0.007566, K_{f 2}=-3.9492, K_{f 3}=-1.281 \\
& \beta_{f 1}, \beta_{f 2}, \beta_{f 3}=\text { Local field constants (set as } 1.0 \text { in the global calibration) } \\
& C \quad=\quad \text { laboratory to field adjustment factor. } \\
& C=10^{M} \\
& V_{b} \quad=\quad \text { Effective binder content (\%) } \\
& V_{a} \quad=\quad \text { air voids (\%) } \\
& \mathrm{CH}=\quad \text { Factor thickness correction (bottom-up and Top-down) }
\end{aligned}
$$$$
M=4.84\left(\frac{V_{b}}{V_{a}+V_{b}}-0.69\right)
$$

For bottom-up cracking, the $\mathrm{CH}$ is computed as:

$$
C H=\frac{1}{0.000398+\frac{0.003602}{1+e^{(11.02-3.49 * h a c)}}}
$$

And, $\mathrm{CH}$ for top-down cracking is computed as:

$$
C H=\frac{1}{0.01+\frac{12}{1+e^{(15.676-2.8186 * h a c)}}}
$$

Where,

$$
h_{a c} \quad=\quad \text { Total HMA thickness (in) }
$$

These equations lead to the final calculation for bottom-up cracking as the percentage of total lane area, as follows:

$$
F C_{\text {bottom }}=\left(\frac{6000}{1+e^{\left(C_{1} * C^{\prime}{ }_{1}+C_{2} * C^{\prime}\right.} 2^{* \log 10(D * 100))}}\right) *\left(\frac{1}{60}\right)
$$

Where,

$$
\begin{array}{lll}
\mathrm{FC}_{\text {bottom }} & = & \text { bottom-up fatigue cracking, percent lane area } \\
\mathrm{D} & = & \text { bottom-up fatigue damage } \\
C_{1} & =1.0 \\
C^{\prime}{ }_{1} & =-2 * C^{\prime}{ }_{2}
\end{array}
$$




$\begin{array}{lll}C_{2} & = & 1.0 \\ C^{\prime}{ }_{2} & = & -2.40874-39.748 *\left(1+\mathrm{h}_{\mathrm{ac}}\right)^{-2.856} \\ h_{a c} & = & \text { Total HMA thickness (in) }\end{array}$

The calculation units for top-down cracking are feet/mile in Equation 2.40

$F C_{\text {top }}=\left(\frac{1000}{1+e^{(7.0-3.5 * \log 10(D * 100))}}\right) *(10.56)$

Where,

$F C_{\text {top }} \quad=\quad$ top-down fatigue cracking, feet $/$ mile

$D \quad=\quad$ top-down damage

\section{Thermal Cracking Prediction Model}

Asphalt pavements are normally constructed without joints; this results in smooth driving characteristics. However, thermal cracking can develop under certain conditions. Dave et al.,

(Dave et al., 2011) describe this as:

During the periods of severe low temperature climatic events, caused by low absolute temperatures or high cooling rates, thermal stresses build up in the continuous asphalt concrete layer. Damage accumulates as thermally induced stresses approach the material strength, and eventually cracks can be formed. This type of cracking is normally referred to as thermal cracking. Thermal cracking in asphalt pavements is often formed in periodic manner and is a prevalent form of pavement distress and damage mechanism in areas with cold climates:

Equation 2.41 is used for calculation of the amount of thermal cracking:

$$
C_{f}=\beta_{1} * N *\left(\frac{\log \frac{c}{h_{a c}}}{\sigma_{d}}\right)
$$

Where,

$C_{f}=$ Predicted thermal cracking, $\mathrm{ft} / \mathrm{mi}$

$\beta_{1}=$ Regression coefficient (global calibration) $=400$

$N \quad=$ Standard normal distribution, determined by assuming the logarithm of depth of cracks is normally distributed with mean equal to the crack depth predicted by the model.

$\sigma_{d}=$ Standard deviation of the log of the depth of cracks, from national calibration 0.769 in

$C \quad=$ Crack depth, in

$h_{a c}=$ thickness asphalt layer, in

According to the Guide, the calculation of the amount of crack propagation induced by a given thermal cooling is calculated through the Paris law crack propagation as follows: 


$$
\begin{aligned}
& \Delta C=A \Delta K^{n} \\
& \Delta K=\sigma_{T I P}\left[0.45+1.99\left(C_{o}\right)^{0.56}\right]
\end{aligned}
$$

Where,

$\Delta C \quad=\quad$ Change in the crack depth due to a cooling cycle

$\Delta K=$ Change in stress intensity factor induced by cooling cycle

$\sigma_{T I P} \quad=\quad$ Stress in the asphalt concrete at depth of crack tip (psi)

$C_{o} \quad=\quad$ Current crack length, $\mathrm{ft}$

$A, n \quad=\quad$ Fracture parameters for the hot mix asphalt.

$A=10^{\left(\beta *\left(4.389-2.52 * \log \left(E_{H M A} * \sigma_{m} * n\right)\right)\right)}$

$n=0.8 *\left(1+\frac{1}{m}\right)$

$\begin{array}{lll}E_{H M A} & = & \text { Dynamic Modulus, psi } \\ \sigma_{m} & = & \text { Undamaged mixture tensile strength, psi } \\ \beta & = & \text { local calibration parameter } \\ m & = & \text { value from the indirect tensile creep compliance laboratory curve }\end{array}$

\subsubsection{Material Properties}

A scheme of the interaction of traffic Model, environmental effects, response models, distress models and performance predictions in MEPDG is given in Figure 5 (NCHRP 1-37A, 2004).:

The major material input properties are described in Table 3, where materials are separated by category and the description of critical response computations, distress-transfer functions and climatic modeling are given for every condition

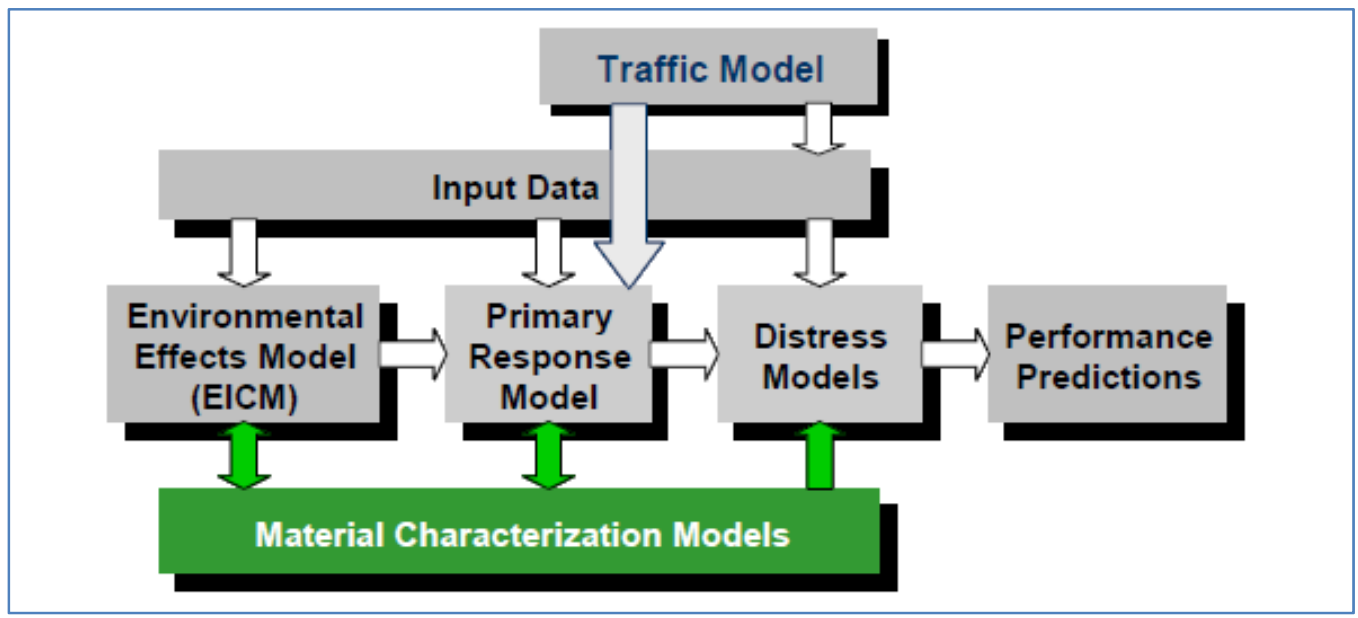

Figure 5: Interaction between materials with other component in MEPDG (NCHRP 1-37A, 2004). 
Table 3: Material Input Considerations by material group (NCHRP 1-37A, 2004).

\begin{tabular}{|c|c|c|c|}
\hline \multirow{2}{*}{$\begin{array}{l}\text { Materials } \\
\text { Category }\end{array}$} & \multicolumn{3}{|c|}{ Materials Inputs Required } \\
\hline & $\begin{array}{l}\text { Materials inputs required for critical } \\
\text { response computations }\end{array}$ & $\begin{array}{c}\text { Additional materials inputs required for } \\
\text { distress/transfer functions }\end{array}$ & $\begin{array}{l}\text { Additional materials inputs required for } \\
\text { climatic modeling }\end{array}$ \\
\hline $\begin{array}{l}\text { Hot-Mix Asphalt Materials } \\
\text { (this covers surface, binder, } \\
\text { base, and subbase courses) }\end{array}$ & $\begin{array}{l}\text { Time-temperature dependent } \\
\text { dynamic modulus }\left(\mathrm{E}^{*}\right) \text { of HMA } \\
\text { mixture. } \\
\text { - Poisson's ratio. }\end{array}$ & $\begin{array}{l}\text { Tensile strength, creep compliance, } \\
\text { coefficient of thermal expansion. }\end{array}$ & $\begin{array}{l}\text { Surface shortwave absorptivity (only } \\
\text { required for surface course), thermal } \\
\text { conductivity, and heat capacity of HMA. } \\
\text { Asphalt binder viscosity (stiffness) } \\
\text { characterization to account for aging. }\end{array}$ \\
\hline $\begin{array}{l}\text { PCC Materials } \\
\text { (this covers surface layer only) }\end{array}$ & $\begin{array}{ll}\text { - } & \text { Static modulus of elasticity }(\mathrm{E}) \\
& \text { adjusted with time. } \\
\text { - } & \text { Poisson's ratio. } \\
\text { - } & \text { Unit weight } \\
\text { - Coefficient of thermal expansion. }\end{array}$ & $\begin{array}{l}\text { Modulus of rupture, split tensile } \\
\text { strength, compressive strength, } \\
\text { cement type, cement content, water- } \\
\text { to-cement (w/c) ratio, ultimate } \\
\text { shrinkage, amount of reversible } \\
\text { shrinkage. } \\
\end{array}$ & $\begin{array}{l}\text { - Surface shortwave absorptivity, thermal } \\
\text { conductivity, and heat capacity of PCC. }\end{array}$ \\
\hline $\begin{array}{l}\text { Chemically Stabilized Materials } \\
\text { (this covers lean concrete, } \\
\text { cement treated, soil cement, } \\
\text { lime-cement-flyash, lime- } \\
\text { flyash, and lime stabilized } \\
\text { layers) }\end{array}$ & $\begin{array}{l}\text { - Elastic modulus }(\mathrm{E}) \text { for high quality } \\
\text { lean concrete, cement treated } \\
\text { material, soil cement, lime-cement- } \\
\text { flyash, and lime-cement-flyash. } \\
\text { Resilient modulus }\left(\mathrm{M}_{\mathrm{f}}\right) \text { for lime } \\
\text { stabilized soil. } \\
\text { - Poisson's ratio. } \\
\text { - Unit weight. }\end{array}$ & $\begin{array}{l}\text { Minimum resilient modulus (used in } \\
\text { flexible design), Modulus of rupture } \\
\text { (used in flexible design), base } \\
\text { erodibility (for rigid design). }\end{array}$ & $\begin{array}{l}\text { - Thermal conductivity and heat capacity of } \\
\text { PCC. }\end{array}$ \\
\hline $\begin{array}{l}\text { Unbound Base/ Subbase and } \\
\text { Subgrade Materials }\end{array}$ & $\begin{array}{ll} & \text { Seasonally adjusted resilient } \\
& \text { modulus }\left(\mathrm{M}_{\mathrm{r}}\right) \text {. } \\
\text { - } & \text { Poisson's ratio. } \\
\text { - } & \text { Unit weight. } \\
\text { - } & \text { Coefficient of lateral pressure. } \\
\end{array}$ & $\begin{array}{l}\text { - Gradation parameters and base } \\
\text { erodibility (for rigid design). }\end{array}$ & $\begin{array}{l}\text { Plasticity index, gradation parameters, } \\
\text { effective grain sizes, specific gravity, } \\
\text { saturated hydraulic conductivity, optimum } \\
\text { moisture contents, parameters to define the } \\
\text { soil water characteristic curve. }\end{array}$ \\
\hline $\begin{array}{l}\text { Recycled Concrete Materials- } \\
\text { Fractured PCC Slabs }\end{array}$ & $\begin{array}{ll}\text { - } & \text { Resilient modulus }\left(\mathrm{M}_{\mathrm{f}}\right) \\
& \text { Poisson's ratio. }\end{array}$ & - $\quad$ Base erodibility (for rigid design). & - Thermal conductivity and heat capacity. \\
\hline $\begin{array}{l}\text { Recycled hot asphalt mix } \\
\text { (central plant processed) }\end{array}$ & \multicolumn{3}{|c|}{ Treated same as hot-mix asphalt surface course. } \\
\hline $\begin{array}{l}\text { Recycled cold asphalt mix } \\
\text { (central plant or on-grade) }\end{array}$ & \multicolumn{3}{|c|}{ Treated same as hot-mix asphalt base course. } \\
\hline $\begin{array}{l}\text { Cold recycled asphalt pavement } \\
\text { (used as aggregate) }\end{array}$ & \multicolumn{3}{|c|}{ Treated same as granular materials with no moisture sensitivity. } \\
\hline Bedrock & $\begin{array}{ll}\text { - } & \text { Elastic modulus (E). } \\
\text { - } & \text { Poisson's ratio. } \\
\text { - Unit weight. } \\
\end{array}$ & None. & None. \\
\hline
\end{tabular}




\subsubsection{Viscosity of Asphalt Binder}

This section presents the analysis of viscosity for asphalt binder according to the models in MEPDG. There are four different models for aging of the asphalt binder developed by Mirza and Witczak (NCHRP 1-37A, 2004) at the University of Maryland. The system for analyzing asphalt binders throughout time and depth is called Global Aging System (GAS). This system enables the analysis of the behavior of different asphalt binders in a given climatic area. A summary of the equations for Global Aging System is showed in Equations 2.46 through 2.54 (NCHRP 1-37A, 2004):

\section{Binder Viscosity:}

$\log \log \eta=A+V T S \log \left(T_{R}\right)$

Where,

$\eta \quad=\quad$ Binder viscosity, $\mathrm{cP}$.

$\mathrm{T}_{\mathrm{R}}=$ Temperature, degree Rankine.

$\mathrm{A}=$ regression intercept.

VTS $=$ regression slope of viscosity temperature susceptibility.

\section{Hardening during construction, original to mix/lay-down model:}

$\log \left(\log \left(\eta_{t=0}\right)\right)=a_{0}+a_{1} \log \left(\log \left(\eta_{\text {orig }}\right)\right)$

$a_{0}=0.054405+0.004082 \times$ code

$a_{1}=0.972035+0.010886 \times$ code

Where,

$\eta_{t=0}=$ mix/lay-down viscosity, $\mathrm{cP}$.

$\eta_{\text {orig }}=$ original viscosity, $\mathrm{cP}$.

code $=$ hardening ratio ( 0 for average). See Table 4 :

Table 4: Recommended code value (MEPDG)

\begin{tabular}{|c|c|c|}
\hline $\begin{array}{c}\text { Mix/Lay-Down } \\
\text { Hardening } \\
\text { Resistance }\end{array}$ & $\begin{array}{c}\text { Expected Hardening } \\
\text { Ratio Values } \\
\text { HR }\end{array}$ & Code Value \\
\hline Excellent to Good & HR $\leq 1.030$ & -1 \\
\hline Average & $1.030 \leq \mathrm{HR} \leq 1.075$ & 0 \\
\hline Fair & $1.075<\mathrm{HR} \leq 1.100$ & 1 \\
\hline Poor & $\mathrm{HR}>1.100$ & 2 \\
\hline
\end{tabular}




\section{- Surface Aging Model:}

$\log \left(\log \left(\eta_{\text {aged }}\right)\right)=\frac{\log \left(\log \left(\eta_{t=0}\right)\right)+A t}{1+B t}$

Where,

$$
\begin{array}{lll}
A & = & -0.004166+1.41213(C)+(C) \log (\text { Maat })+(D) \log \left(\log \left(\eta_{\mathrm{t}=0}\right)\right) \\
B & = & 0.197725+0.068384 \log (C) \\
C & = & 10^{\left(274.4946-193.831 \log \left(T_{R}\right)+33.9366 \log \left(T_{R}\right)^{2}\right.} \\
D & = & -14.5521+10.47662 \log \left(T_{R}\right)-1.88161 \log \left(T_{R}\right)^{2} \\
\eta_{\text {aged }} & = & \text { aged viscosity, cP. } \\
\eta_{t=0}= & \text { viscosity at mix/lay-down, cP. } \\
M a a t & = & \text { mean annual air temperature, }{ }^{\circ} \mathrm{F} \\
T_{R} & = & \text { Temperature, Rankine. } \\
t & = & \text { time in months. }
\end{array}
$$

- Air void adjustment:

$$
\begin{aligned}
& \log \left(\log \left(\eta_{\text {aged }}\right)^{\prime}\right)=F_{V} \log \left(\log \left(\eta_{\text {aged }}\right)\right) \\
& F_{V}=\frac{1+1.0367 \times 10^{-4}(V A)(t)}{1+6.1798 \times 10^{-4}(t)} \\
& V A=\frac{V A_{\text {orig }}+0.011(t)-2}{1+4.24 \times 10^{-4}(t)(\text { Maat })+1.169 \times 10^{-3}\left(\frac{t}{\eta_{\text {orig }, 77}}\right)}+2
\end{aligned}
$$

Where,

$\eta_{\text {aged }} \quad=\quad$ aged viscosity, $\mathrm{cP}$.

VA $A_{\text {orig }} \quad$ initial air voids.

$t \quad=\quad$ time in months.

Maat $=$ mean annual air temperature, ${ }^{\circ} \mathrm{F}$

$\eta_{\text {orig, } 77}=\quad$ original binder viscosity at $77^{\circ} \mathrm{F}$, MPoise.

\section{- Viscosity Depth-Model:}

$\eta_{t, z}=\frac{\eta_{t}(4+E)-E\left(\eta_{t=0}\right)(1-4 z)}{4(1+E z)}$

Where,

$\eta_{t, z}=$ aged viscosity at time $\mathrm{t}$, and depth $z$, MPoise.

$\eta_{\mathrm{t}}=$ aged surface viscosity at time $\mathrm{t}$, MPoise.

$\eta_{t=0}=\quad$ viscosity at mix/lay-down, $\mathrm{cP}$. 


$$
\begin{array}{ll}
Z & =\text { Depth, in. } \\
\mathrm{E} & =23.83 \mathrm{e}^{(-0.0308 \text { Maat })} \\
\text { Maat } & =\text { mean annual air temperature, }{ }^{\circ} \mathrm{F}
\end{array}
$$

\subsubsection{Developing of the Master Curve for Asphalt Concrete}

The master curve explains how the dynamic modulus of the asphalt concrete changes as a function of frequencies (loading rate), and temperature. The curve is built on the principle of time-temperature superposition for a reference temperature, normally $70^{\circ} \mathrm{F}$. Table 5 shows the information needed to construct the master curve at different levels according to MEPDG.

\begin{tabular}{|c|c|c|}
\hline $\begin{array}{c}\text { Material } \\
\text { Group } \\
\text { Category }\end{array}$ & $\begin{array}{l}\text { Input } \\
\text { Level }\end{array}$ & Description \\
\hline \multirow{3}{*}{$\begin{array}{c}\text { Asphalt } \\
\text { Materials }\end{array}$} & 1 & $\begin{array}{l}\text { - Conduct } \mathrm{E}^{*} \text { (dynamic modulus) laboratory test (NCHRP 1-28A) at loading } \\
\text { frequencies and temperatures of interest for the given mixture. } \\
\text { - Conduct binder complex shear modulus }\left(\mathrm{G}^{*}\right) \text { and phase angle }(\delta) \text { testing on the } \\
\text { proposed asphalt binder (AASHTO T315) at } \omega=1.59 \mathrm{~Hz}(10 \mathrm{rad} / \mathrm{s}) \text { over a range } \\
\text { of temperatures. } \\
\text { - From binder test data estimate Ai-VTSi for mix-compaction temperature. } \\
\text { - Develop master curve for the asphalt mixture that accurately defines the time- } \\
\text { temperature dependency including aging. }\end{array}$ \\
\hline & 2 & $\begin{array}{l}\text { - No } E^{*} \text { laboratory test required. } \\
\text { - Use } E^{*} \text { predictive equation. } \\
\text { - Conduct } \mathrm{G}^{*}-\delta \text { on the proposed asphalt binder (AASHTO T315) at } \omega=1.59 \mathrm{~Hz} \\
\text { (10 rad/s) over a range of temperatures. The binder viscosity or stiffness can also } \\
\text { be estimated using conventional asphalt test data such as Ring and Ball Softening } \\
\text { Point, absolute and kinematic viscosities, or using the Brookfield viscometer. } \\
\text { - Develop Ai-VTSi for mix-compaction temperature. } \\
\text { - Develop master curve for asphalt mixture that accurately defines the time- } \\
\text { temperature dependency including aging. }\end{array}$ \\
\hline & 3 & $\begin{array}{l}\text { - No } E^{*} \text { laboratory testing required. } \\
\text { - Use E* predictive equation. } \\
\text { - Use typical Ai-VTS- values provided in the Design Guide software based on PG, } \\
\text { viscosity, or penetration grade of the binder. } \\
\text { - Develop master curve for asphalt mixture that accurately defines the time- } \\
\text { temperature dependency including aging. }\end{array}$ \\
\hline
\end{tabular}

Table 5: Asphalt Dynamic Modulus ( $\left.\mathrm{E}^{*}\right)$ estimation at various hierarchical input levels for new or reconstruction design.

Source: http://onlinepubs.trb.org/onlinepubs/archive/mepdg/Part2_Chapter2_Materials.pdf

For representing the master curve a sigmoidal function is used, as defined in Equation

2.55:

$\log \left(E^{*}\right)=\delta+\frac{\alpha}{1+e^{\beta+\gamma\left(\log \left(t_{r}\right)\right)}}$

Where,
$E^{*} \quad=\quad$ dynamic modulus
$t_{r}=$ time of loading at the reference temperature
$\delta=\quad$ fitting parameter, that indicates the minimum value of $E^{*}$ 
$\alpha=$ fitting parameter, $\delta+\alpha$ represents the maximum value of $E^{*}$

$\beta$ and $\gamma=$ parameters describing the shape of the sigmoidal function

The parameters delta $(\delta)$ and alpha $(\alpha)$ depend on the aggregate gradation, binder content and air voids. The parameter beta $(\beta)$ and gamma $(\gamma)$ are function of the asphalt binder and the values of $\delta$ and $\alpha$.

The general form for calculating the shift factors is given in Equation 2.56:

$$
\begin{aligned}
& t_{r}=\frac{t}{a(T)} \\
& \log \left(t_{r}\right)=\log (t)-\log [a(T)]
\end{aligned}
$$

Where,

$t_{r} \quad=$ time of loading at the reference temperature

$t \quad=$ time of loading at temperature of interest

$a(T)=$ Shift factor as a function of temperature

$T \quad=$ Temperature of interest.

Equation 2.58 is used in MEPDG for calculate the shift factor (NCHRP 1-37A, 2004):

$$
\begin{aligned}
\log \left(t_{r}\right)= & \log (t)-c\left(\log (\eta)-\log \left(\eta_{T_{r}}\right)\right) \\
& \text { Where, } \\
t_{r} \quad & =\text { Reduce time, sec } \\
t & =\text { Loading time, sec } \\
\eta & =\text { Viscosity at the temperature of interest, } \mathrm{cP} \\
\eta_{T_{r}} & =\text { Viscosity at reference temperature and RTFO aging, } \mathrm{cP} \\
c & =\text { is a fitting parameter }
\end{aligned}
$$

For Level 1 analysis the fitting parameters $(\delta, \alpha \beta, \gamma$ and $c)$ are determined through laboratory testing and analysis. 1.25588 for Level 2 and 3. For Level 1 statistical analysis of test data is required to determine $\mathrm{c}$.

Although not explicitly stated in the MEPDG documentation, by using Equations 2.57 and 2.58 and algebraic manipulation, the shift factor is:

$$
\log [a(T)]=c\left(\log (\eta)-\log \left(\eta_{T_{r}}\right)\right)
$$


For Levels 2 and 3 the fitting parameters are estimated as a function of commonly measured asphalt mix properties. Equation $2.60^{1}$, a predictive empirical equation developed under NCHRP 1-37A, is used for estimating the dynamic modulus.

$$
\begin{aligned}
\log \left|E^{*}\right|=3.750063+0.02932 \rho_{200}-0.001767\left(\rho_{200}\right)^{2}-0.002841 \rho_{4}-0.058097 V_{a} \\
-0.802208\left(\frac{V_{\text {beff }}}{V_{\text {beff }}+V_{a}}\right) \\
+\frac{3.871977-0.0021 \rho_{4}+0.003958 \rho_{38}-0.000017\left(\rho_{38}\right)^{2}+0.00547 \rho_{34}}{1+e^{(-0.603313-0.313351 * \log (f)-0.383532 * \log (\eta))}}
\end{aligned}
$$

where,

$\left|E^{*}\right|=$ asphalt mix dynamic modulus, psi

$\eta \quad=$ binder viscosity, $10^{6}$ poise (at any temperature, degree of aging)

$f \quad=$ loading frequency, $\mathrm{Hz}$

$V_{a} \quad=\%$ air voids in the mix

$V_{\text {beff }}=\%$ effective bitumen content, by volume

$\rho_{34}=\%$ retained on the $3 / 4$ inch sieve, by total aggregate weight (cumulative)

$\rho_{38}=\%$ retained on the $3 / 8$ inch sieve, by total aggregate weight (cumulative)

$\rho_{4} \quad=\%$ retained on the No. 4 sieve, by total aggregate weight (cumulative); and

$\rho_{200}=\%$ passing the No. 200 sieve, by total aggregate weight.

Equation 2.60 uses volumetric properties of the mix, gradation of the mix, viscosity of the binder and loading frequency. It can be used for any loading frequency and temperature.

The viscosity of asphalt binder at the temperature of interest is a critical input parameter for Equation 2.60.

For unaged viscosity the magnitude can be obtained by Rotational Viscometer testing, absolute viscosity or it can be calculated using the Equation 2.46 given by ASTM. If the A and VTS of the binder are unknown, MEPDG provides estimates for applying Equation 2.46 as a function of the binder Performance Grade. The coefficients were obtained for binders conditioned with the RTFO. Thus, the short term age of the asphalt binder is directly estimated from Equation 2.60. Table 6 contains the parameters to calculate the viscosity of the binder. (NCHRP 1-37A, 2004).

\footnotetext{
${ }^{1}$ There are actually multiple equations for predicting dynamic modulus. The equation used in the body of the NCHRP Report 1-37A is presented here, but other options are available to the user of MEPDG.
} 
Table 6: Recommended RTFO A and VTS parameters based on asphalt PG grade

\begin{tabular}{|c|c|c|c|c|c|c|c|c|c|c|c|c|c|c|}
\hline \multirow{3}{*}{$\begin{array}{c}\text { High } \\
\text { Temp } \\
\text { Grade }\end{array}$} & \multicolumn{14}{|c|}{ Low Temperature Grade } \\
\hline & \multicolumn{2}{|c|}{-10} & \multicolumn{2}{|c|}{-16} & \multicolumn{2}{|c|}{-22} & \multicolumn{2}{|c|}{-28} & \multicolumn{2}{|c|}{-34} & \multicolumn{2}{|c|}{-40} & \multicolumn{2}{|c|}{-46} \\
\hline & VTS & A & VTS & A & VTS & A & VTS & A & VTS & A & VTS & A & VTS & A \\
\hline 46 & & & & & & & & & -3.901 & 11.504 & -3.393 & 10.101 & $\mid-2.905$ & 8.755 \\
\hline 52 & -4.570 & 13.386 & -4.541 & 13.305 & -4.342 & 12.755 & -4.012 & 11.840 & -3.602 & 10.707 & -3.164 & 9.496 & -2.736 & 8.310 \\
\hline 58 & -4.172 & 12.316 & -4.147 & 12.248 & -3.981 & 11.787 & -3.701 & 11.010 & -3.350 & 10.035 & -2.968 & 8.976 & & \\
\hline 64 & -3.842 & 11.432 & -3.822 & 11.375 & -3.680 & 10.980 & -3.440 & 10.312 & -3.134 & 9.461 & -2.798 & 8.524 & & \\
\hline 70 & -3.566 & 10.690 & -3.548 & 10.641 & -3.426 & 10.299 & -3.217 & 9.715 & -2.948 & 8.965 & -2.648 & 8.129 & & \\
\hline 76 & -3.331 & 10.059 & -3.315 & 10.015 & -3.208 & 9.715 & -3.024 & 9.200 & -2.785 & 8.532 & & & & \\
\hline 82 & -3.128 & 99.514 & -3.114 & 99.475 & -3.019 & 9.209 & -2.856 & 8.750 & -2.642 & \begin{tabular}{|l|l|}
8.151 \\
\end{tabular} & & & & \\
\hline
\end{tabular}

The regression coefficients are given for viscosity grade by MEPDG. With the use of the regression coefficients it is possible to provide an effect on the change of viscosity, which occurs during mixing and compaction stages.

The procedure to obtain the master curve and shift factor in MEPDG under Level 2 and 3 is developed following using 2.55 that represents the sigmoidal form. Using this concept and the dynamic modulus predictive equation, the coefficients obtained are:

$$
\begin{aligned}
& \delta=3.750063+0.02932 \rho_{200}-0.001767\left(\rho_{200}\right)^{2}-0.002841 \rho_{4}-0.058097 V_{a}-0.802208\left[\frac{V b_{e f f}}{V b_{e f f}+V_{a}}\right] \\
& \alpha=3.871977-0.0021 \rho_{4}+0.003958 \rho_{38}-0.000017 \rho_{38}^{2}+0.005470 \rho_{34} \\
& \beta=-0.603313-0.393532 \log \left(\eta_{T r}\right) \\
& \gamma=0.313351 \\
& c=1.255882
\end{aligned}
$$

The master curve is expressed in terms of binder viscosity, the GAS is considered within the calculation. 


\section{Chapter 3 RESEARCH METHODOLOGY}

This research concentrates on the designation of specific Performance Grade Asphalt binders for different areas in West Virginia. The objective is to make a selection that fits the parameters of design, and is also economical for West Virginia. The analysis has three parts. First, the determination of the asphalt binder calculated with the LTPP Bind V3.1, where the adjustment for depth, traffic, speed and reliability is done. Second, the analysis of the response of two flexible pavement structures for a period of design of 20 years using the MEPDG, where the binder asphalt is varied in order to determine the extent of permanent deformation, longitudinal cracking, alligator cracking, terminal IRI and thermal cracking for five climatic conditions. Finally, an investigation in MEPDG about viscosity and dynamic modulus is shown.

The research sequence was:

- Select pavement structures

- Select climatic zones in West Virginia.

- Determination of asphalt binder with LTPP Bind V3.1

- Selection of the traffic parameters for MEPDG analysis

- Identify material parameters needed for Level 3 MEPDG analysis

- Select analysis parameters and performance criteria

- Perform MEPDG analysis

- Investigate MEPDG Analysis

For continuity of the research effort into MEPDG at WVU, most of the input parameters used for this analysis were based on the values used by Orobio (2010). These include the pavement structures, traffic levels, and material characterization.

\subsection{Selection of the Pavement Structures}

Two pavement structures were selected for this research. These pavement structures are similar to the structures used in the state of West Virginia. The structures are as follows:

Structure \# 1: This structure has a full depth asphalt pavement; it has four layers and a subgrade. The thicknesses and material types are given in Figure 6.

Structure \# 2: This structure is a conventional asphalt pavement; it has three layers and a subgrade. The thicknesses and material types are given in Figure 7.

\subsection{Selection of climatic zones in West Virginia}

West Virginia is located in the Appalachian region of the US. West Virginia has nonuniform climatic conditions. Therefore, it is to be expected that different asphalt binders will perform differently across the state. 
STRUCTURE \# 1

FULL-DEPTH ASPHALT PAVEMENT CONCRETE

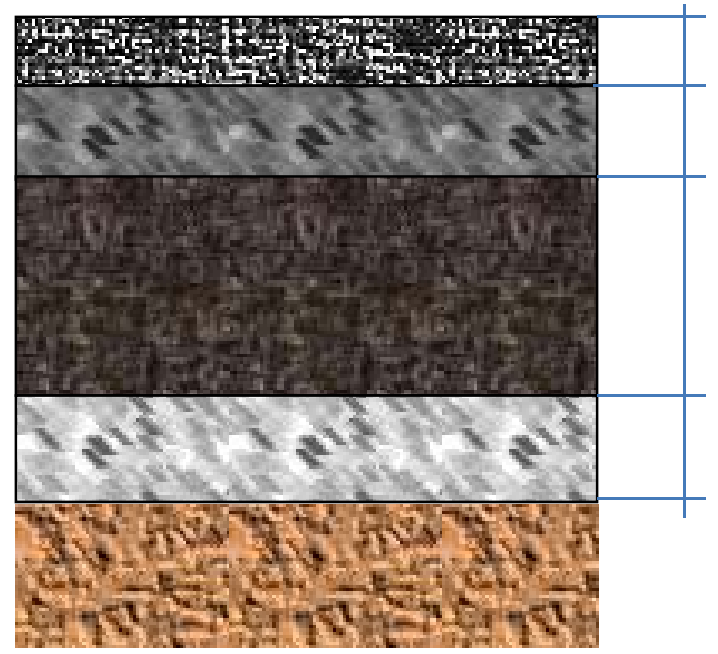

2 in Asphalt Concrete (9.5 mm mix)

3 in Asphalt Concrete (19mm mix)

10 in Asphalt Concrete (37.5 mm mix)

3 in Permeable Asphalt treated base

Subgrade

Figure 6: Pavement Structure \#1

STRUCTURE \# 2

CONVFNTIONAI, ASPHAI,T FI,FXIRI,E, PAVFMFNT STRIJCTIJRE,

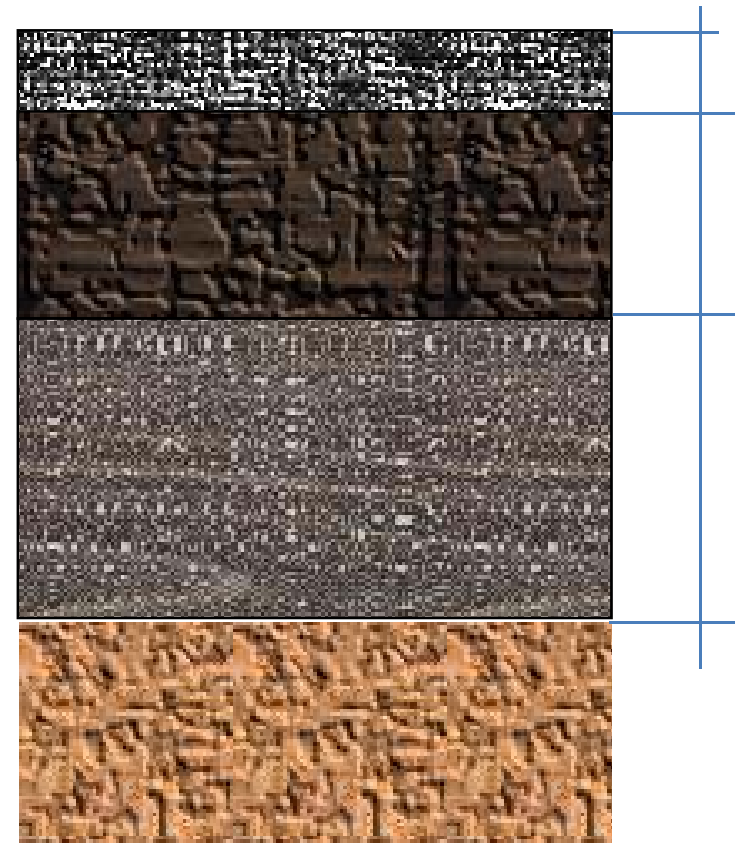

4 in Dense graded Asphalt Concrete 1.5 in $9.5 \mathrm{mix}$

2.5 in. $19 \mathrm{~mm}$ mix

10 in Granular Aggregate Base

20 in Granular Aggregate Sub-base

Figure 7: Pavement Structure \#2

Subgrade 
While there are over 77 weather stations in West Virginia in the LTPPBIND software MEPDG has only 10 weather stations in West Virginia; Beckley, Bluefield, Charleston, Clarksburg, Elkins, Huntington, Martinsburg, Morgantown, Parkersburg and Wheeling. Unfortunately none of the MEPDG weather stations are along the eastern border in the mountainous area. Five MEPDG weather stations representing a broad geographical distribution in the state were selected for the MEPDG analysis, as shown on Figure 8.

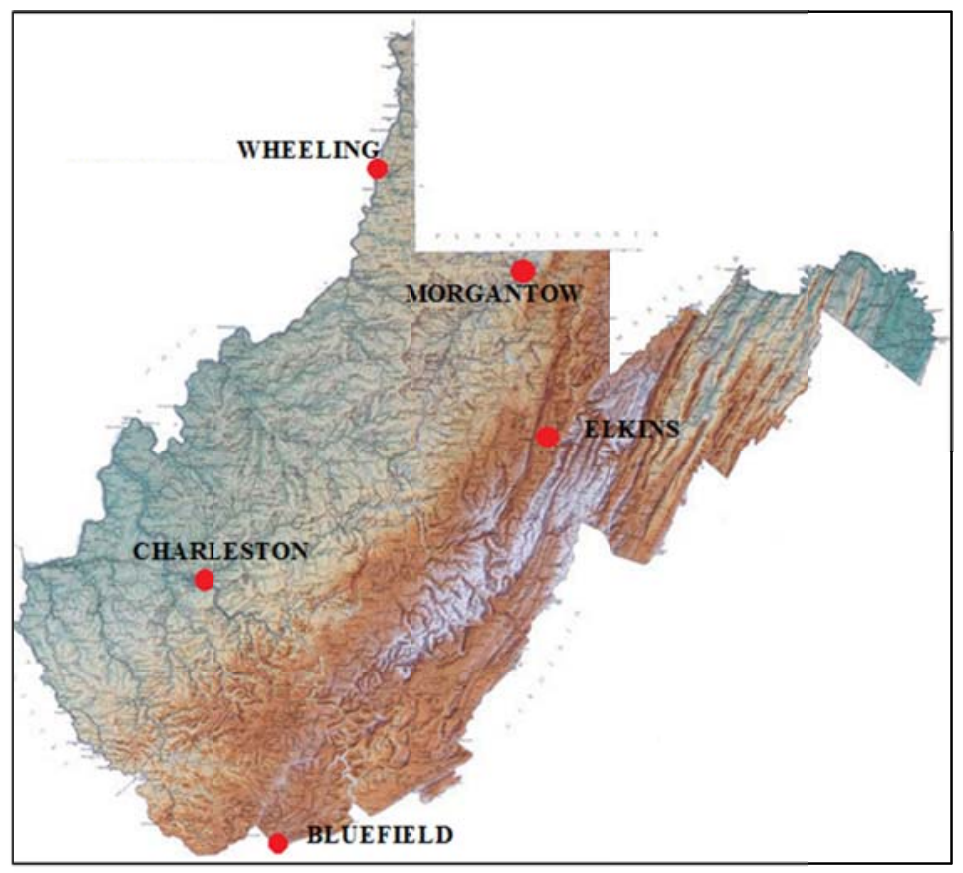

Figure 8: MEPDG weather stations selected for analysis

\subsection{Determination of asphalt binder with LTPP Bind V3.1}

LTPPBind V3.1 was used to identify the recommended binder grades for the climatic zones selected for the analysis. For structure \#1, a traffic level of greater than 30 million ESAL with fast traffic speed was selected. For structure \#2, a traffic loading between 10 and 30 million ESAL and fast traffic speed was selected. For structure \#1 the binder recommendation as a function of depth was analyzed. This was not necessary for structure \#2 as only the surface layer has asphalt concrete.

\subsection{Selection of the traffic parameters for MEPDG analysis}

Two Annual Average Daily Traffic (AADT) inputs are selected. The highest AADT is used in the strong structure (full-depth pavement), and the lowest AADT is used in the weak structure (conventional pavement). The other traffic parameters are given in Table 7:

This study used Level 3 inputs for MEPDG; most of the parameters are selected as default values. The inputs for traffic parameters are presented in Appendix A. 


\subsection{Material characterization}

Each layer of the two pavement structures, including unbound materials, (subgrade and asphalt concrete layers) needs a complete material characterization. The information displayed in Appendix A contains the input data for all materials.

\subsection{Analysis Parameter and Performance Criteria}

MEPDG requires the definition of the analysis parameters and their respective performance criteria to be established for design. The response obtained for each set of inputs is thus compared with the performance criteria on a trial-and-error basis. For both pavement structures the Analysis Parameters and Performance Criteria (failure limits) are defined in Table 8:

Table 7: Traffic Inputs

\begin{tabular}{|l|c|c|}
\hline \multicolumn{1}{|c|}{ Parameter } & Structure \#1 & Structure \#2 \\
\hline Initial AADT (Two way) & 40000 & 2000 \\
\hline $\begin{array}{l}\text { AADTT Distribution by } \\
\text { vehicle class }\end{array}$ & $\begin{array}{c}\text { Principal Arterials - Interstate and Defense Routes } \\
\text { (Default M-E PDG) }\end{array}$ \\
\hline Monthly Adjustment & Default (Level 3) & Default (Level 3) \\
\hline Hourly Distribution & Default (Level 3) & Default (Level 3) \\
\hline $\begin{array}{l}\text { Number of lanes in the } \\
\text { design direction }\end{array}$ & 2 & 2 \\
\hline $\begin{array}{l}\text { Percent of trucks in design } \\
\text { direction (\%) }\end{array}$ & 50 & 50 \\
\hline $\begin{array}{l}\text { Percent of trucks in design } \\
\text { lane (\%) }\end{array}$ & 95 & 95 \\
\hline Operational Speed (mph) & (mefault (Level 3) & Default (Level 3) \\
\hline Traffic growth (\%) & Default (Level 3) & Default (Level 3) \\
\hline $\begin{array}{l}\text { Axle load distribution } \\
\text { factors }\end{array}$ & Default (Level 3) & Default (Level 3) \\
\hline Number axles/truck & \\
\hline $\begin{array}{l}\text { Axle configuration } \\
\text { (spacing, tire pressure) }\end{array}$ & & 60 \\
\hline
\end{tabular}


Table 8: Performance Criteria

\begin{tabular}{|c|c|}
\hline Analysis Parameter & Performance Criteria \\
\hline Terminal IRI (in/mile) & 172 \\
\hline $\begin{array}{c}\text { AC Surface Down Cracking } \\
\text { Longitudinal Cracking (ft./mi) }\end{array}$ & 2000 \\
\hline $\begin{array}{c}\text { AC Bottom Up Cracking } \\
\text { Alligator Cracking (\%) }\end{array}$ & 25 \\
\hline AC Thermal Fracture (ft./mi) & 2000 \\
\hline Permanent Deformation (in) Total Pavement & 0.75 \\
\hline Permanent Deformation (in AC only) & 0.25 \\
\hline
\end{tabular}

The design life of the pavement is 20 years.

\subsection{MEPDG analysis}

A combination of four asphalt binders and the five climatic conditions selected for the two pavement structures. This resulted in 40 MEPDG runs.

The output values analyzed from this experiment with MEPDG software were permanent deformation for the asphalt layer, permanent deformation for the total pavement structure, longitudinal cracking, alligator cracking, terminal IRI (roughness) and thermal cracking after the design period of 20 years. The results of the MEPDG analysis were evaluated to determine if the predicted pavement performance was influenced by the binder type.

\subsection{Investigation MEPDG analysis}

\subsubsection{Analysis of Viscosity}

The estimation of viscosity with the time and depth through the life of the pavement structure was calculated based on the equations documented in Chapter 2 in order to find whether pavements with PG58-28, PG64-22, PG70-22 and PG76-22 binder behave differently under the same conditions of temperature, time and depth. The aging, in terms of the viscosity of the binder, was evaluated for a 20 year design period. The aging was evaluated for depths in the range of 0.5 to 18 inches.

\subsubsection{Dynamic modulus master curve for asphalt concrete}

As shown in Chapter 2, the master curve for asphalt concrete is a function of the aggregate gradation, mix volumetric properties, and binder viscosity. Assuming the gradation and volumetric parameters of the mix do not change over time, the binder viscosity becomes the only parameter affecting the dynamic modulus of the asphalt concrete over the life of the pavement. The dynamic modulus, in turn, affects the response of the structure under different temperature, traffic, and operational speed conditions. 


\section{Chapter 4 RESULTS AND ANALYSIS}

\subsection{LTPPBind Analysis}

LTTBIND V3.1 has 77 weather stations for West Virginia as shown on Figure 9. LTPPBind V3.1 recommends the use of base asphalt binders for every station, the selection of the base binder is made for low and high temperature with a desired percentage of reliability from 50 to $98 \%$. For selection of the base binder grade, the traffic is less than 3 million ESALS and the traffic speed is "fast". Figure 10 shows general types of output available from the program. In addition to stations, the program shows elevations, high and low air temperature, number of degree days, and the high and low recommended binder grades (this figure shows the base binder grades for $98 \%$ reliability but $50 \%$ is also available).

Figures 11 and 12 show the distribution of the recommended low and high temperature grades for WV for the "standard conditions"; i.e. fast speed, traffic less than 3 million ESALS, and $12.5 \mathrm{~mm}$ rut depth over the life of the pavement. A base binder with a high temperature rating of $64^{\circ} \mathrm{C}$ is suitable for the entire state. There are 31 stations where a $-28^{\circ} \mathrm{C}$ binder is required for $98 \%$ reliability; the number of stations requiring a $-28^{\circ} \mathrm{C}$ binder changes with the reliability as:

\begin{tabular}{cc} 
Reliability & $\begin{array}{c}\text { Number of } \\
\text { Stations }\end{array}$ \\
\hline 83 & 0 \\
84 & 3 \\
90 & 4 \\
95 & 18 \\
98 & 31
\end{tabular}

A base binder grade of PG 64-22 gives a minimum of 90\% reliability for West Virginia. The low temperature binder grade is selected to minimize the potential for thermal cracking, which is a long-term pavement performance issue that occurs after the binder has hardened and becomes brittle. Selection of a "softer" grade of binder may help minimize thermal cracking, but the cost effectiveness of this option should be carefully considered. Figure 13 shows the recommended binders for each weather station for standard conditions and $98 \%$ reliability. 


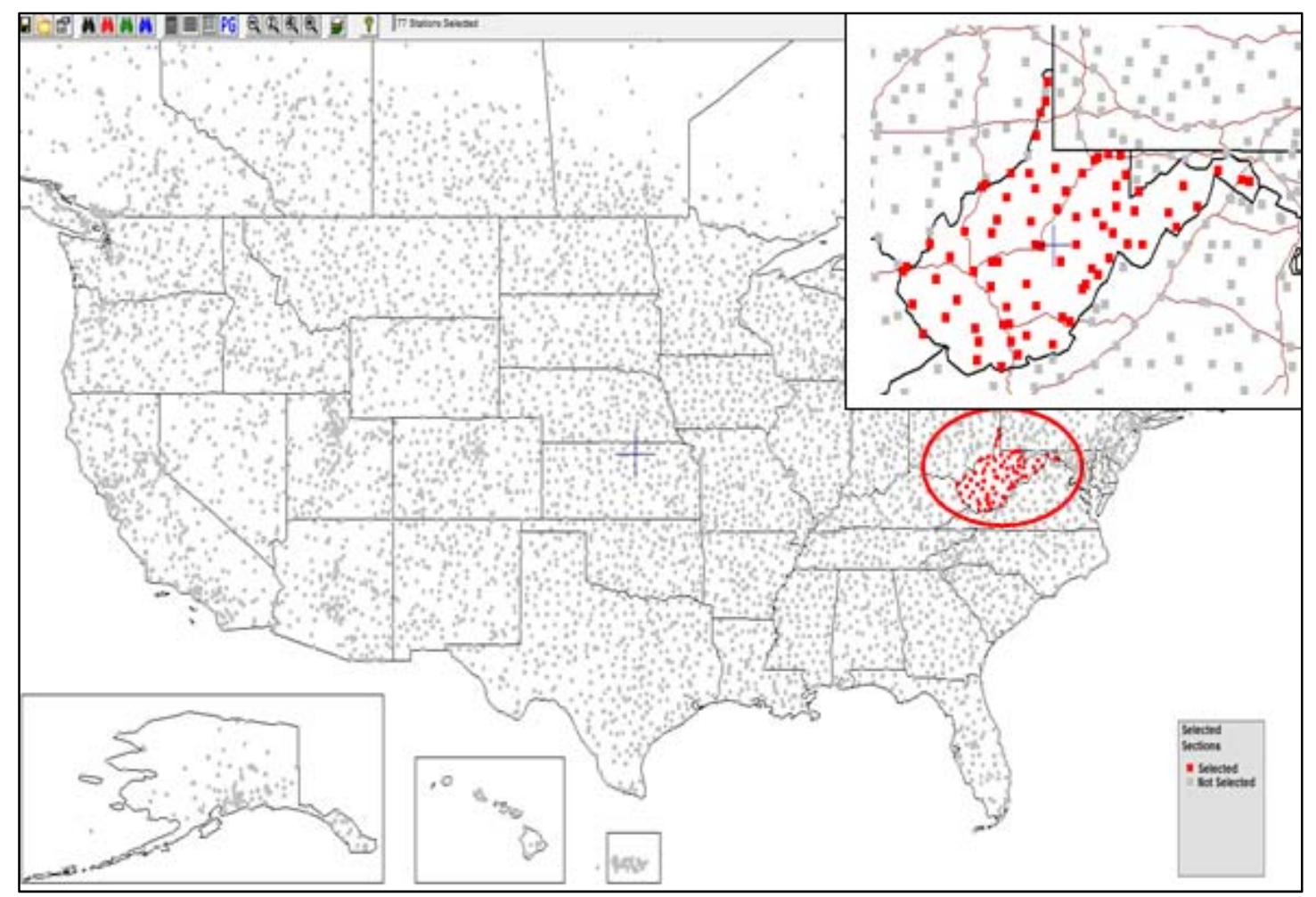

Figure 9: Stations in the State of West Virginia (WV)

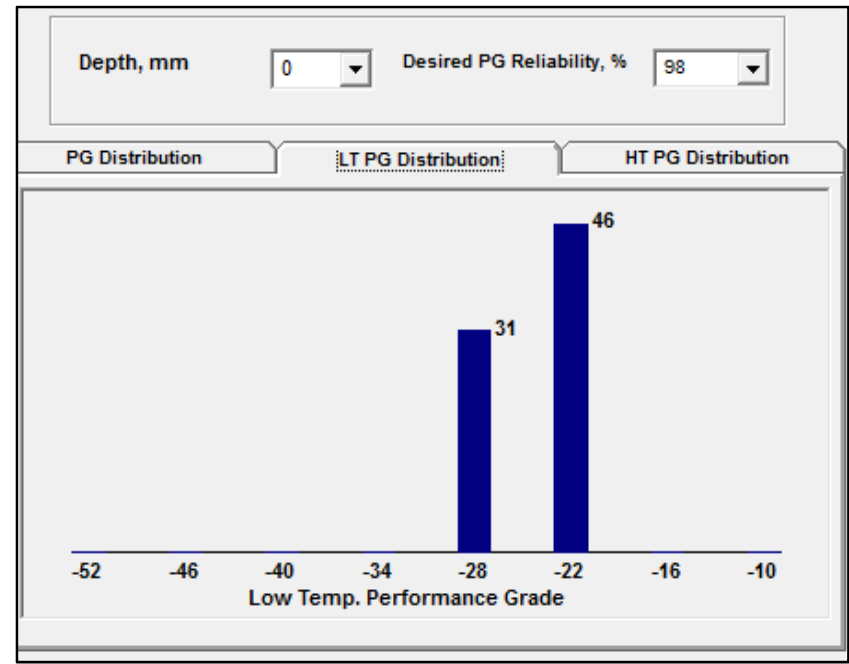

Figure 11: Low Temperature PG distribution

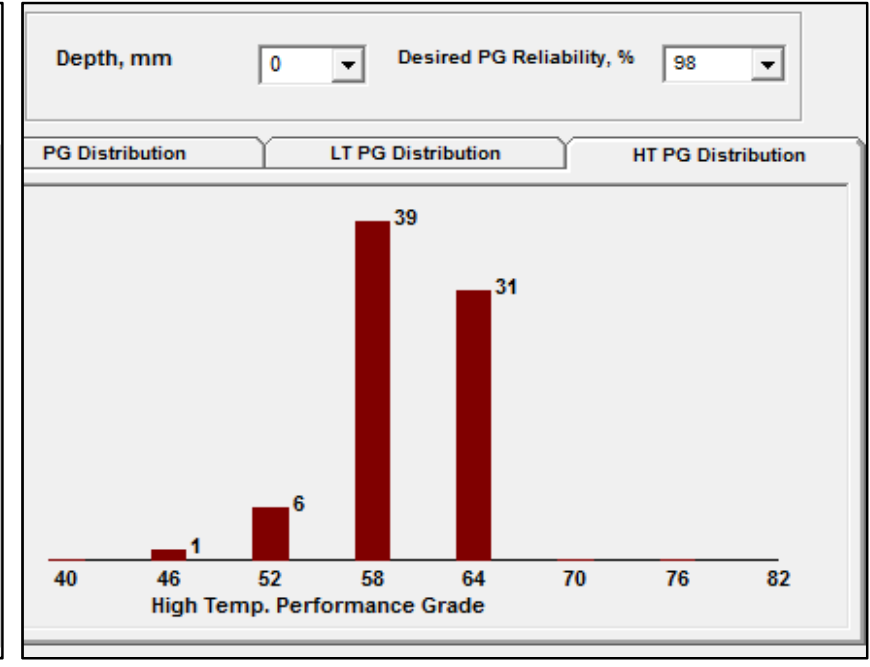

Figure 12: High Temperature PG distribution 

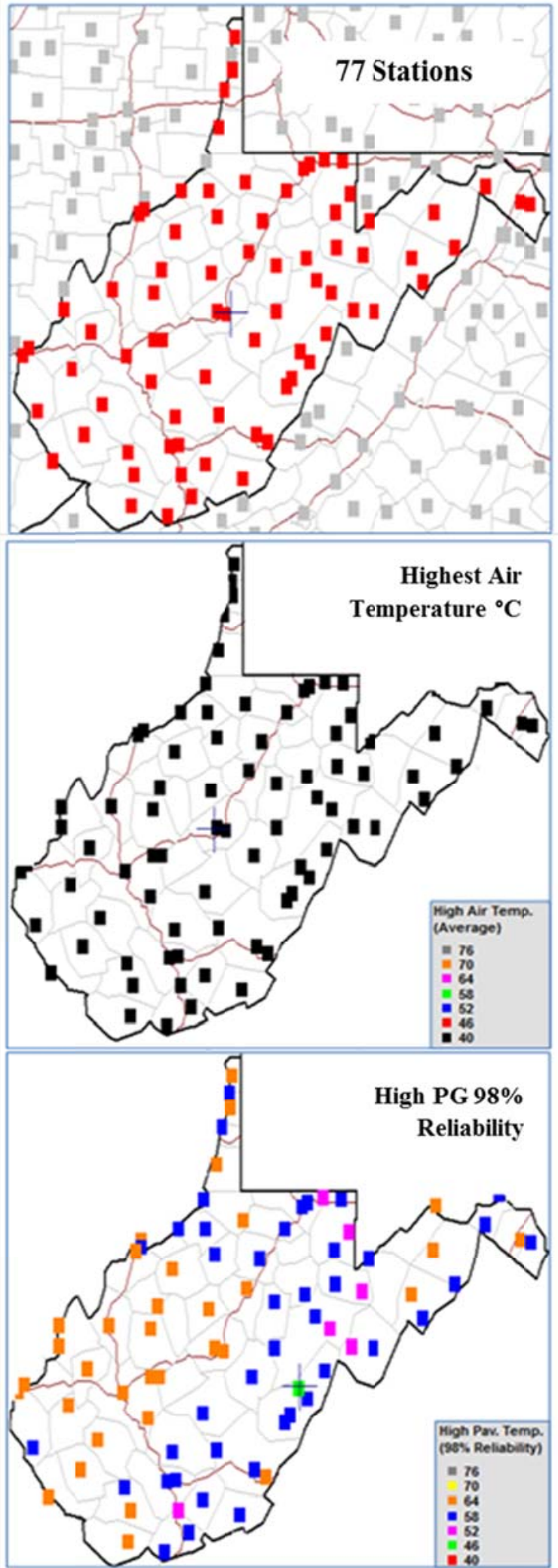

Figure 10: Climatic Condition in West Virginia
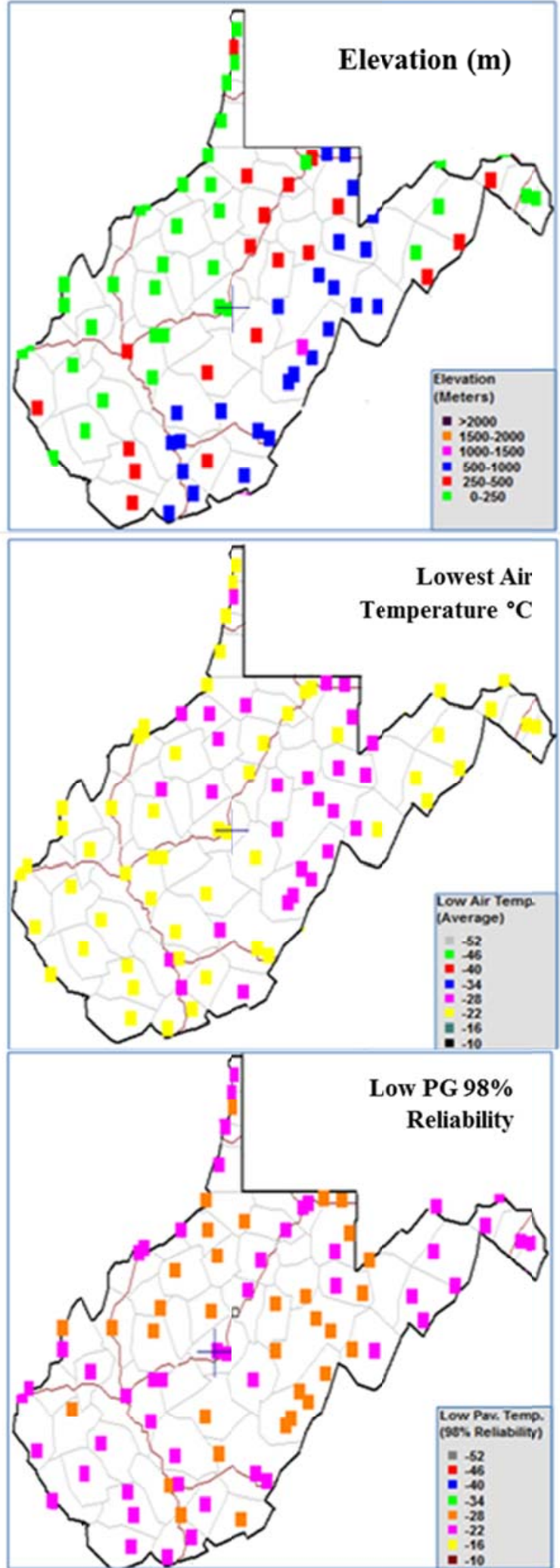


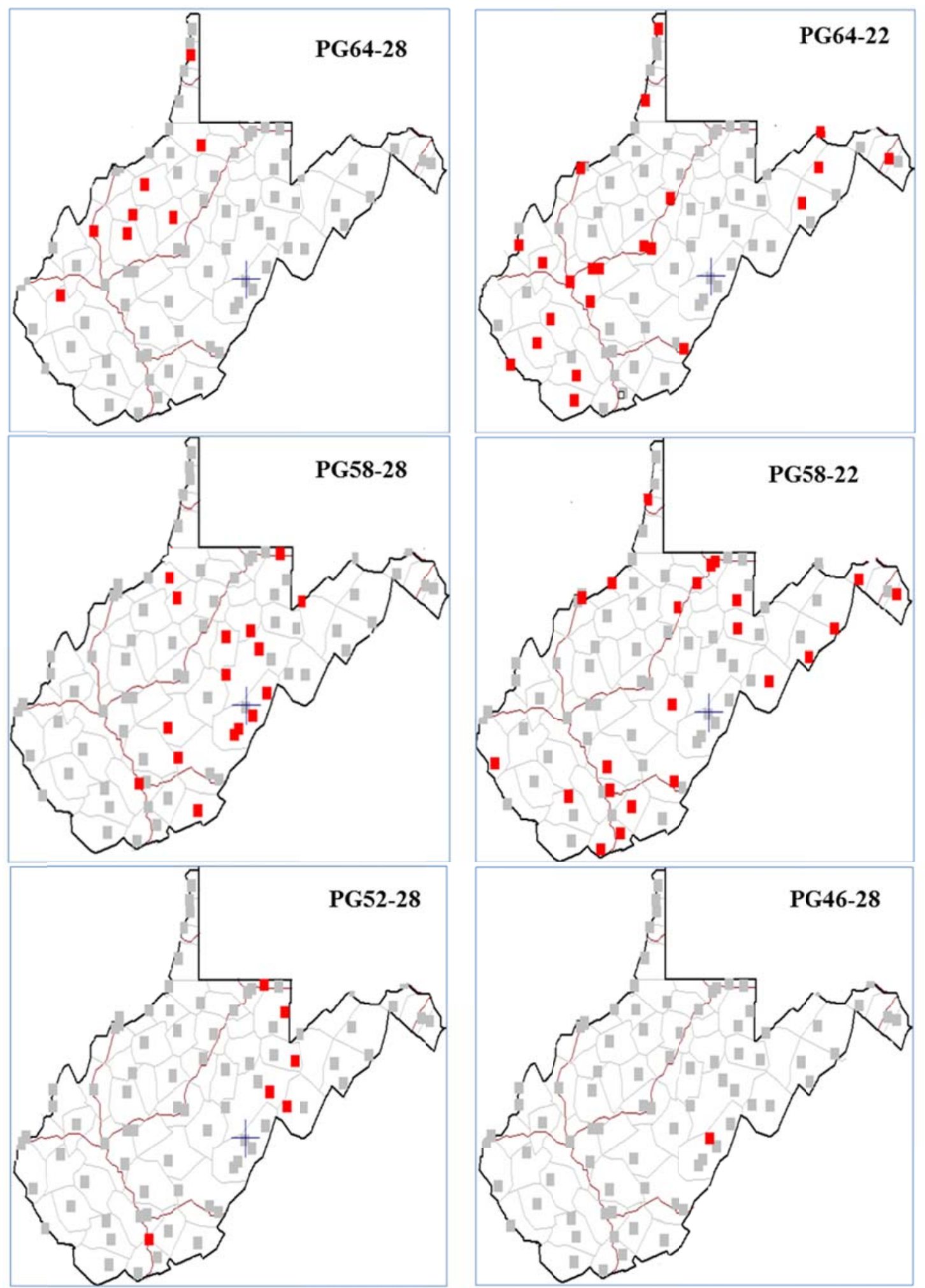

Figure 13: Distribution of Performance Grade Binder in West Virginia 98\% Reliability 


\subsubsection{LTPPBind recommended Performance Grade}

Table 9 presents the LTPPBind temperature and environmental parameters for the analysis areas. LTPPBind V3.1 allows the analysis of the five closest stations to the city selected. This option was used for the evaluation of the binder selection as binders would be selected for an area, not a single location. The weather stations used for each of the analysis locations is listed in Table 9. Table 10 presents the corresponding base asphalt binder recommendations. The default depth for determining the base PG is zero; traffic speed is "fast"; and the number of loads is $<0.3 \times 10^{6}$ ESAL's. Reliability can be set between 50 and $98 \%$. A list of PG Binders within this range of reliability is provided for the selected analysis locations. At least three asphalt binders can be used in each analysis area as the asphalt base Performance Grade, depending on the level of reliability

Table 9: LTPPBind V3.1 temperature and location parameters for analysis areas

\begin{tabular}{|c|c|c|c|c|c|c|c|}
\hline \multicolumn{2}{|c|}{$\begin{array}{c}\text { Weather } \\
\text { Station }\end{array}$} & \multirow{2}{*}{$\begin{array}{l}\text { Latitude } \\
\text { Degree }\end{array}$} & \multicolumn{2}{|c|}{$\begin{array}{l}\text { Lowest Yearly } \\
\text { Air Temperature }\end{array}$} & \multicolumn{2}{|c|}{$\begin{array}{c}\text { High Yearly } \\
\text { Air Temperature }\end{array}$} & \multirow{2}{*}{$\begin{array}{c}\text { Yearly } \\
\text { Degree } \\
\text { Days } \\
>10 \\
\text { Degree C }\end{array}$} \\
\hline City & Station Id. & & mean C & $\begin{array}{l}\text { Standard } \\
\text { Dev. C }\end{array}$ & mean C & $\begin{array}{l}\text { Standard } \\
\text { Dev. C }\end{array}$ & \\
\hline Bluefield & $\begin{array}{l}\text { WV } 0921 \\
\text { WV } 0355 \\
\text { VA } 1209 \\
\text { WV } 3353 \\
\text { WV } 3072\end{array}$ & 37.30 & -22.0 & 4.1 & 28.9 & 1.6 & 2519 \\
\hline Morgantown & $\begin{array}{l}\text { WV } 6202 \\
\text { WV } 6212 \\
\text { WV } 1900 \\
\text { WV } 1083 \\
\text { WV } 2920\end{array}$ & 39.66 & -22.1 & 4.1 & 32.4 & 1.7 & 2582 \\
\hline Wheeling & $\begin{array}{l}\text { WV } 7018 \\
\text { WV } 9368 \\
\text { OH } 1152 \\
\text { OH } 8025 \\
\text { WV } 6248\end{array}$ & 40.14 & -21.1 & 4.1 & 31.7 & 1.6 & 2792 \\
\hline Elkins & $\begin{array}{l}\text { WV } 2718 \\
\text { WV } 3464 \\
\text { WV } 0633 \\
\text { WV } 6867 \\
\text { WV } 1220\end{array}$ & 38.89 & -24.6 & 3.6 & 30.2 & 1.4 & 2555 \\
\hline Charleston & $\begin{array}{l}\text { WV } 1570 \\
\text { WV } 1723 \\
\text { WV } 5365 \\
\text { WV } 1959 \\
\text { WV } 9683\end{array}$ & 38.37 & -19.0 & 4.0 & 33.1 & 1.4 & 3080 \\
\hline
\end{tabular}


Table 10: LTPPBind V3.1 base Performance Grade at the surface

\begin{tabular}{|c|c|c|c|c|}
\hline \multirow{2}{*}{$\begin{array}{l}\text { BASE } \\
\text { PERFORMANCE } \\
\text { GRADE/LOCATION }\end{array}$} & \multicolumn{2}{|c|}{$\begin{array}{c}\text { Pavement } \\
\text { Temperature }\end{array}$} & \multirow{2}{*}{$\begin{array}{c}\text { High } \\
\text { Reliability } \\
\%\end{array}$} & \multirow{2}{*}{$\begin{array}{c}\text { Low } \\
\text { Reliability } \\
\%\end{array}$} \\
\hline & High $\left({ }^{\circ} \mathrm{C}\right)$ & $\operatorname{Low}\left({ }^{\circ} \mathrm{C}\right)$ & & \\
\hline \multirow{4}{*}{ BLUEFIELD } & 51.5 & -13.2 & 50 & 50 \\
\hline & 52 & -16 & 75 & 78 \\
\hline & 58 & -16 & 98 & 78 \\
\hline & 58 & -22 & 98 & 98 \\
\hline \multirow{3}{*}{ MORGANTOWN } & 54.6 & -13.8 & 50 & 50 \\
\hline & 58 & -16 & 98 & 73 \\
\hline & 58 & -22 & 98 & 98 \\
\hline \multirow{3}{*}{ WHEELING } & 53.6 & -13 & 50 & 50 \\
\hline & 58 & -16 & 98 & 80 \\
\hline & 58 & -22 & 98 & 98 \\
\hline \multirow{3}{*}{ ELKINS } & 52.6 & -17.2 & 50 & 50 \\
\hline & 58 & -22 & 98 & 94 \\
\hline & 58 & -28 & 98 & 98 \\
\hline \multirow{4}{*}{ CHARLESTON } & 56.9 & -12.2 & 50 & 50 \\
\hline & 58 & -16 & 87 & 85 \\
\hline & 58 & -22 & 87 & 98 \\
\hline & 64 & -22 & 98 & 98 \\
\hline
\end{tabular}

\section{Effect of depth}

Equation 2.15 was developed to compute the pavement temperature as a function of depth. Attempts to recreate the temperature corrections with depth found a discrepancy in the values produced with Equation 2.15 and the output from LTPPBind V3.1. The original SHRP (Mohseni, 1998) high temperature model was developed for a depth below the pavement of $20 \mathrm{~mm}$. Equation 2.15 was entered into Excel and it was determined that the depth correction factors could be reproduced by adding 20 to the height term as shown in Equation 4.1.

Tpav $=54.32+0.78$ Tair -0.0025 Lat $^{2}-15.14 \log _{10}(H+25+20)+z\left(9+0.61 \sigma_{\text {air }}{ }^{2}\right)^{1 / 2}$

The temperature correction factor is computed as the difference between Tpav computed for $\mathrm{H}=0$ and Tpav for the desired depth. Since only the delta with respect to depth is needed, only the depth term, H, in Equation 4.1 is needed. In other words, the depth correction factor is independent of the air temperature, latitude and reliability.

The fact that the depth correction factor is not properly documented causes confusion in the selection of the proper depth for the analysis of layers below the pavement surface. It appears that the developers of LTPPBind V3.1 intended for the user to input a depth of 0 for 
determining the binder for the surface layer. The Colorado Asphalt Pavement Association explicitly recommends this (CAPA, 2006).

\section{Correction for traffic volume and speed}

These base PG binders are corrected by traffic and depth for full-depth asphalt pavement and conventional pavement structures. According to the LTPPBind documentation the traffic and speed adjustments are made using Table 11. However the output of the software has different correction values as shown in Table 11. The difference in the correction factors range from 0.1 to 3.9 , which is sufficient to cause a difference in the binder grade selected. The source of the discrepancy between the documentation and the program could not be determined.

Table 11: Comparison of LTPPBind documentation and program correction factors for temperature and traffic speed.

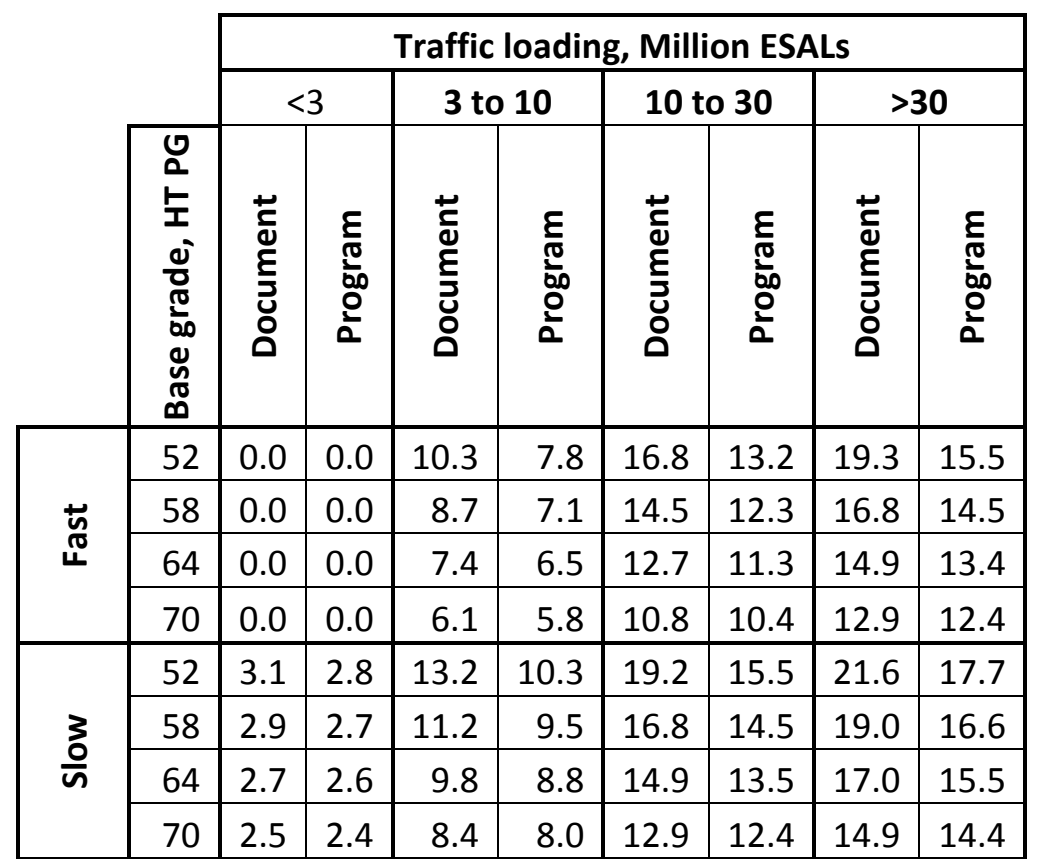

\section{Final LTPPBind V3.1 binder recommendations}

The binder grade recommendations for the two pavement structures selected for the analysis are presented in Tables 12 and 13. These tables present the full recommendations that can be obtained from the software. In reality, it would not be practical to specify each of the recommended binder grades for a single pavement structure. Due to the issues raised with the proper selection of depth, Tables 12 and 13 include the LTPPBind V3.1 recommendations for depth of 0 and $25 \mathrm{~mm}$, in addition to the mid points of the depths for each layer.

\subsubsection{Selection of Performance Grade}

The standard binder grade used in West Virginia is a PG 64-22. The standard grade can be adjusted for design conditions. Some DOH pavement designers have specified PG 58-28 
when their selection is supported by analysis using LTPPBind V3.1. However, due to availability issues PG 58-28 carries a premium price for both the cost of the material and the additional transportation costs. PG 70-22 is frequently specified for the surface layers of high traffic volume roads such as interstates and other four-lane divided highways. For special design situations, such as heavy traffic, slow moving traffic or sections where rutting is a problem a PG 76-22 can be specified for the wearing layers. When either a PG 70-22 or a PG 76-22 is specified for the surface, a PG 64-22 can be used for layers 4 inches below the pavement surface.

Considering the DOH binder selection parameters, Table 14 and 15 were compiled to compare the LTPPBind V3.1 recommendations, for 98\% reliability, versus DOH practices for Structure \#1 and Structure \#2 respectively. Differences are indicated by bold numbers. Since Structure \#1 is assumed to have the highest level of traffic, selection of a PG 76-22 binder for the wearing may be appropriate. Structure \#1 is assumed to have a 2 inch wearing course placed on a 3 inch base. The typical WVDOH design would use the same binder for both layers, but LTPPBind V3.1 recommends an upper temperature grade of 64 for all sections except Charleston. Due to the higher temperatures in Charleston, a 76 grade is recommended for the wearing course and 70 grade is recommended for the first base course. This is a higher temperature grade than the current practice, but as pointed out in the literature review, it is not uncommon for LTPPBind V3.1 to recommend higher grades compared to LTPPBind V2.1 for the high temperature. The locations where a -16 grade lower temperature grade is recommended can be accommodated by a lower temperature grade of -22. LTPPBindV3.1 recommends a low temperature grade of -28 for the surface course for Morgantown and Elkins. This is for a $98 \%$ reliability. A low temperature grade of -22 has a reliability of $62 \%$ for Morgantown and $50 \%$ for Elkins. If the analysis point is set at $25.4 \mathrm{~mm}$ a low temperature grade of -22 gives 98 percent reliability for all the analysis stations. Similar observations were made for Structure \#2 which had a lower traffic level than Structure \#1.

The five analysis stations were selected based on their availability in MEPDG. Unfortunately MEPDG does not accommodate the coldest regions of WV. To examine the recommendations of LTPPBindV3.1 for cold areas, recommendations for Snowshoe, Station WV 8308, the weather station with the coldest temperatures were analyzed for the maximum and minimum traffic as shown in Table 16. With the maximum traffic the high temperature grade is 64 and for the minimum traffic (no grade bumping) the high temperature grade is 46 . In both cases the low temperature grade is -28 for 98 percent reliability. A low temperature grade of -22 provides a reliability of 83 percent. 
Table 12: Performance Grade from LTPPBind V3.1 Structure \#1 adjusted for depth and traffic $>30 \times 10^{6}$ ESALs

\begin{tabular}{|c|c|c|c|c|c|c|c|c|}
\hline \multirow{3}{*}{$\begin{array}{l}\text { Weather } \\
\text { Station }\end{array}$} & \multirow{3}{*}{$\begin{array}{l}\text { Layer } \\
\mathbf{N}^{\circ}\end{array}$} & \multicolumn{2}{|c|}{ Thickness } & \multirow{3}{*}{$\begin{array}{c}\text { Analysis } \\
\text { point } \\
\text { depth } \\
\text { from } \\
\text { surface }\end{array}$} & \multicolumn{4}{|c|}{$\begin{array}{l}\text { PERFORMANCE } \\
\text { GRADE }\end{array}$} \\
\hline & & & & & Reliab & $=50 \%$ & Reliabi & $=98 \%$ \\
\hline & & in & $\mathrm{mm}$ & & $\begin{array}{l}\text { High } \\
\left({ }^{\circ} \mathrm{C}\right)\end{array}$ & $\begin{array}{l}\text { Low } \\
\left({ }^{\circ} \mathrm{C}\right)\end{array}$ & $\begin{array}{l}\text { High } \\
\left({ }^{\circ} \mathrm{C}\right)\end{array}$ & $\begin{array}{l}\text { Low } \\
\left({ }^{\circ} \mathrm{C}\right)\end{array}$ \\
\hline \multirow{6}{*}{ Bluefield } & Base & - & - & - & 58 & -16 & 58 & -22 \\
\hline & & & & 0 & 70 & -16 & 70 & -22 \\
\hline & 1 & 2 & 50.8 & 25.4 & 64 & -16 & 70 & -22 \\
\hline & 2 & 3 & 76.2 & 88.9 & 64 & -16 & 64 & -22 \\
\hline & 3 & 10 & 254 & 254.0 & 58 & -10 & 58 & -16 \\
\hline & 4 & 3 & 76.2 & 419.1 & 58 & -10 & 58 & -16 \\
\hline \multirow{6}{*}{ Morgantown } & Base & - & - & - & 58 & -16 & 58 & -22 \\
\hline & & & & 0 & 70 & -16 & 70 & -28 \\
\hline & 1 & 2 & 50.8 & 25.4 & 70 & -16 & 70 & -22 \\
\hline & 2 & 3 & 76.2 & 88.9 & 64 & -16 & 64 & -22 \\
\hline & 3 & 10 & 254 & 254.0 & 58 & -10 & 64 & -22 \\
\hline & 4 & 3 & 76.2 & 419.1 & 58 & -10 & 64 & -22 \\
\hline \multirow{6}{*}{ Wheeling } & Base & - & - & - & 58 & -16 & 58 & -22 \\
\hline & & & & 0 & 70 & -16 & 76 & -22 \\
\hline & 1 & 2 & 50.8 & 25.4 & 70 & -16 & 70 & -22 \\
\hline & 2 & 3 & 76.2 & 88.9 & 64 & -16 & 70 & -22 \\
\hline & 3 & 10 & 254 & 254.0 & 64 & -10 & 64 & -16 \\
\hline & 4 & 3 & 76.2 & 419.1 & 64 & -10 & 64 & -16 \\
\hline \multirow{6}{*}{ Elkins } & Base & - & - & - & 58 & -16 & 58 & -228 \\
\hline & & & & 0 & 70 & -22 & 70 & -28 \\
\hline & 1 & 2 & 50.8 & 25.4 & 70 & -16 & 70 & -22 \\
\hline & 2 & 3 & 76.2 & 88.9 & 64 & -16 & 64 & -22 \\
\hline & 3 & 10 & 254 & 254.0 & 58 & -16 & 64 & -22 \\
\hline & 4 & 3 & 76.2 & 419.1 & 58 & -16 & 64 & -22 \\
\hline \multirow{6}{*}{ Charleston } & Base & - & - & - & 58 & -16 & 64 & -22 \\
\hline & & & & 0 & 76 & -16 & 76 & -22 \\
\hline & 1 & 2 & 50.8 & 25.4 & 70 & -16 & 76 & -22 \\
\hline & 2 & 3 & 76.2 & 88.9 & 70 & -10 & 70 & -16 \\
\hline & 3 & 10 & 254 & 254.0 & 64 & -10 & 64 & -16 \\
\hline & 4 & 3 & 76.2 & 419.1 & 64 & -10 & 64 & -16 \\
\hline
\end{tabular}


Table 13: Performance Grade from LTPPBind V3.1 Structure $\# 2$ adjusted for depth and traffic 10 to $30 \times 10^{6}$ ESALs

\begin{tabular}{|c|c|c|c|c|c|c|c|c|}
\hline \multirow{3}{*}{$\begin{array}{l}\text { Weather } \\
\text { Station }\end{array}$} & \multirow{3}{*}{$\begin{array}{l}\text { Layer } \\
\mathbf{N}^{\circ}\end{array}$} & \multirow{2}{*}{\multicolumn{2}{|c|}{ Thickness }} & \multirow{3}{*}{$\begin{array}{c}\begin{array}{c}\text { Analysis } \\
\text { point } \\
\text { depth } \\
\text { from } \\
\text { surface }\end{array} \\
\mathrm{mm}\end{array}$} & \multicolumn{4}{|c|}{$\begin{array}{c}\text { PERFORMANCE } \\
\text { GRADE }\end{array}$} \\
\hline & & & & & \multicolumn{2}{|c|}{ Reliability = $50 \%$} & \multicolumn{2}{|c|}{ Reliability = 98\% } \\
\hline & & in & $\mathrm{mm}$ & & $\begin{array}{l}\text { High } \\
\left({ }^{\circ} \mathrm{C}\right) \\
\end{array}$ & $\begin{array}{l}\text { Low } \\
\left({ }^{\circ} \mathrm{C}\right)\end{array}$ & $\begin{array}{l}\text { High } \\
\left({ }^{\circ} \mathrm{C}\right)\end{array}$ & $\begin{array}{l}\text { Low } \\
\left({ }^{\circ} \mathrm{C}\right)\end{array}$ \\
\hline \multirow{4}{*}{ Bluefield } & Base & - & - & - & 58 & -16 & 58 & -22 \\
\hline & & & & 0 & 70 & -16 & 70 & -22 \\
\hline & & & & 25 & 64 & -16 & 64 & -22 \\
\hline & 1 & 4 & 101.6 & 50.8 & 64 & -16 & 64 & -22 \\
\hline \multirow{4}{*}{ Morgantown } & Base & - & - & - & 58 & -16 & 58 & -28 \\
\hline & & & & 0 & 70 & -16 & 70 & -28 \\
\hline & & & & 25 & 64 & -16 & 70 & -22 \\
\hline & 1 & 4 & 101.6 & 50.8 & 64 & -16 & 64 & -22 \\
\hline \multirow{4}{*}{ Wheeling } & Base & - & - & - & 58 & -16 & 58 & -22 \\
\hline & & & & 0 & 70 & -16 & 70 & -22 \\
\hline & & & & 25 & 70 & -16 & 70 & -22 \\
\hline & 1 & 4 & 101.6 & 50.8 & 64 & -16 & 70 & -22 \\
\hline \multirow{4}{*}{ Elkins } & Base & - & - & - & 58 & -22 & 58 & -28 \\
\hline & & & & 0 & 70 & -22 & 70 & -28 \\
\hline & & & & 25 & 64 & -16 & 70 & -22 \\
\hline & 1 & 4 & 101.6 & 50.8 & 64 & -16 & 64 & -22 \\
\hline \multirow{4}{*}{ Charleston } & Base & - & - & - & 58 & -16 & 64 & -22 \\
\hline & & & & 0 & 70 & -16 & 76 & -22 \\
\hline & & & & 25 & 70 & -16 & 70 & -22 \\
\hline & 1 & 4 & 101.6 & 50.8 & 70 & -10 & 70 & -22 \\
\hline
\end{tabular}


Table 14: Performance Grade adjusted Structure \#1 compared to typical WVDOH grades

\begin{tabular}{|c|c|c|c|c|c|c|c|c|}
\hline \multirow{3}{*}{$\begin{array}{l}\text { Weather } \\
\text { Station }\end{array}$} & \multirow{3}{*}{$\begin{array}{l}\text { Layer } \\
\mathbf{N}^{\circ}\end{array}$} & \multirow[b]{3}{*}{ in } & \multirow[b]{3}{*}{$\mathrm{mm}$} & \multirow{3}{*}{$\begin{array}{l}\text { Analysis } \\
\text { point } \\
\text { depth } \\
\text { from } \\
\text { surface } \\
\text { mm }\end{array}$} & \multicolumn{4}{|c|}{$\begin{array}{c}\text { PERFORMANCE } \\
\text { GRADE }\end{array}$} \\
\hline & & & & & \multicolumn{2}{|c|}{ LTPPBind V3.1 } & \multicolumn{2}{|c|}{ Typical WVDOr } \\
\hline & & & & & $\begin{array}{l}\text { High } \\
\left({ }^{\circ} \mathrm{C}\right)\end{array}$ & $\begin{array}{l}\text { Low } \\
\left({ }^{\circ} \mathrm{C}\right)\end{array}$ & $\begin{array}{l}\text { High } \\
\left({ }^{\circ} \mathrm{C}\right)\end{array}$ & $\begin{array}{l}\text { Low } \\
\left({ }^{\circ} \mathrm{C}\right)\end{array}$ \\
\hline \multirow{6}{*}{ Bluefield } & Base & - & - & - & 58 & -22 & & \\
\hline & & & & 0 & 70 & -22 & 70 & -22 \\
\hline & 1 & 2 & 50.8 & 25.4 & 70 & -22 & 70 & -22 \\
\hline & 2 & 3 & 76.2 & 88.9 & 64 & -22 & 70 & -22 \\
\hline & 3 & 10 & 254 & 254 & 58 & -16 & 64 & -22 \\
\hline & 4 & 3 & 76.2 & 419.1 & 58 & -16 & 64 & -22 \\
\hline \multirow{6}{*}{ Morgantown } & Base & - & - & - & 58 & -22 & & \\
\hline & & & & 0 & 70 & -28 & 70 & -22 \\
\hline & 1 & 2 & 50.8 & 25.4 & 70 & -22 & 70 & -22 \\
\hline & 2 & 3 & 76.2 & 88.9 & 64 & -22 & 70 & -22 \\
\hline & 3 & 10 & 254 & 254 & 64 & -22 & 64 & -22 \\
\hline & 4 & 3 & 76.2 & 419.1 & 64 & -22 & 64 & -22 \\
\hline \multirow{6}{*}{ Wheeling } & Base & - & - & - & 58 & -22 & & \\
\hline & & & & 0 & 76 & -22 & 70 & -22 \\
\hline & 1 & 2 & 50.8 & 25.4 & 70 & -22 & 70 & -22 \\
\hline & 2 & 3 & 76.2 & 88.9 & 70 & -22 & 70 & -22 \\
\hline & 3 & 10 & 254 & 254 & 64 & -16 & 64 & -22 \\
\hline & 4 & 3 & 76.2 & 419.1 & 64 & -16 & 64 & -22 \\
\hline \multirow{6}{*}{ Elkins } & Base & - & - & - & 58 & -28 & & \\
\hline & & & & 0 & 70 & -28 & 70 & -22 \\
\hline & 1 & 2 & 50.8 & 25.4 & 70 & -22 & 70 & -22 \\
\hline & 2 & 3 & 76.2 & 88.9 & 64 & -22 & 70 & -22 \\
\hline & 3 & 10 & 254 & 254 & 64 & -22 & 64 & -22 \\
\hline & 4 & 3 & 76.2 & 419.1 & 64 & -22 & 64 & -22 \\
\hline \multirow{6}{*}{ Charleston } & Base & - & - & - & 64 & -22 & & \\
\hline & & & & 0 & 76 & -22 & 70 & -22 \\
\hline & 1 & 2 & 50.8 & 25.4 & 76 & -22 & 70 & -22 \\
\hline & 2 & 3 & 76.2 & 88.9 & 70 & -16 & 70 & -22 \\
\hline & 3 & 10 & 254 & 254 & 64 & -16 & 64 & -22 \\
\hline & 4 & 3 & 76.2 & 419.1 & 64 & -16 & 64 & -22 \\
\hline
\end{tabular}


Table 15: Performance Grade adjusted Structure \#2 compared to typical WVDOH grades

\begin{tabular}{|c|c|c|c|c|c|c|c|c|}
\hline \multirow{3}{*}{$\begin{array}{l}\text { Weather } \\
\text { Station }\end{array}$} & \multirow{3}{*}{$\begin{array}{l}\text { Layer } \\
\mathbf{N}^{\circ}\end{array}$} & \multirow[b]{3}{*}{ in } & \multirow[b]{3}{*}{$\mathrm{mm}$} & \multirow{3}{*}{$\begin{array}{c}\begin{array}{c}\text { Analysis } \\
\text { point }\end{array} \\
\begin{array}{c}\text { depth } \\
\text { from } \\
\text { surface }\end{array} \\
\mathrm{mm}\end{array}$} & \multicolumn{4}{|c|}{$\begin{array}{c}\text { PERFORMANCE } \\
\text { GRADE } \\
\end{array}$} \\
\hline & & & & & \multicolumn{2}{|c|}{ LTPPBind V3.1 } & \multicolumn{2}{|c|}{ Typical WVDOH } \\
\hline & & & & & $\begin{array}{l}\text { High } \\
\left({ }^{\circ} \mathrm{C}\right)\end{array}$ & $\begin{array}{l}\text { Low } \\
\left({ }^{\circ} \mathrm{C}\right)\end{array}$ & $\begin{array}{l}\text { High } \\
\left({ }^{\circ} \mathrm{C}\right)\end{array}$ & $\begin{array}{l}\text { Low } \\
\left({ }^{\circ} \mathrm{C}\right)\end{array}$ \\
\hline \multirow{3}{*}{ Bluefield } & Base & - & - & - & 58 & -22 & & \\
\hline & & & & 0 & 70 & -22 & 70 & -22 \\
\hline & 1 & 4 & 101.6 & 50.8 & 64 & -22 & 70 & -22 \\
\hline \multirow{3}{*}{ Morgantown } & Base & - & - & - & 58 & -28 & & \\
\hline & & & & 0 & 70 & -28 & 70 & -22 \\
\hline & 1 & 4 & 101.6 & 50.8 & 64 & -22 & 70 & -22 \\
\hline \multirow{3}{*}{ Wheeling } & Base & - & - & - & 58 & -22 & & \\
\hline & & & & 0 & 70 & -22 & 70 & -22 \\
\hline & 1 & 4 & 101.6 & 50.8 & 70 & -22 & 70 & -22 \\
\hline \multirow{3}{*}{ Elkins } & Base & - & - & - & 58 & -28 & & \\
\hline & & & & 0 & 70 & -28 & 70 & -22 \\
\hline & 1 & 4 & 101.6 & 50.8 & 64 & -22 & 70 & -22 \\
\hline \multirow{3}{*}{ Charleston } & Base & - & - & - & 64 & -22 & & \\
\hline & & & & 0 & 76 & -22 & 70 & -22 \\
\hline & 1 & 4 & 101.6 & 50.8 & 70 & -22 & 70 & -22 \\
\hline
\end{tabular}

Table 16: Performance Grade for Snowshoe weather station

\begin{tabular}{|c|c|c|c|c|c|c|c|c|c|c|}
\hline \multirow{4}{*}{$\begin{array}{l}\text { Weather } \\
\text { Station }\end{array}$} & \multirow{4}{*}{$\begin{array}{l}\text { Layer } \\
\mathbf{N}^{\circ}\end{array}$} & \multirow{3}{*}{$\begin{array}{l}\text { Mid- } \\
\text { point of } \\
\text { layer } \\
\text { depth } \\
\text { from } \\
\text { surface }\end{array}$} & \multicolumn{8}{|c|}{$\begin{array}{l}\text { PERFORMANCE } \\
\text { GRADE }\end{array}$} \\
\hline & & & \multicolumn{4}{|c|}{ Traffic $>30 \times 10^{6}$} & \multicolumn{4}{|c|}{ Traffic $<0.3 \times 10^{6}$} \\
\hline & & & \multicolumn{2}{|c|}{$\begin{array}{c}\text { Reliability }= \\
50 \%\end{array}$} & \multicolumn{2}{|c|}{$\begin{array}{c}\text { Reliability }= \\
98 \%\end{array}$} & \multicolumn{2}{|c|}{ Reliability = $\mathbf{5 0} \%$} & \multicolumn{2}{|c|}{$\begin{array}{c}\text { Reliability }= \\
98 \%\end{array}$} \\
\hline & & $\mathrm{mm}$ & $\begin{array}{l}\text { High } \\
\left({ }^{\circ} \mathrm{C}\right)\end{array}$ & $\begin{array}{l}\text { Low } \\
\left({ }^{\circ} \mathrm{C}\right)\end{array}$ & $\begin{array}{l}\text { High } \\
\left({ }^{\circ} \mathrm{C}\right)\end{array}$ & $\begin{array}{l}\text { Low } \\
\left({ }^{\circ} \mathrm{C}\right)\end{array}$ & $\begin{array}{l}\text { High } \\
\left({ }^{\circ} \mathrm{C}\right)\end{array}$ & $\begin{array}{l}\text { Low } \\
\left({ }^{\circ} \mathrm{C}\right)\end{array}$ & $\begin{array}{l}\text { High } \\
\left({ }^{\circ} \mathrm{C}\right)\end{array}$ & $\begin{array}{l}\text { Low } \\
\left({ }^{\circ} \mathrm{C}\right)\end{array}$ \\
\hline \multirow{6}{*}{ Snowshoe } & Base & - & 46 & -22 & 46 & -28 & 46 & -22 & 46 & -28 \\
\hline & & 0 & 64 & -22 & 64 & -28 & 46 & -22 & 46 & -28 \\
\hline & 1 & 25.4 & 58 & -22 & 58 & -28 & 40 & -22 & 46 & -28 \\
\hline & 2 & 88.9 & 52 & -16 & 58 & -28 & 40 & -16 & 40 & -28 \\
\hline & 3 & 254.0 & 52 & -16 & 52 & -22 & 40 & -16 & 40 & -22 \\
\hline & 4 & 419.1 & 52 & -16 & 52 & -22 & 40 & -16 & 40 & -22 \\
\hline
\end{tabular}




\subsubsection{Binders for MEPDG analysis}

The purpose of the LTPPBind analysis was to both explore the binder recommendations for West Virginia and to select binder grades for use in the MEPDG analysis. To study the effect of binder selection of predicted pavement performance a range of binders broader than the recommendations of LTPPBind was desired. Figures 14 and 15 give the binder grade for each analysis section for both pavement structures, and the corresponding reliability. The selected binders assure the PG covers the low and high temperature grades that may be selected for the analysis areas. The percentage of the reliability is written in parenthesis, the first value corresponds to the percentage of reliability for high temperature and the second number the percentage of reliability for low temperature. The reliability level always increases when the higher temperature grade increases and increases as the low temperature grade decreases as well. Sometimes the percentage of reliability is the same for two different temperature values. Temperatures above the maximum value obtained for the higher reliability has the same percentage of reliability.

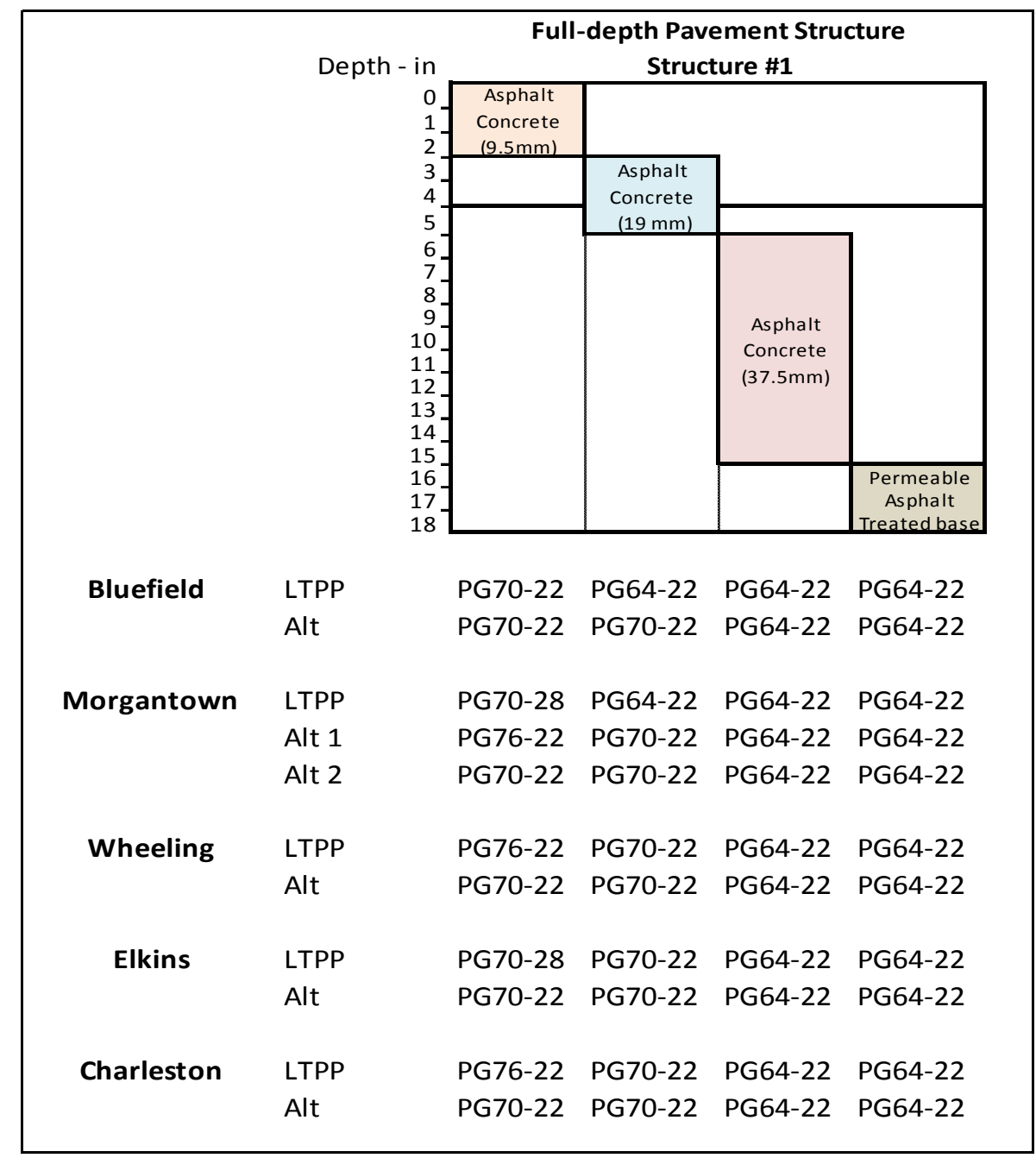

Figure 14: PG Binder Selection Structure \#1 


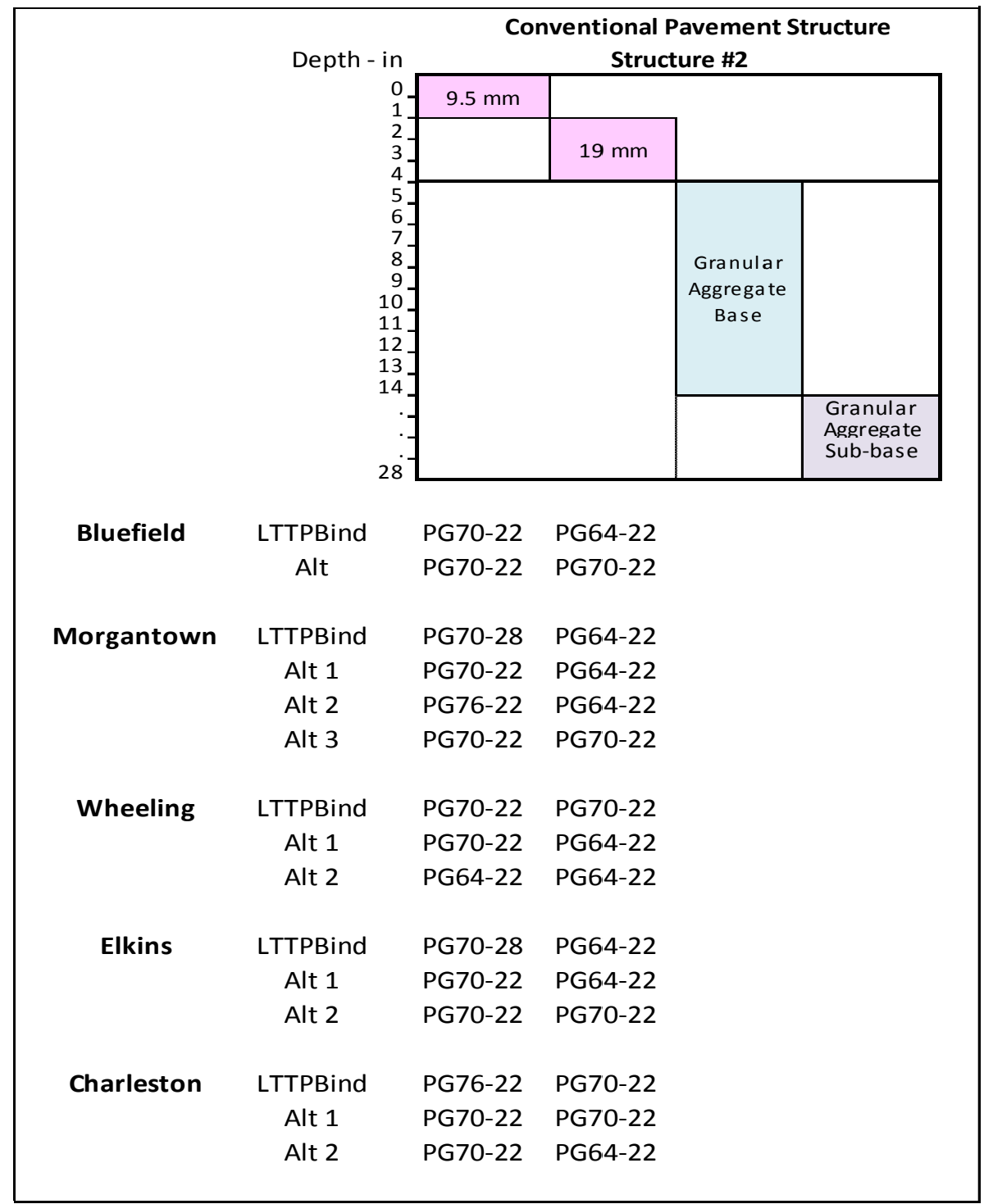

Figure 15: $P G$ Binder Selection Structure \#2

In addition to the binders specified in Figures 14 and 15, an analysis was performed assuming the binder selected for the pavement remained constant throughout the depth. The five analysis locations were analyzed for the two pavement structures and four binders: PG 58-28, PG 64-22, PG 70-22, and PG 76-22.

\subsection{MEPDG Analysis}

A MEPDG analysis was performed for each of the five analysis locations, for the two pavement structures, two modes of binder selection; varying the binder through the pavement structure based on the LTPPBind V3.1 analysis and using a single binder for the entire pavement structure. Table 17 shows the main climatic characteristics of the analysis locations. 
Table 17: Climatic Characteristics of the selected stations

\begin{tabular}{|c|c|c|c|c|c|c|c|}
\hline $\begin{array}{c}\text { Section } \\
\text { name }\end{array}$ & $\begin{array}{c}\text { Elevation } \\
\text { (ft.) }\end{array}$ & $\begin{array}{c}\text { Latitude } \\
\text { (Deg.,Min.) }\end{array}$ & $\begin{array}{c}\text { Longitude } \\
\text { (Deg., } \\
\text { Min.) }\end{array}$ & $\begin{array}{c}\text { Mean } \\
\text { Annual air } \\
\text { Temperature } \\
\left({ }^{\circ} \mathbf{F}\right)\end{array}$ & $\begin{array}{c}\text { Mean } \\
\text { annual } \\
\text { Rainfal } \\
\text { ( (in) }\end{array}$ & $\begin{array}{c}\text { Freezing } \\
\text { Index } \\
\left({ }^{\circ} \mathbf{F} \text {-days) }\right.\end{array}$ & $\begin{array}{c}\text { Average } \\
\text { Annual } \\
\text { number of } \\
\text { Freeze/Tha } \\
\text { w Cycles }\end{array}$ \\
\hline Bluefield & 2685 & 37,30 & 81,22 & 50.49 & 40.75 & 500.75 & 71 \\
\hline Morgantown & 1152 & 39,38 & 79,55 & 53.15 & 43.27 & 445.97 & 56 \\
\hline Wheeling & 594 & 40,11 & 80,39 & 51.95 & 37.76 & 534.99 & 49 \\
\hline Elkins & 980 & 38,37 & 79,51 & 50.06 & 44.96 & 605.78 & 88 \\
\hline Charleston & 1026 & 38,23 & 81,35 & 55.16 & 44.69 & 287.16 & 58 \\
\hline
\end{tabular}

\subsubsection{Analysis based on LTPPBind V3.1 recommendations}

The following analysis uses the binders selected from the LTPPBind V3.1 as identified in Figures 14 and 15.

\section{Structure \#1}

Figures 16 through 20 show the progression of distresses for Structure \#1 for Bluefield. The corresponding graphs for the other analysis locations are given in Appendix B. The trends for all the analysis locations are similar. This analysis demonstrates there is little difference in the predicted performance of Structure \#1. Figures 21 to 25 show the predicted pavement performance over a 20 year analysis period for the five analysis locations and the different alternative binder selections as defined in Figure 14. MEPDG predicts excess rutting in the pavement structure; all sections and design alternatives have more than of $0.25 \mathrm{in}$. rutting in the pavement structure, which is the default limit in MEPDG. However, the default limit for total pavement rutting, including the subgrade, is $0.75 \mathrm{in}$. and all the sections are well below this limit. The amount of predicted cracking is very low for all modes of cracking, alligator, longitudinal (top down), and thermal. Thermal cracking was not displayed on a figure as the predicted thermal cracking is zero for all analysis situations.

Since a typical analysis of pavement structures in WV plans for an overlay at about year 15, the graphs for the distress at 180 months are presented in Figures 26 to 30. As expected, since the distress at 20 years is less than the limits, the 180 month analysis is also below the limits. The IRI for the 20 year analysis period is approximately $120 \mathrm{in} / \mathrm{mi}$. whereas the IRI for 180 months is approximately 100 to $105 \mathrm{in} / \mathrm{mi}$. The relatively small differential in the IRI is due to the small differential in the prediction of the other distresses since IRI is predicted as a function of these distresses, Equation 2.21. 


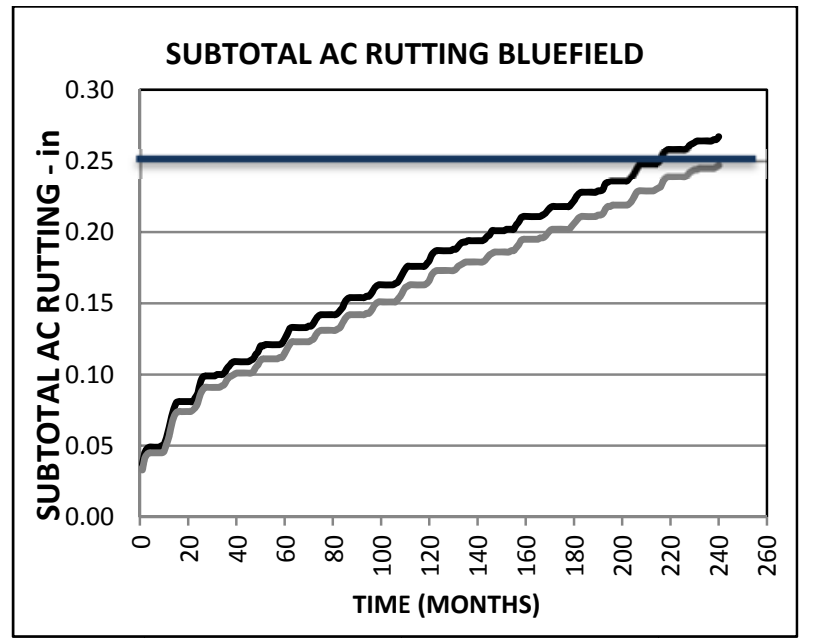

Figure 16: Effect of $\mathrm{PG}$ Asphalt Binder on AC Rutting Structure \#1

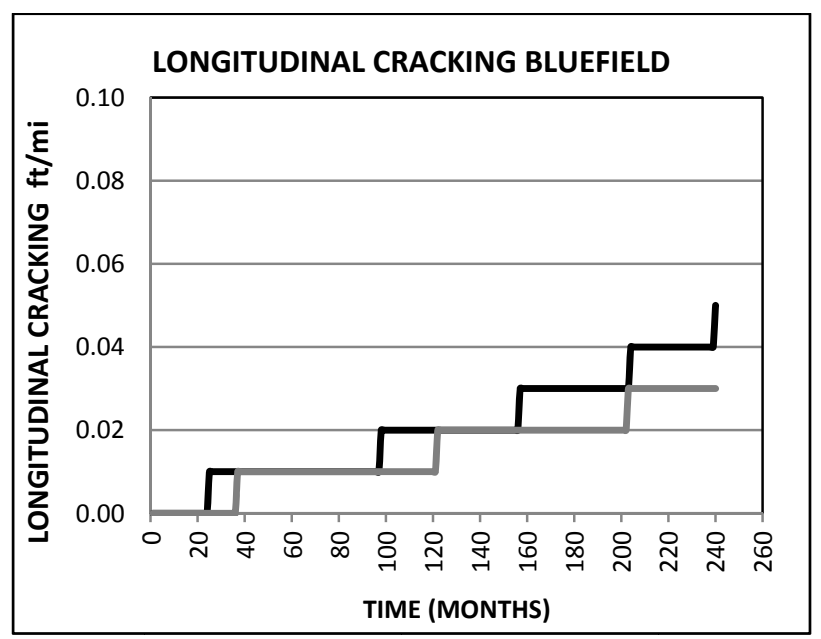

Figure 17: Effect of PG Asphalt Binder on Longitudinal Structure \#1

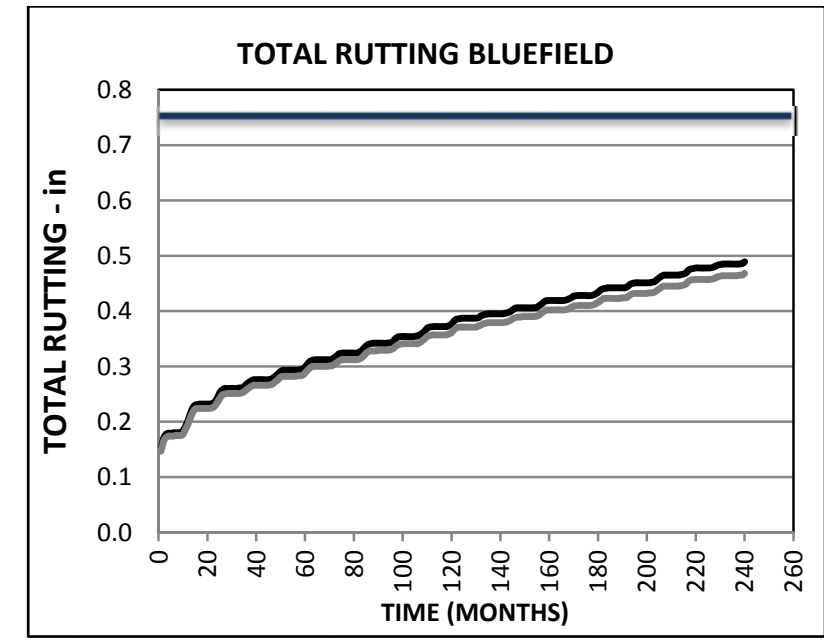

Figure 18: Effect of PG Asphalt Binder on Total Rutting Structure \#1

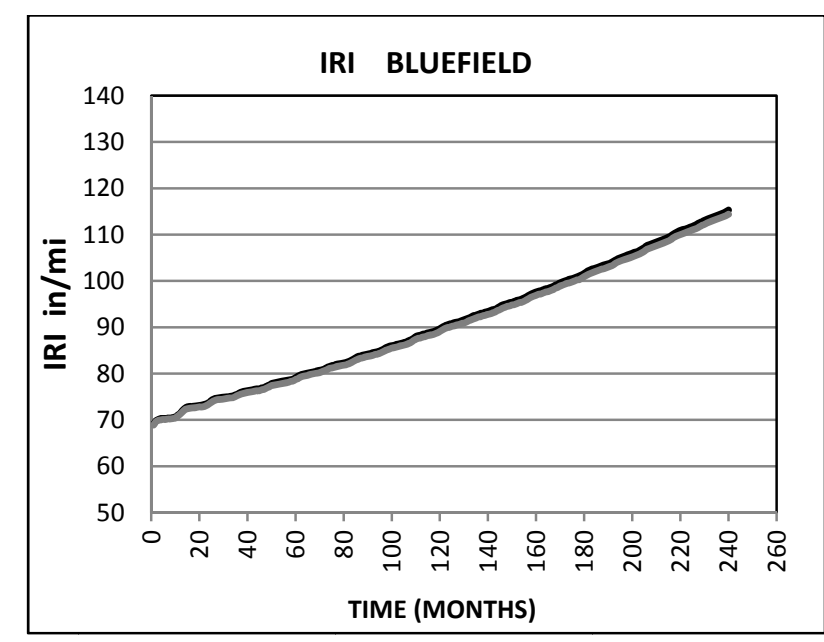

Figure 19: Effect of PG Asphalt Binder on IRI Structure \#1

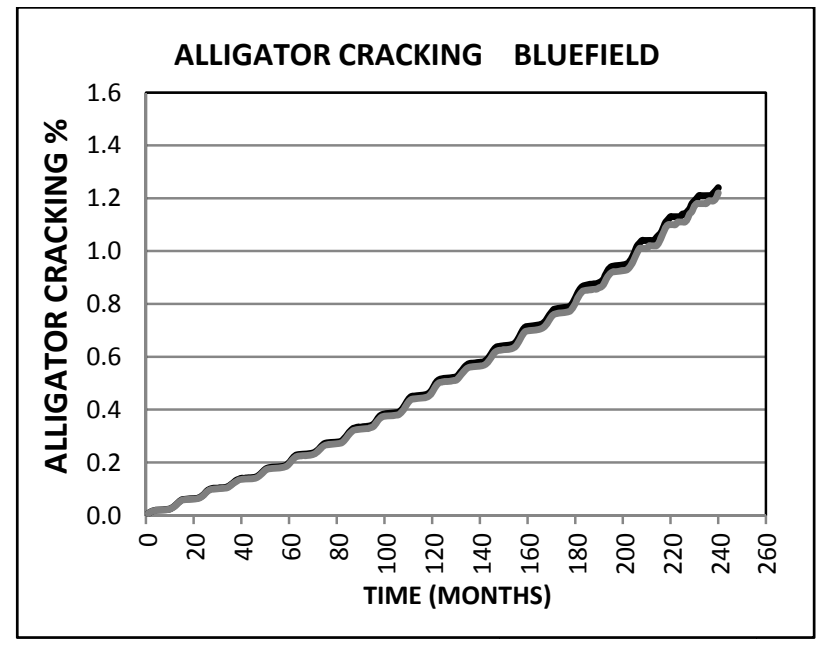

Figure 20: Effect of PG Asphalt Binder on Alligator Structure \#1

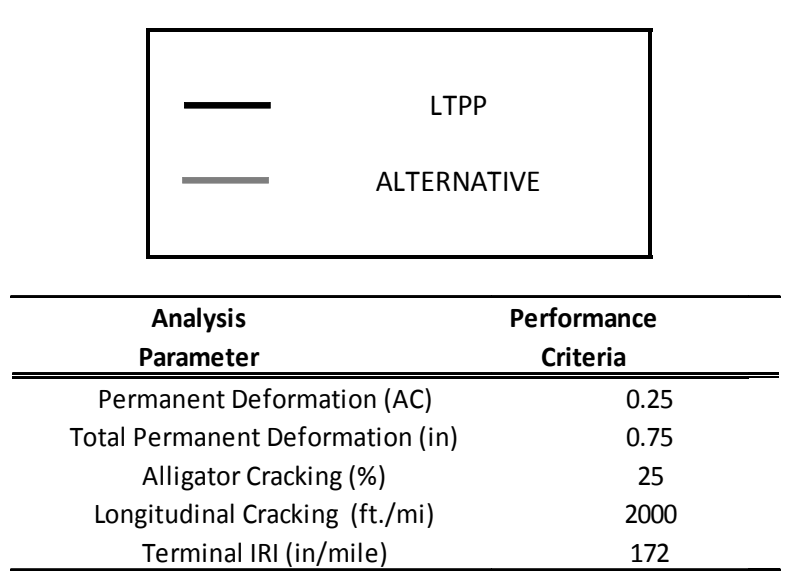




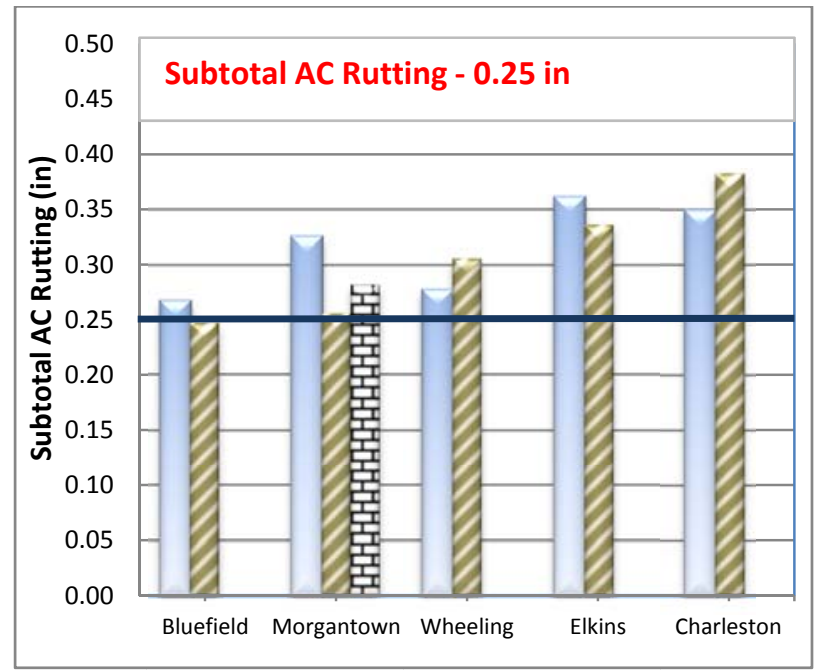

Figure 21: AC Rutting 240 months Structure \#1

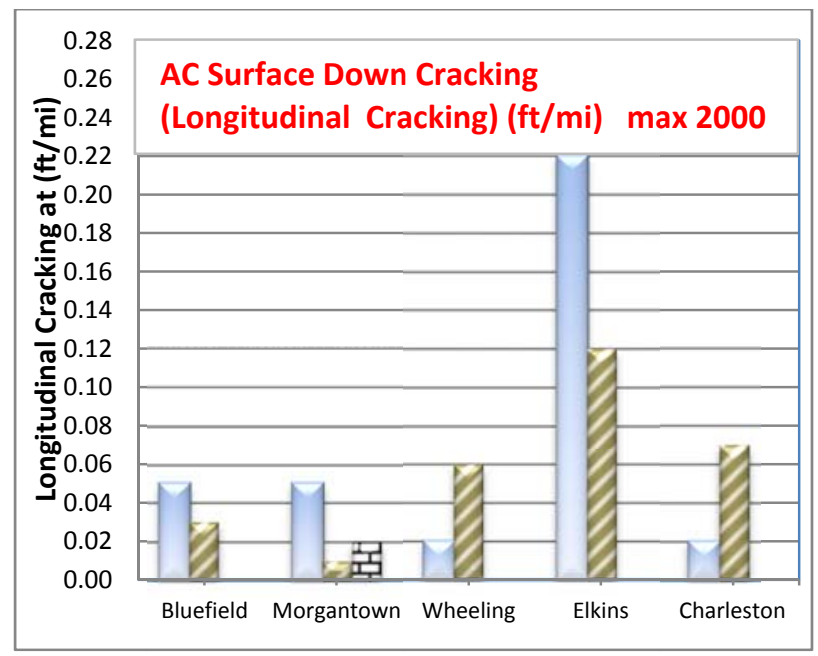

Figure 22: Longitudinal cracking 240 months Structure \#1

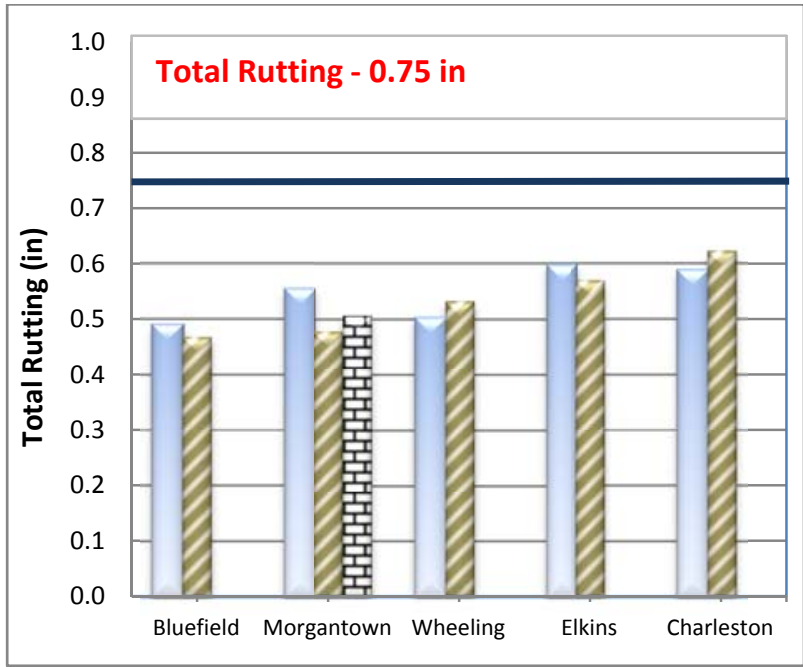

Figure 23: Total Rutting 240 months Structure \#1

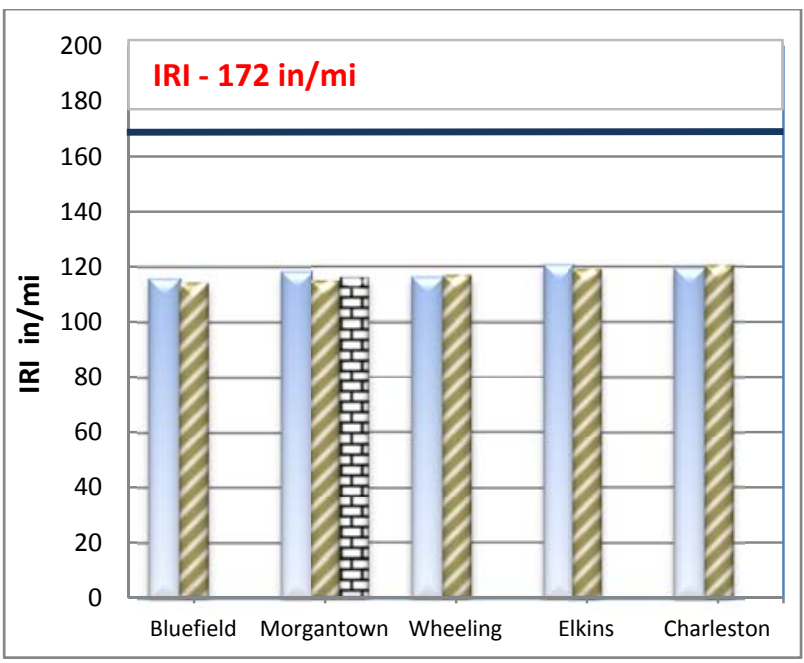

Figure 24: IRI 240 months Structure \#1

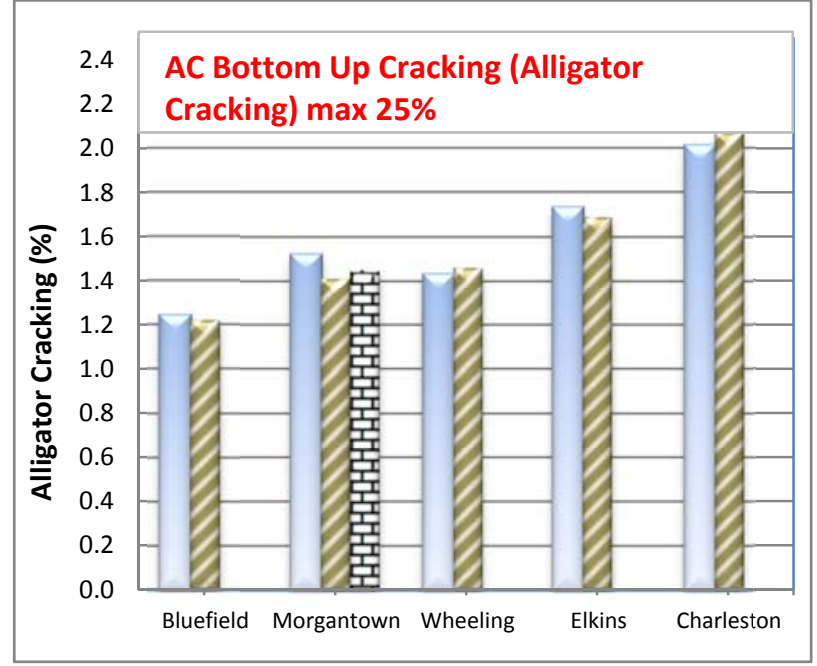

Figure 25: Alligator cracking 240 months Structure\#1

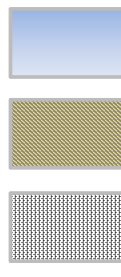

LTPP

ALT1

ALT2 


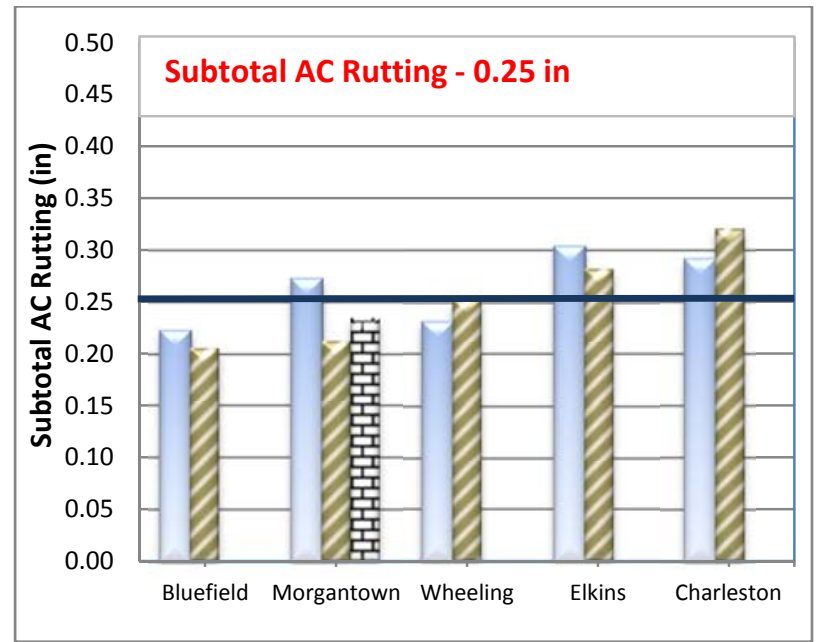

Figure 26: AC Rutting 180 months Structure \#1

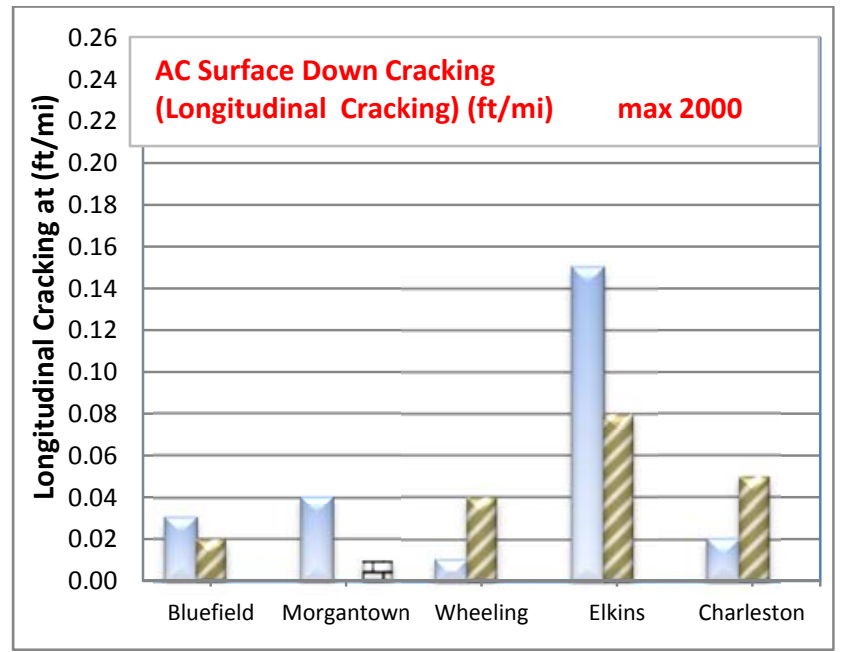

Figure 27: Longitudinal cracking 180 months

Structure \#1

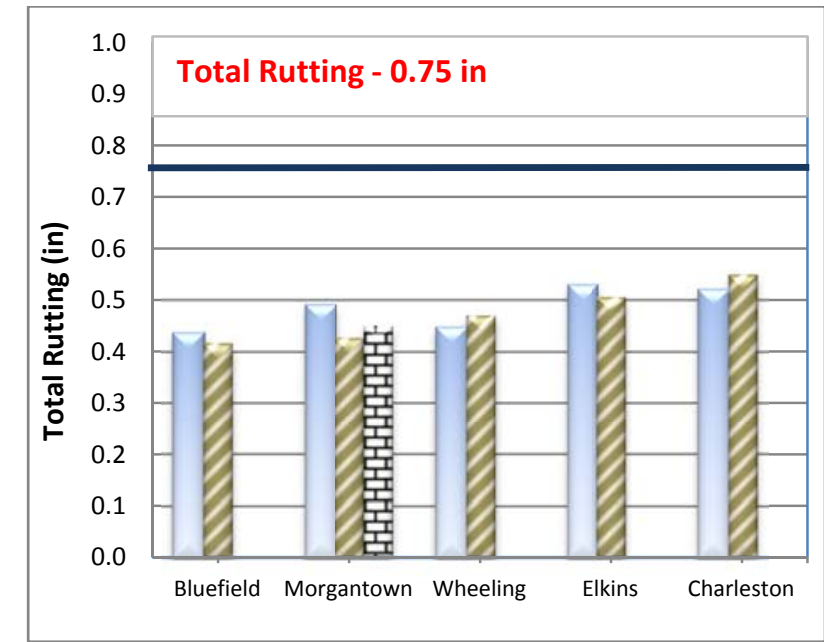

Figure 28: Total Rutting 180 months Structure \#1

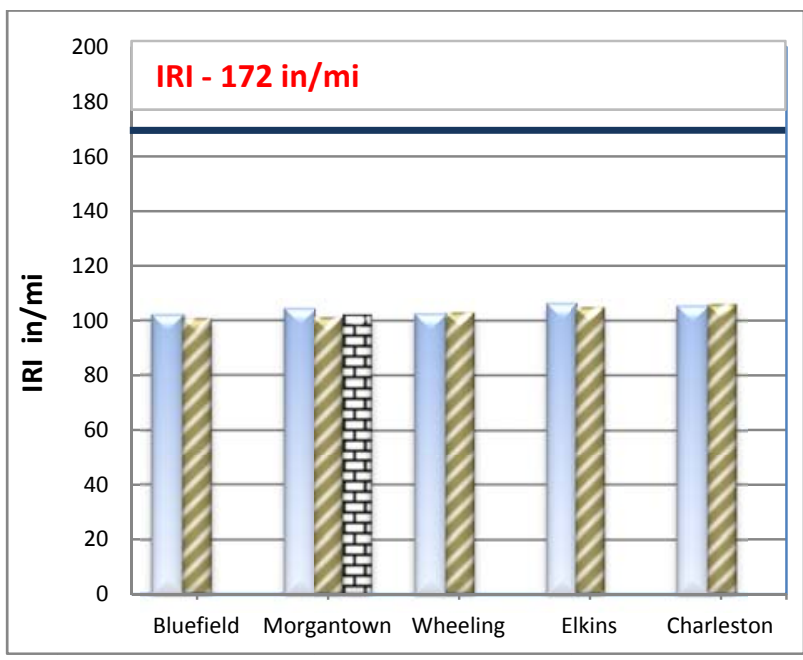

Figure 29: IRI 180 months Structure \#1

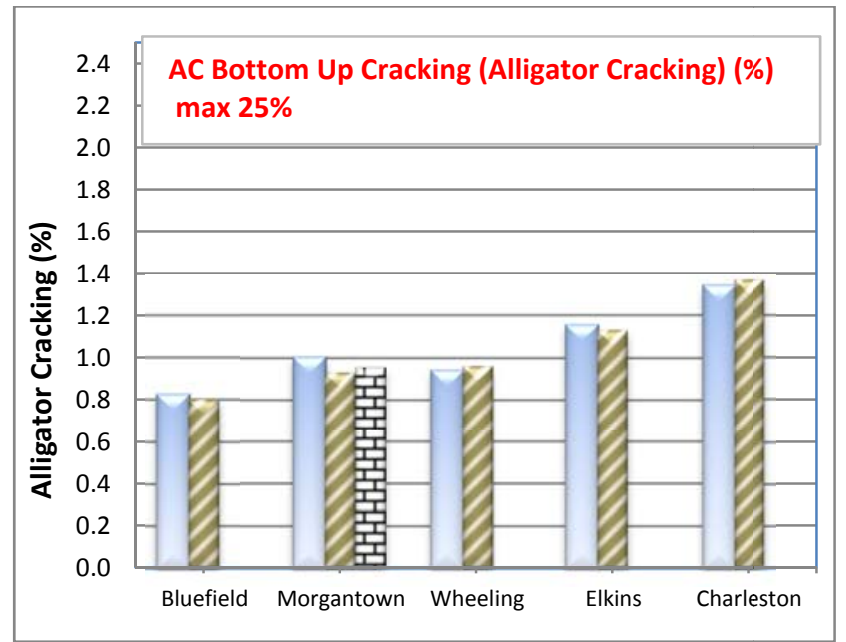

Figure 30: Alligator cracking 180 months Structure\#1

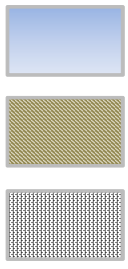

LTPP

ALT1

ALT2 
The differential amount of distress for each analysis situation due to the differences in binder selection indicates that for the analysis performed MEPDG is not sensitive to binder type when LTPPBind V3.1, adjusted for practical considerations, is used to select the binders.

\section{Structure 2}

Figures 31 through 35 show the progression of distresses for Structure \#8 for Bluefield. The corresponding graphs for the other analysis locations are given in Appendix B. The trends for all the analysis locations are similar. This analysis demonstrates there is little difference in the predicted performance of Structure \#2. Figures 36 to 40 show the predicted pavement performance over a 20 year analysis period for the five analysis locations and the different alternative binder selections as defined in Figure 15. MEPDG predicts excess distress (except for thermal cracking) for all the distress types for the 20 year analysis period.

The predictions for 180 months are presented in Figures 41 to 45 . The rutting at 15 years is near the limits for all analysis locations and binder selections. However, the amount of alligator and longitudinal cracking is excessive. MEPDG predicts alligator cracking will occur an approximately 40 percent of the pavement surface. More than $7500 \mathrm{ft} / \mathrm{mi}$. of longitudinal cracking is predicted. Roughness is predicted to be approximately $140 \mathrm{in} / \mathrm{mi}$., which is less than the default limit. This analysis suggests the pavement structure is not adequate for the traffic level. However, it is meaningful to include this structure in this research to investigate the predictions of distresses.

The differential amount of distress for each analysis situation due to the differences in binder selection indicates that for the analysis performed MEPDG is not sensitive to binder type when LTPPBind V3.1, adjusted for practical considerations, is used to select the binders.

\subsubsection{Analysis based on a single binder type}

The preceding analysis demonstrated little effect of the binder type on the MEPDG predicted performance of the pavement structure. Since binder type selection is important to the objective of this thesis the topic was investigated further by analyzing both structures assuming the asphalt concrete in all layers were constructed with a single binder type. Four binder types selected for this analysis were: PG 58-28, PG 64-22, PG 70-22 and PG 76-22.

\section{Structure \#1}

The distress predictions for the single binder analysis are shown in Figures 46 to 50 for Bluefield; the corresponding figures for the other locations are presented in Appendix B. As expected, as the high temperature grade of the binder increases the performance improves. This is the expected result for all distresses except for thermal cracking. Unfortunately, MEPDG did not predict any thermal cracking. If this result for thermal cracking is accepted then there is no reason for selecting a low temperature grade binder such as a PG 58-28. Appendix HH of the Guide shows the equations, models and calibration for prediction of thermal cracking. Based on these models, the MEPDG computer program should be predicting thermal cracking. Zborowski (2007) and Nogaj (2011) have also documented the issue with the prediction of thermal cracking. 


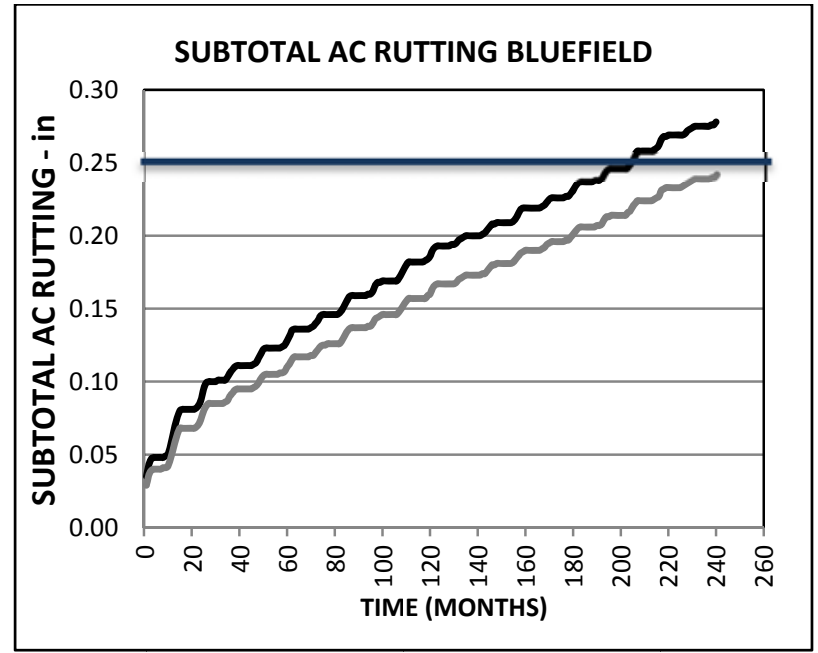

Figure 31: Effect of PG Asphalt Binder on AC Rutting Structure \#2

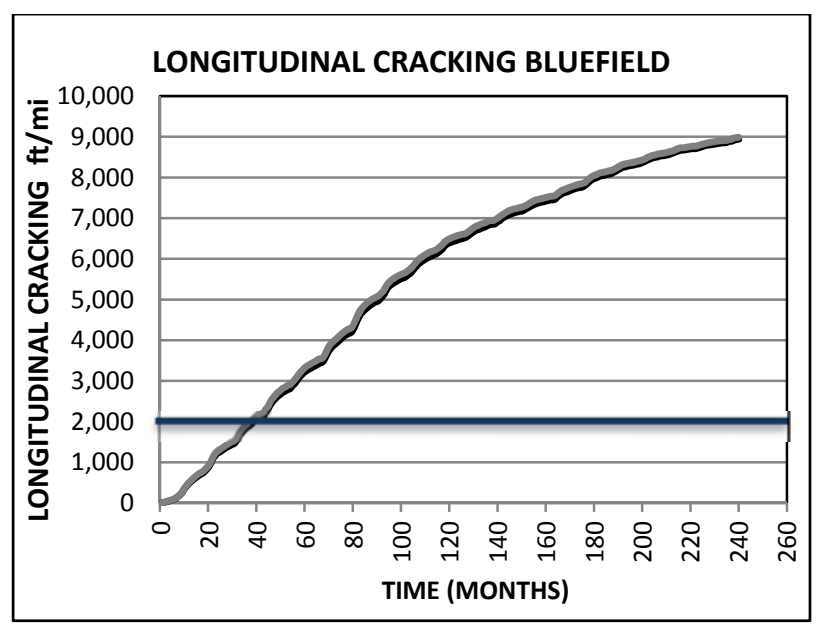

Figure 32: Effect of PG Asphalt Binder on Longitudinal Structure \#2

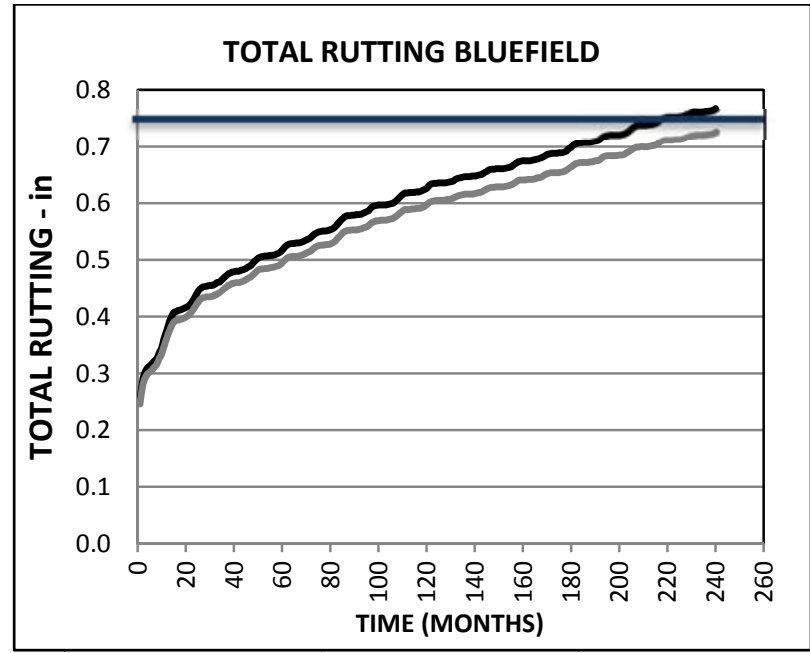

Figure 33: Effect of PG Asphalt Binder on Total Rutting Structure \#2

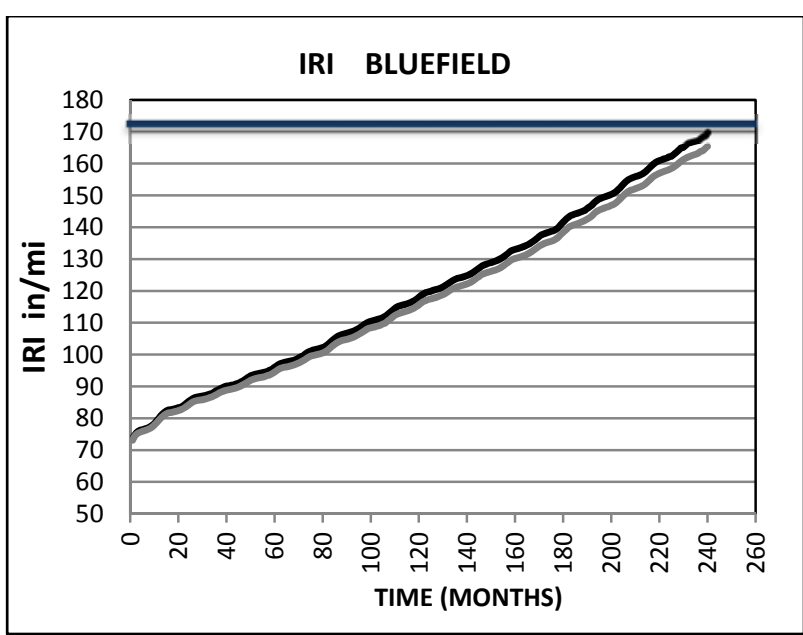

Figure 34: Effect of PG Asphalt Binder on IRI Structure \#2

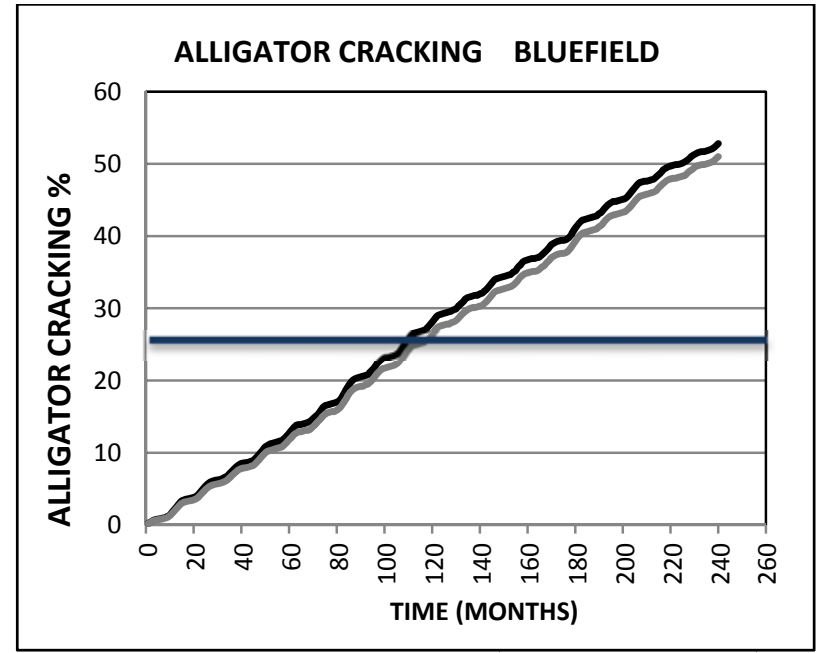

Figure 35: Effect of PG Asphalt Binder on Alligator Structure \#2

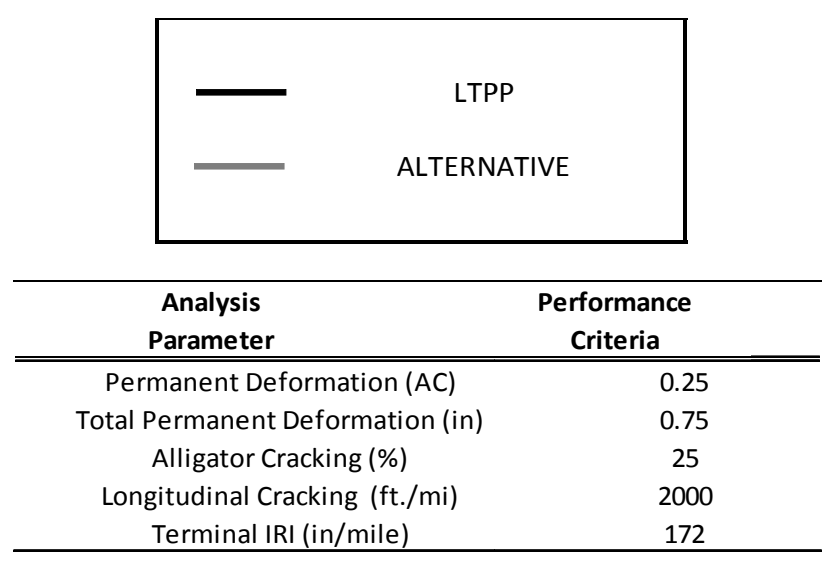




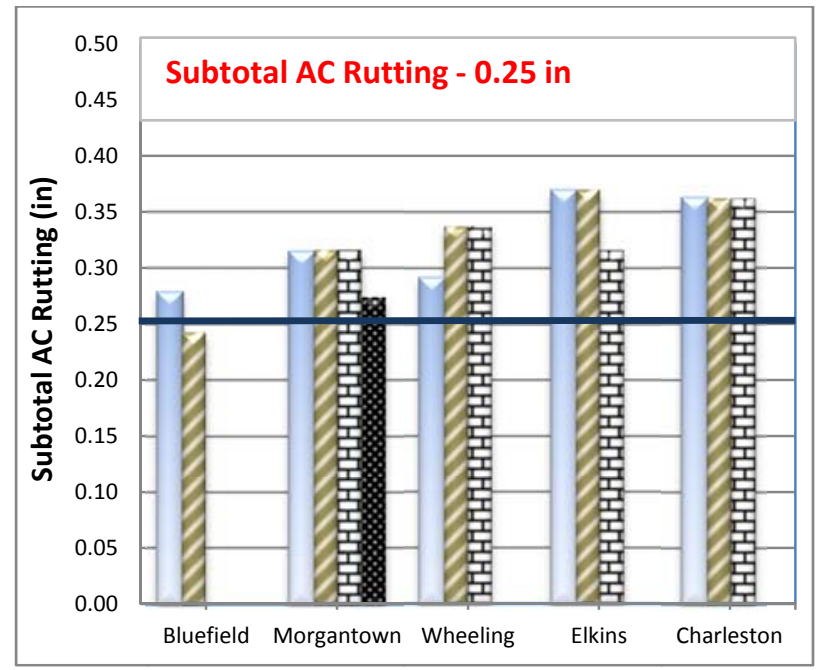

Figure 36: AC Rutting 240 months Structure \#2

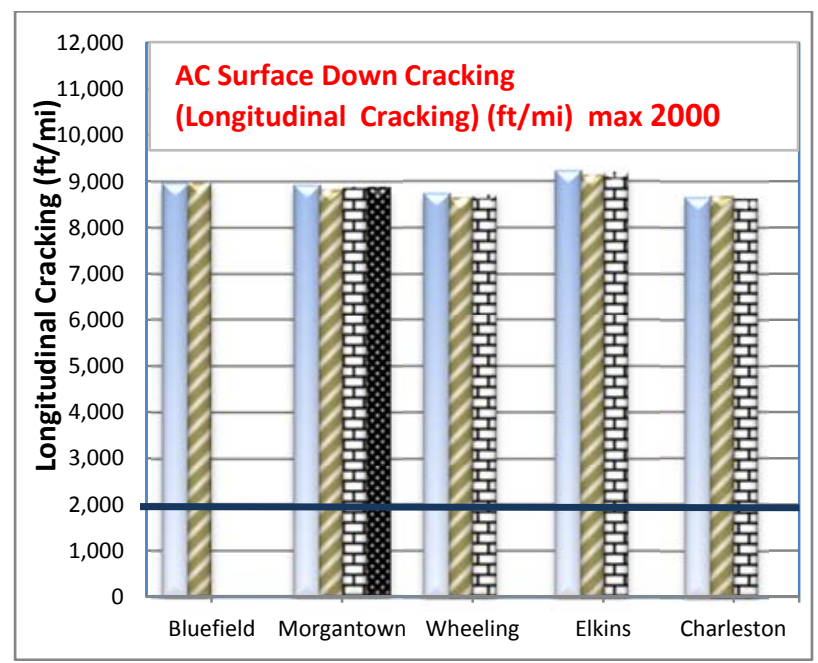

Figure 37: Longitudinal cracking 240 months Structure \#2

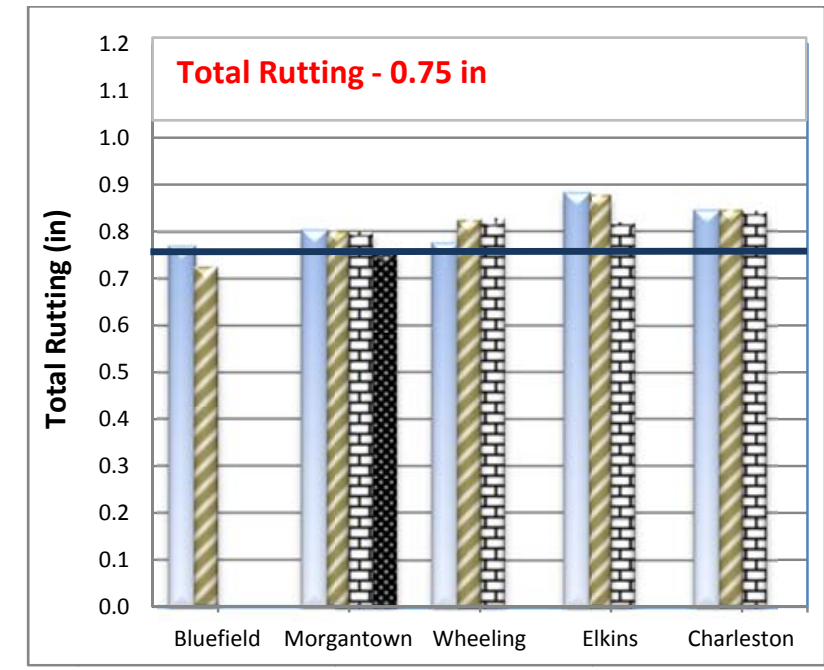

Figure 38: Total Rutting 240 months Structure \#2

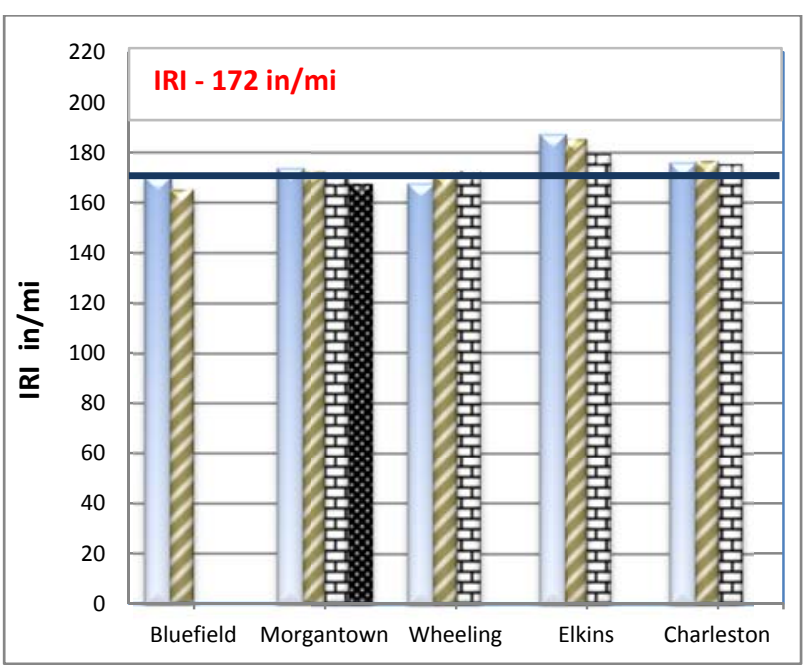

Figure 39: IRI 240 months Structure \#2

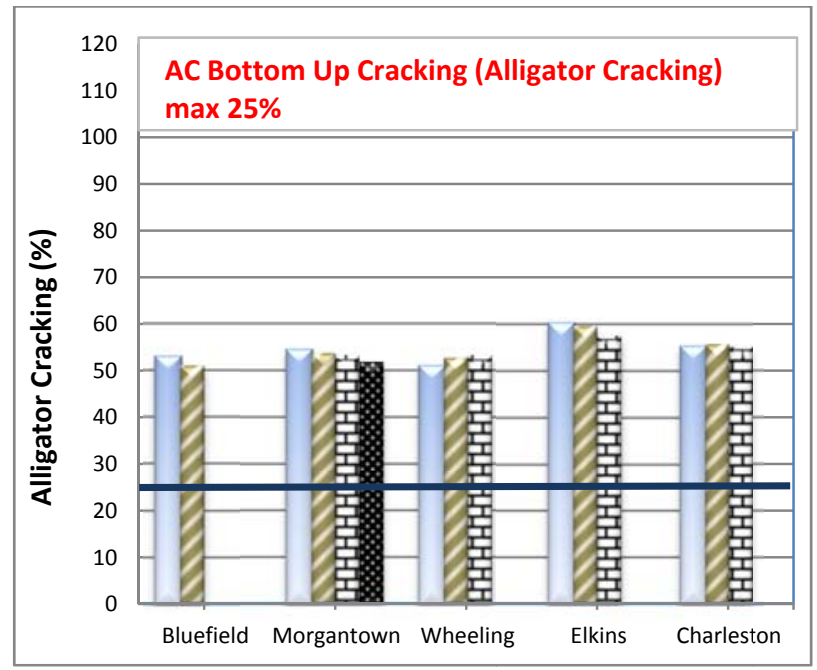

Figure 40: Alligator cracking 240months Structure ${ }^{\circ} \# 2$

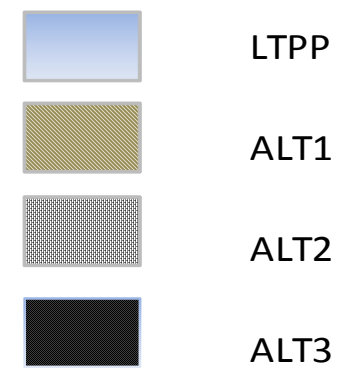




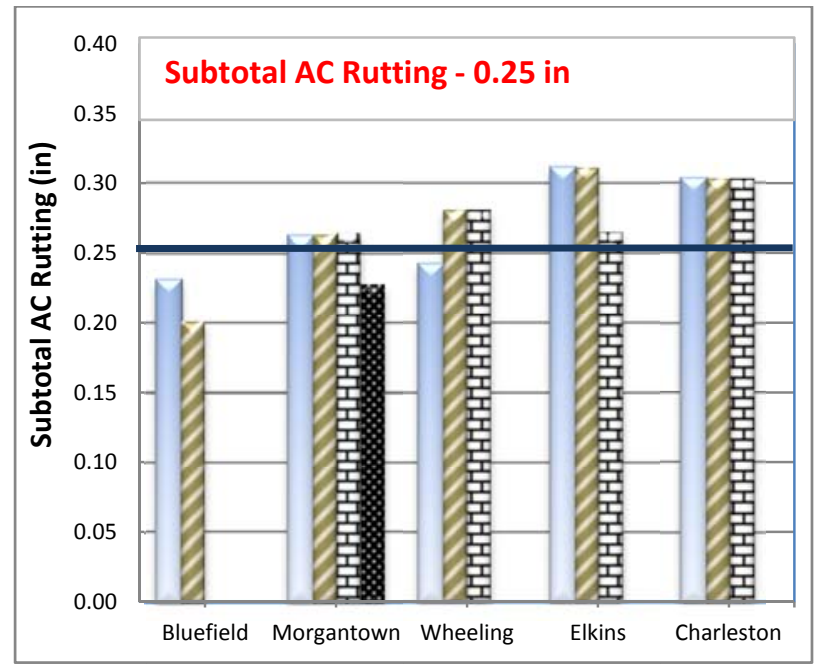

Figure 41: AC Rutting 180 months Structure \#2

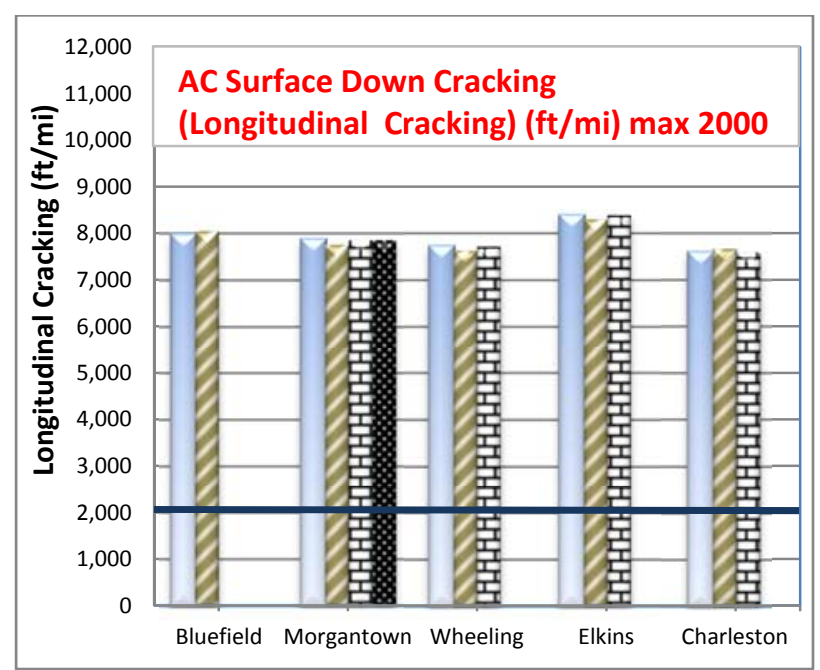

Figure 42: Longitudinal cracking 180 months Structure \#2

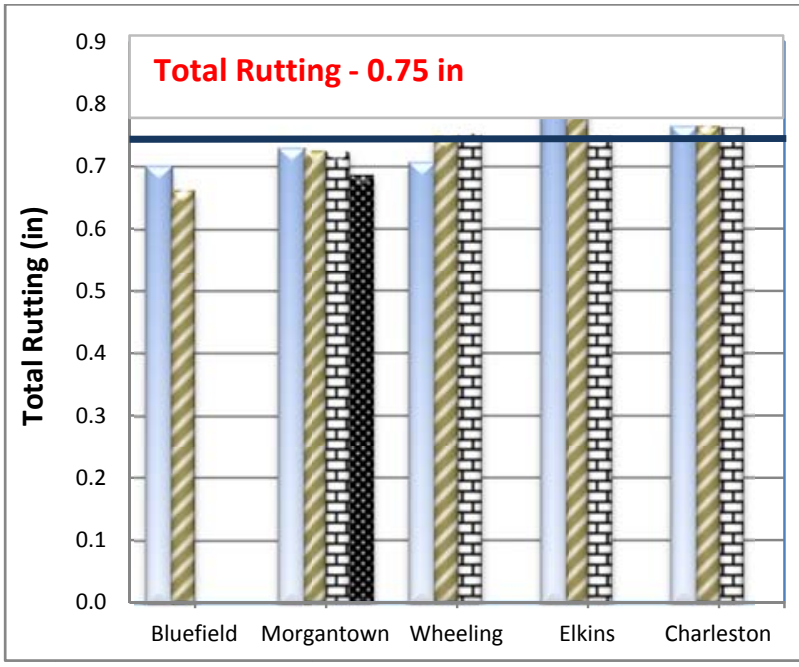

Figure 43: Total Rutting 180 months Structure \#2

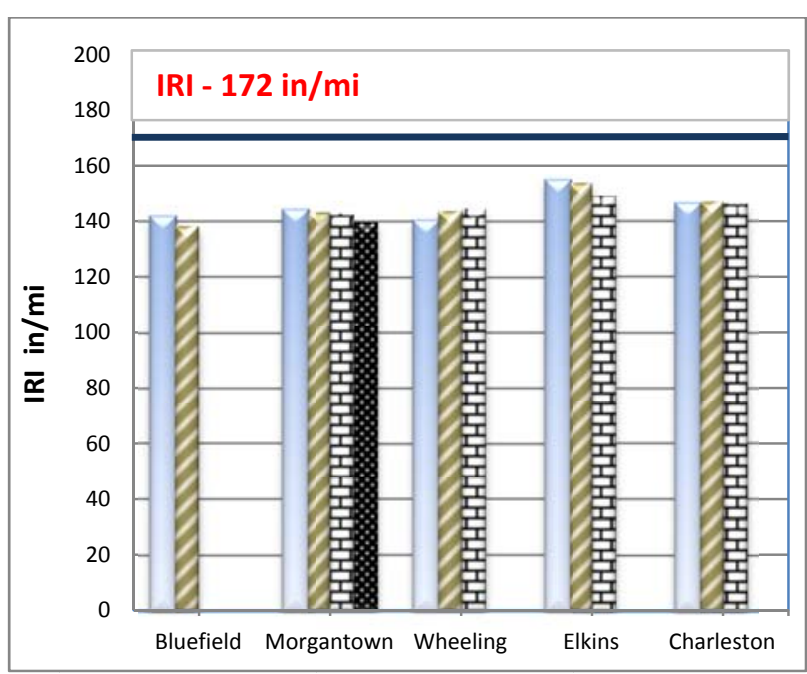

Figure 44: IRI 180 months Structure \#2

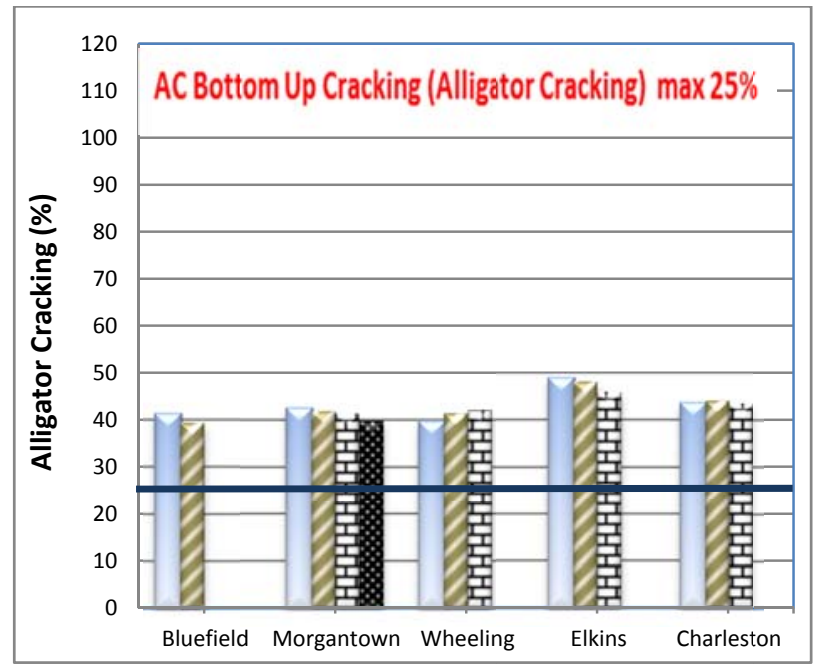

Figure 45: Alligator cracking 180 months Structure ${ }^{\circ} \# 2$

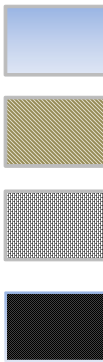

LTPP

ALT1

ALT2

ALT3 


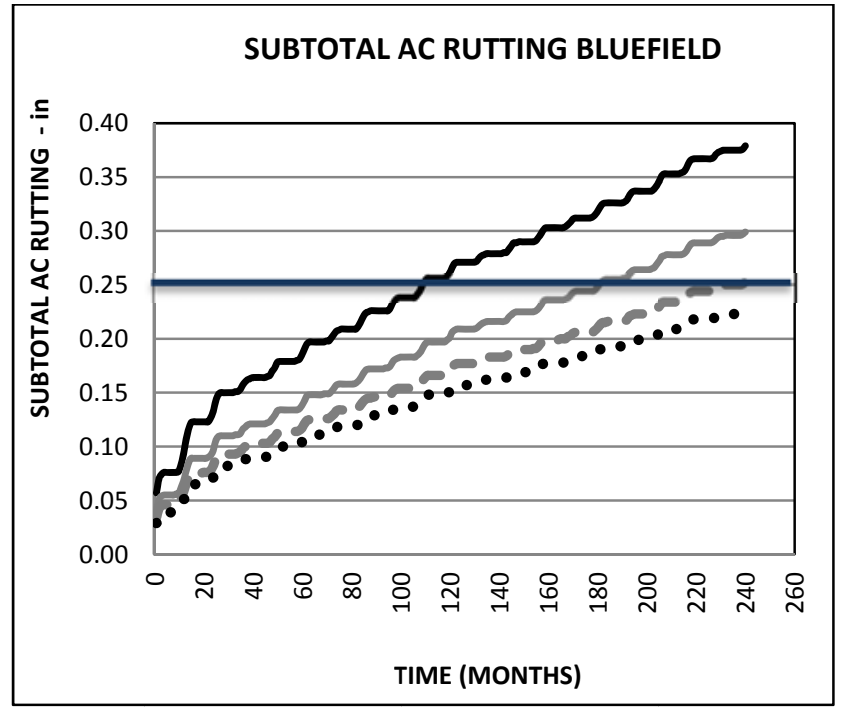

Figure 46: AC Rutting as a function of PG Binder type Structure \#1

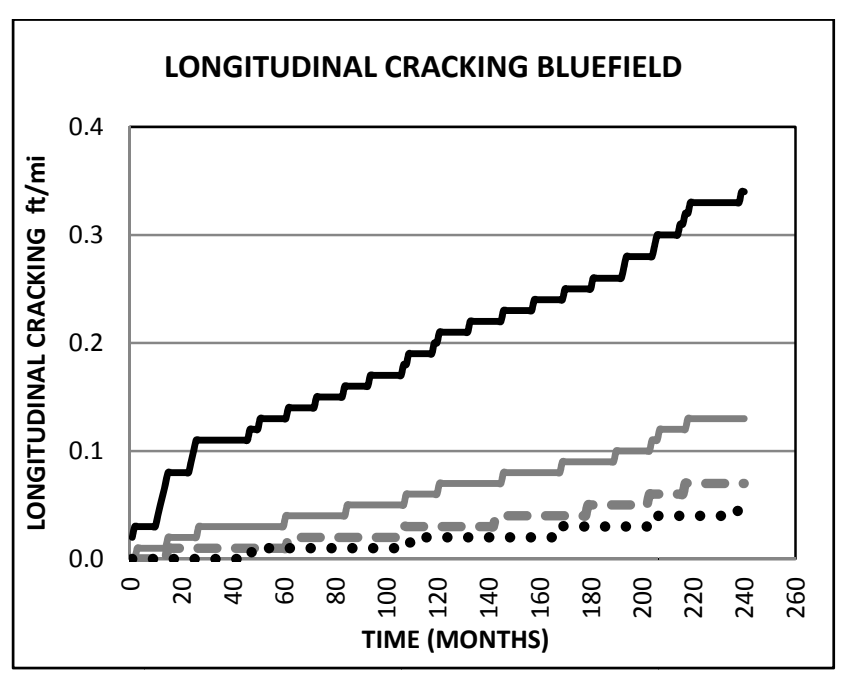

Figure 47: Longitudinal cracking as a function of PG Binder type Structure \#1

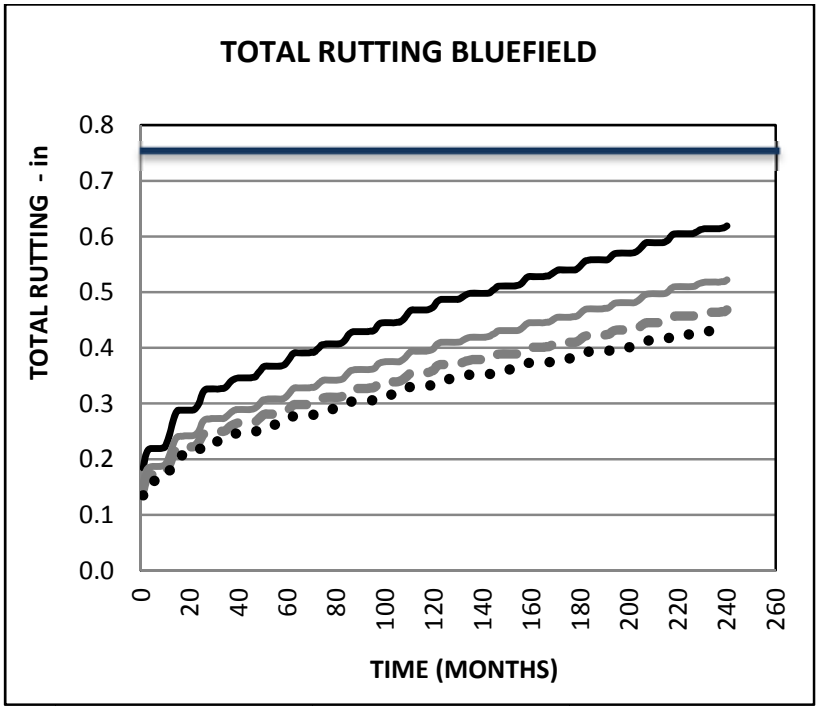

Figure 48: Total Rutting as a function of PG Binder type Structure \#1

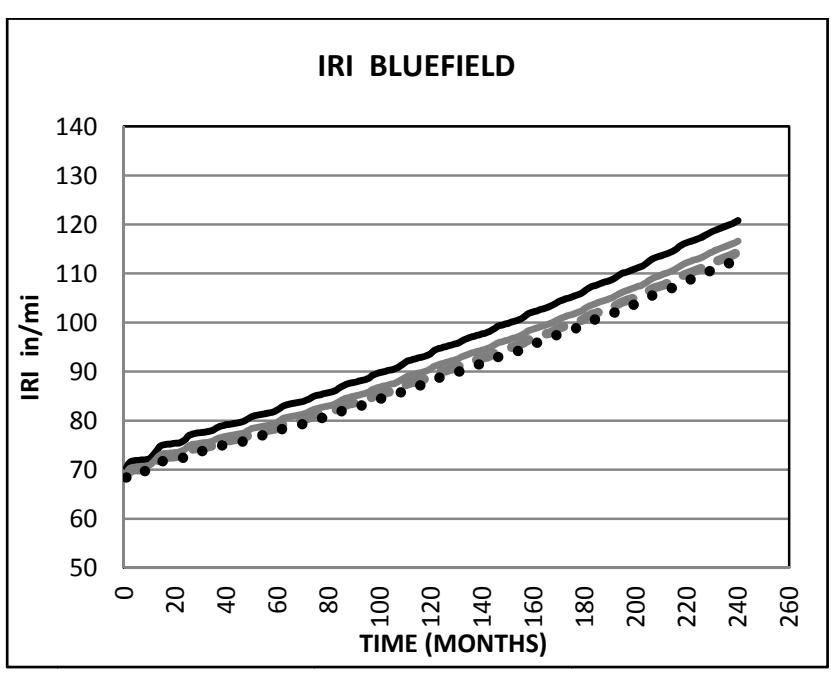

Figure 49: IRI as a function of PG Binder type Structure \#1

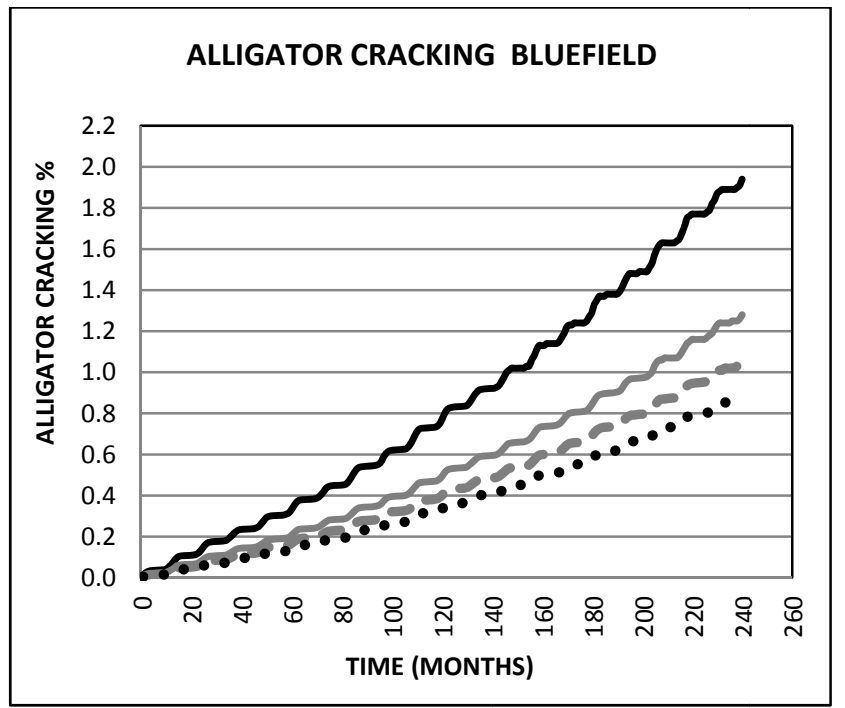

Figure 50: Alligator cracking as a function of $\mathrm{PG}$ Binder type Structure \#1

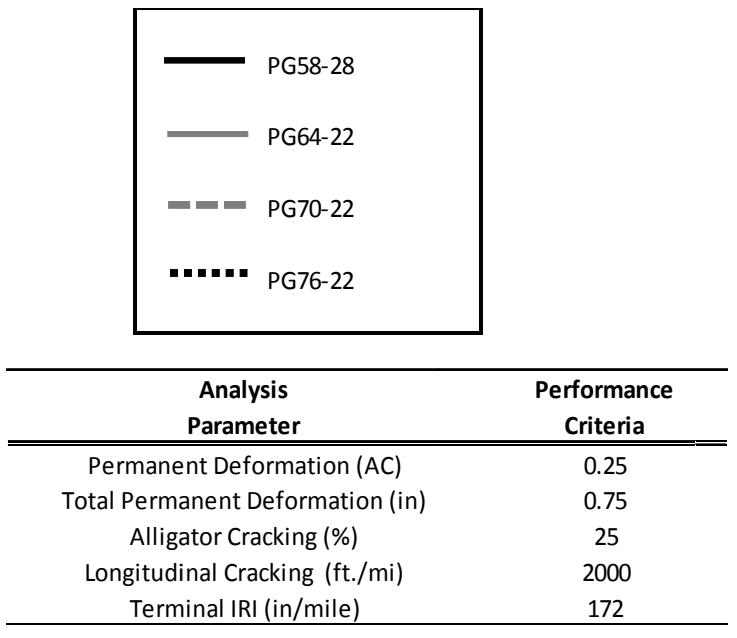


Figures 51 to 55 compare the different binders to the binder selected based on the LTPPBind V3.1 analysis (Figure 14) for 240 months. In all cases the PG 76-22 binder has the best rutting performance. However, the rutting performance of the PG 64-22 is only slightly more than the PG 76-22. The LTPPBind V3.1 recommendations for Wheeling and Charleston have a PG 76-22 for the surface. The predicted performance for these sights was only slightly less than the predicted performance with PG 76-22 used for the entire pavement structure. This suggests that the benefit of PG 76-22 is limited to the surface layers. Although Figures 53 and 54 indicate better cracking performance using the PG 76-22, the amount of cracking predicted is very small indicating binder selection has very little effect on cracking. Figure 55 indicates binder selection does not have a meaningful influence on roughness.

\section{Structure \#2 Original Design Concept}

Structure \#2, as defined in Figure 7, has a 4 inch surface layer, so it is reasonable to construct the entire hot mix layer with a single binder. Figures 56 to 60 show the predicted distress development for Bluefield, assuming a single binder type for the asphalt concrete layer. The figures for the other analysis locations are presented in Appendix B. The expected trend with binder grade is confirmed for rutting as the higher temperature grade binders have less predicted rutting. For all binders the predicted cracking is excessive, but there are no particular trends on longitudinal cracking. The alligator cracking is less as the high temperature binder grade increases, but the predicted amount of cracking that the differences in the amount of cracking are not meaningful. Roughness is similar, the higher temperature grade binders have better performance, but the amount of roughness is excessive. Figures 56 to 60 indicate that the expected performance of this section would not be acceptable at 15 years. Following the MEPDG protocol, for design the analysis should be repeated with a more substantial structure.

Figures 61 to 65 compare the distresses for the single binder type and the LTPPBind recommendation for all analysis locations. The analysis with a single binder type was analyzed as a single four inch layer. For the LTPPBind V3.1 recommendations the surface was modeled as a 1.5 inch layer with a $9.5 \mathrm{~mm}$ mix and a 2.5 inch base (binder coarse) with a $19 \mathrm{~mm}$ mix. For Wheeling, the LTPPBind recommendation was to use PG 70-22 for both layers. Hence, the comparison of the Wheeling section for the LTPPBind and the PG 70-22 shows the predicted effect of using different mixes for the wearing and binder coarse. MEPDG predicts a minor difference in performance, but the magnitude of the differences in not meaningful. 


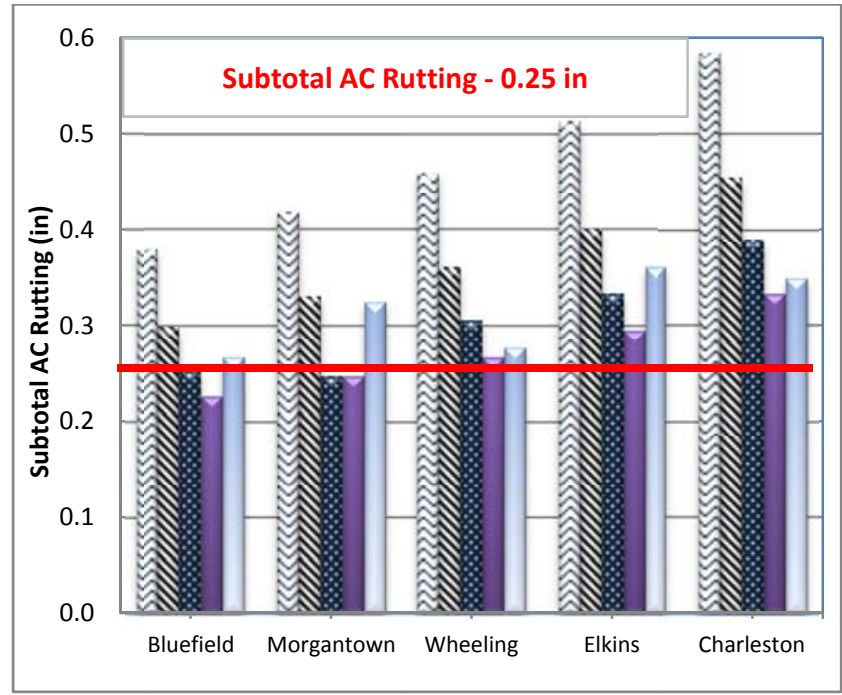

Figure 51: AC Rutting as a function of $\mathrm{PG}$ Binder type 240 months Structure \#1

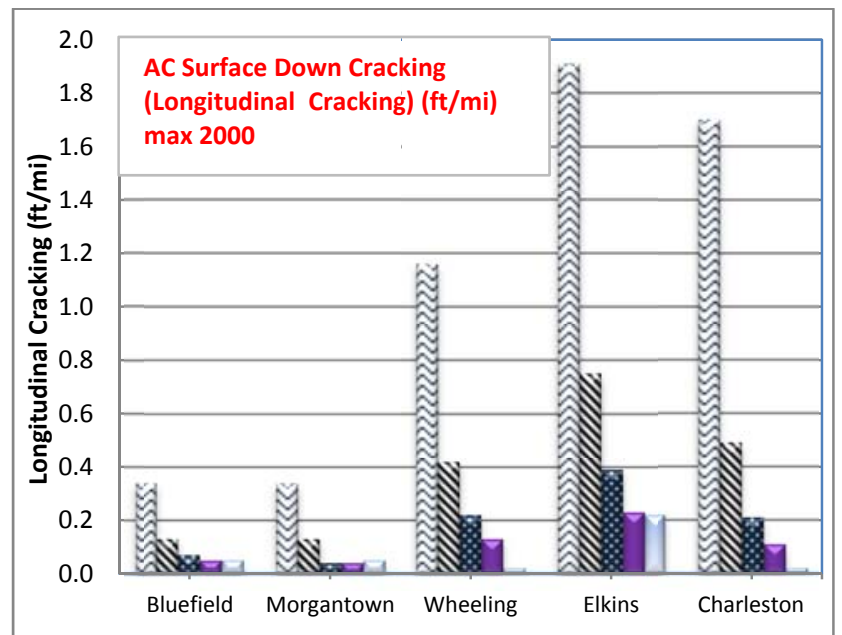

Figure 52: Longitudinal cracking as a function of PG Binder type 240 months Structure \#1

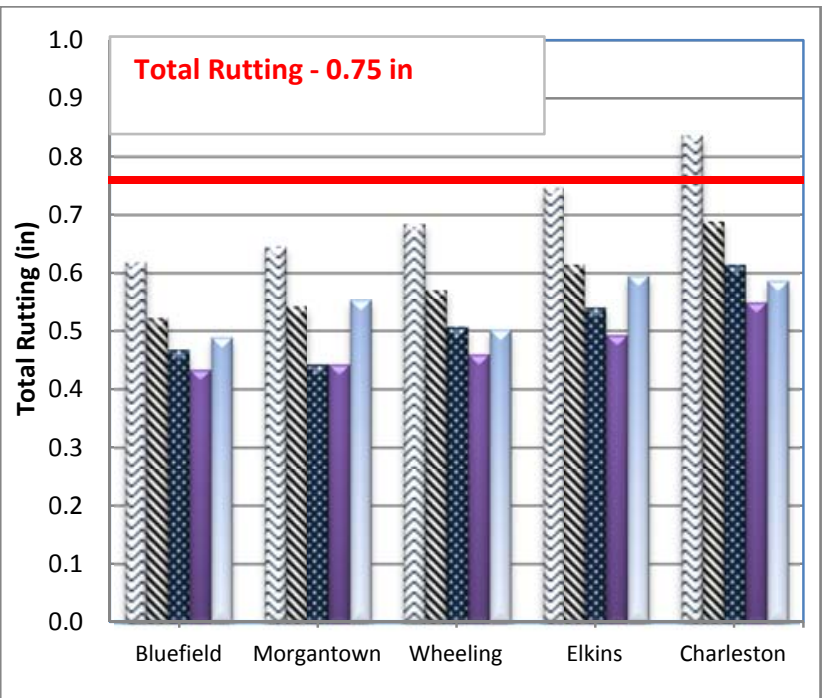

Figure 53: Total Rutting as a function of $\mathrm{PG}$ Binder type 240 months Structure \#1

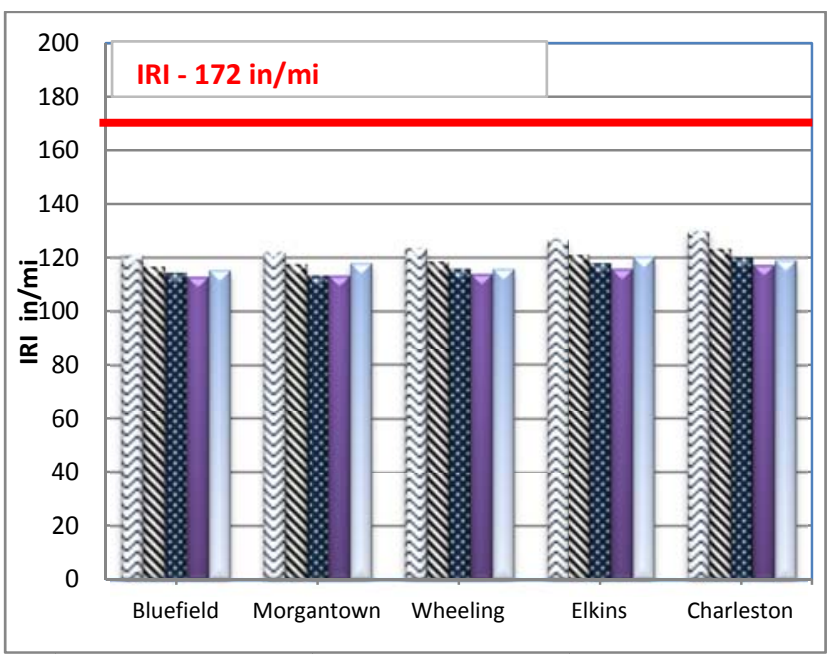

Figure 54: IRI as a function of PG Binder type 240 months Structure \#1

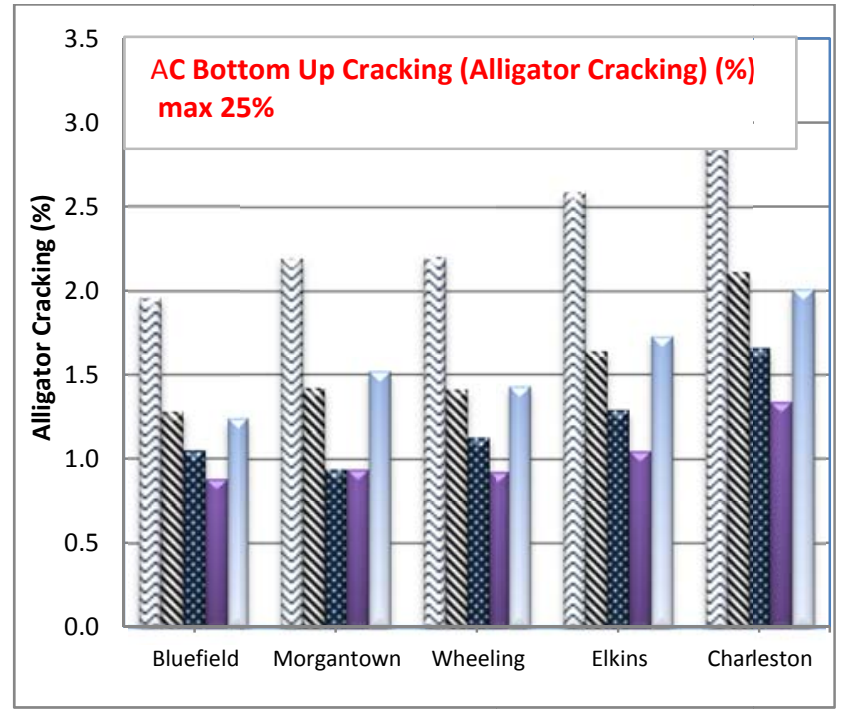

Figure 55: Alligator cracking as a function of $\mathrm{PG}$ Binder type 240 months Structure \#1

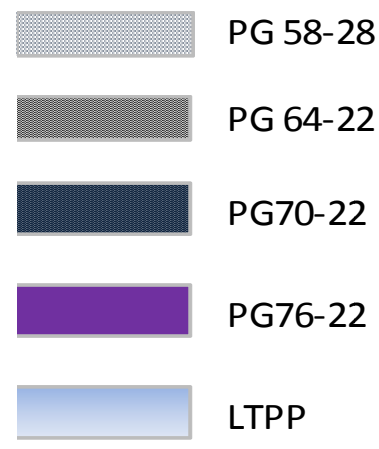




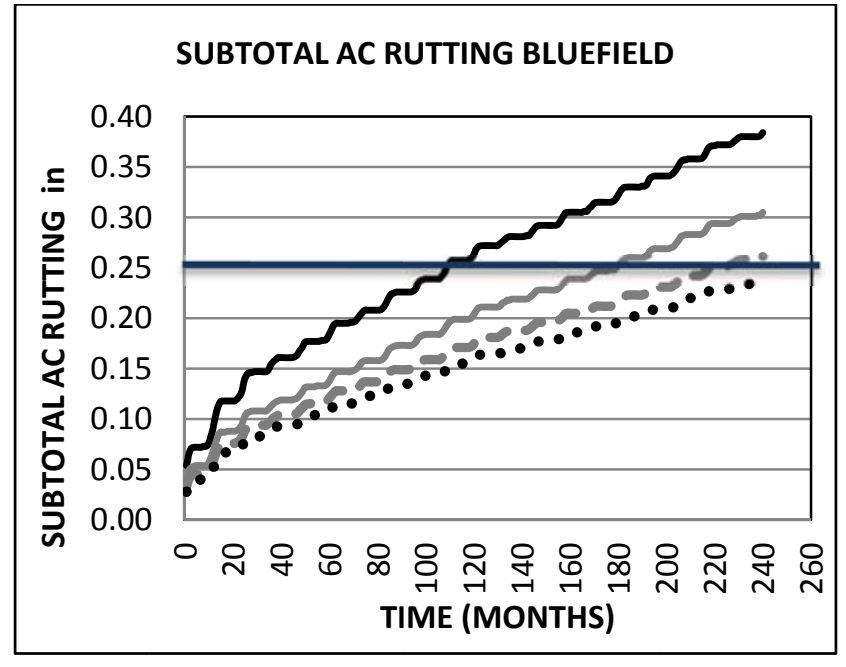

Figure 56: AC Rutting as a function of PG Binder type Structure \#2

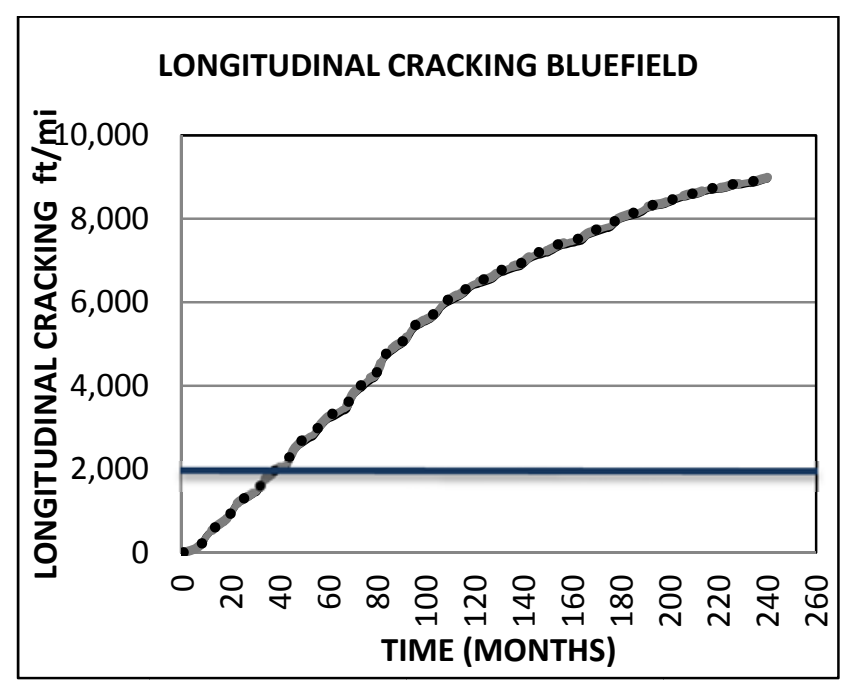

Figure 57: Longitudinal cracking as a function of PG Binder type Structure \#2

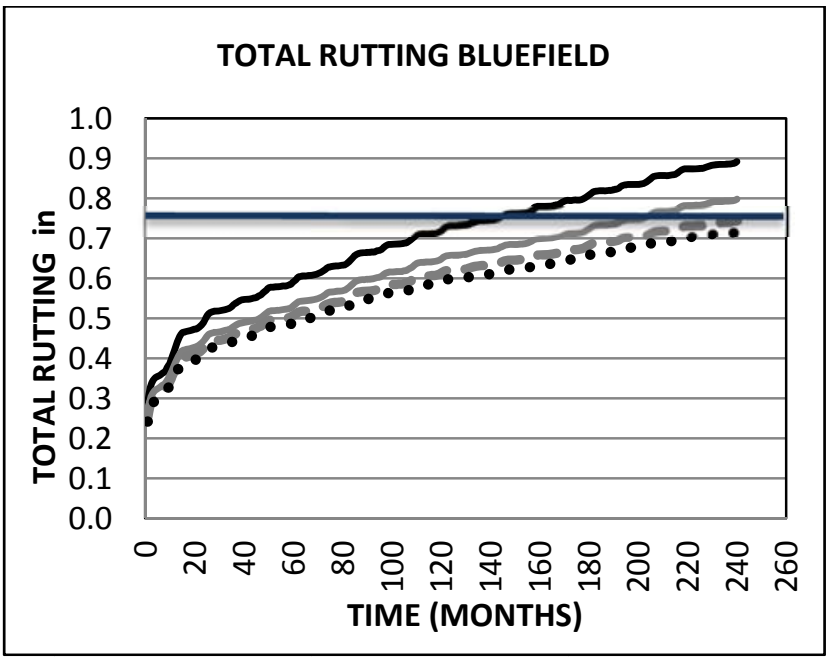

Figure 58: Total Rutting as a function of PG Binder type Structure \#2

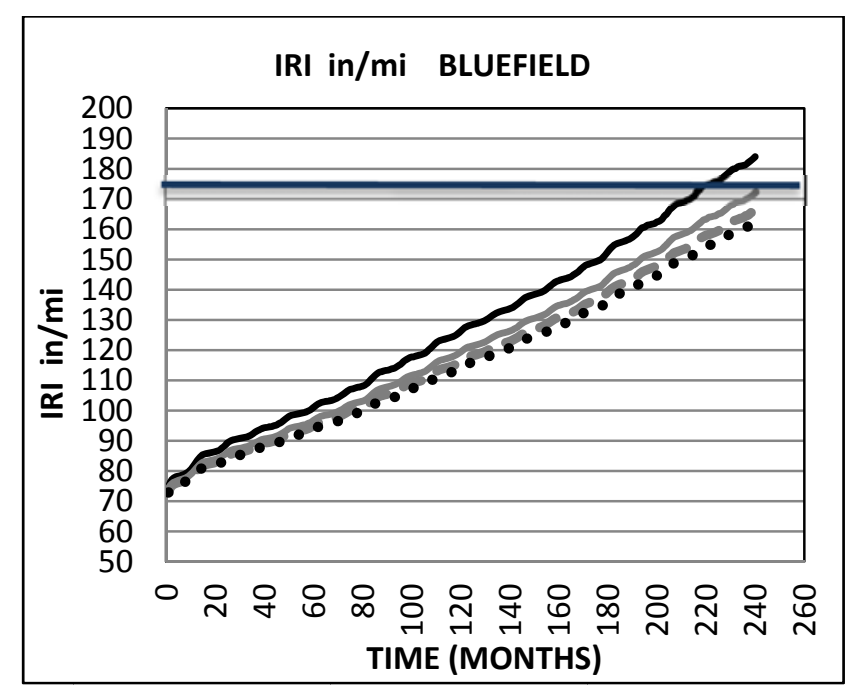

Figure 59: IRI as a function of $\mathrm{PG}$ Binder type Structure \#2

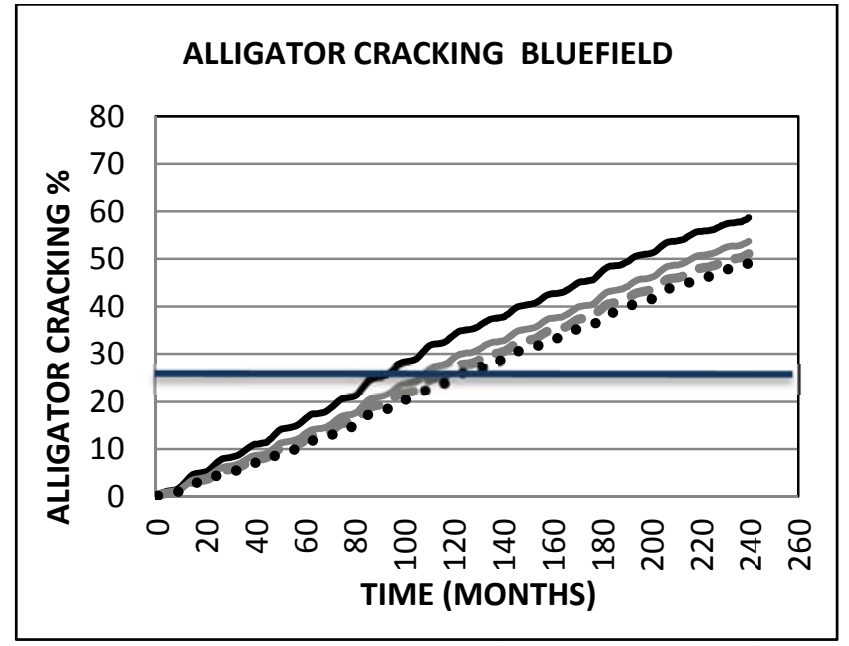

Figure 60: Alligator cracking as a function of $\mathrm{PG}$ Binder type Structure \#2

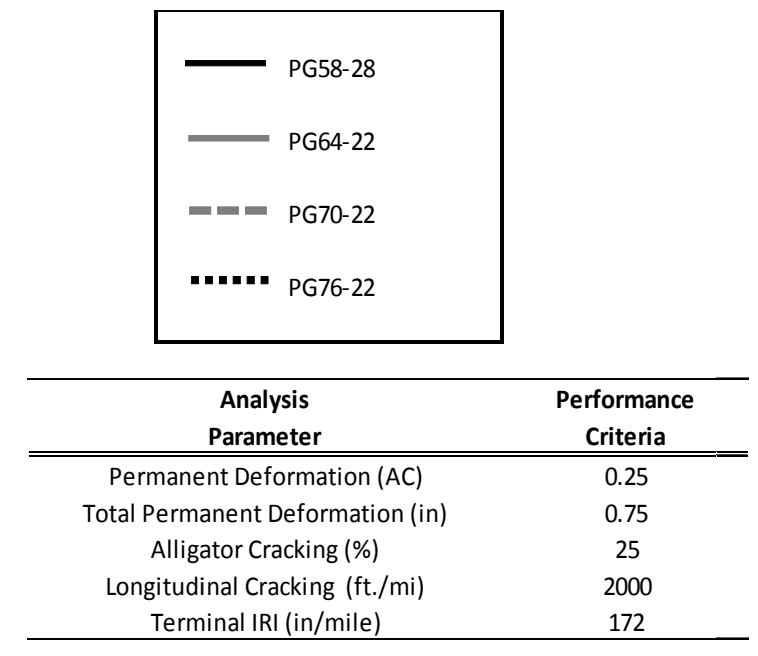




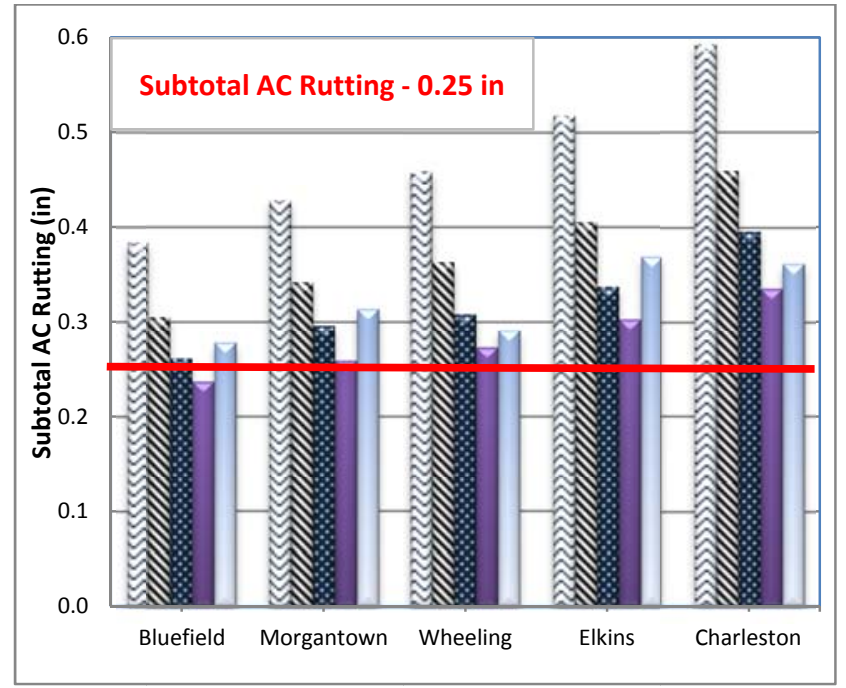

Figure 61: AC Rutting as a function of PG Binder type 240 months Structure \#2

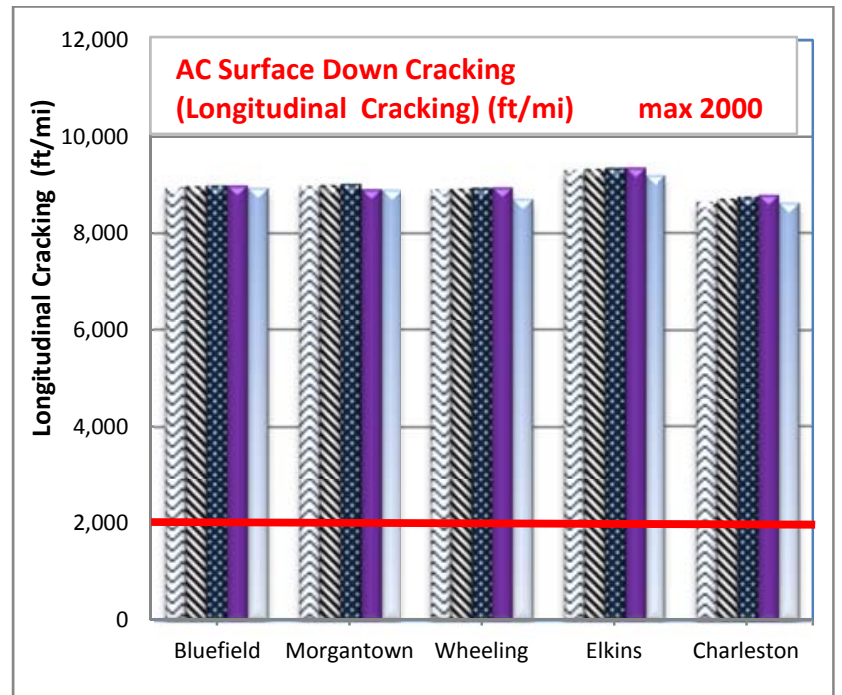

Figure 62: Longitudinal cracking as a function of PG Binder type 240 months Structure \#2

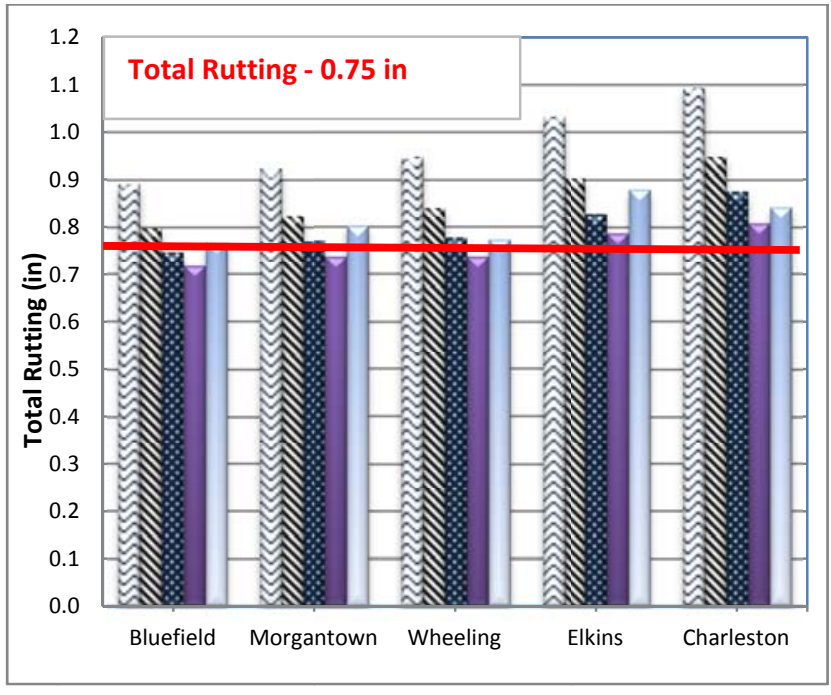

Figure 63: Total Rutting as a function of PG Binder type 240 months Structure \#2

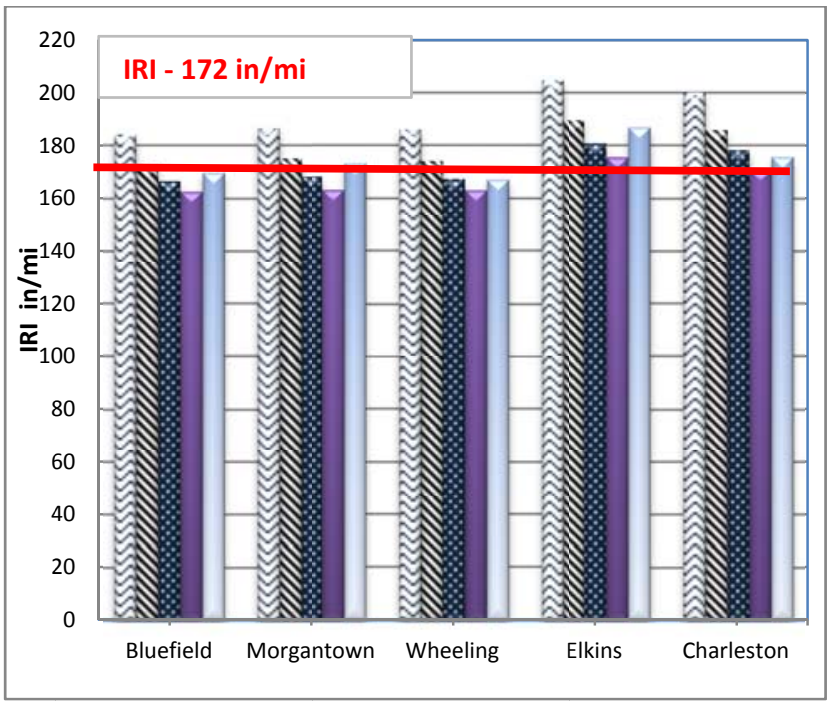

Figure 64: IRI as a function of PG Binder type 240 months Structure \#2

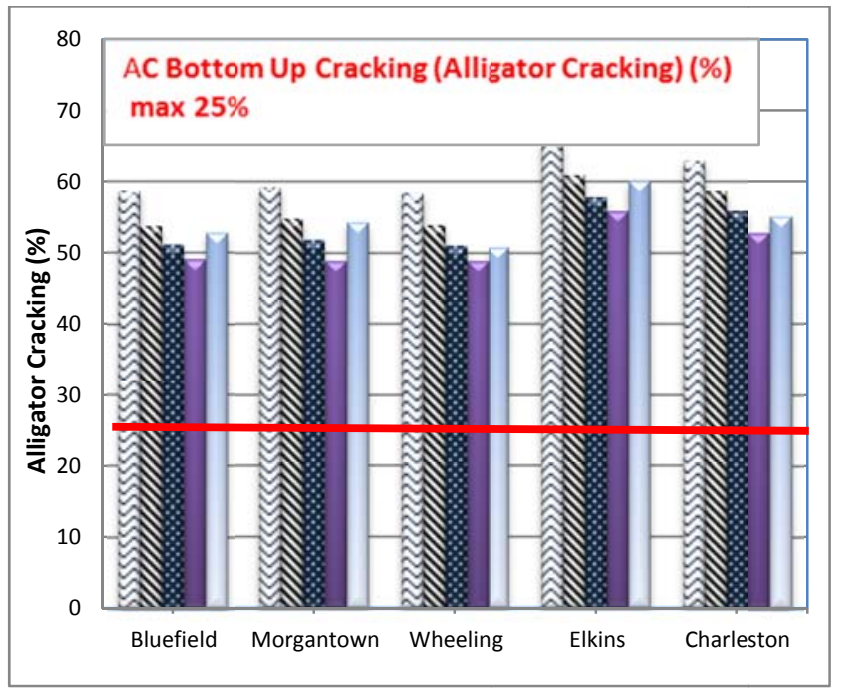

Figure 65: Alligator cracking as a function of $\mathrm{PG}$ Binder type 240 months Structure \#2

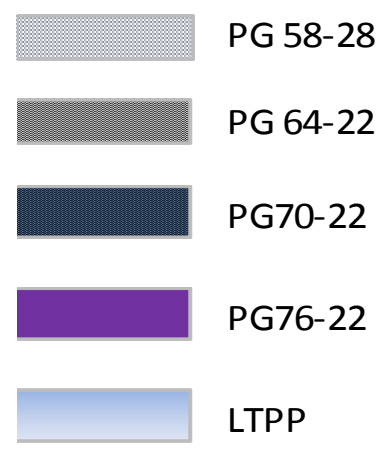




\section{Structure \#2 Modified Design Concept}

The predicted performance of the original Structure \#2 is marginal, especially for alligator cracking. This problem was investigated by altering the surface thickness for the Bluefield analysis location. The asphalt concrete layers assumed for this analysis were 1.5, 4.0, 6.0, 8.0, 10.0, and 12.0 inches. The top 1.5 inches was assumed to be a PG 70-22, $9.5 \mathrm{~mm}$ mix; the balance of the asphalt concrete was assumed to be a PG 64-22, $19 \mathrm{~mm}$ mix. The base, subbase, and subgrade were assumed to be the same as in the original structure. Figures 66 to 70 show the development of distress for the 240 month analysis period. For all but the predicted longitudinal cracking distress, the performance of the pavement increases with increasing the asphalt concrete thickness. For longitudinal cracking the 1.5 inch surface actually performs better than the 4 inch surface. This phenomenon has been observed by others. The hypothesis to explain this behavior is that thin surfaces behave as flexible membranes and stresses are transmitted to the support layers. As the thickness of the asphalt concrete layer increases, the amount of the load being carried in the asphalt concrete increases, but the thickness is insufficient to carry the increased loads, so more distress is predicted. As the thickness of the surface increases further the asphalt concrete layers become more of a rigid structure capable of distributing the distresses within the asphalt concrete layer, so the performance of the pavement with respect to the predicted longitudinal distress. Figures 71 to 75 show the predicted performance for the different distresses for a 15 year analysis period. It appears a 6 inch asphalt concrete layer, 1.5 in of $9.5 \mathrm{~mm}$ and 4.5 of $19 \mathrm{~mm}$, would be adequate, although there is some risk that the longitudinal cracking may be excessive. 


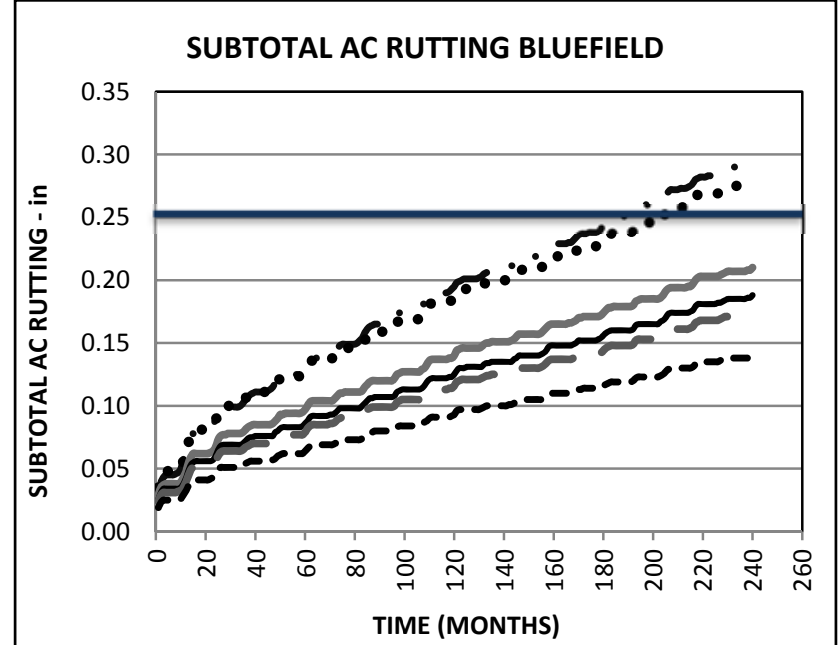

Figure 66: $\mathrm{AC}$ Rutting as a function of $\mathrm{AC}$ thickness Structure \#2

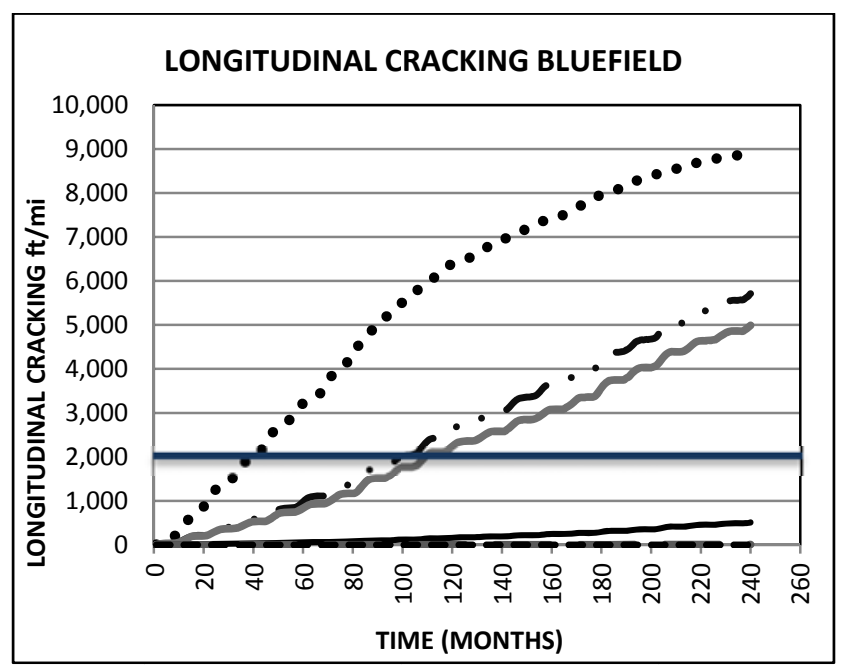

Figure 67: Longitudinal cracking as a function of AC thickness Structure \#2

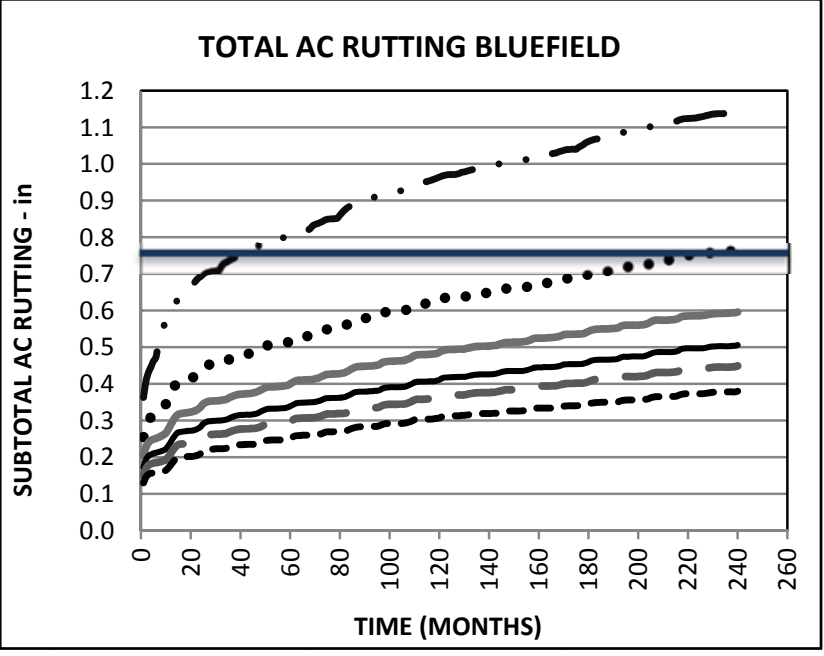

Figure 68: Total Rutting as a function of $\mathrm{AC}$ thickness Structure \#2

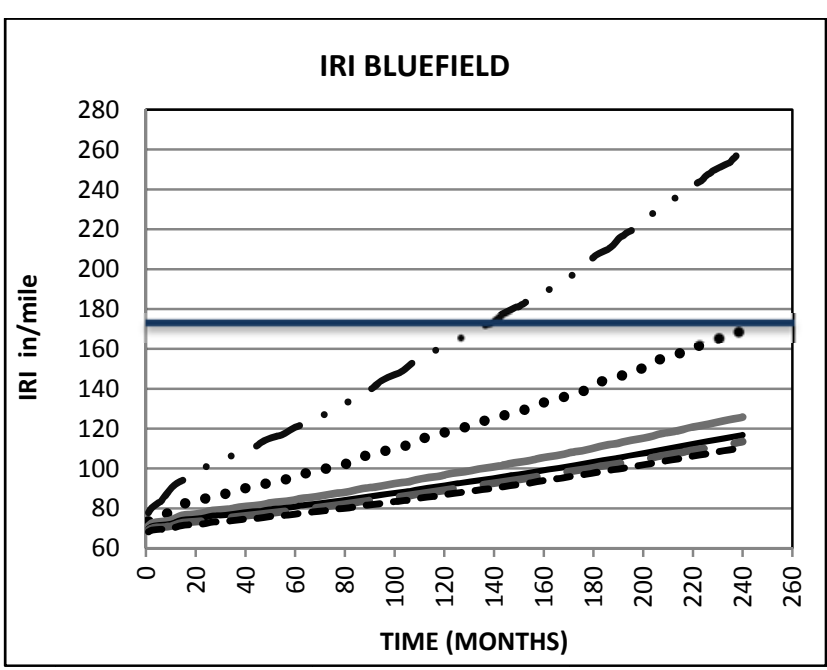

Figure 69: IRI as a function of $A C$ thickness Structure \#2

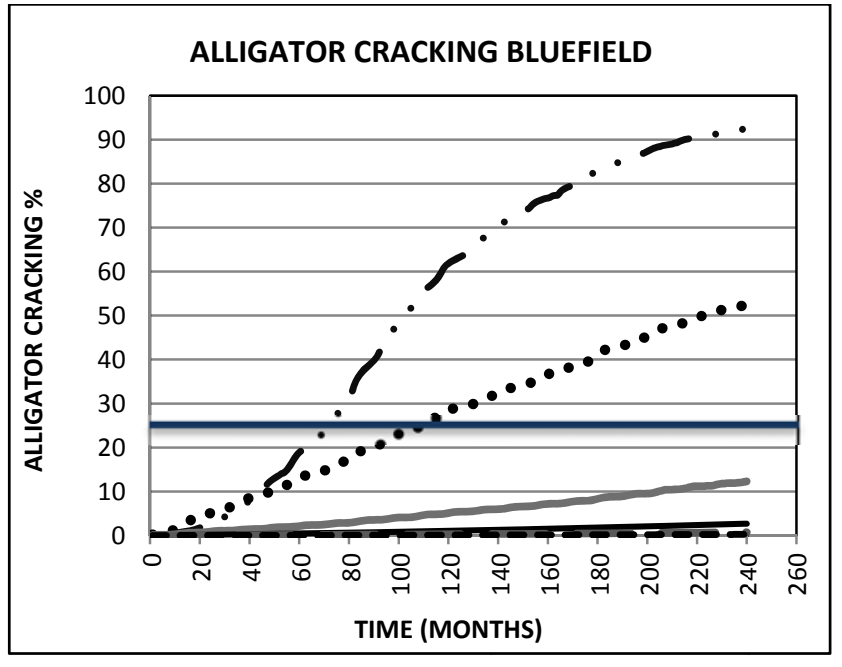

Figure 70: Alligator cracking as a function of $\mathrm{AC}$ thickness Structure \#2

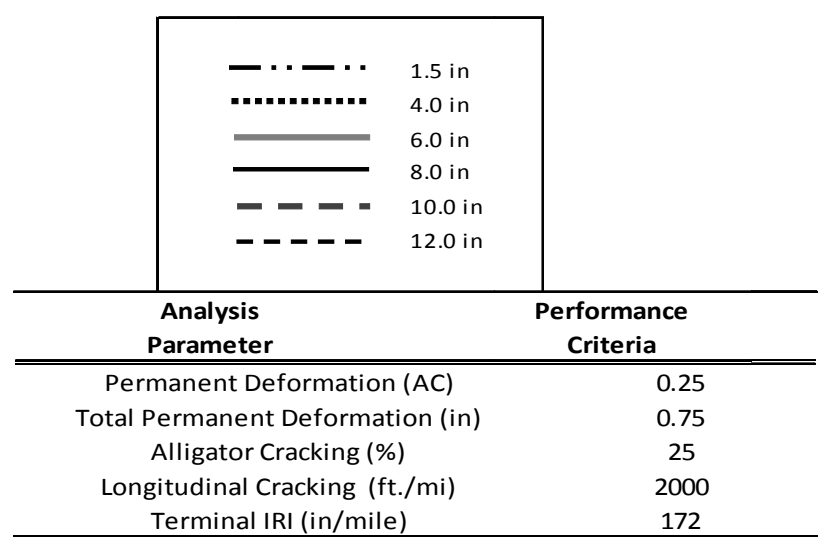




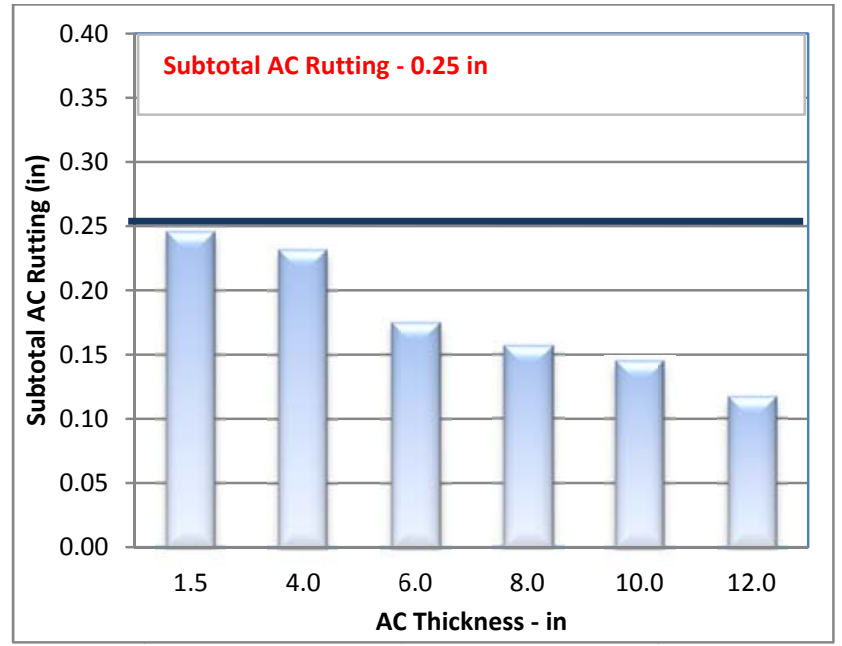

Figure 71: AC Rutting as a function of $\mathrm{AC}$ thickness 180 months Structure \#2

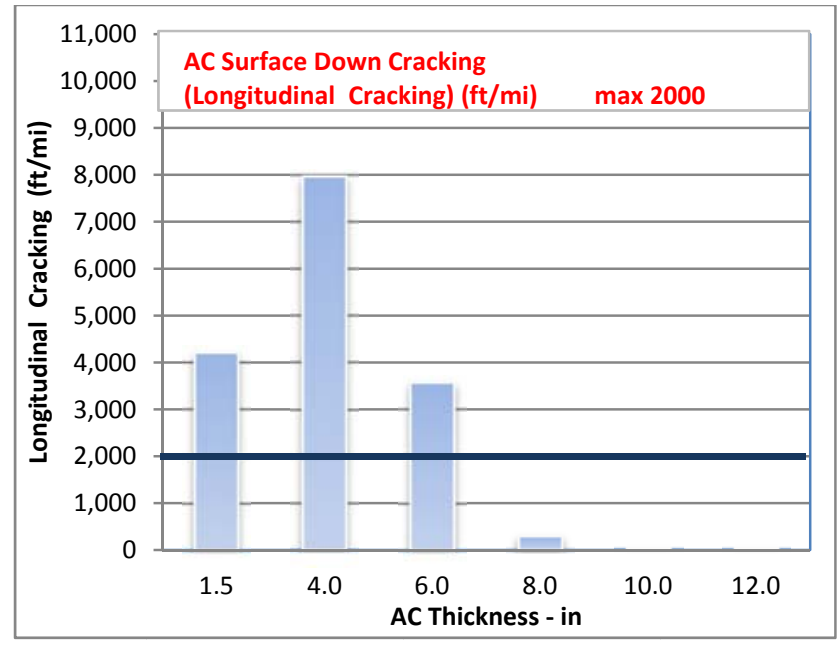

Figure 72: Longitudinal cracking as a function of AC thickness 180 months Structure \#2

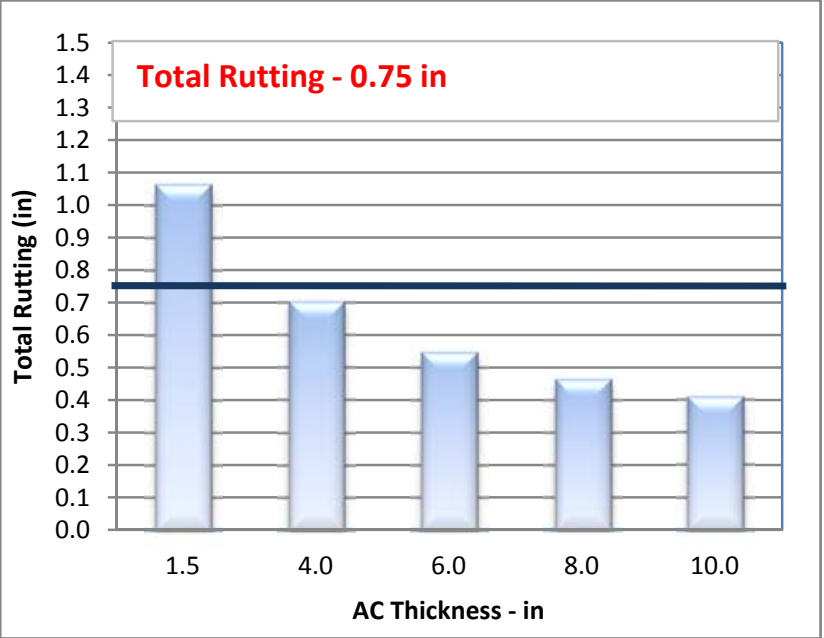

Figure 73: Total Rutting as a function of AC thickness 180 months Structure \#2

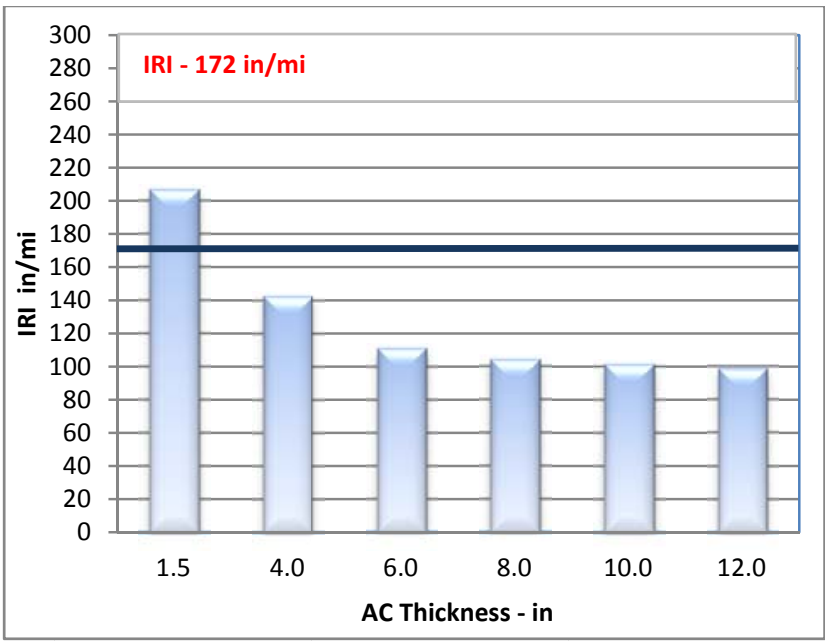

Figure 74: IRI as a function of AC thickness 180 months Structure \#2

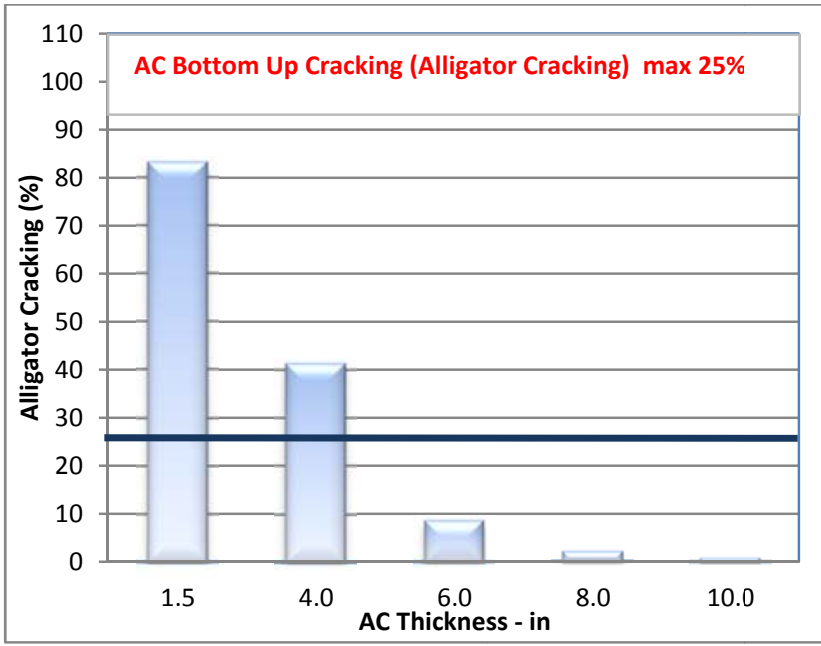

Figure 75: Alligator cracking as a function of $\mathrm{AC}$ thickness 180 months Structure \#2 


\subsection{Analysis of Viscosity}

Due to the relatively similar predicted performance of the different binders it was decided to investigate some of the internal calculations of MEPDG to track the performance analysis. The default values for a Level 3 analysis were used. The predicted performance is based on the strains predicted in the various layers. Only Structure \#1 was used in the analysis as it is a full depth asphalt concrete pavement. For other factors being equal, these strains are a function of the modulus of the asphalt layers. If the gradation and volumetric parameters are kept constant, then the modulus is a function of the binder viscosity. The following investigates how the viscosity varies with depth and age. The analysis was performed for the five analysis locations to include the "weathering" effect.

The analysis of viscosity uses Equation 2.46 to estimate the viscosity as a function of the temperature in degrees Rankine. The constants in the equation vary depending on the binder type. MEPDG provides an output of the viscosity that was compiled into Figure 66. This viscosity assumes short term aging to simulate the viscosity of the binder following construction.

Figure 76 is the traditional method for plotting viscosity temperature curves, so it appears the viscosity values are very close. However, the ordinate is a log scale which masks the differences in viscosity. For example at $70^{\circ}$ Fahrenheit the viscosity of the PG 58-28 and 76-22 are $3.02 \times 10^{8}$ and $2.95 \times 10^{9} \mathrm{cP}$, respectively, basically an order of magnitude difference. The model for viscosity includes a maxim limit of $2.69 \times 10^{12} \mathrm{cP}$ which applies to low temperature analysis.

The temperature of the pavement structure varies with depth, so the selection of a viscosity for the determination of the modulus becomes a function of the depth of the analysis point in the pavement structure. MEPDG divides the pavement structure into sub-layers for this analysis. The sub-layers obtained from MEPDG for Structure \#1 are: 0.5, 1.0, 2.0, 3.0, 4.0, 5.0, 15.0 and 18.0 inches. To model seasonal effects, the climate model divides each month into five sub-seasons and a mean temperature is applied to each. To show the range of temperature variation with depth the coldest period for January and the hottest period for July were plotted in Figure 77 for the Bluefield location, as a typical example.

The final factor in the determination of the viscosity is the aging model to capture the hardening of the binder with time. Figure 78 shows aging effect on viscosity for 0.5 inches and Bluefield. Appendix C presents the graphs for the other depths and analysis locations, which show similar trends. Note the temperatures on this graph are used in determining the viscosity at one point in time; the aging models use the temperature variations throughout the year to compute the aging changes in viscosity. It appears that the aging model affects the aging of the binder near the surface. However, MEPDG does not allow the viscosity to exceed $2.69 \times 10^{12}$ $\mathrm{cP}$; this limit controls over the viscosity determined for the aged binder with a net result being that the aging model contributes little to the predicted pavement performance. 


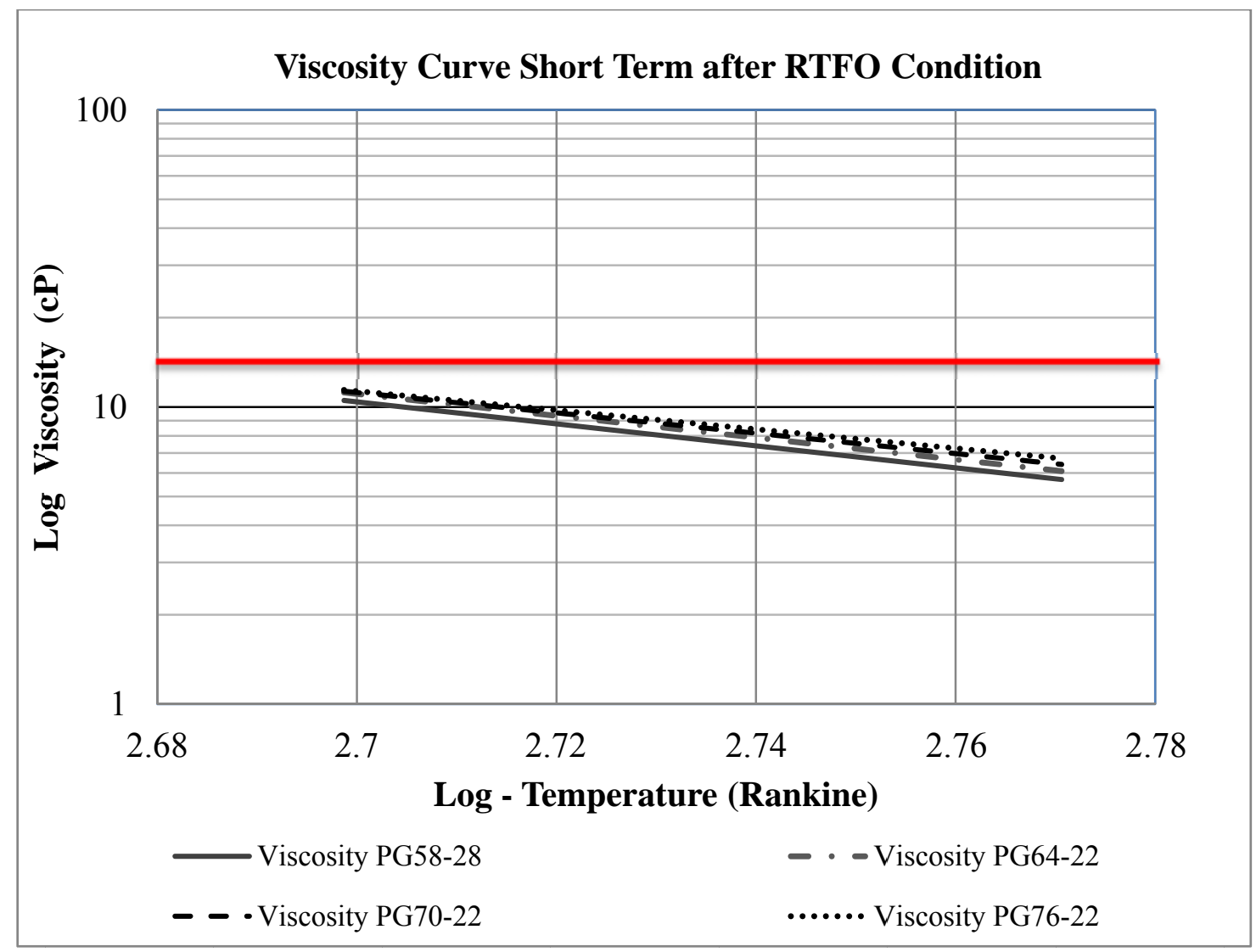

Figure 76: Viscosity for short term after RTFO Condition

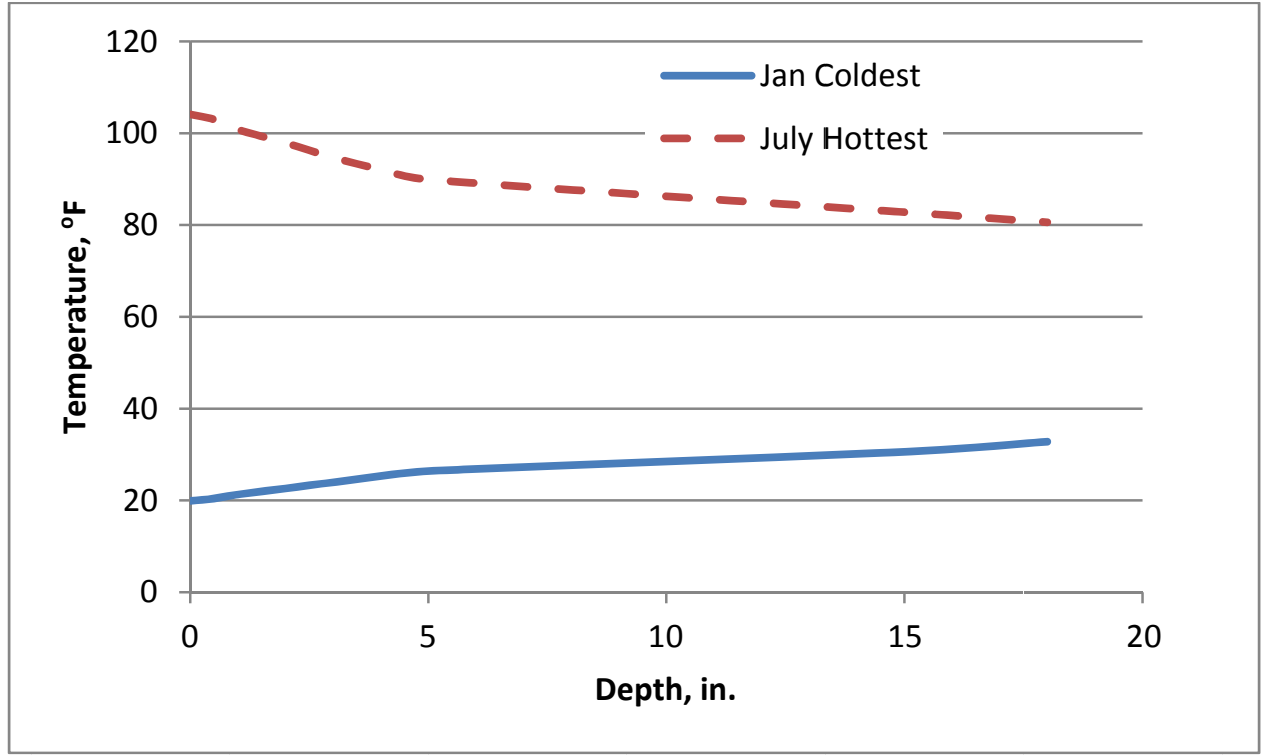

Figure 77: Variation in temperature with depth for Bluefield. 


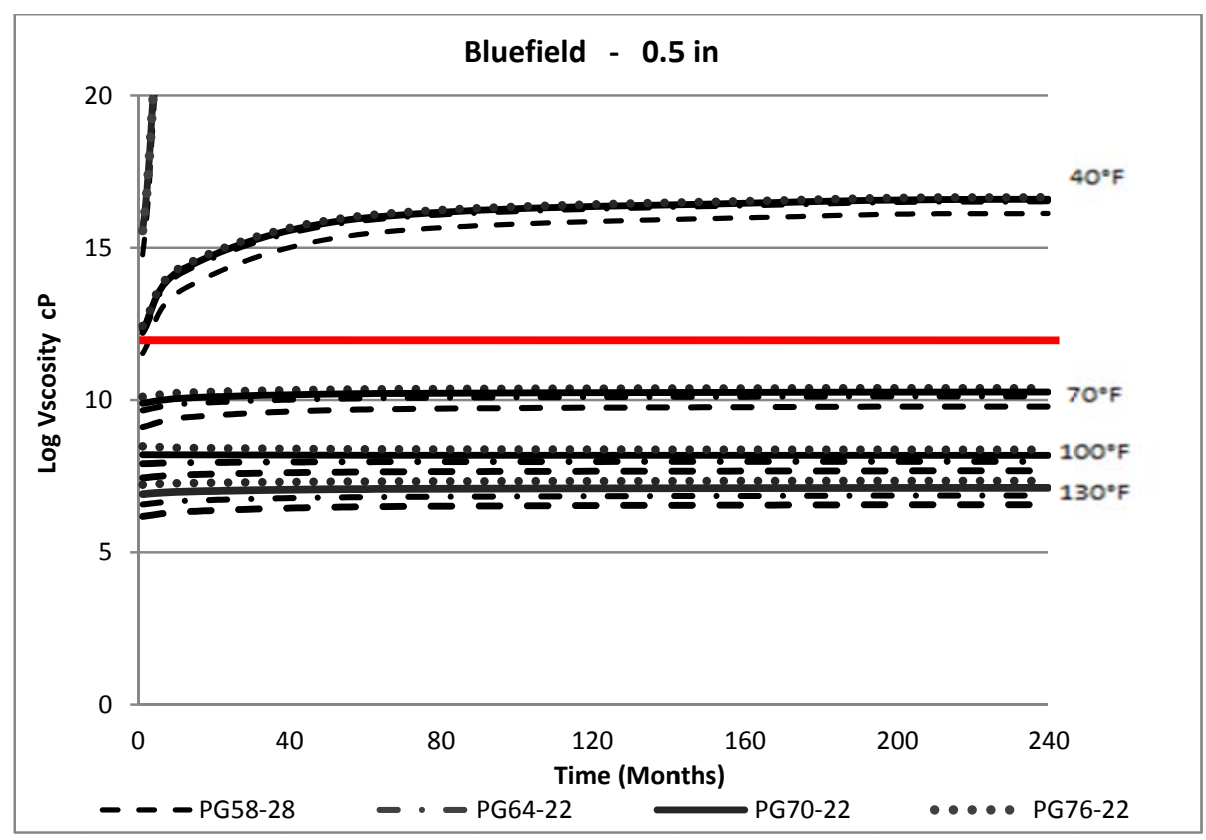

Figure 78: Aging effect on viscosity

\subsection{Master curve for Asphalt Concrete Mix}

The viscosity of the binder, along with mix design parameters, is used in Equation 2.60 to establish the dynamic modulus master curve for the hot mix. Figure 79 shows the dynamic modulus for a typical $9.5 \mathrm{~mm}$ Superpave mix. As the binder high temperature grade increases, the master curve indicates the stiffness of the mix increases for all loading times as would be expected. Figure 79 is the master curve for the dynamic modulus as a function of the reduced time. However, when analyzing a pavement with MEPDG the loading time is essentially assumed to be a constant and a function of the estimated traffic speed and the temperature of the mix is the parameter that produces variations in the modulus of the asphalt concrete. Thus, the shift factor, Equation 2.56, is used to determine the reduced time of loading associated with different temperatures. The shift factor depends on the binder type and temperature. However, as shown of Figure 80 the shift factor is not sensitive to the binder grades selected for this study. 


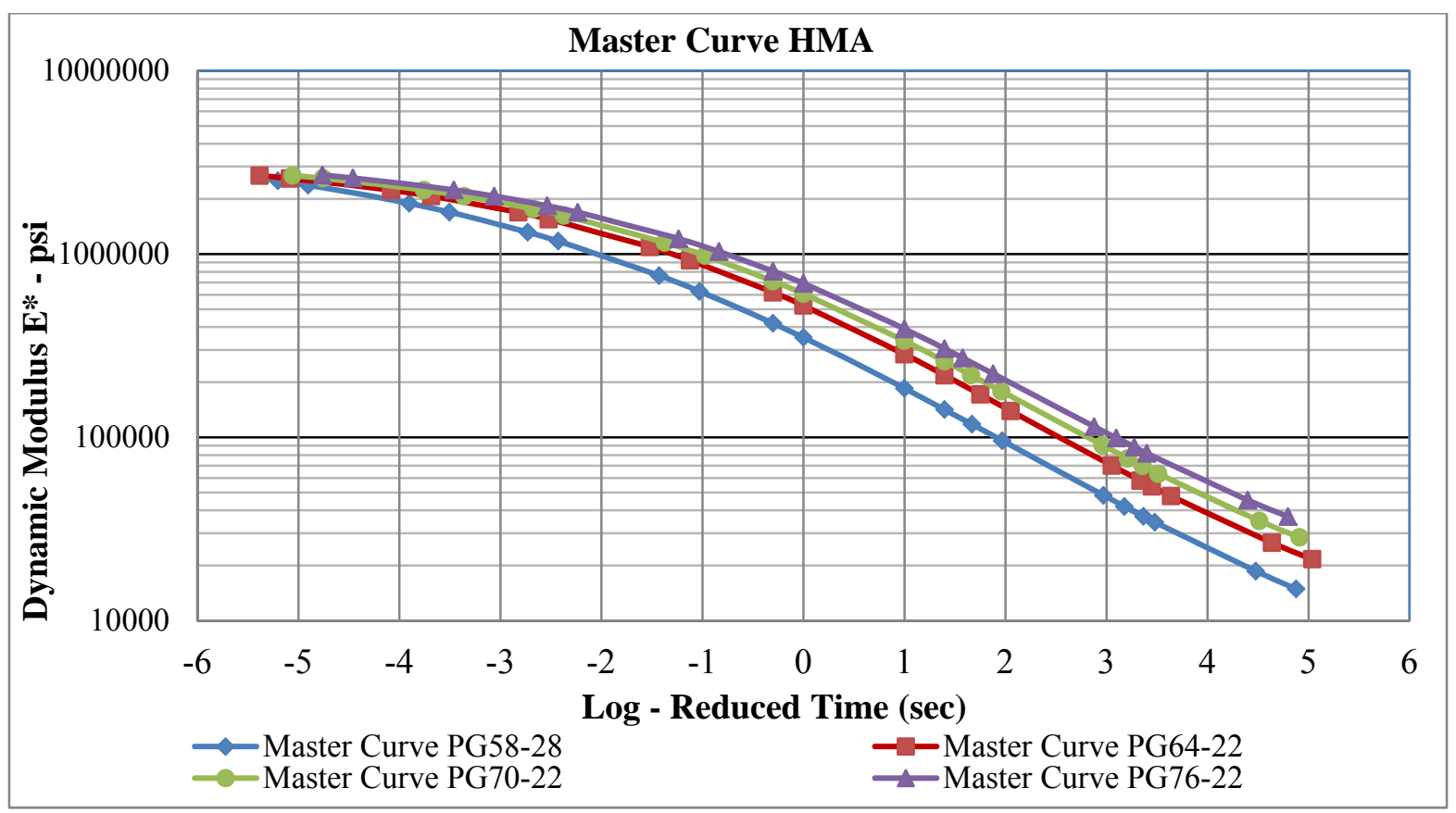

Figure 79: Master Curves for PG58-28, PG64-22, PG70-22 and PG76-22 for $9.5 \mathrm{~mm}$ surface mix

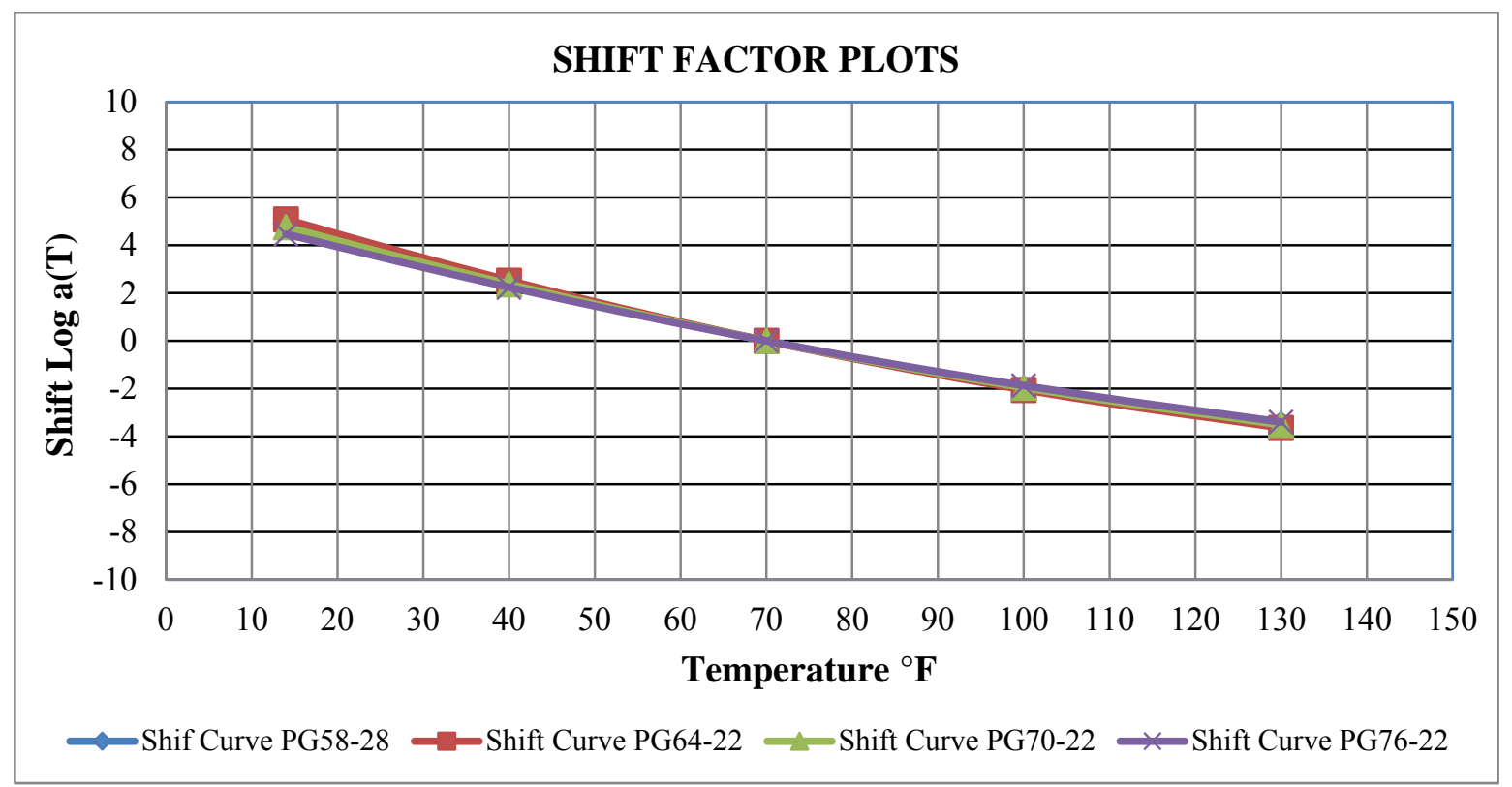

Figure 80: Shift Factors for PG58-28, PG64-22, PG70-22 and PG76-22

Figure 81 shows the variance in the dynamic modulus for a two year period for the Bluefield analysis section. During the winter months the dynamic modulus of all grades is the same due to the upper viscosity limit used in MEPDG. There is some differential in the modulus of the different grades during the higher temperature seasons. From Figure 81 it appears that the modulus associated for the different binder grades is very similar during approximately half of 
the year which could contribute to the observation that the effect of binder grade on performance was less than anticipated.

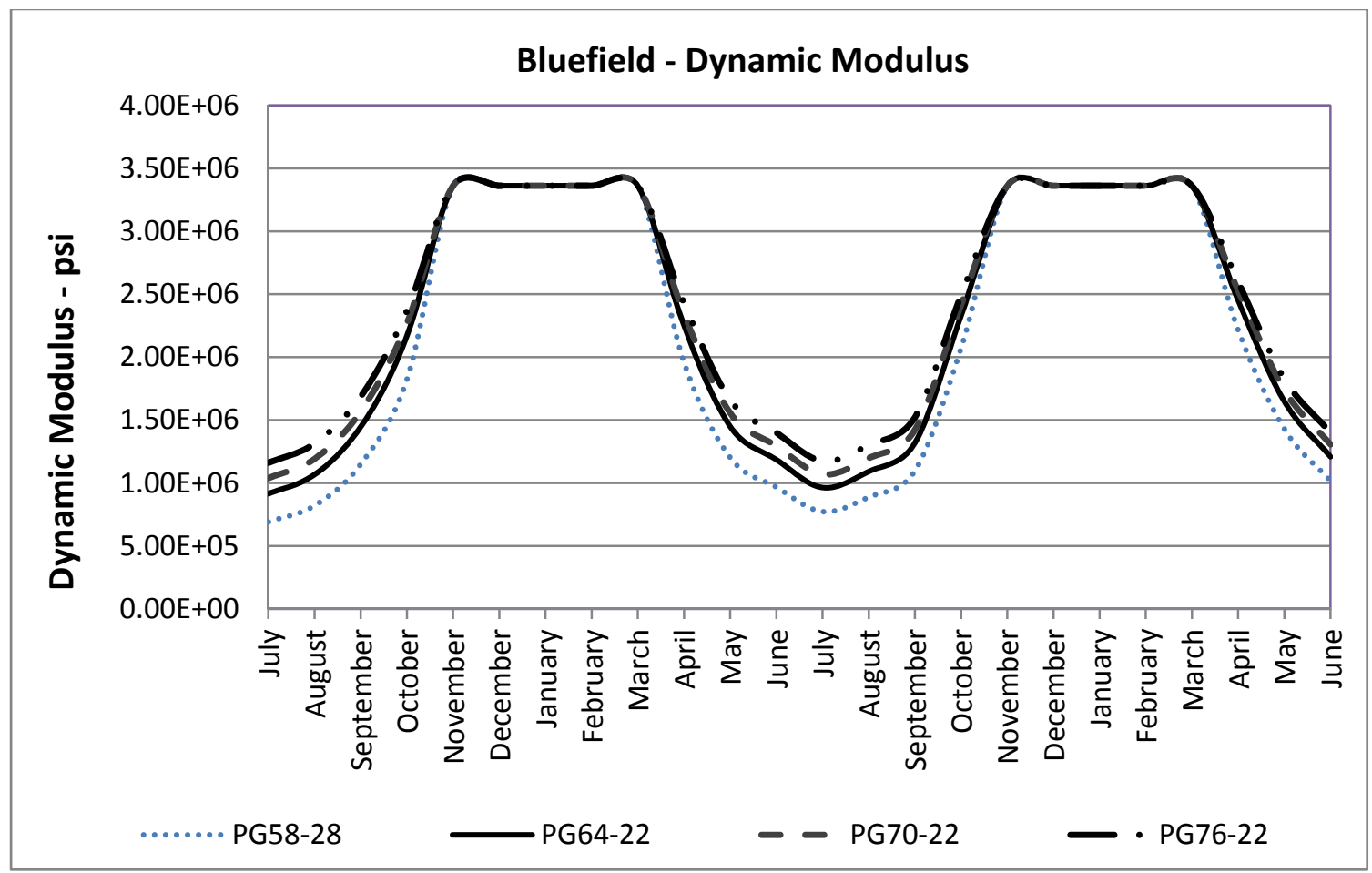

Figure 81: Dynamic Modulus - Bluefield

In MEPDG the dynamic modulus of the asphalt concrete is used in the elastic layer theory computation of the stresses and strains in the pavement which are intern used for the distress predictions. However, since there is limited differential between the modulus values of the different binders it would be anticipated that there should be limited predicted differential performance of the binders in terms of the different binder types, which is the case as demonstrated by Figures 31 to 35 for Bluefield and the associated figures for the other analysis locations as presented in Appendix C. 


\section{Chapter 5 CONCLUSIONS AND RECOMMENDATIONS}

LTPPBind V3.1 is updated software for the selection of binder grades. The recommendations produced by V3.1 are frequently one high temperature grade more than was recommended by the previous version of LTPPBind. The method for grade bumping the high temperature for slow speeds and the quantity of the traffic loads has been revised. The "bump" is specified as a number of degrees that are added to the high temperature base grade. The procedure for selecting the low temperature grade did not change between the two most recent versions of LTPPBind.

LTPPBind V3.1 was used to select binders for two pavement structures for five locations throughout the state. The binders recommended, 98 percent reliability, for the surface layer of Structure \#1 were PG 76-22 for Charleston and Wheeling, PG 70-22 for Bluefield, and PG 70-28 for Morgantown and Elkins. The recommendations for Structure \#2 were the same except for Wheeling where a PG 70-22 is adequate for the lower level of traffic. While the documentation of LTPPBind V3.1 indicates there is no change in the method for selecting the low temperature grade, a PG 70-28 binder is recommended for both Morgantown and Elkins. Due to the range between the high and low temperature, this should be a modified binder of a range that is not commonly specified. Therefore, the cost effectiveness of this binder should be considered prior to specifying it.

Unfortunately, LTPPBind does not offer a methodology for evaluating the cost effectiveness of binder choices. However, MEPDG does have the potential capacity to predict the performance differential that may be attributed to the binder type. MEPDG was used to evaluate two pavement structures for five locations in the state.

The results obtained with MEPDG were not entirely satisfying. The low temperature models failed to predict thermal cracking even when extreme cases were used to test the limits of the model. There were also limited differential performance predictions due to binder type for the other distress modes. An investigation of the models used in MEPDG demonstrated the extent of hardening predicted by the aging model is negligible as shown on Figure 76.

Temperature variations throughout the year do have a major effect on the modulus of the asphalt concrete as expected. However, differential performance due to binder type was much less than anticipated. There is a thermal effect on the modulus for the different binders during the summer months, so there is some differential prediction in the distresses. However, for almost half of the year the maximum limit on viscosity controls the predicted dynamic modulus and hence there is no differential in the predicted pavement performance.

While LTPPBind V3.1 has 77 weather stations for West Virginia, MEPDG is limited to 10 weather stations. Unfortunately there are no MEPDG weather stations in the easternmountainous region of the state. If the WVDOH wished to design a pavement in Pocahontas County the Elkins weather station must be used. 
The analysis performed during this research did not identify a need to change the WVDOH binder selection process.

The development of the mechanistic pavement design concept is an ongoing process. There are several states working on the implementation of the MEPDG concept and other researchers working on refining many aspects of the design process. AASHTO has issued the DARWin-ME software as a commercial version of the design software. Based on the quantity of research being performed at the state and national level to refine, enhance and improve the MEPDG it is clear that the pavement engineering community has reservations about the current incarnation of the design package. Although the analysis in this study was performed with MEPDG V1.1 (release 8/31/2009) there is no indication in the literature that the performance predication ability of DARWin-ME is different from MEPDG V1.1 in a manner that would alter the conclusions. 


\section{REFERENCES}

AASHTO (2008). Mechanistic-Empirical Pavement Design Guide: A Manual of Practice. Washington, 2008.

Advanced Asphalt Technologies (2011). A manual for Design of Hot Mix Asphalt with Commentary. NCHRP Report 673. Transportation Research Board of the National Academies. Washington, 2011.

Bahia, H.; Nam, K.; Delgadillo, R. (2004). Development of Guidelines for PG Binder Selection for Wisconsin. Wisconsin Department of Transportation, Madison, WI, December 2004.

Bosscher, P. J., Bahia H. U., Thomas S., and Russell J. S. (1998). Relationship Between Pavement Temperature and Weather Data: Wisconsin Field Study to Verify SuperPave Algorithm. Transportation Research Record No. 1609, TRB, Washington, DC, October 1998.

Brown E. R., Kandhal P.S., Roberts F.L., Kim Y.R., Lee D-Y., Kennedy T.W. (2009). Hot Mix Asphalt Materials, Mixture Design and Construction. National Asphalt Pavement Association, Third Edition December, 2009

CAPA, (2006). Guideline for the Design and Use of Asphalt Pavements for Colorado Roadways. Colorado Asphalt Pavement Association. CO, $2^{\text {nd }}$ Edition, January 2006.

Dave , E.V., Leon, S. and Park K., (2011). Thermal Cracking Prediction Model and Software for Asphalt Pavements.T\&DI Congress ASCE, 2011.

Garcia, G. and Thompson, M., (2007). HMA Dynamic Modulus Predictive Models A review FHWA-ICT-07-005. Illinois Center for Transportation, Urbana, IL, 2007.

GDOT (2006). Asphalt Pavement Selection Guidelines Georgia Georgia Department of Transportation. Forest Park, GA, 2006

Huang, Y. H., (2004). Pavement Analysis and Design. Pearson Education. New Jersey, 2004.

Lukanen, E. O., Han, C., Skok Jr, E. L. (1998). Probabilistic Method of Aspahlt Binder Selection Based on Pavement Temperature. TRB National Research Council 1609, Vol. 77, Washington DC October 1998.

MAPA (2008). Comprehensive Guide to PG Asphalt Binder Selection in Minnesota. Minnesota. Asphalt Pavement Association. New Brighton, MN, December 2008.

McMillan Ch., Scarlett J.R.(1999). Development of Performance Graded Binder Selection Method for Canadian Airports Pavements. Prepared for the 1999 Federal Aviation Administration Technology Transfer Conference, Quebec, Canada, April 1999. 
Mohseni A. (1998). LTPP Seasonal Asphalt Concrete (AC) Pavement Association Temperature Models. Office of Engineering R\&D. Federal Highway Administration, Rockville, MD, September 1998.

Mohseni, A. (1997). Seasonal AC pavement temperature (SAPT) Database. Presented at meeting of the Transportation Research Board Data Analysis Working Group Meeting. Washington, DC 1997

Mohseni, A., Carpenter S., and D'Angelo J., (2005). Development of SUPERPAVE HighTemperature Performance Grade (PG) Based on Rutting Damage. Association of Asphalt Paving Technologists Long Beach, CA, Vol.74, 2005.

Monhseni, A (2005). LTPPBIND V3.1 A SUPERPAVE Binder Selection Program. Washington Pavement Systems LLC, Maiden, MD, September 2005.

NCHRP Project 1-37A, (2004). Guide for Mechanistic-Empirical Design of New and Nogaj, M., (2011). Sensitivity Analyses of Flexible Pavement Performance in VT, NY and MA using the Mechanistic-Empirical Ravement Design Guide. University of New Hampshire, Durham, NH, December 2011.

Orobio, A. (2010). Sensitivity analysis of flexible pavement performance parameters in the mechanistic-empirical design guide. West Virginia University, WV, November 2010.

Prowell, B. D. (1999). Selection and Evaluation of Performance-Graded Asphalt Binder for Virginia.: Virginia Department of Transportation, Charlottesville, Virginia 1999.

Rehabilitated Pavements Structures. TRB, National Research Council Washington, DC:, 2004 $<$ http://www.trb.org/mepdg/>.

Robertson, W. D. (1997). Determining The Winter Design Temperature for Asphalt Pavements. Transportation Association of Canada, Ottawa, Ontario Canada, October 1997.

Shah, A.(2004). The influence of Binder and mixture properties on the performance of AC pavements. ProQuest Dessertations and Thesis, Purdue University. West Lafayette, IN, April 2004.

WSDOT (2011). Pavement Interactive, Washington Department of Transportation, Division of Highways. Cited: February 22, 2012.

$<$ http://training.ce.washington.edu/WSDOT/Modules/05_mix_design/superpave.htm>

Yoder, E. J. and Witczak, M. W., (1975). Principles of Pavement Design. Wiley \& Sons, Inc, New York ,1975.

Zborowski, A., (2007). Development of a Modified Superpave Thermal Cracking Model for Asphalt Concrete Mixtures Based on the Fracture Energy Approach. Arizona State University, Tempe, AZ, December 2007. 
Appendix A

Inputs (Traffic and Material Characterization) 
Traffic

Two-away annual average daily traffic (AADT)

Percent of heavy vehicles (class 4 or higher)

Number of lanes in design direction

Percent of trucks in design direction

Percent of truck in the design line

Operational speed: $60 \mathrm{mph}$

Traffic growth: compound

\section{Traffic adjustment factors}

Monthly adjustment

Vehicle class distribution

Hourly distribution

Axle load distribution

Axle

type

Single axle

Tandem

Tridem

Quad

\section{General traffic inputs}

Mean wheel location (inches from the lane marking)

Traffic wander standard deviation (in)

Design lane width (ft)

Number axles

truck

Axle configuration

Average axle width ( $\mathrm{ft}$ )

Dual tire spacing (in)

Tire pressure (psi)

Axle spacing (in)

Tandem axle

Tridem axle

Quad axle

\section{Structure Structure}

1 2 $40000 \quad 2000$

$\begin{array}{rr} & 5 \\ 50 & 0 \\ 2 & 2 \\ & 5 \\ 50 & 0 \\ & 9 \\ 95 & 5 \\ & 6 \\ 60 & 0 \\ 4 & 4\end{array}$

Default

Default

Default

Default

Default

Default

Default

Default

18

10

12

Default

8.5

12

120

51.6

49.2

49.2 
Structure 1 - Full-depth asphalt pavement

Layer 1 (asphalt concrete layer) $\mathbf{9 . 5} \mathbf{~ m m ~ m i x ~}$

Surface short-wave absorptive

$0.8-0.90$

Asphalt

Asphalt material type

concrete

Layer thickness (in)

2

Asphalt mix

Cumulative \% retained \#3/4 inch sieve

0

Cumulative \% retained \#3/8 inch sieve

7

Cumulative \% retained \#4 inch sieve

43

Passing \#200 sieve

4.5

Asphalt binder

Reference temperature $\left({ }^{\circ} \mathrm{F}\right)$

70

Volumetric properties as built

Effective binder content

$4.5-6.5$

$3-10$

Air voids

$145-150$

Poisson's ratio: 0.35

$0.25-0.40$

Thermal properties

Thermal conductivity asphalt (BTU/hr-ft-oF

0.67

Heat capacity asphalt (BTU/lb-oF)

0.23

Layer $\mathbf{2}$ (asphalt concrete layer) $\mathbf{1 9} \mathbf{~ m m ~ m i x ~}$

Surface short-wave absorptive

$0.8-0.90$

Asphalt

Asphalt material type

concrete

3

Asphalt mix

Cumulative \% retained \#3/4 inch sieve

2

29

Cumulative \% retained \#3/8 inch sieve

52

Cumulative \% retained \#4 inch sieve

5.3

Passing \#200 sieve

Asphalt binder

Reference temperature $\left({ }^{\circ} \mathrm{F}\right)$

70

Volumetric properties as built

Effective binder content

$3.5-6$

Air voids

$3-10$

Total unit weight (pcf)

$145-150$

Poisson's ratio: 0.35

$0.25-0.40$

Thermal properties

Thermal conductivity asphalt (BTU/hr-ft-oF

Heat capacity asphalt (BTU/lb-oF)

0.23 
Layer $\mathbf{3}$ (asphalt concrete layer) $\mathbf{3 7} \mathbf{~ m m ~ m i x ~}$

Surface short-wave absorptive

$0.8-0.90$

Asphalt

Asphalt material type

concrete

Layer thickness (in)

10

Asphalt mix

Cumulative \% retained \#3/4 inch sieve 33

Cumulative \% retained \#3/8 inch sieve 55

Cumulative \% retained \#4 inch sieve 64

Passing \#200 sieve 3.6

Asphalt binder

Reference temperature $\left({ }^{\circ} \mathrm{F}\right)$

70

Volumetric properties as built

Effective binder content

$2.5-4$

Air voids

$6-12$

Total unit weight (pcf)

$145-150$

Poisson's ratio: 0.35

$0.25-0.40$

Thermal properties

Thermal conductivity asphalt (BTU/hr-ft-oF

Heat capacity asphalt (BTU/lb-oF)

0.23

Layer 4 (asphalt treated permeable base)

Surface short-wave absorptive

$0.8-0.90$

Asphalt

Asphalt material type

concrete

Layer thickness (in)

3

Asphalt mix

Cumulative \% retained \#3/4 inch sieve

30

Cumulative \% retained \#3/8 inch sieve

80

Cumulative \% retained \#4 inch sieve

85

Passing \#200 sieve

2

Asphalt binder

Reference temperature $\left({ }^{\circ} \mathrm{F}\right)$

70

Volumetric properties as built

Effective binder content

$2-3$

Air voids

$15-20$

Total unit weight (pcf)

$145-150$

Poisson's ratio: 0.35

$0.25-0.40$

Thermal properties

Thermal conductivity asphalt (BTU/hr-ft-oF

Heat capacity asphalt (BTU/lb-oF)

0.23 


$\begin{array}{lc}\text { Layer } \mathbf{5} \text { (Subgrade) } & \\ \text { Unbound material (classification): } & \mathrm{MH} \\ \text { Poisson's ratio } & 0.35 \\ \text { Coefficient of lateral pressure Ko : 0.5 } & 0.5-0.70 \\ \text { Modulus (psi) } & 6000 \\ \text { Gradation } & \\ \text { Plasticity index (PI) } & 5 \\ \text { Liquid limit (LL) } & 45 \\ \text { Compact layer } & \text { yes } \\ \text { Index properties from sieve analysis } & \\ \text { \% passing \# 200 } & 54.3 \\ \text { \% passing \#40 } & 74.2 \\ \text { \% passing \#4 } & 86.9 \\ \text { D10 (mm) } & 0.000338 \\ \text { D20 } & 0.001145 \\ \text { D30 } & 0.003876 \\ \text { D60 } & 0.1234 \\ \text { D90 } & 9.109\end{array}$

Structure 2 - Conventional Flexible Asphalt pavement

Layer 1 (asphalt concrete layer) $9.5 \mathrm{~mm}$ mix

$\begin{array}{ll}\text { Surface short-wave absorptive } & 0.8-0.90\end{array}$

Asphalt

Asphalt material type

concrete

Layer thickness (in)

1.5

Asphalt mix

Cumulative $\%$ retained $\# 3 / 4$ inch sieve 0

Cumulative \% retained \#3/8 inch sieve 7

Cumulative \% retained \#4 inch sieve 43

Passing \#200 sieve $\quad 4.5$

Asphalt binder

Reference temperature $\left({ }^{\circ} \mathrm{F}\right) \quad 70$

Volumetric properties as bilt

Effective binder content $\quad 4.5-6.5$

$\begin{array}{lr}\text { Air voids } & 3-10\end{array}$

$\begin{array}{lr}\text { Total unit weight (pcf) } & 145-150\end{array}$

Poisson's ratio: $0.35 \quad 0.25-0.40$

Thermal properties

Thermal conductivity asphalt (BTU/hr-ft-oF: $0.67 \quad 0.5-0.8$

Heat capacity asphalt (BTU/Ib-oF): $0.23 \quad 0.22-0.5$ 
Layer $\mathbf{2}$ (asphalt concrete layer) $\mathbf{1 9} \mathbf{~ m m ~ m i x ~}$

Surface short-wave absorptive

$0.8-0.90$

Asphalt

Asphalt material type

concrete

Layer thickness (in)

2.5

Asphalt mix

Cumulative $\%$ retained \#3/4 inch sieve

2

29

Cumulative \% retained \#3/8 inch sieve

52

Cumulative \% retained \#4 inch sieve

5.3

Passing \#200 sieve

\section{Asphalt binder}

Reference temperature $\left({ }^{\circ} \mathrm{F}\right)$

70

Volumetric properties as built

Effective binder content

$3.5-6$

Air voids

$3-10$

Total unit weight (pcf)

$145-150$

Poisson's ratio: 0.35

$0.25-0.40$

Thermal properties

Thermal conductivity asphalt (BTU/hr-ft-oF

0.67

Heat capacity asphalt (BTU/lb-oF)

0.23

\section{Layer 3 (Unbound Base)}

Unbound material (classification): Crashed Stone

Crashed Stone

Poisson's ratio: 0.35

$0.15-0.25$

Coefficient of lateral pressure Ko : 0.5

$0.5-0.60$

Modulus (psi)

$25000-35000$

ICM (Climate model input for this layer's material)

Gradation

Plasticity index (PI)

5

Liquid limit (LL)

45

Compact layer

Index properties from sieve analysis

\%passing \# 200

yes

\%passing \#40

8.7

\%passing \#4

20

D10 (mm)

44.7

D20

0.1035

D30

0.425

1.306

D60

10.82

D90

46.19

index

User overridable

properties

Maximum dry unit weight (PCF)

127.2 
Specific gravity

Sat hydraulic conductivity (ft/hr)

Optimum gravimetric water content (\%)

Degree of saturation of optimum \%

Overridable soil water characteristic curve:

Af: 65.23

Bf: 1.034

Cf: 0.4994

Hf: 500
2.7

0.051

7.4

61.2

7.255

1.333

0.8242

117.4

\section{Layer 4 (unbound Sub-Base)}

Unbound material (classification)

Crushed Gavel

Poisson's ratio: 0.35

$0.15-0.25$

Coefficient of lateral pressure Ko : 0.5

$0.5-0.6$

Modulus (psi)

$15000-25000$

ICM (Climate model input for this layer's material)

Gradation

Plasticity index (PI)

5

Liquid limit (LL)

45

Compact layer

yes

Index properties from sieve analysis

\%passing \# 200

8.7

\%passing \#40

20

\%passing \#4

44.7

D10 (mm)

0.1035

D20

0.425

D30

1.306

D60

10.82

D90

46.19

\section{User overridable}

index

Maximum dry unit weight (PCF)

properties

Specific gravity

127.2

2.7

Sat hydraulic conductivity (ft/hr)

0.051

Optimum gravimetric water content (\%)

7.4

Degree of saturation of optimum \%

61.2

Overridable soil water characteristic curve:

Af: 65.23

7.255

Bf: 1.034

1.333

Cf: 0.4994

0.8242 


$\begin{array}{lc}\text { Layer } 5 \text { (Subgrade) } & \\ \text { Unbound material (classification): } & \mathrm{MH} \\ \text { Poisson's ratio: 0.35 } & 0.3-0.40 \\ \text { Coefficient of lateral pressure Ko : } 0.5 & 0.2-0.70 \\ \text { Modulus (psi) } & 5000-9000 \\ \text { ICM (Climate model input for this layer's material) } & \\ \text { Gradation } & \\ \text { Plasticity index (PI) } & 5 \\ \text { Liquid limit (LL) } & 45 \\ \text { Compact layer } & \text { yes/not } \\ & \\ \text { Index properties from sieve analysis } & \\ \text { \%passing \# 200 } & 54.3 \\ \text { \%passing \#40 } & 74.2 \\ \text { \%passing \#4 } & 86.9 \\ \text { D10 (mm) } & 0.000338 \\ \text { D20 } & 0.001145 \\ \text { D30 } & 0.003876 \\ \text { D60 } & 0.1234 \\ \text { D90 } & 9.109 \\ & \\ \text { User overridable } & \text { index } \\ \text { Maximum dry unit weight (PCF) } & 127.2 \\ \text { Specific gravity } & 2.7 \\ \text { Sat hydraulic conductivity (ft/hr) } & 11.4 \\ \text { Optimum gravimetric water content (\%) } & 74.4 \\ \text { Degree of saturation of optimum \% } & \\ \text { Overridable soil water characteristic curve: } & 65.23 \\ \text { Af: } 65.23 & 1.034 \\ \text { Bf: } 1.034 & 0.4994 \\ \text { Cf: } 0.4994 & 500 \\ \text { Hf: } 500 & \\ & \\ & \\ & \\ & \end{array}$


Appendix B

Analysis of Pavement Distresses Structure \#1 and Structure \#2 


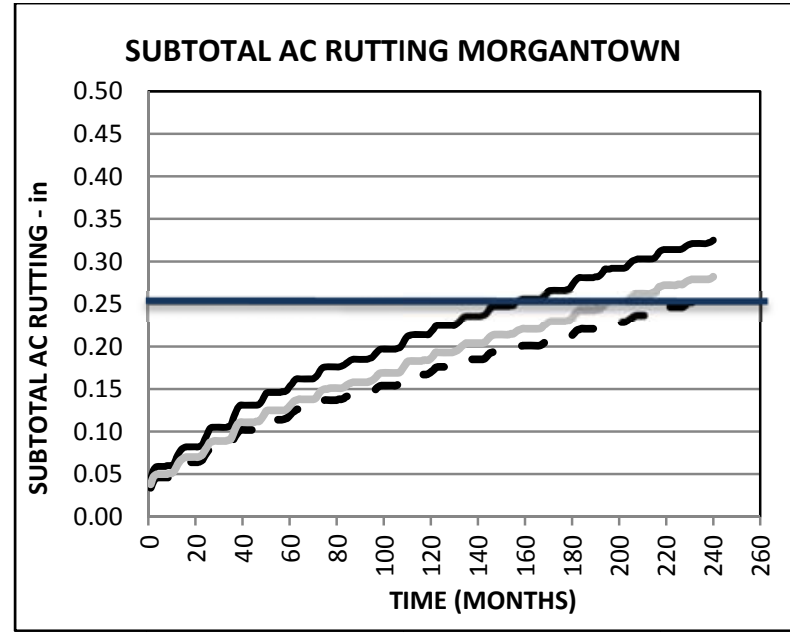

Figure 82: Effect of PG Asphalt Binder on AC Rutting Structure \#1

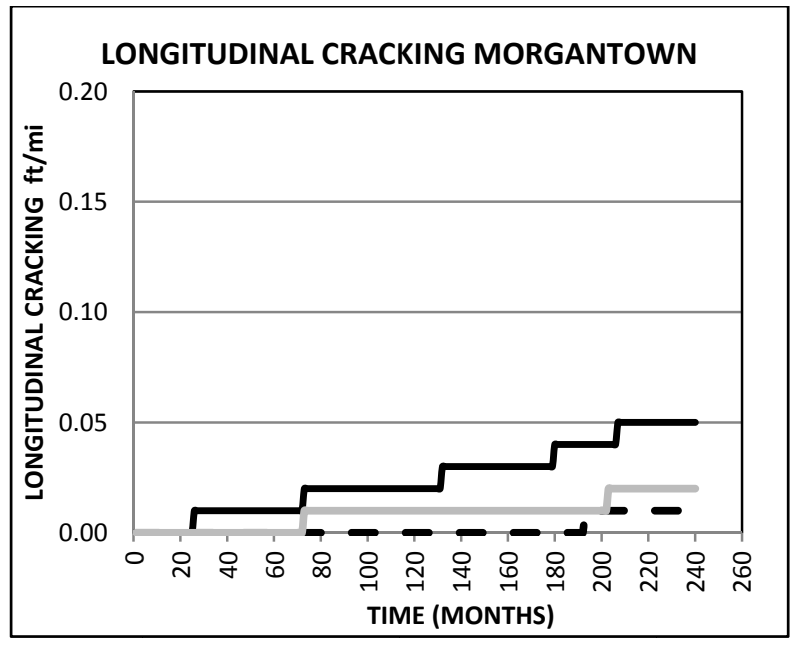

Figure 83: Effect of PG Asphalt Binder on Longitudinal cracking Structure \#1

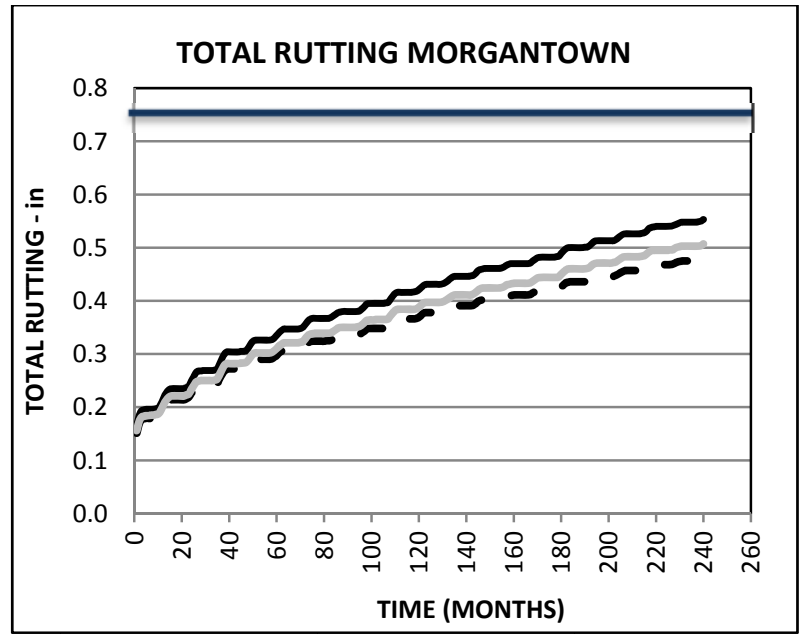

Figure 84: Effect of PG Asphalt Binder on Total Rutting Structure \#1

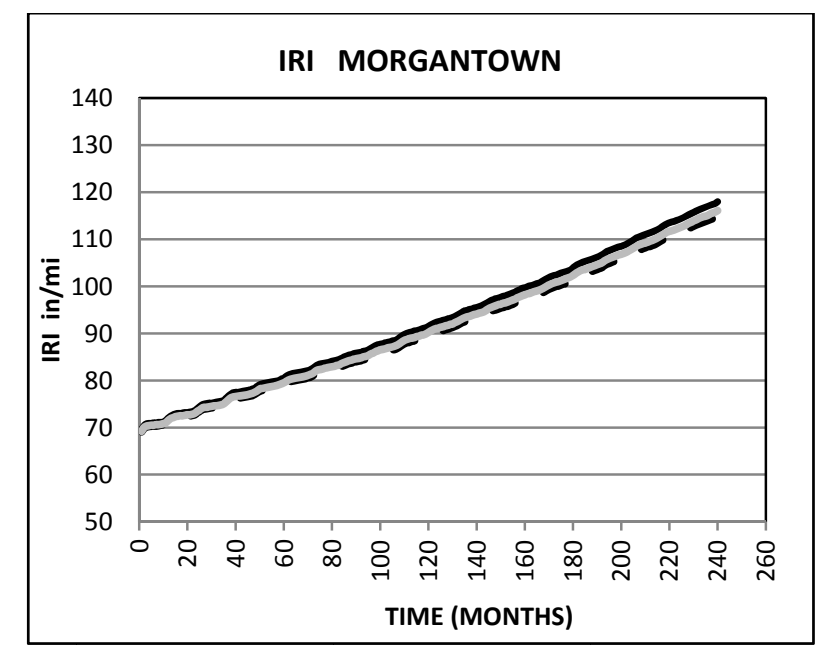

Figure 85: Effect of PG Asphalt Binder on IRI Structure \#1

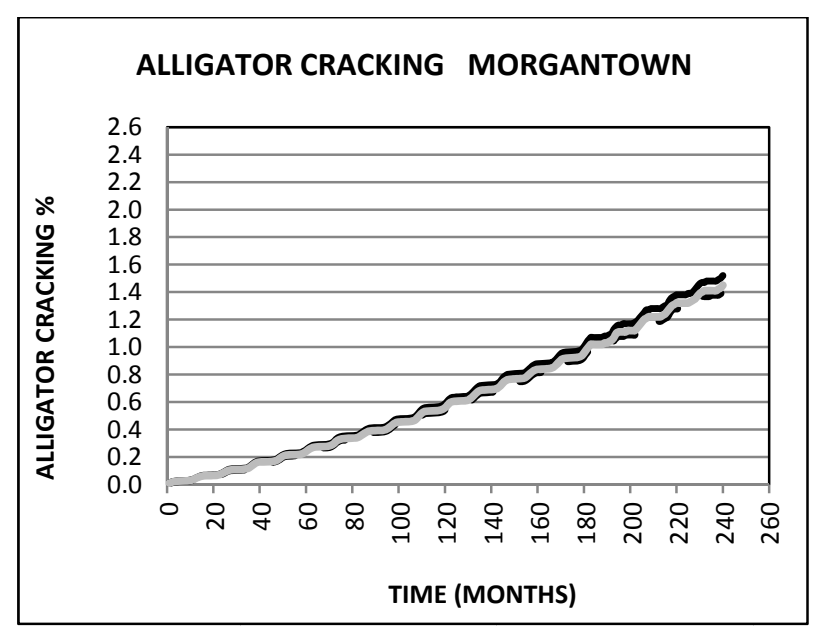

Figure 86: Effect of PG Asphalt Binder on Alligator cracking Structure \#1

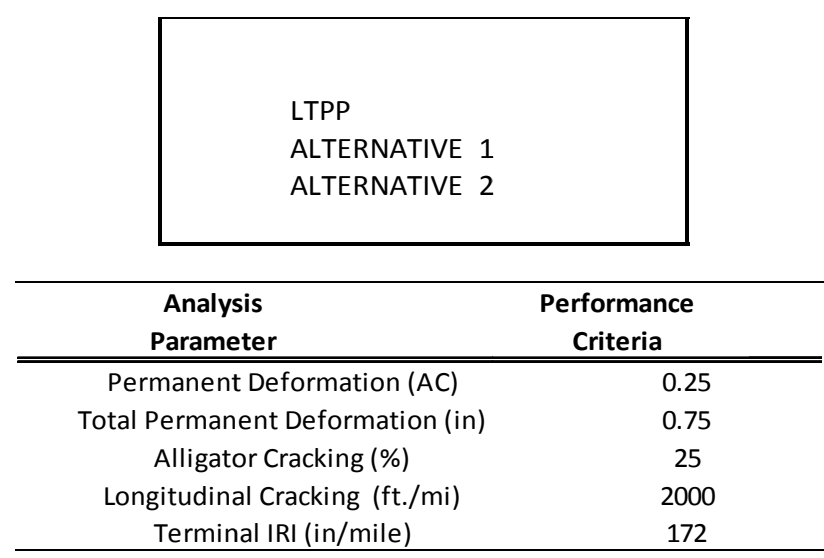




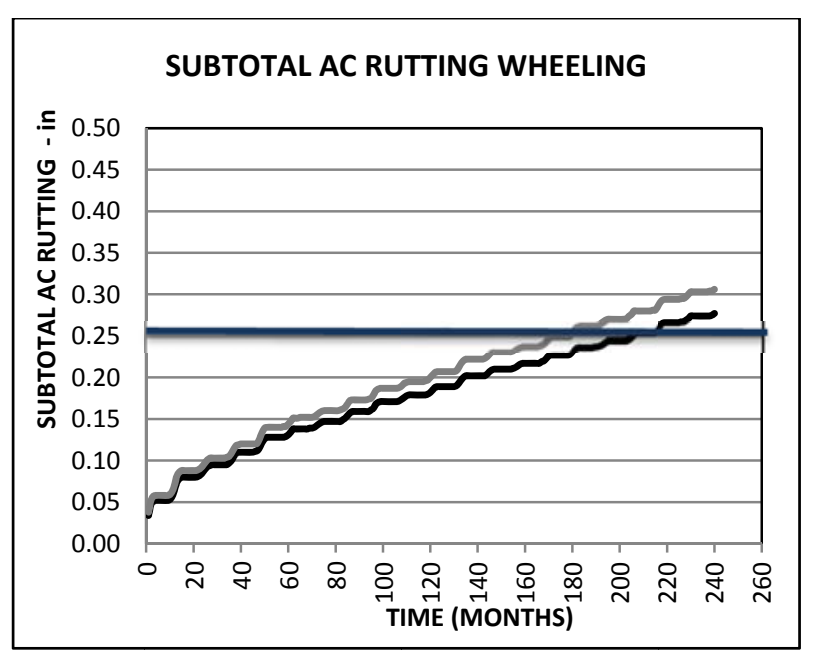

Figure 87: Effect of PG Asphalt Binder on AC Rutting Structure \#1

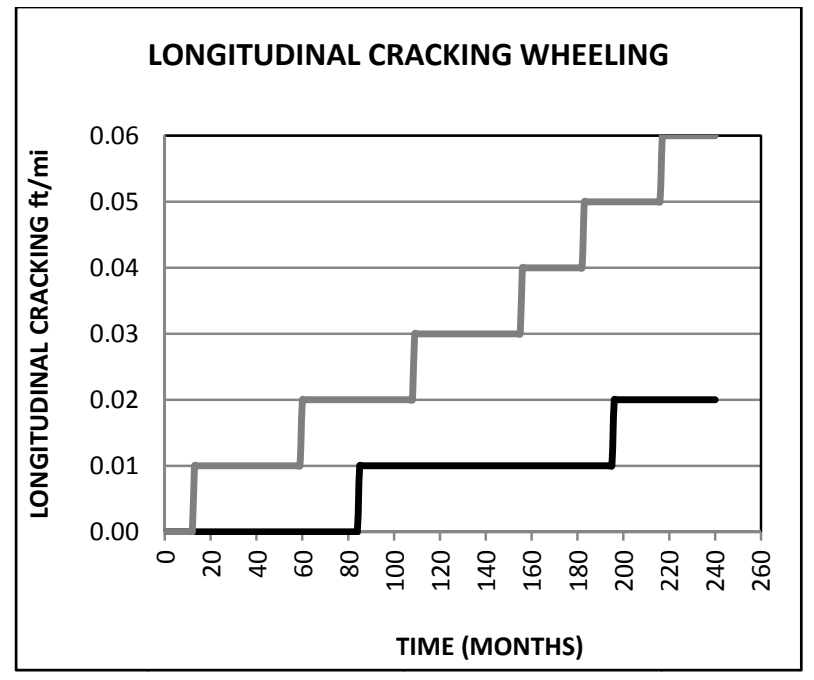

Figure 88: Effect of PG Asphalt Binder on Longitudinal cracking Structure \#1

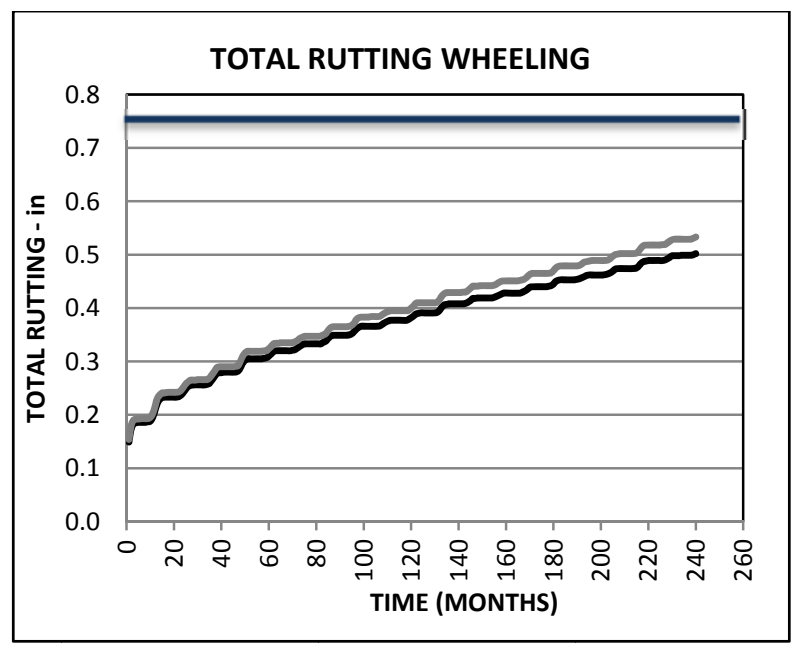

Figure 89: Effect of PG Asphalt Binder on Total Rutting Structure \#1

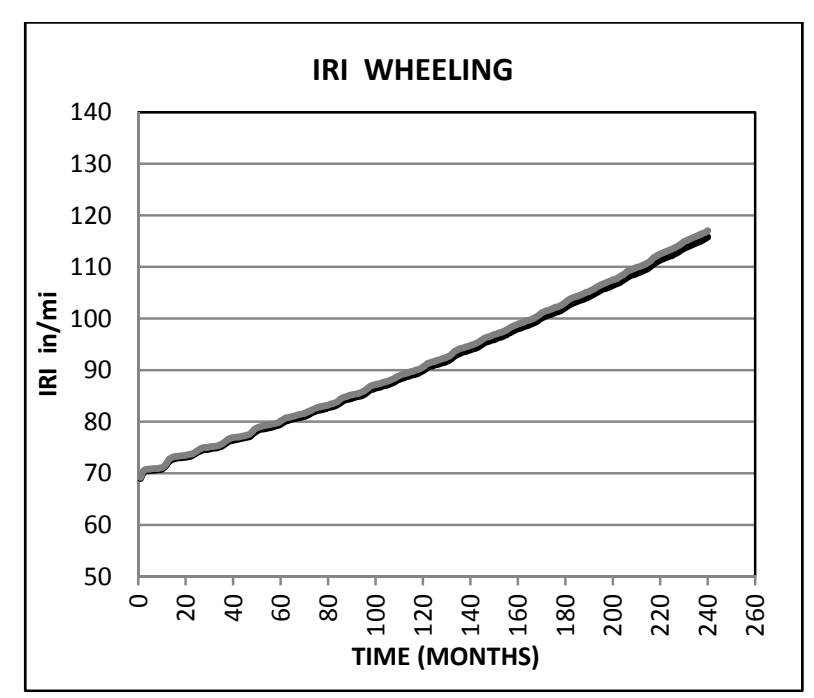

Figure 90: Effect of PG Asphalt Binder on IRI

Structure \#1

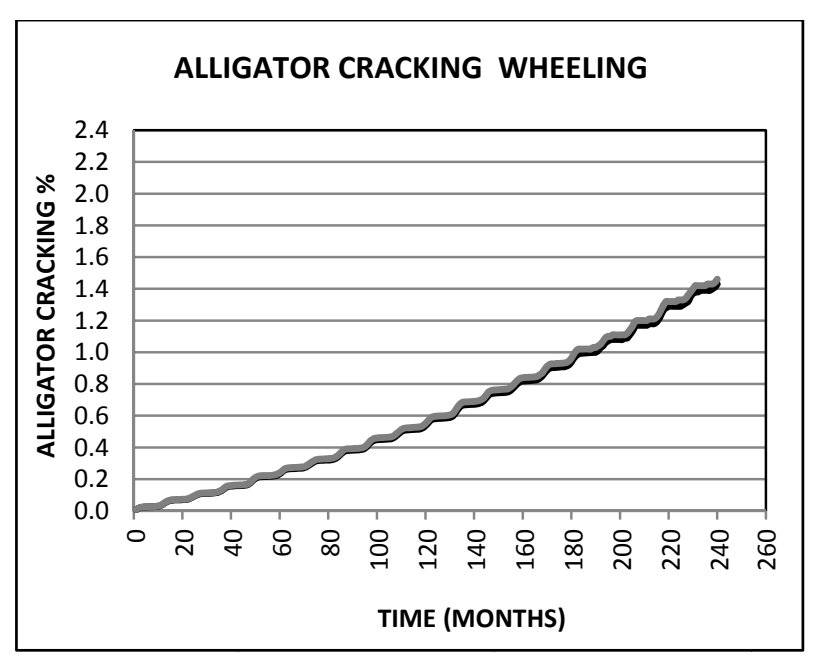

Figure 91: Effect of PG Asphalt Binder on Alligator cracking Structure \#1

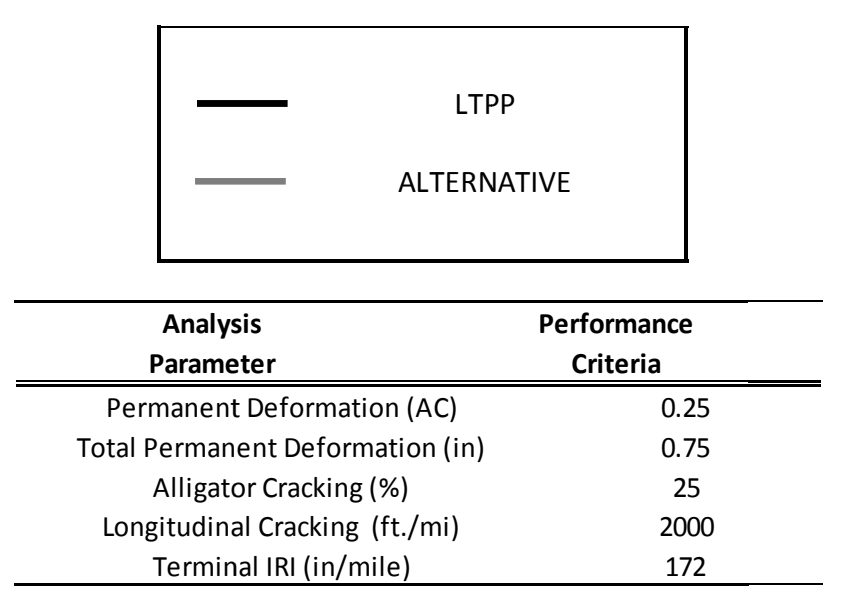




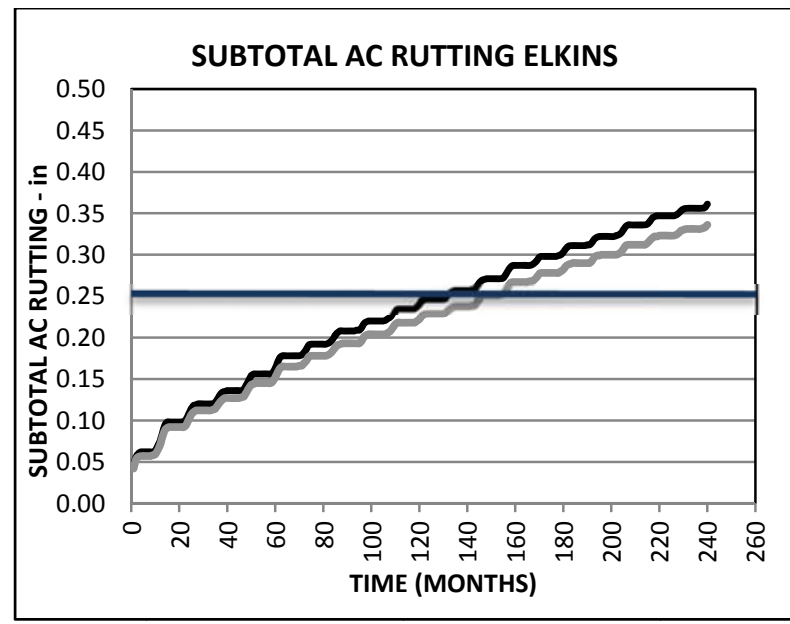

Figure 92: Effect of PG Asphalt Binder on AC Rutting Structure \#1

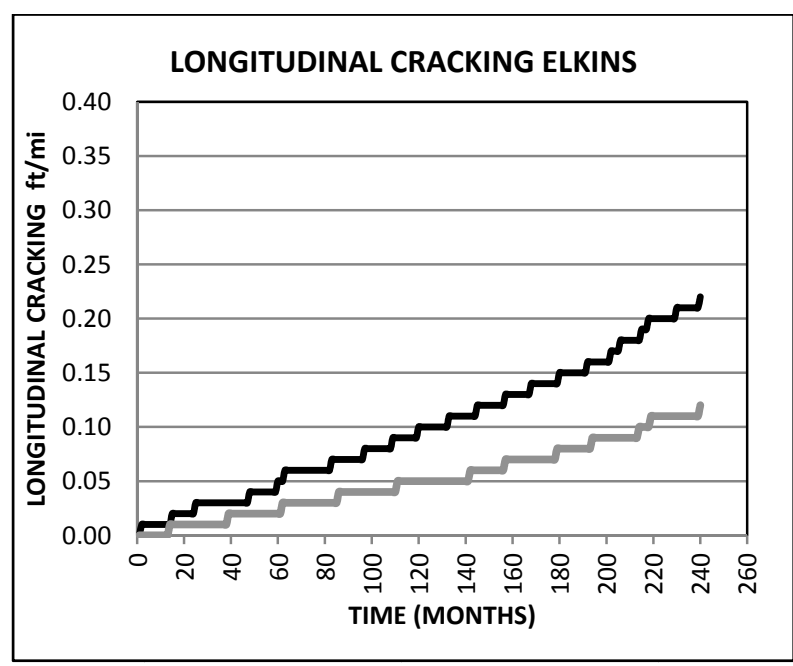

Figure 93: Effect of PG Asphalt Binder on Longitudinal cracking Structure \#1

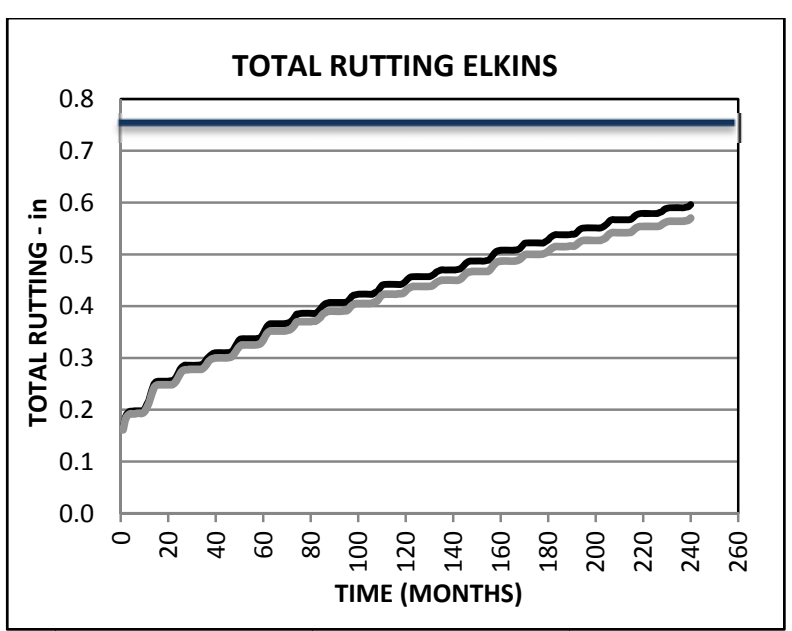

Figure 94: Effect of PG Asphalt Binder on Total Rutting Structure \#1

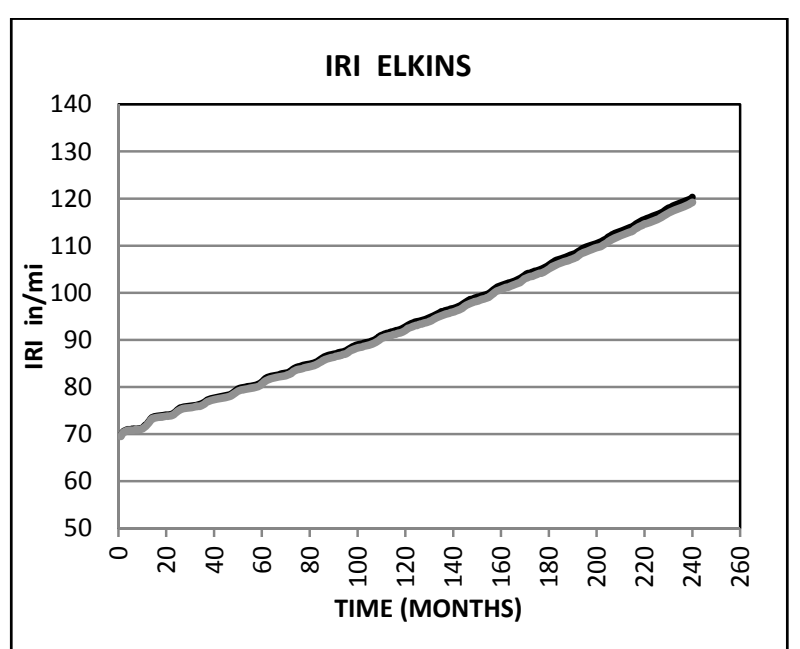

Figure 95: Effect of PG Asphalt Binder on

Longitudinal Structure \#1

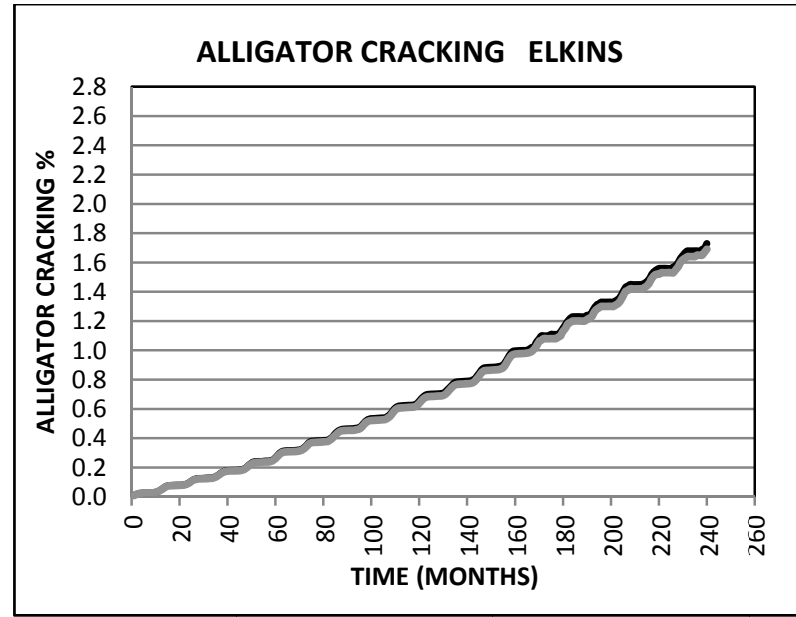

Figure 96: Effect of PG Asphalt Binder on Alligator cracking Structure \#1

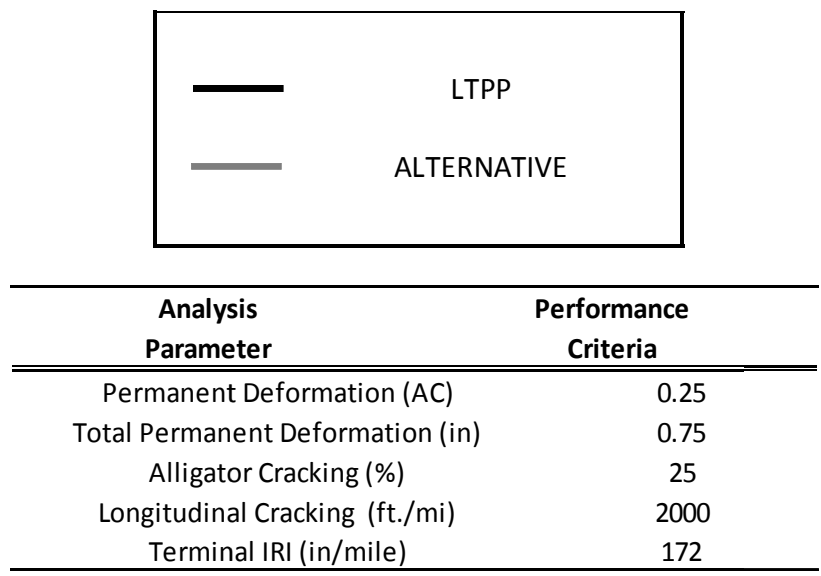




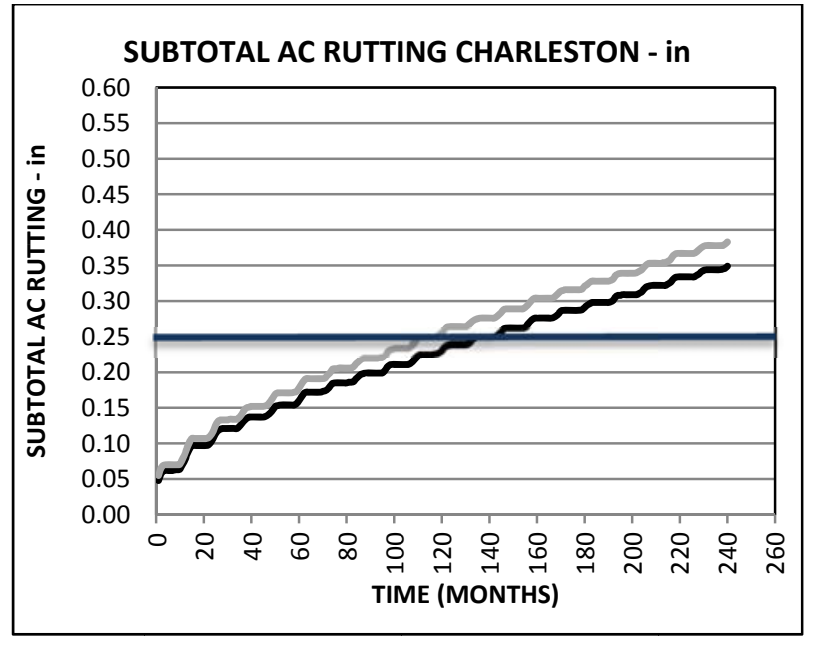

Figure 97: Effect of PG Asphalt Binder on AC Rutting Structure \#1

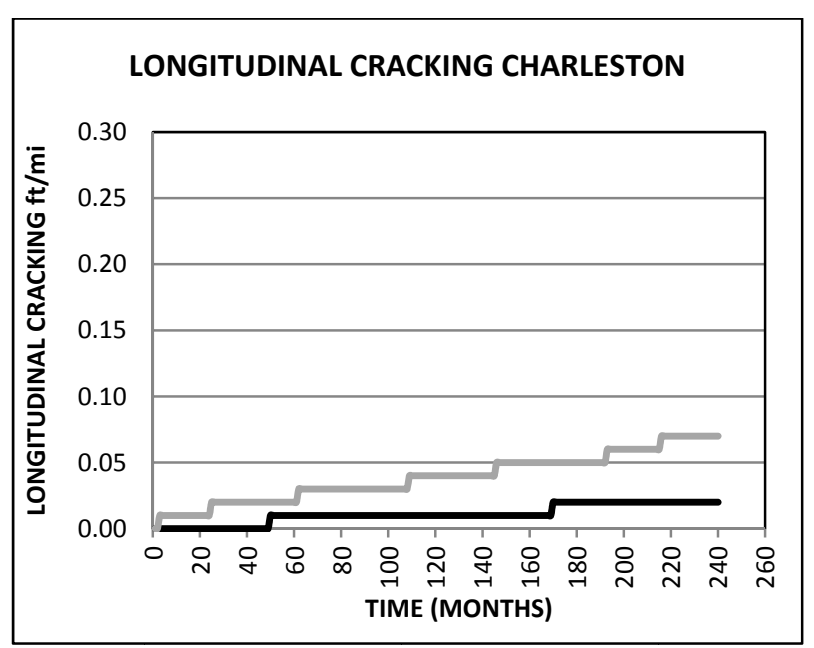

Figure 98: Effect of PG Asphalt Binder on

Longitudinal Structure \#1

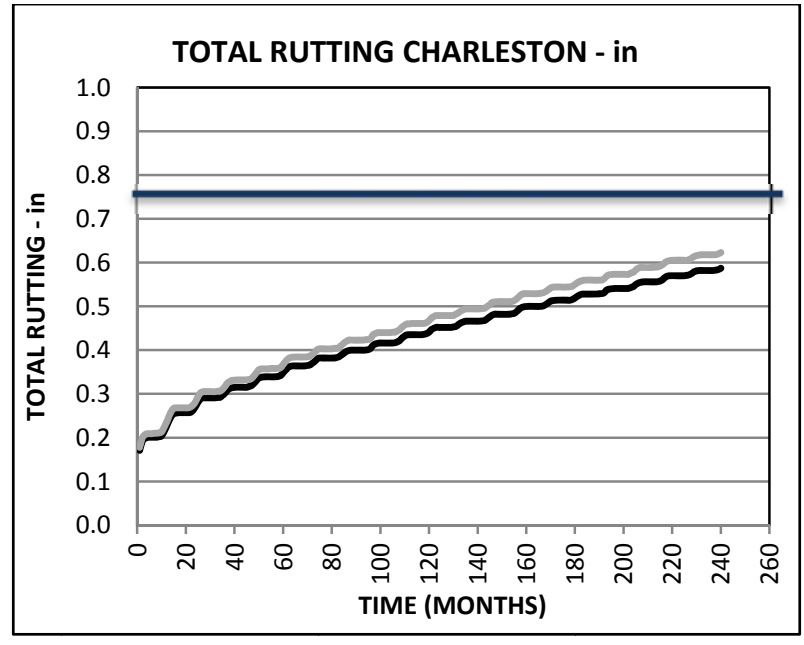

Figure 99: Effect of PG Asphalt Binder on Total Rutting Structure \#1

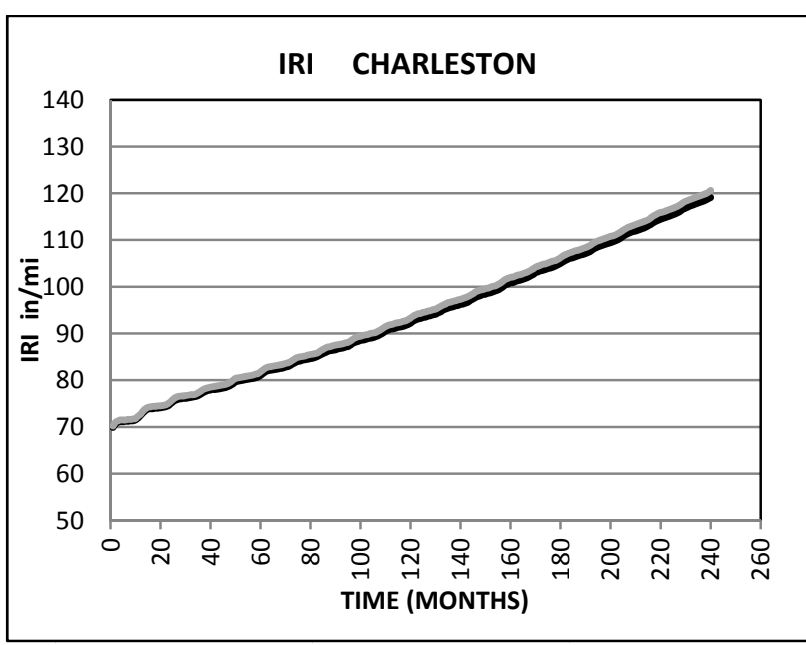

Figure 100: Effect of PG Asphalt Binder on

Longitudinal Structure \#1

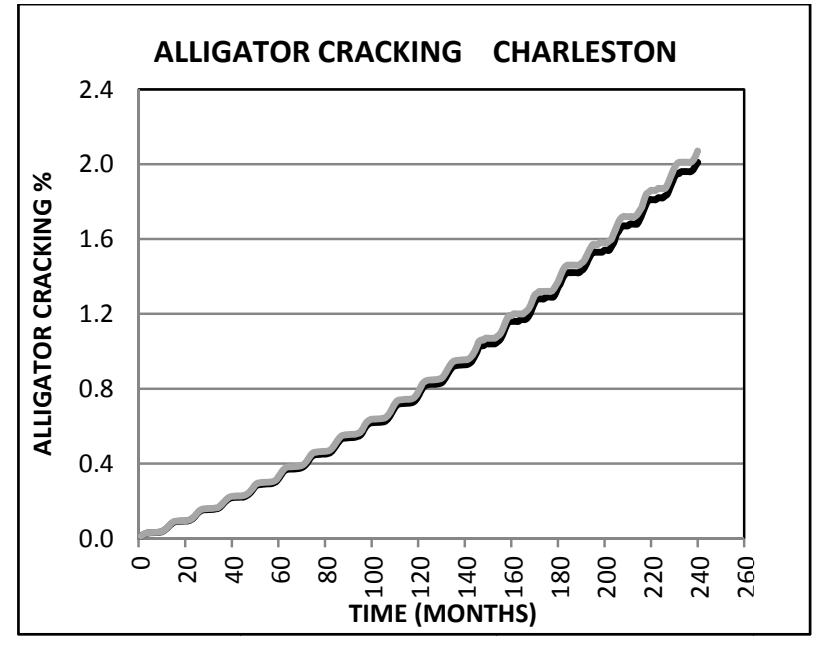

Figure 101: Effect of $P G$ Asphalt Binder on Alligator Structure \#1

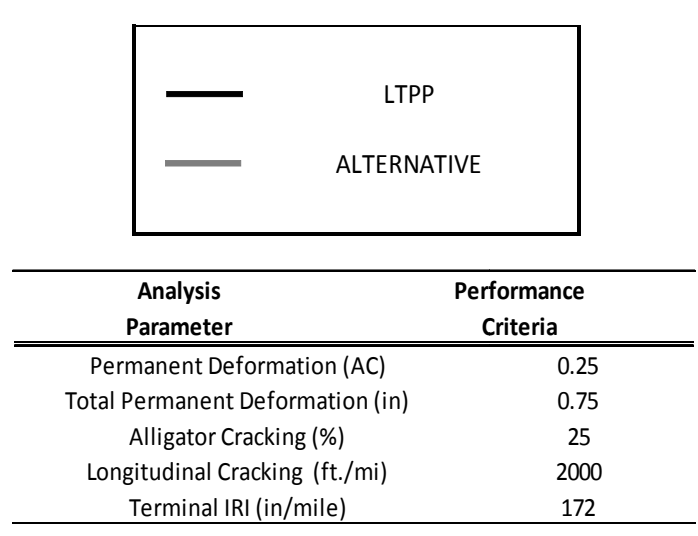




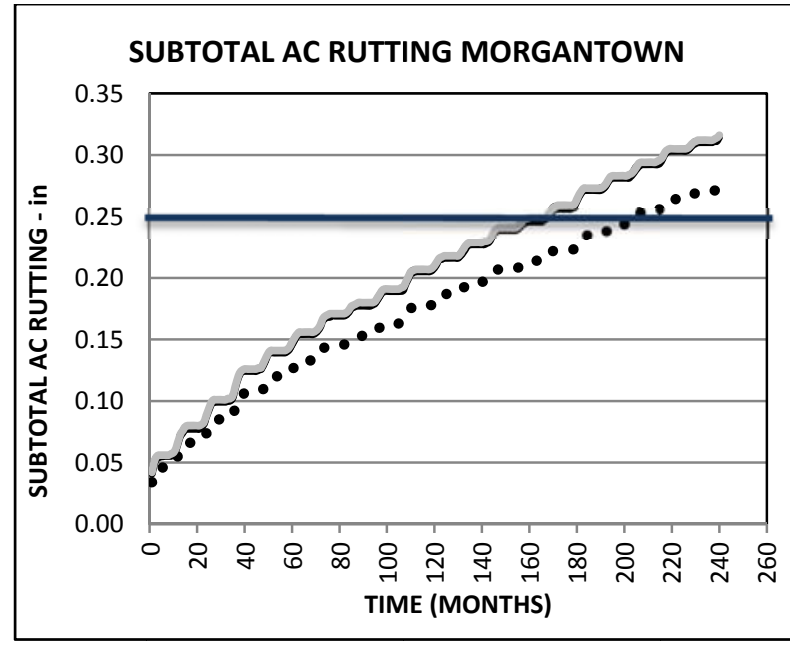

Figure 102: Effect of PG Ashalt Binder on AC Rutting Structure \#2

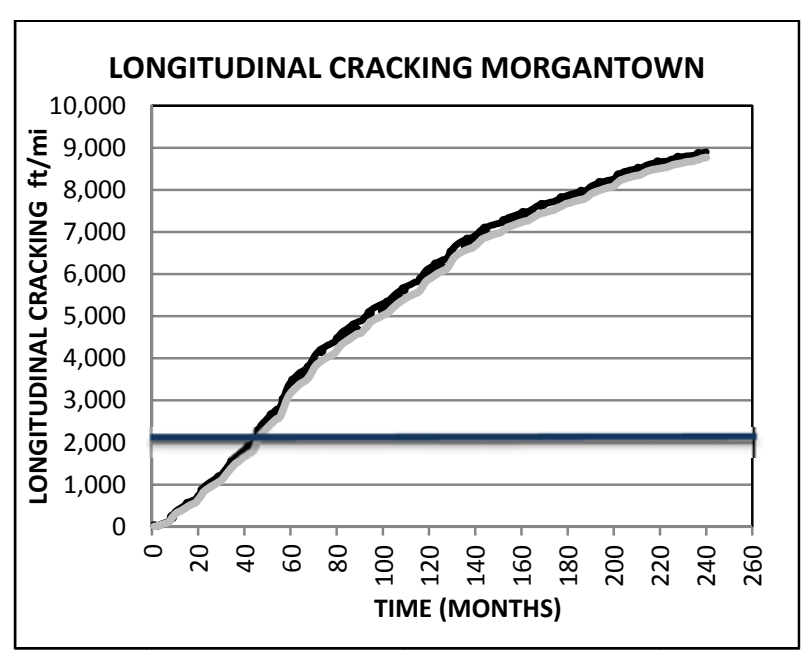

Figure 103: Effect of $P G$ Asphalt Binder on Longitudinal Structure \#2

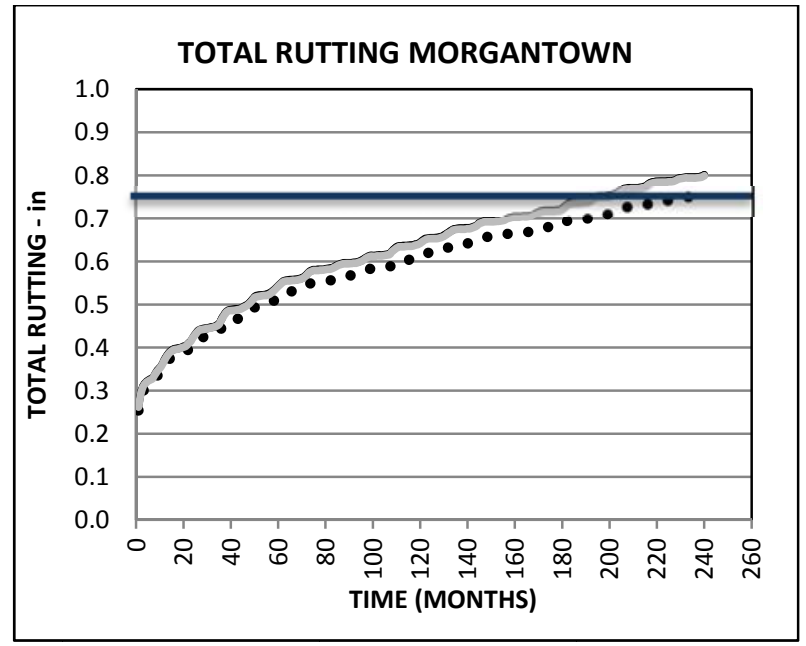

Figure 104: Effect of PG Asphalt Binder on Total Rutting Structure \#2

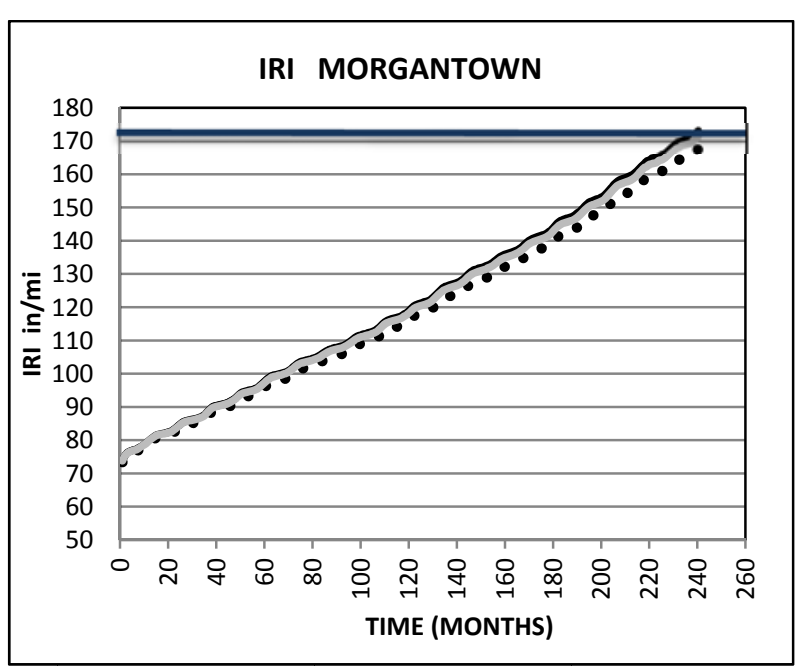

Figure 105: Effect of PG Asphalt Binder on Longitudinal Structure \#2

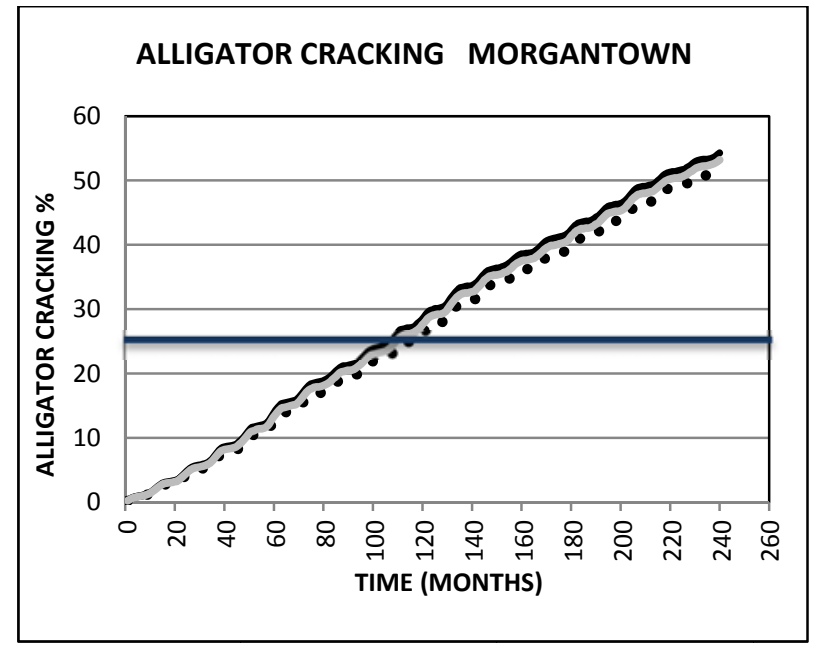

Figure 106: Effect of $P G$ Asphalt Binder on Alligator Structure \#2

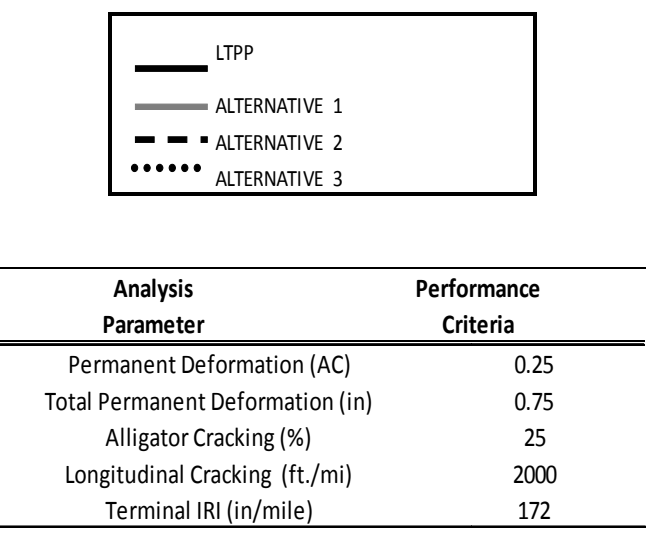




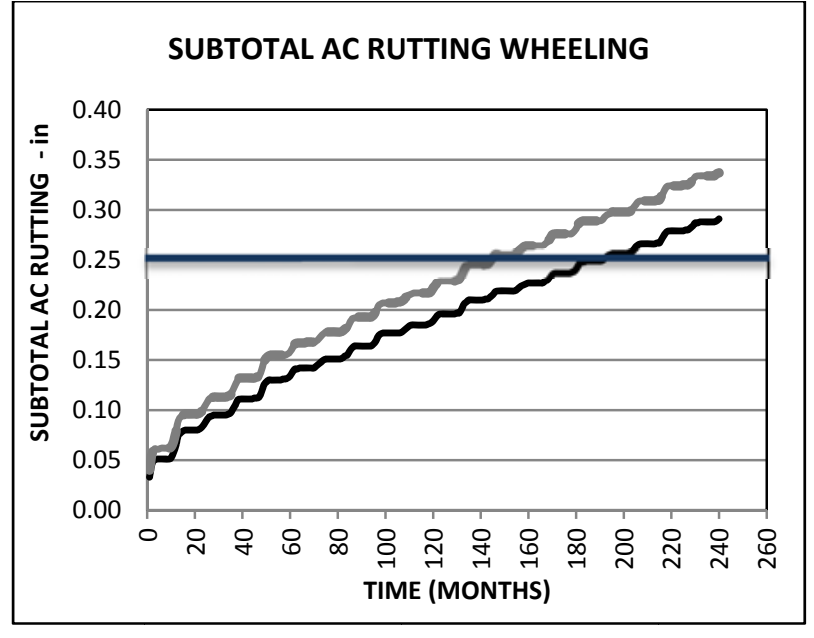

Figure 107: Effect of PG Asphalt Binder on AC Rutting Structure \#2

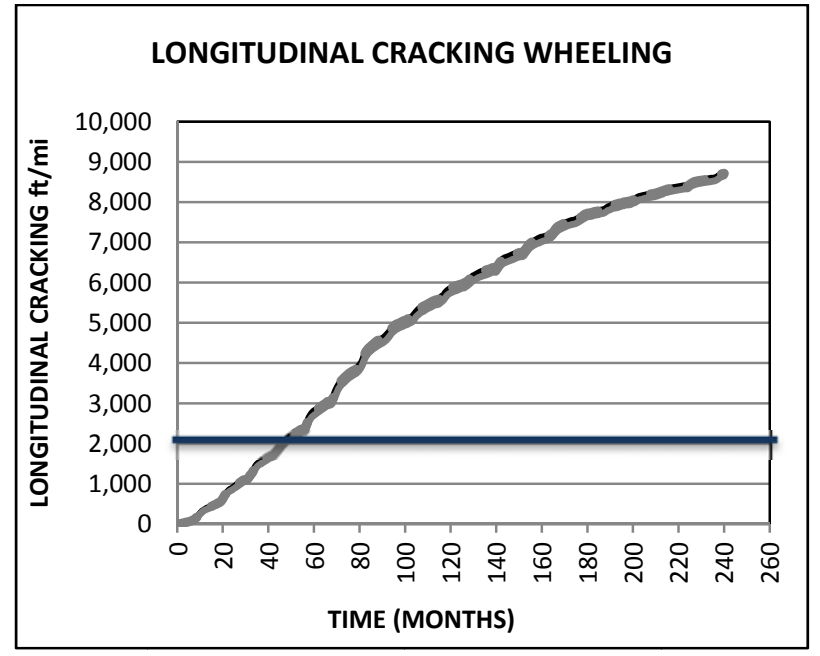

Figure 108: Effect of $P G$ Asphalt Binder on

Longitudinal Structure \#2

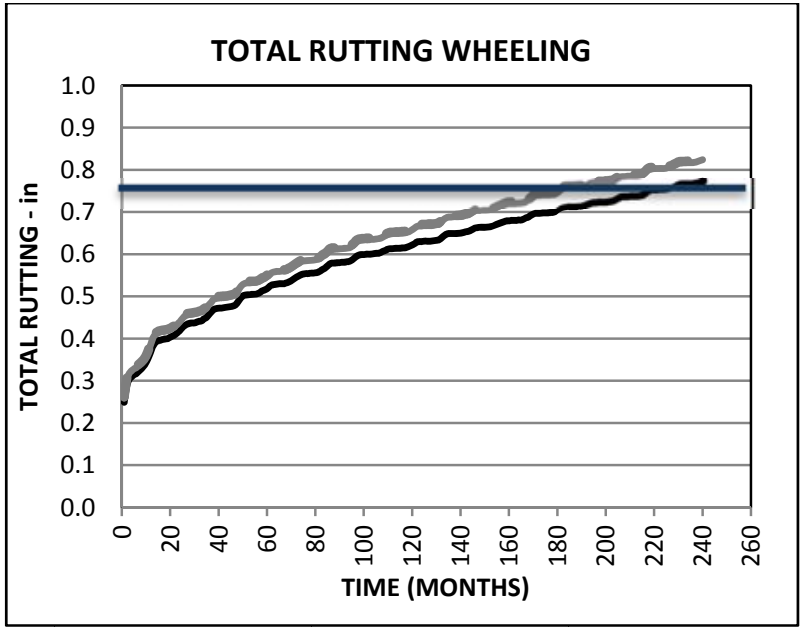

Figure 109: Effect of PG Asphalt Binder on Total Rutting Structure \#2

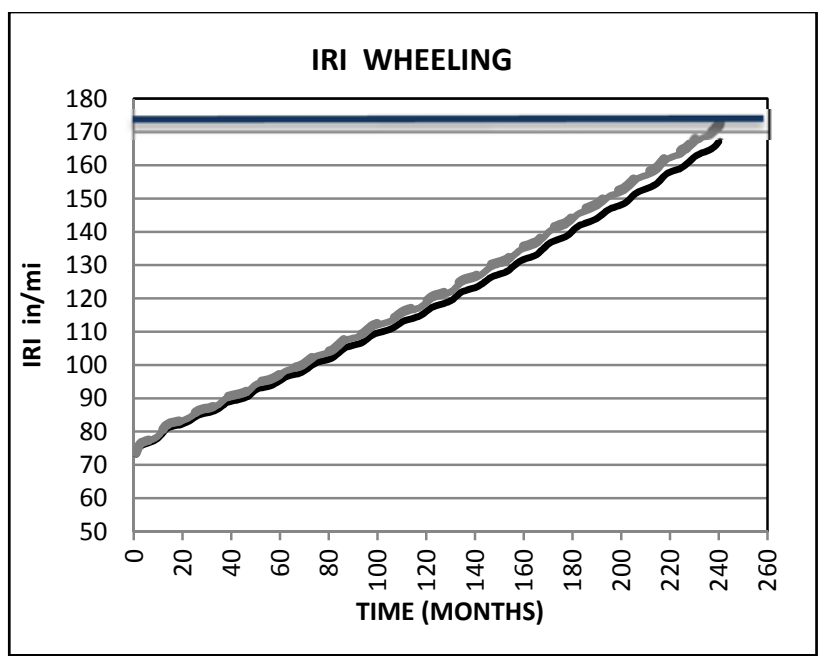

Figure 110: Effect of $P G$ Asphalt Binder on

Longitudinal Structure \#2

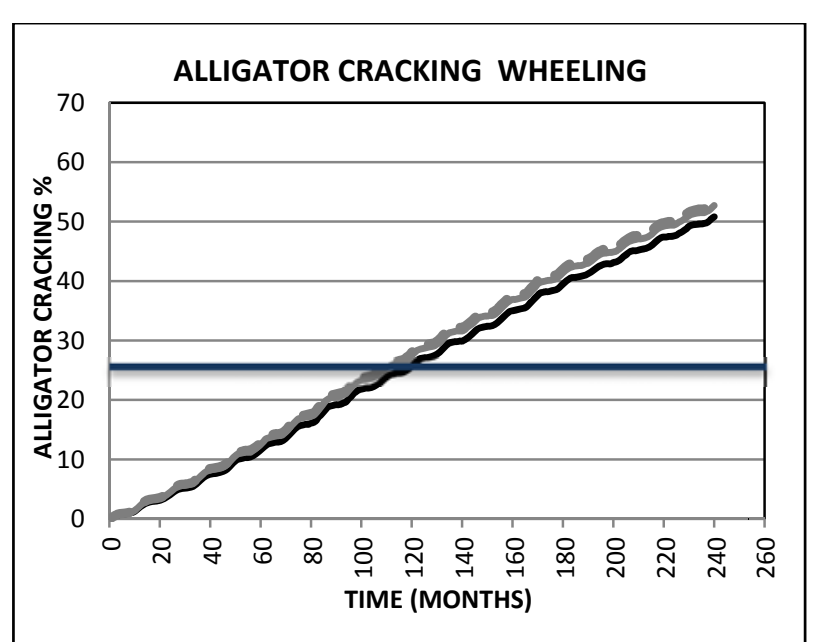

Figure 111: Effect of $P G$ Asphalt Binder on Alligator Structure \#2

\begin{tabular}{|cc}
\hline & \\
& \\
& \\
\hline & \\
Analysis & Performance \\
Parameter & Criteria \\
\hline \hline Permanent Deformation (AC) & 0.25 \\
Total Permanent Deformation (in) & 0.75 \\
Alligator Cracking (\%) & 25 \\
Longitudinal Cracking (ft./mi) & 2000 \\
Terminal IRI (in/mile) & 172 \\
\hline
\end{tabular}




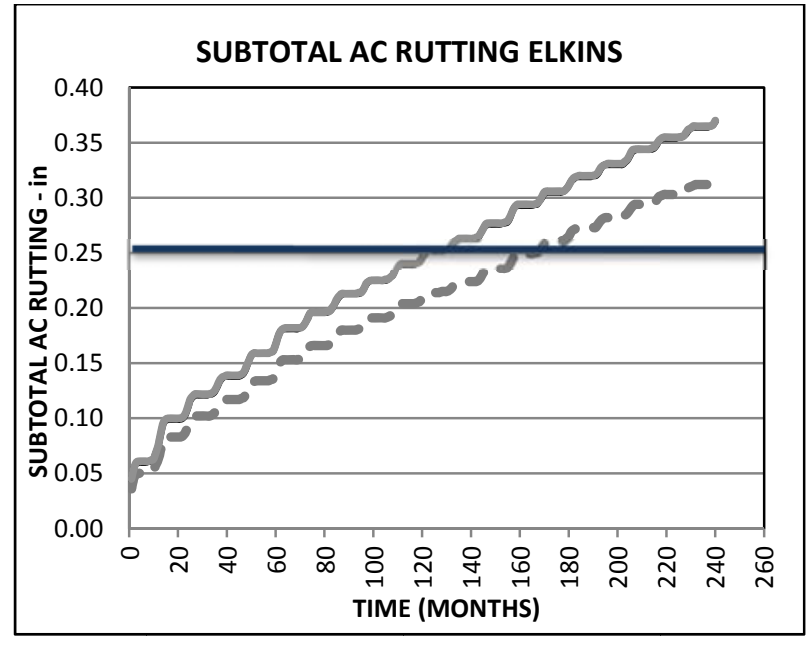

Figure 112: Effect of $\mathrm{PG}$ Asphalt Binder on $\mathrm{AC}$ Rutting Structure \#2

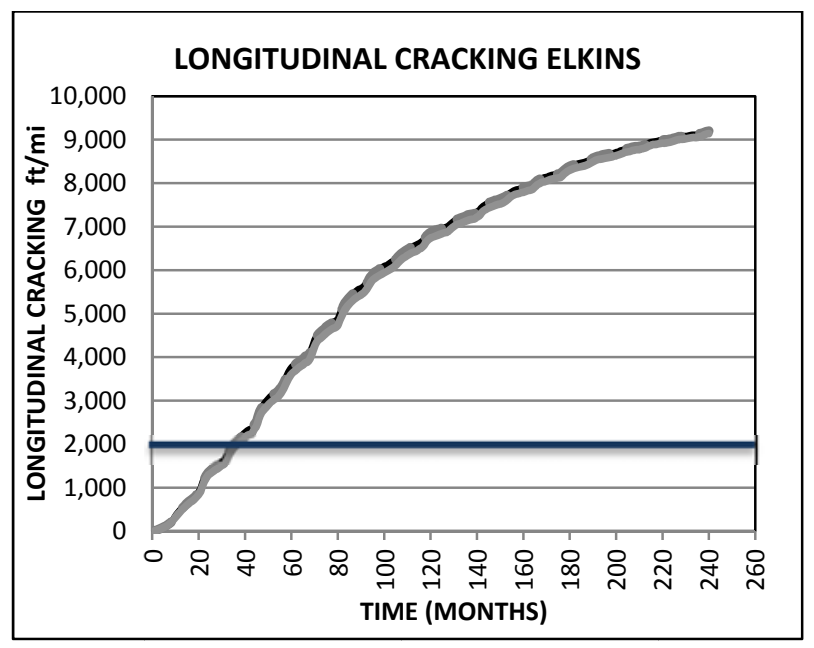

Figure 113: Effect of $P G$ Asphalt Binder on Longitudinal Structure \#2

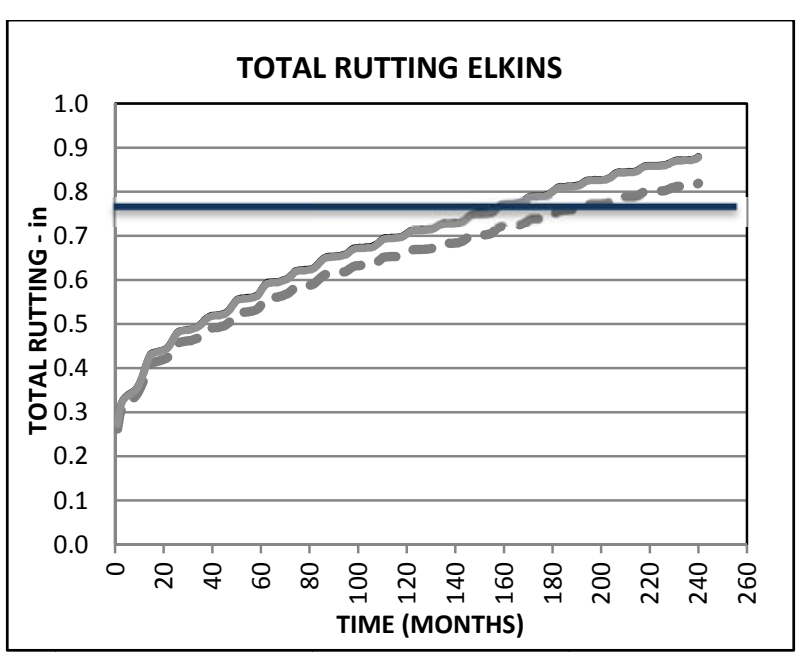

Figure 114: Effect of PG Asphalt Binder on Total Rutting Structure \#2

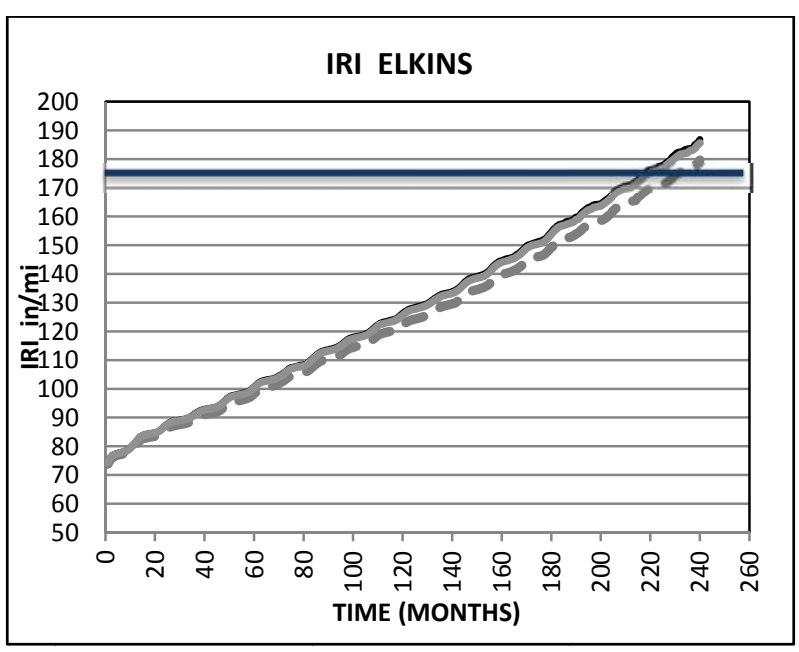

Figure 115: Effect of PG Asphalt Binder on Longitudinal Structure \#2

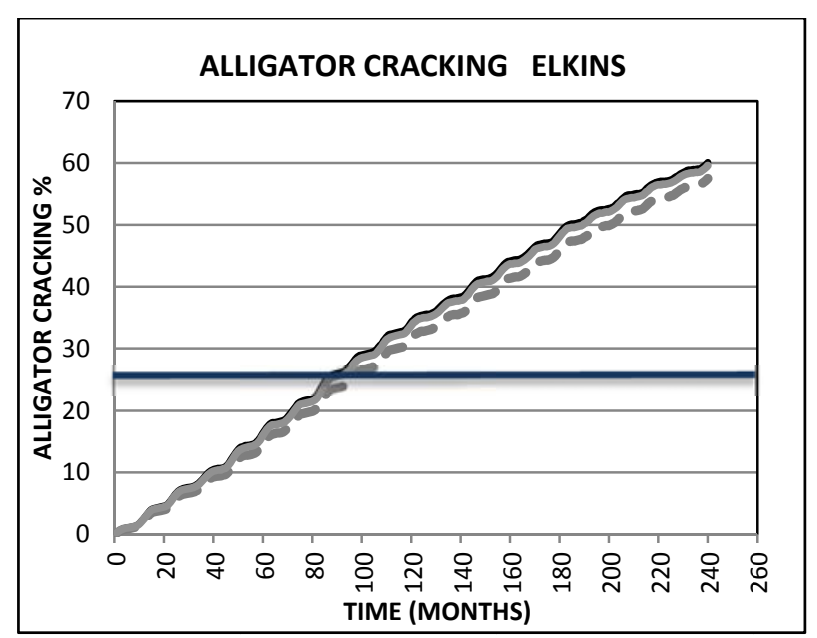

Figure 116: Effect of $P G$ Asphalt Binder on Alligator Structure \#2

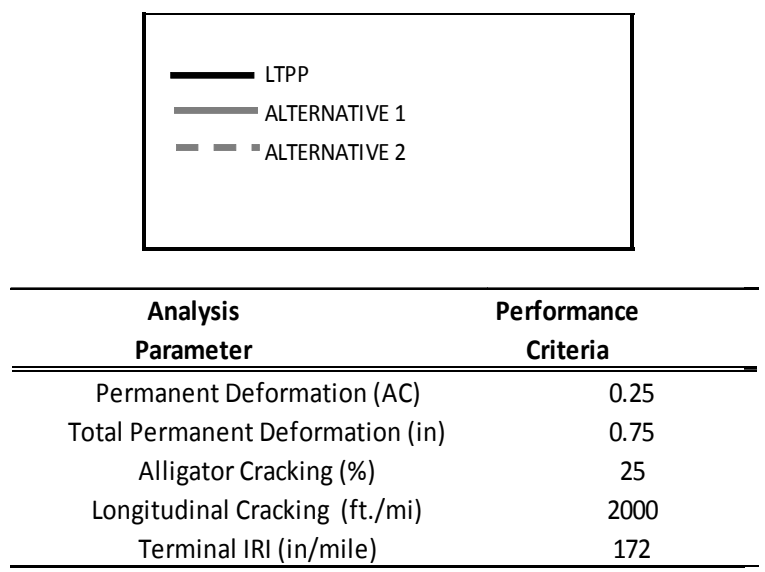




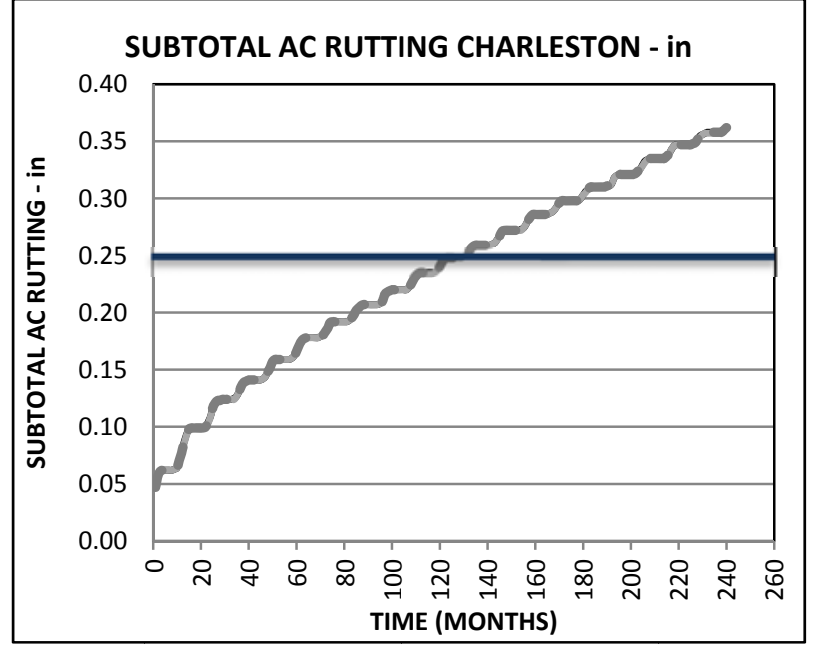

Figure 117: Effect of $P G$ Asphalt Binder on $A C$ Rutting Structure \#2

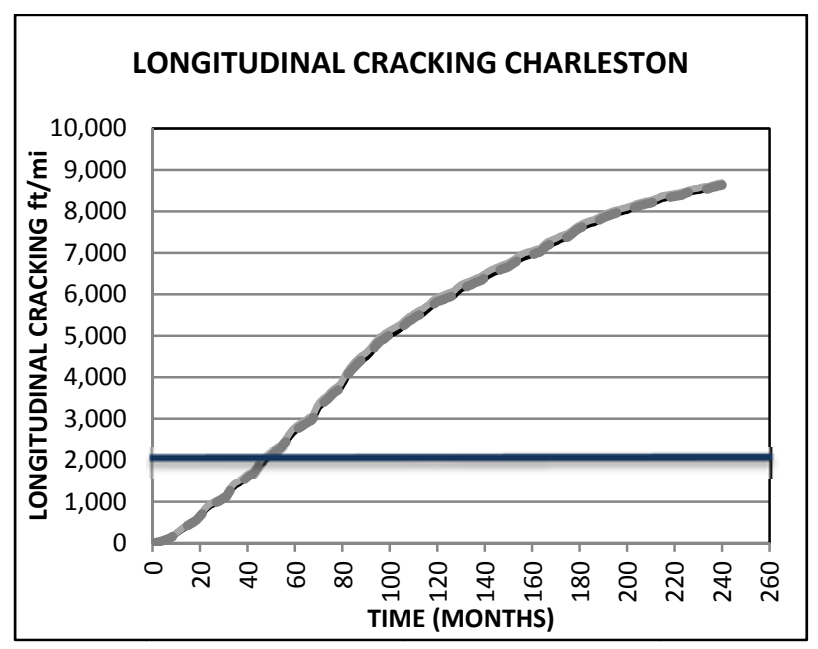

Figure 118: Effect of $P G$ Asphalt Binder on Longitudinal Structure \#2

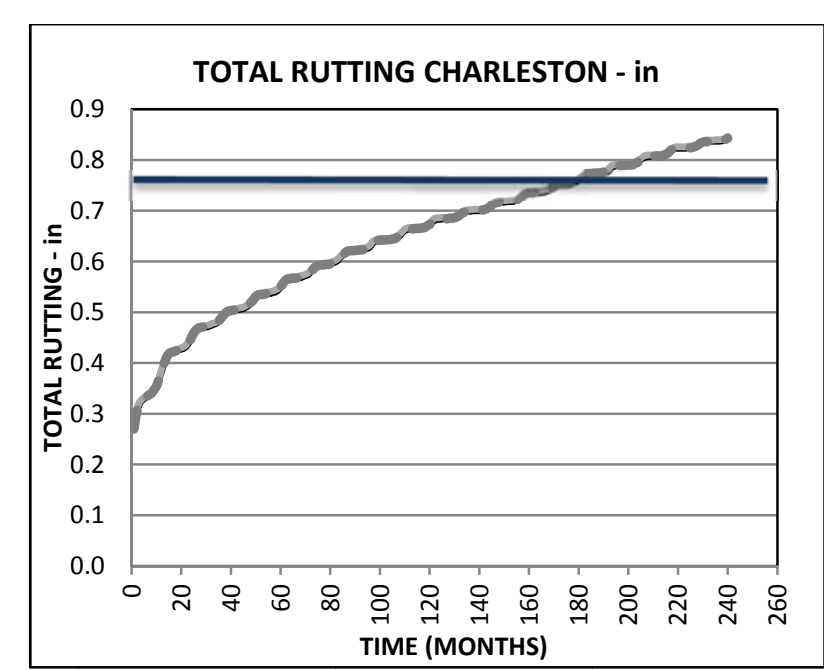

Figure 119: Effect of PG Asphalt Binder on Total Rutting Structure \#2

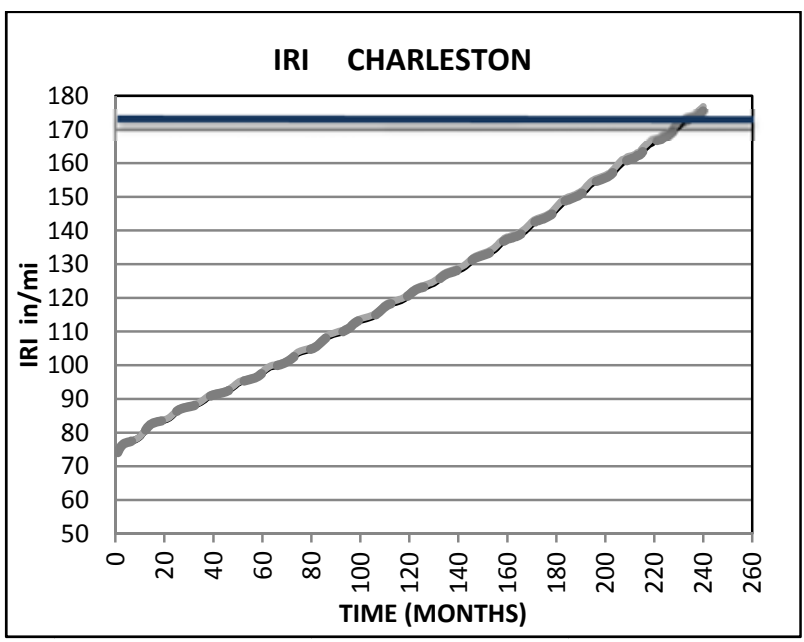

Figure 120: Effect of PG Asphalt Binder on Longitudinal Structure \#2

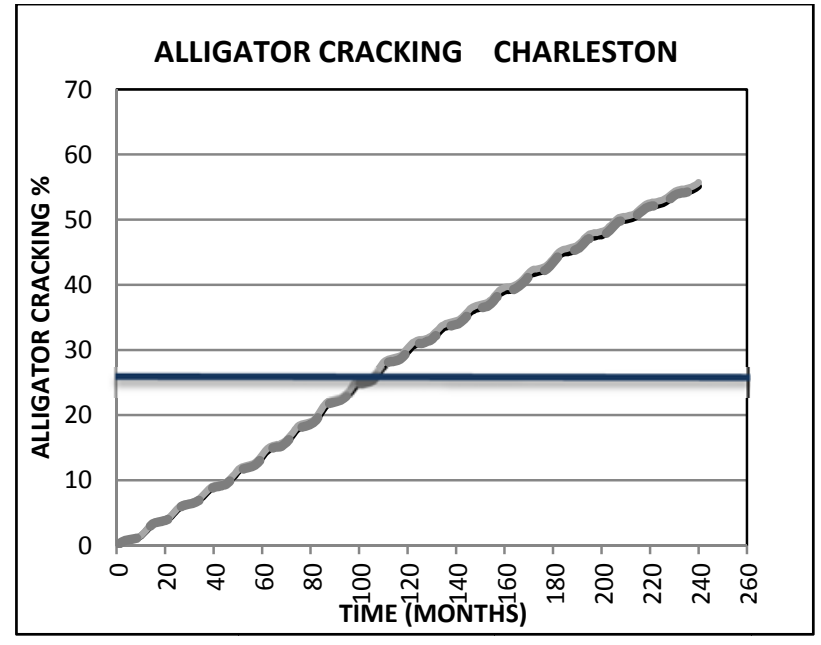

Figure 121: Effect of $P G$ Asphalt Binder on Alligator Structure \#2

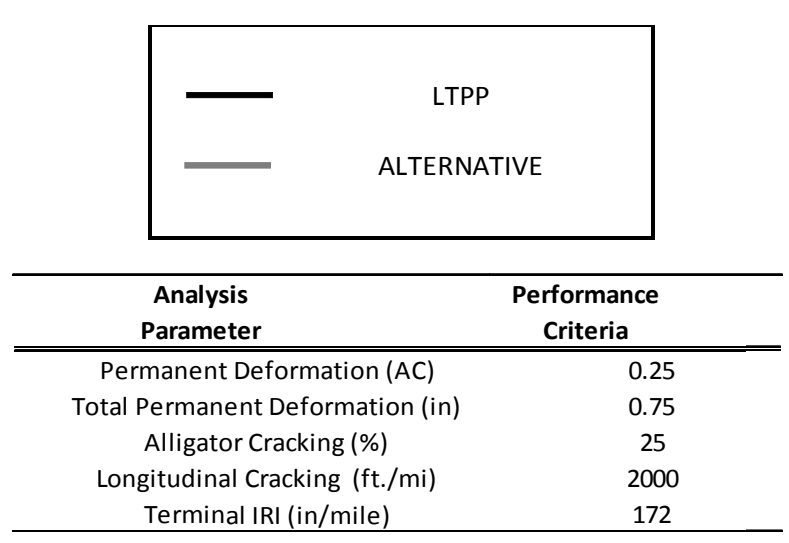




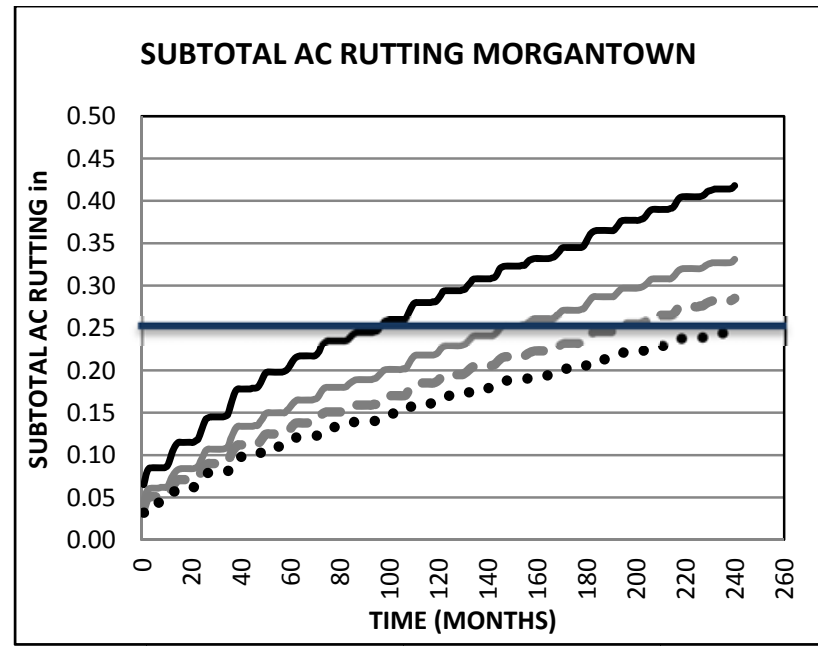

Figure 122: AC Rutting as a function of $P G$ Binder type Structure \#1

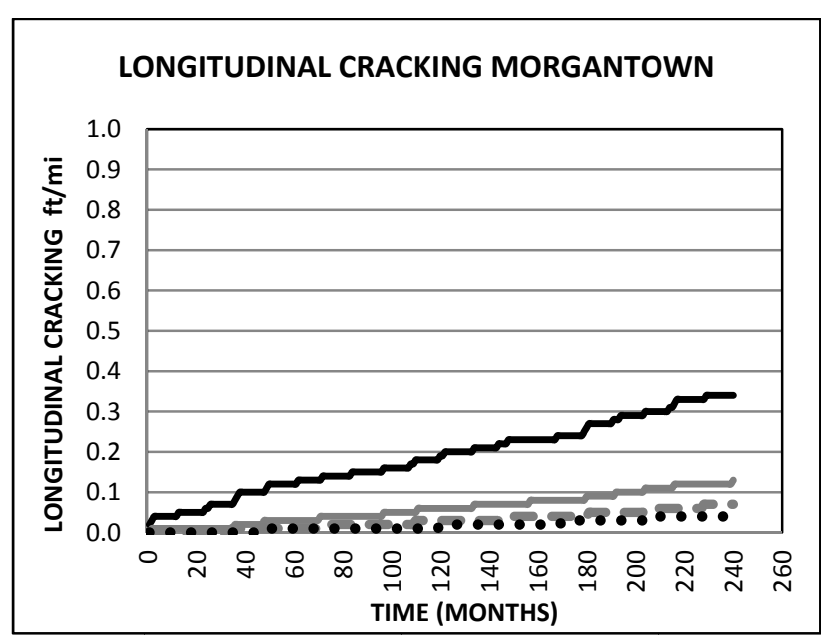

Figure 123: Longitudinal cracking as a function of PG Binder type Structure \#1

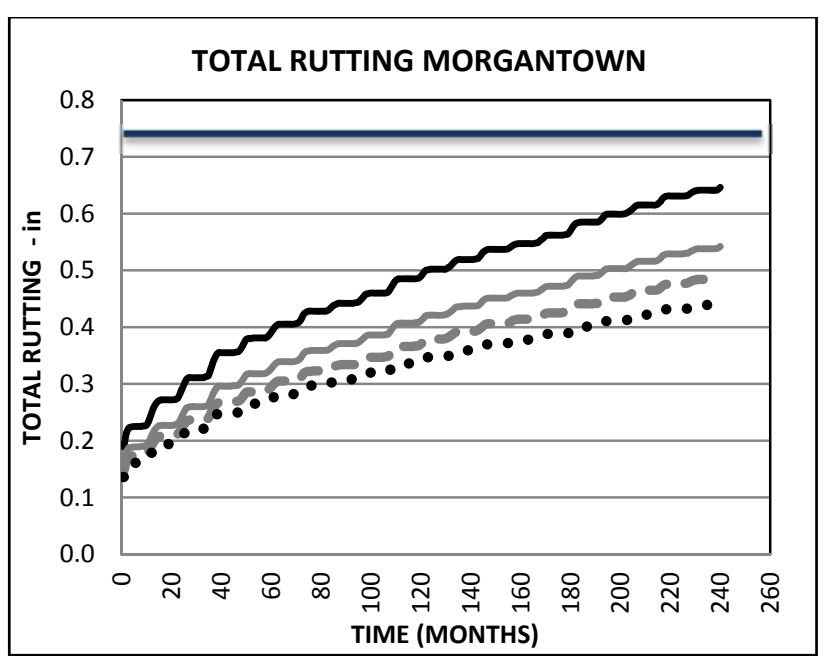

Figure 124: Total Rutting as a function of $P G$ Binder type Structure \#1

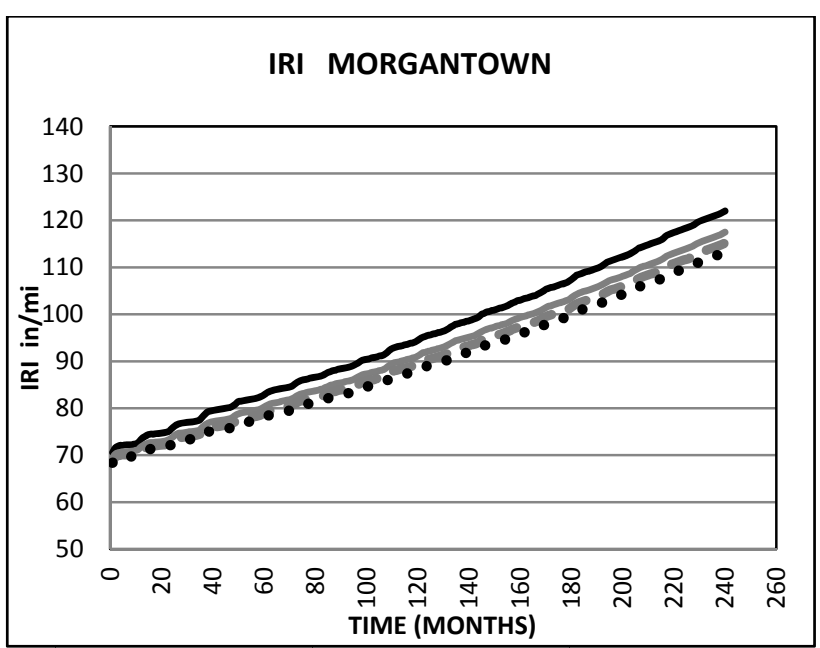

Figure 125: IRI as a function of $P G$ Binder type Structure \#1

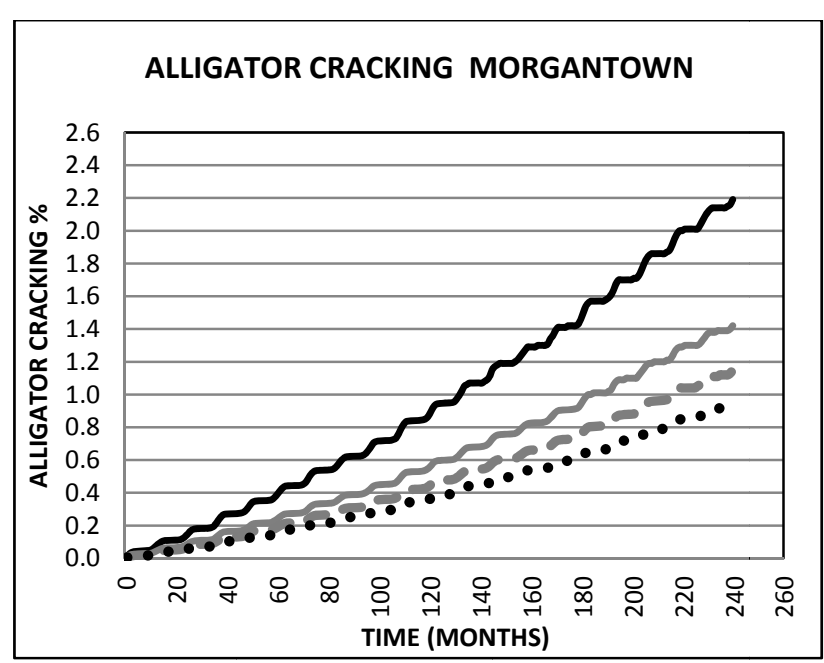

Figure 126: Alligator cracking as a function of $P G$ Binder type Structure \#1

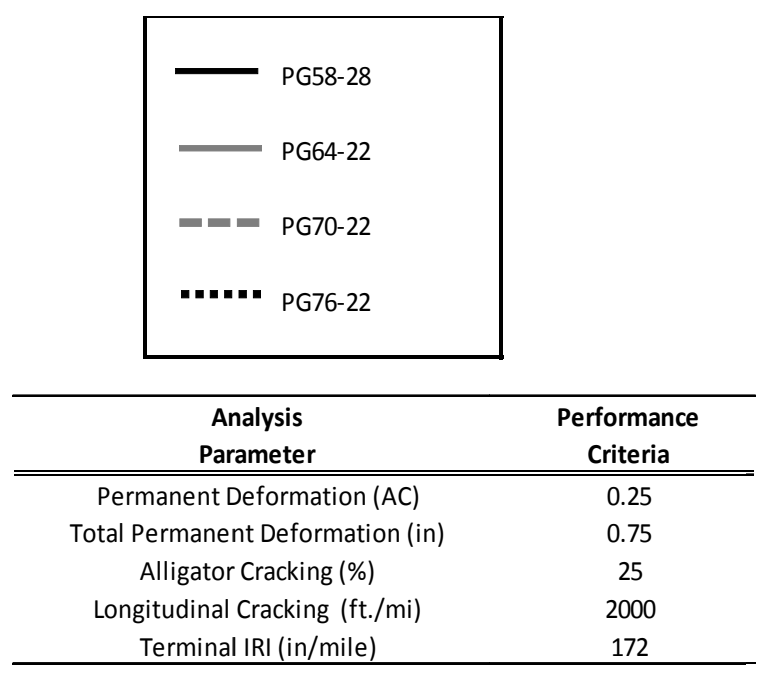




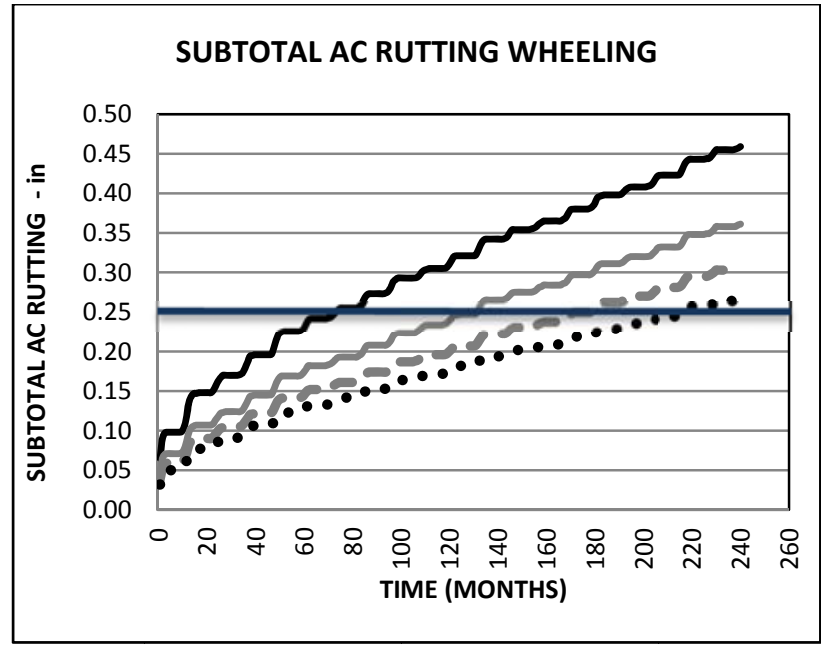

Figure 127: AC Rutting as a function of $P G$ Binder type Structure \#1

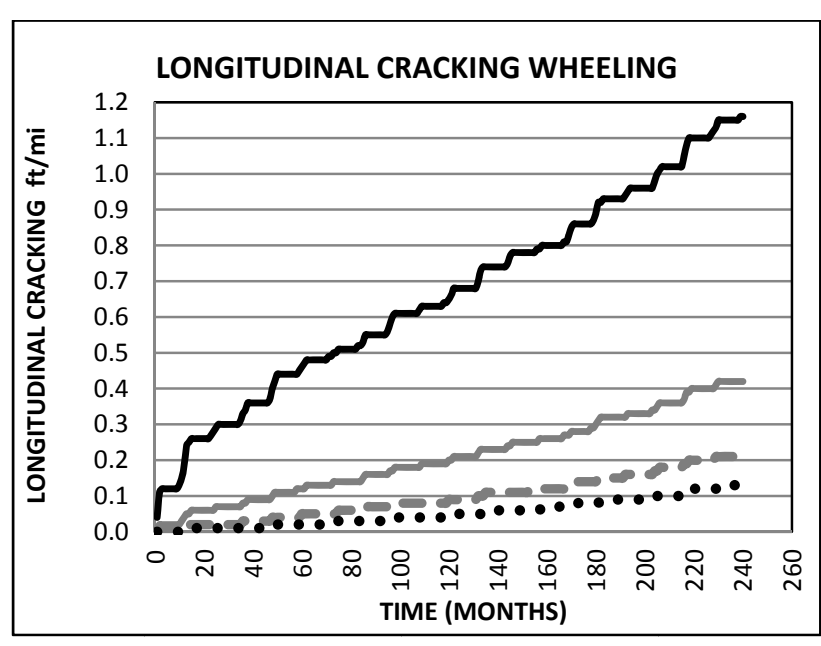

Figure 128: Longitudinal cracking as a function of PG Binder type Structure \#1

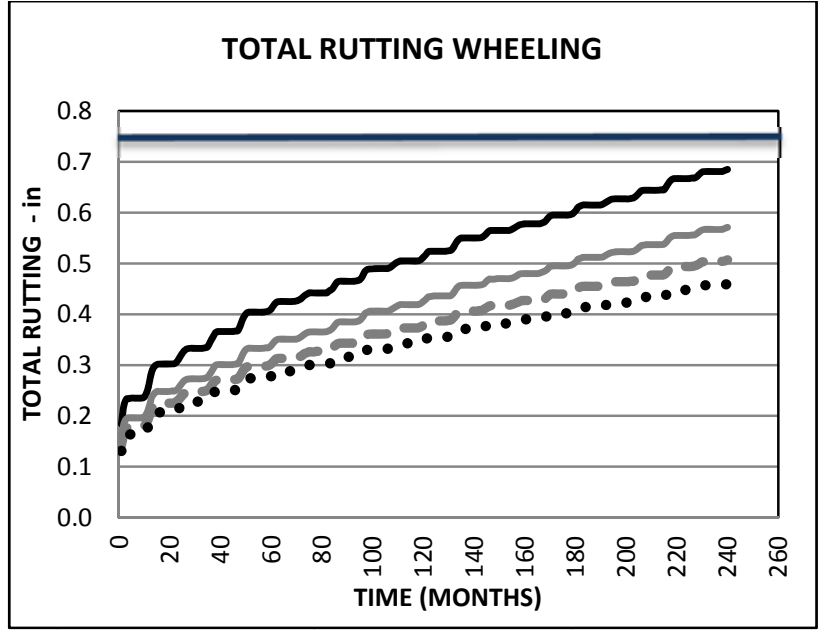

Figure 129: Total Rutting as a function of $P G$

Binder type Structure \#1

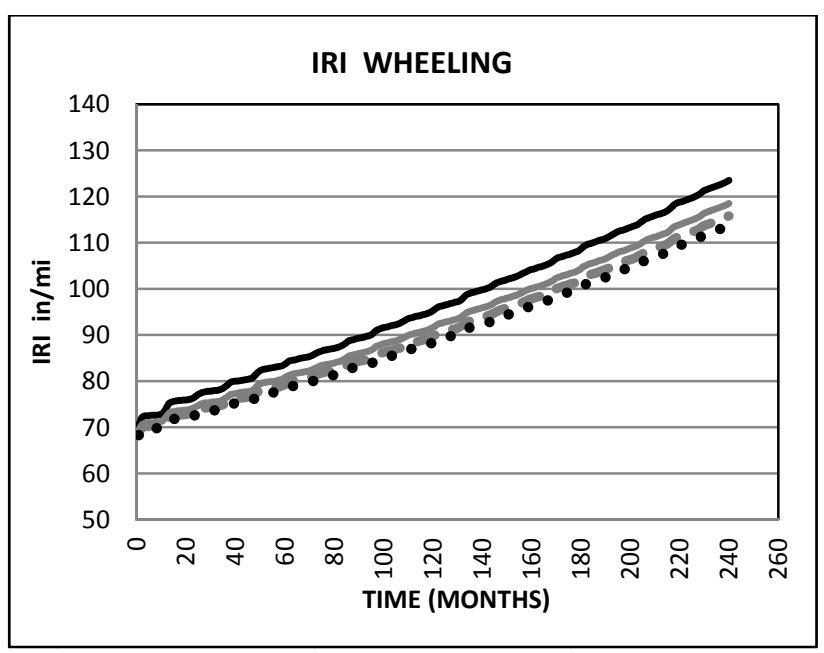

Figure 130: IRI as a function of $P G$ Binder type

Structure \#1

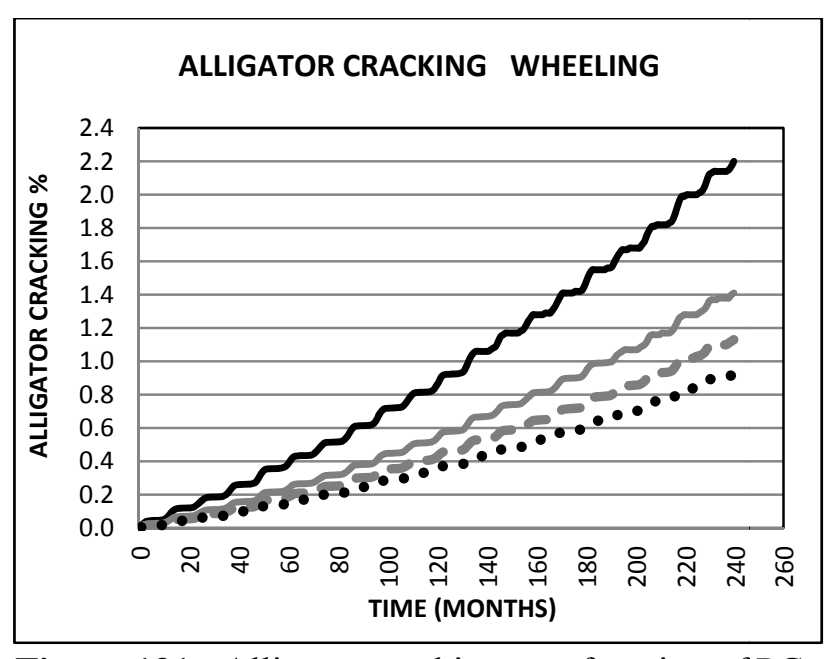

Figure 131: Alligator cracking as a function of $P G$ Binder type Structure \#1

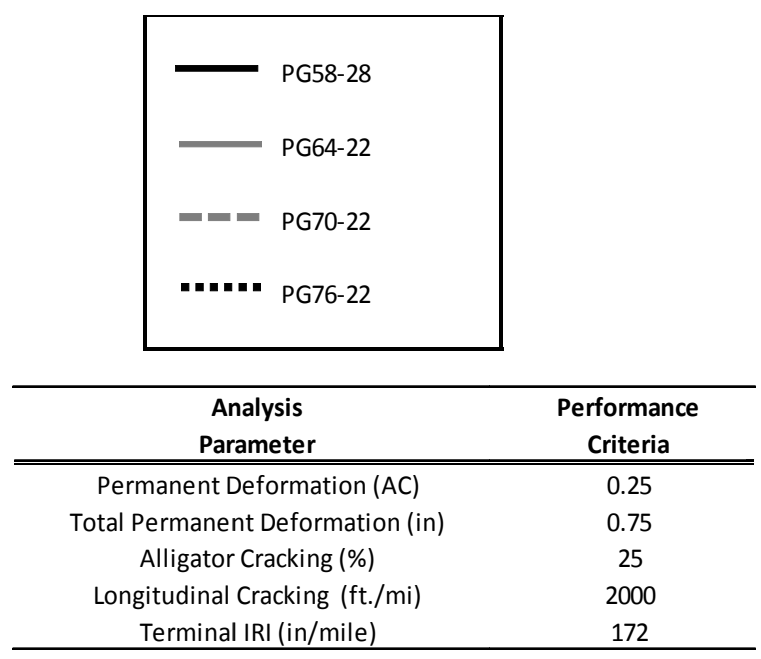




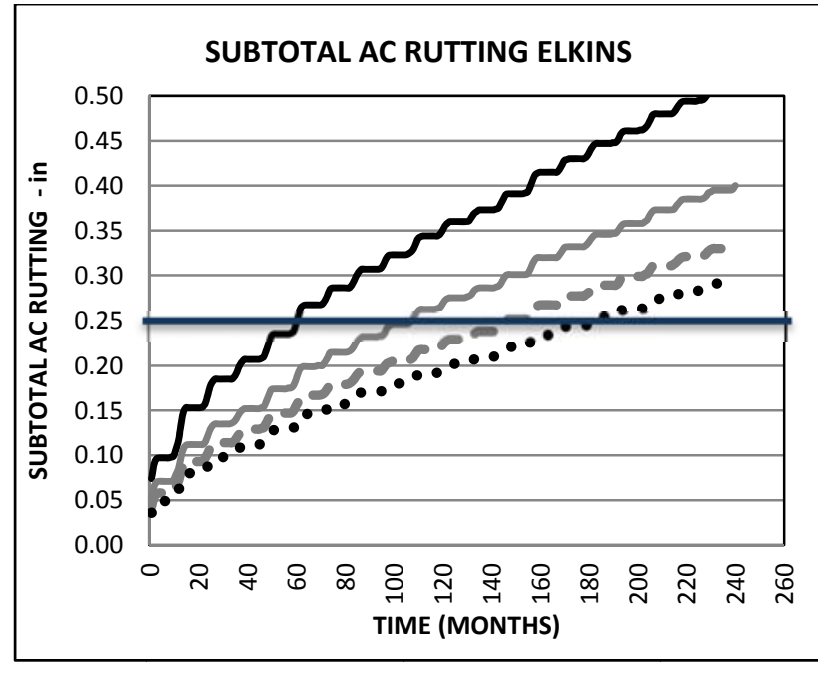

Figure 132: AC Rutting as a function of PG Binder type Structure \#1

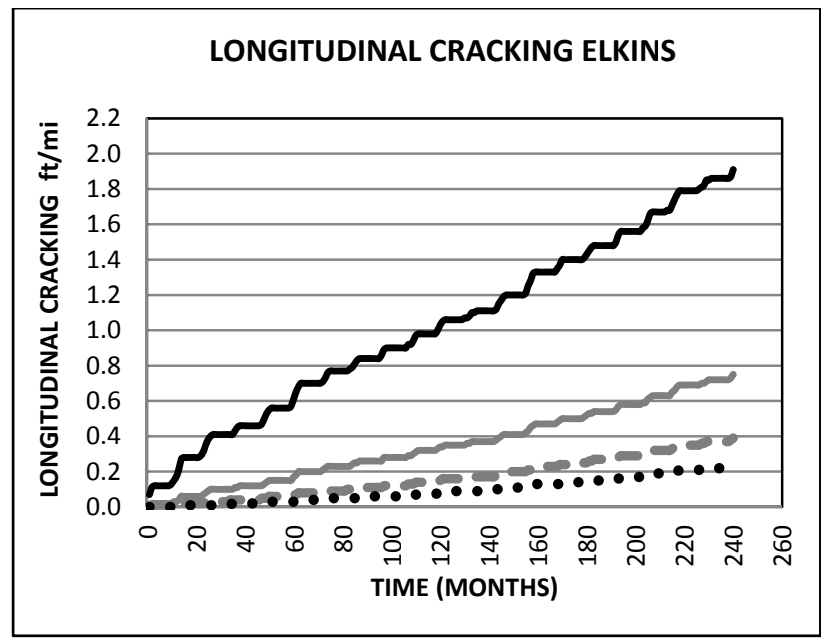

Figure 133: Longitudinal cracking as a function of PG Binder type Structure \#1

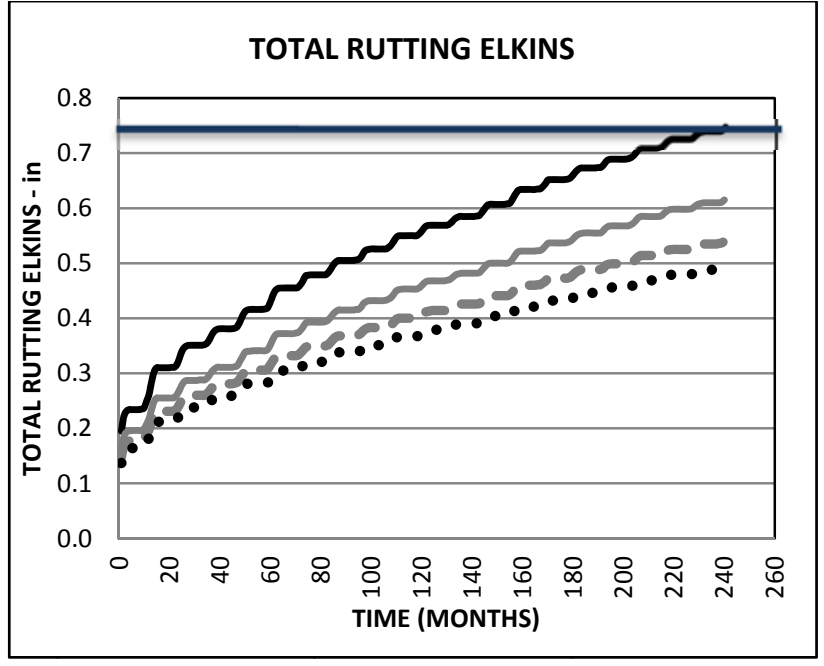

Figure 134: Total Rutting as a function of $P G$ Binder type Structure \#1

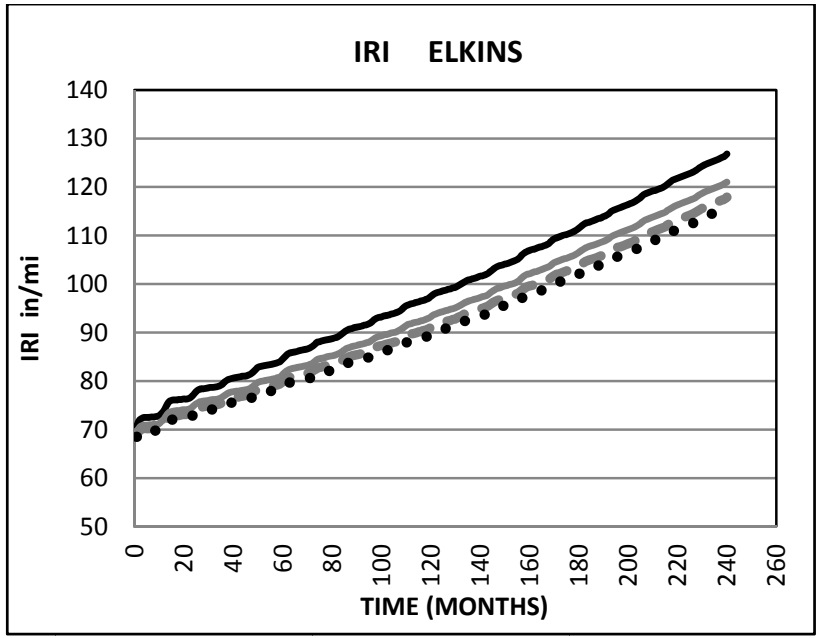

Figure 135: IRI as a function of $\mathrm{PG}$ Binder type Structure \#1

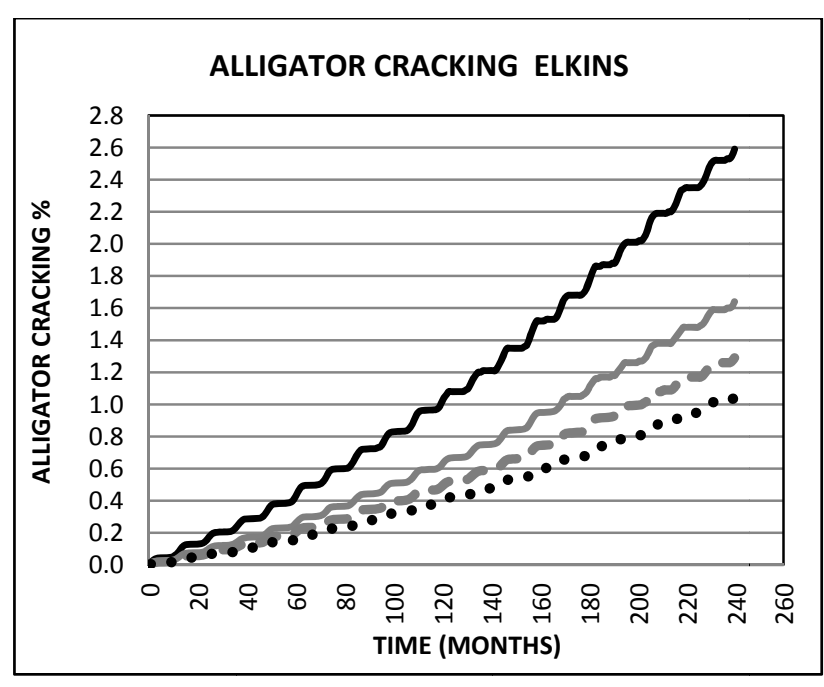

Figure 136: Alligator cracking as a function of $\mathrm{PG}$ Binder type Structure \#1

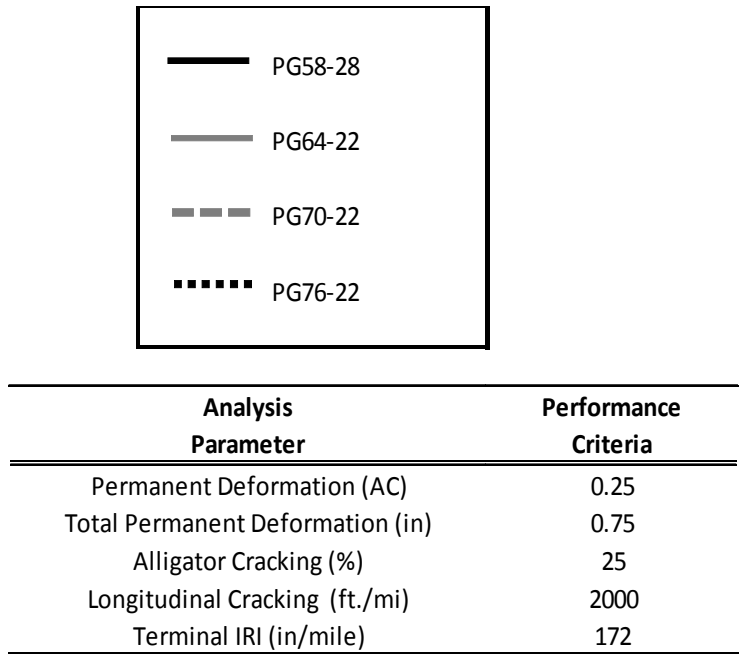




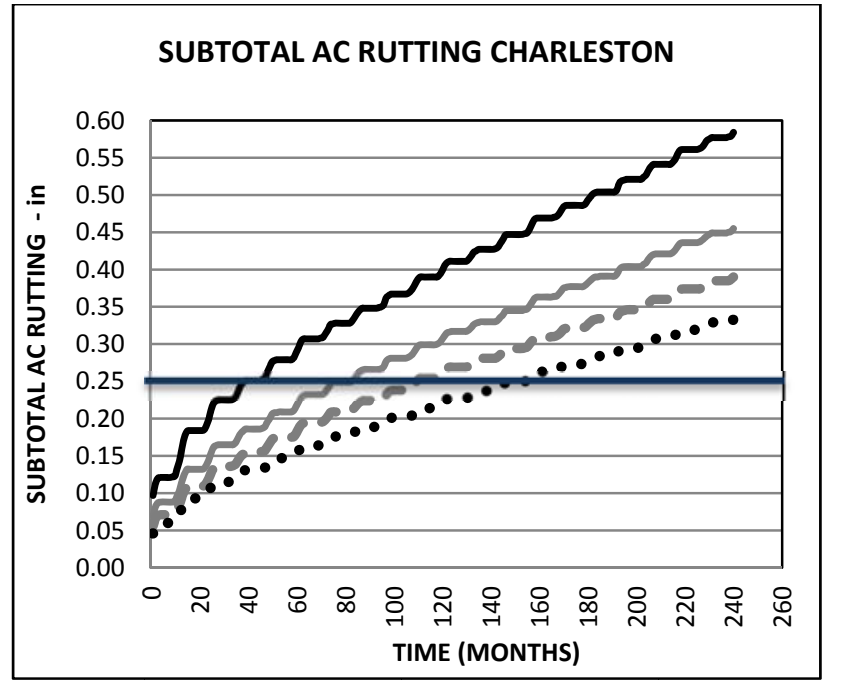

Figure 137: AC Rutting as a function of PG Binder type Structure \#1

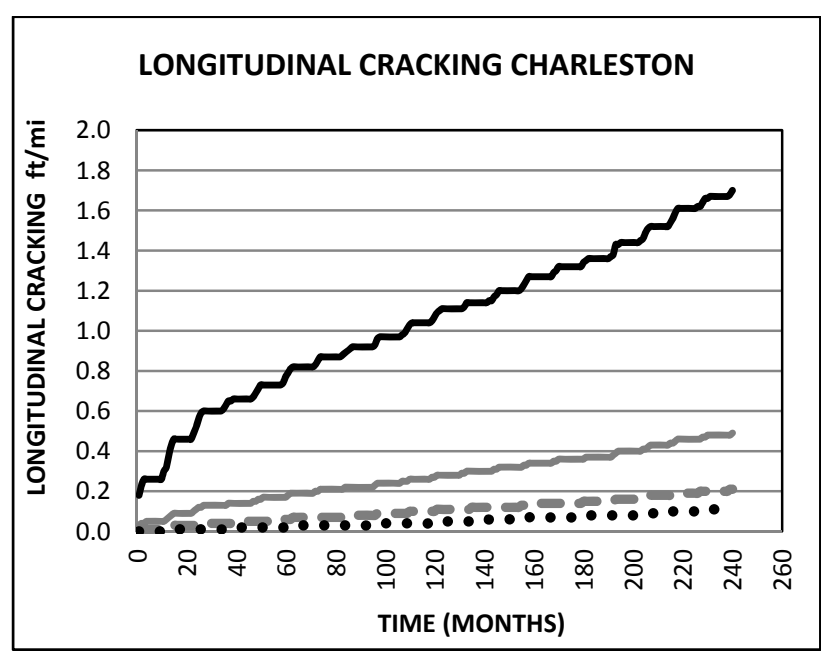

Figure 138: Longitudinal cracking as a function of PG Binder type Structure \#1

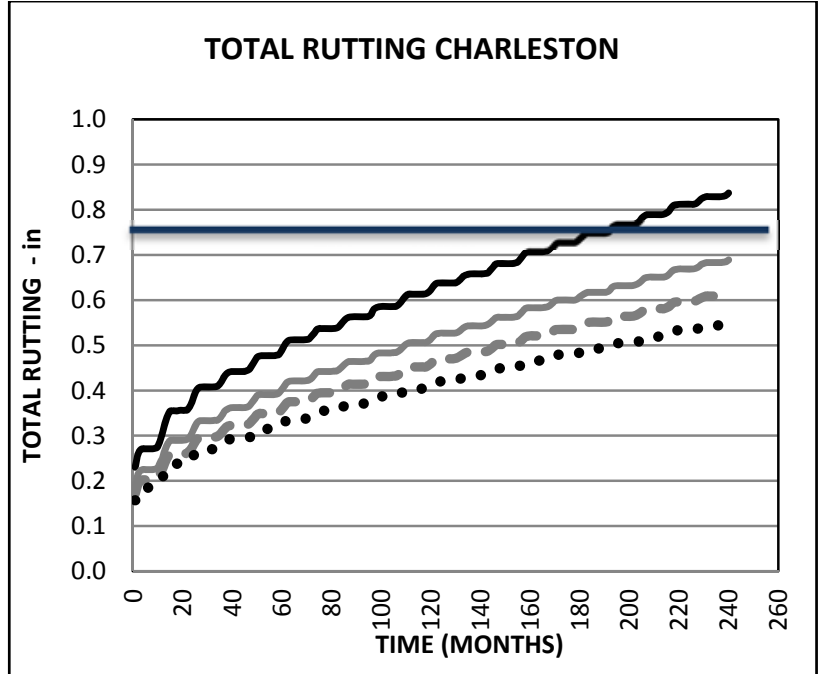

Figure 139: Total Rutting as a function of $P G$ Binder type Structure \#1

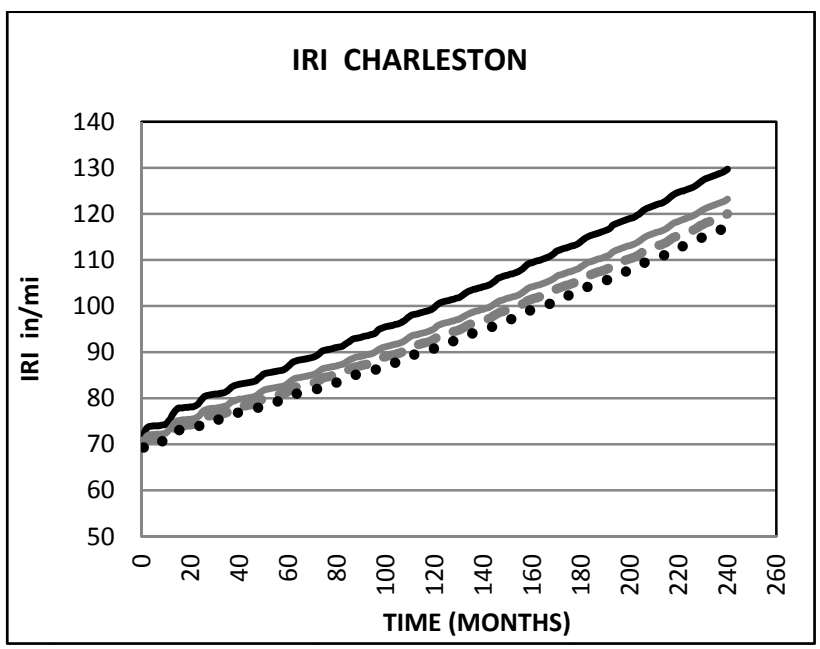

Figure 140: IRI as a function of $P G$ Binder type Structure \#1

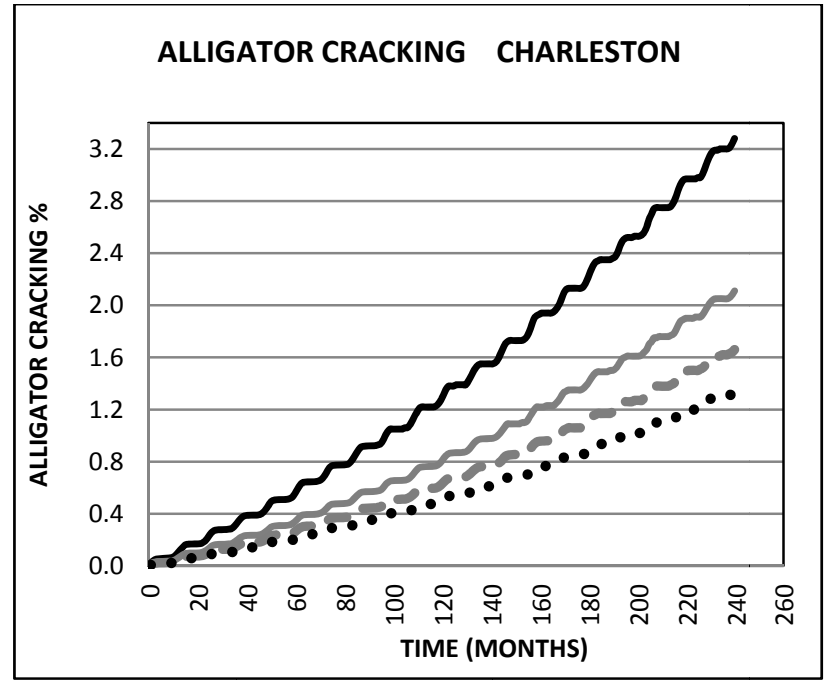

Figure 141: Alligator cracking as a function of $P G$ Binder type Structure \#1

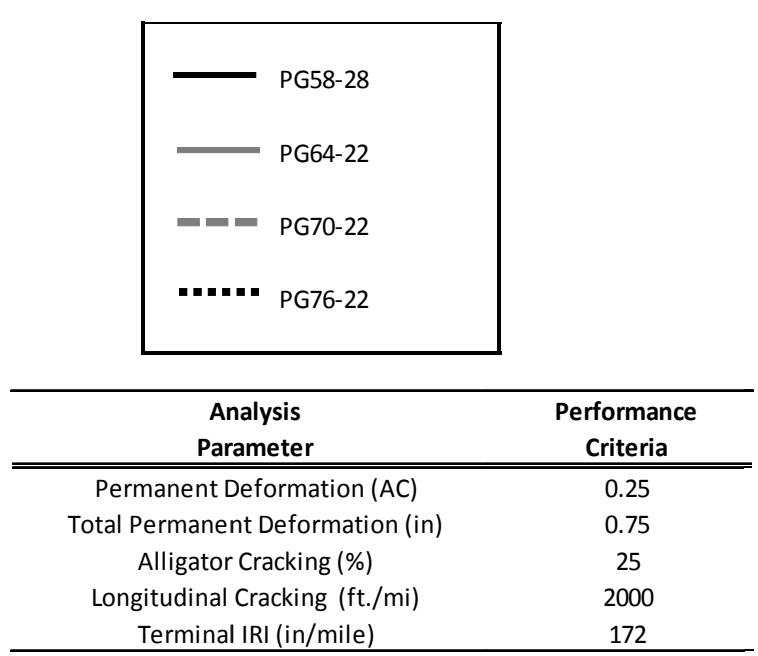




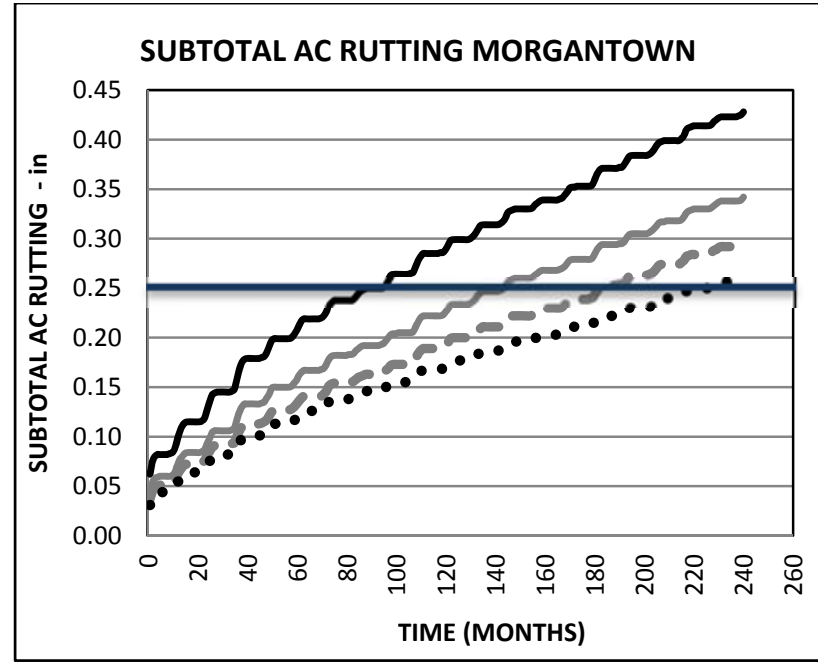

Figure 142: AC Rutting as a function of $P G$ Binder type Structure \#2

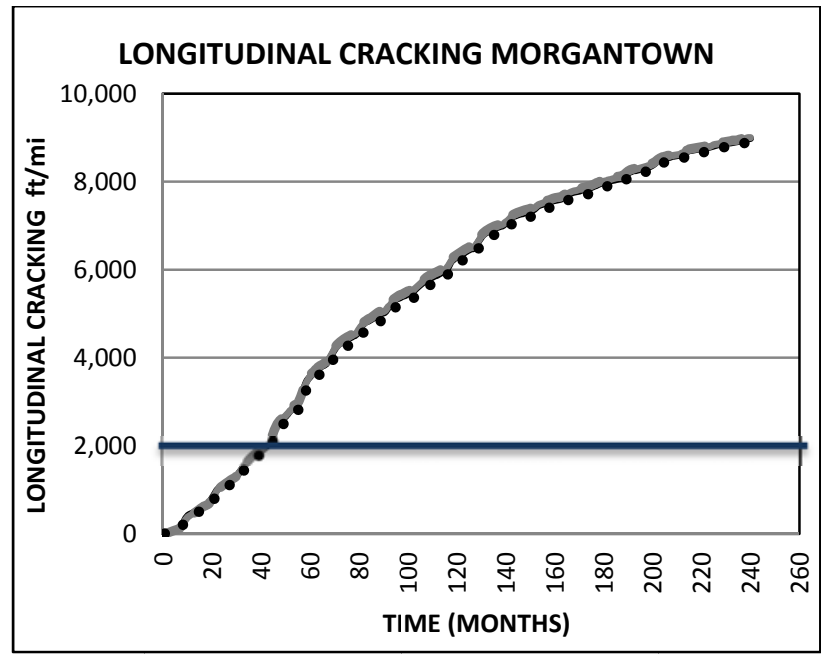

Figure 143: Longitudinal cracking as a function of PG Binder type Structure \#2

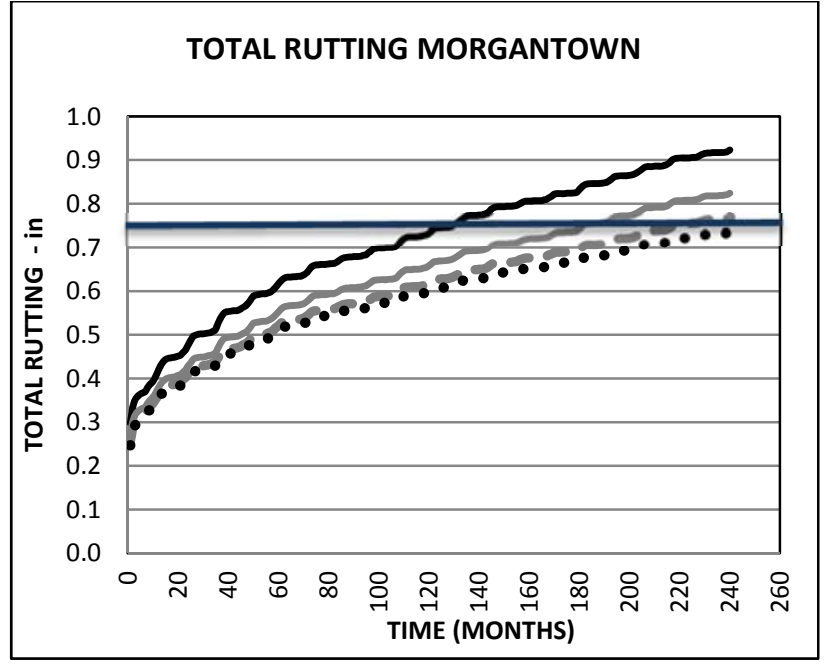

Figure 144: Total Rutting as a function of $\mathrm{PG}$ Binder type Structure \#2

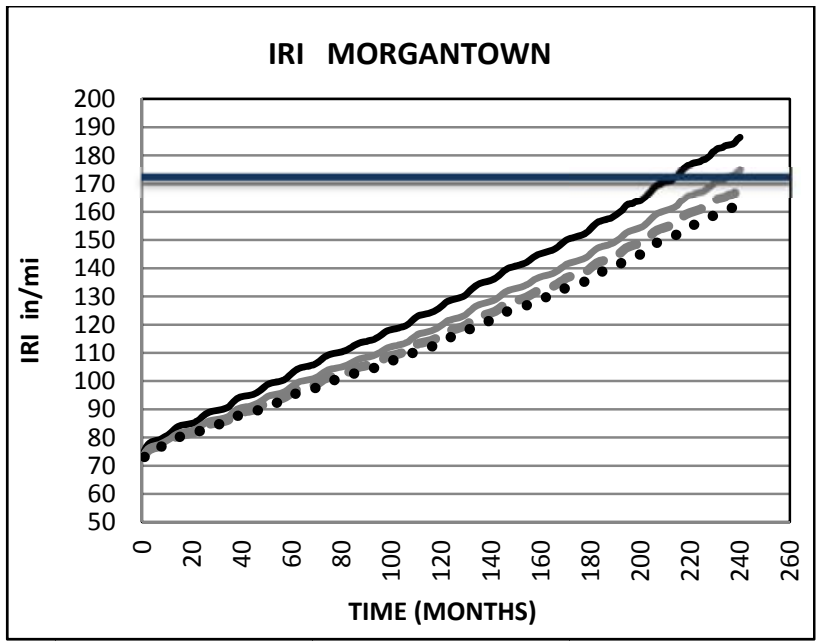

Figure 145: IRI as a function of $\mathrm{PG}$ Binder type Structure \#2

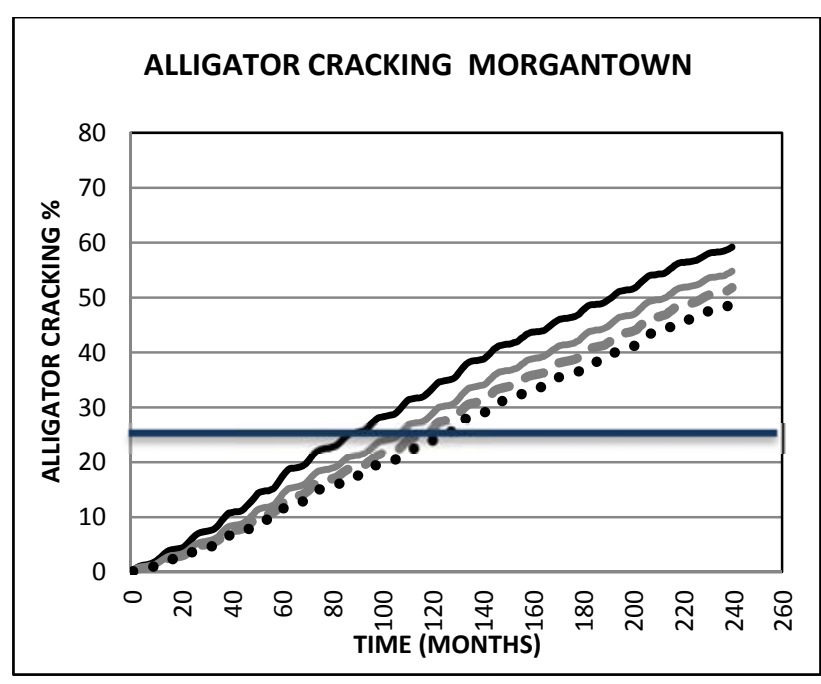

Figure 146: Alligator cracking as a function of $\mathrm{PG}$ Binder type Structure \#2

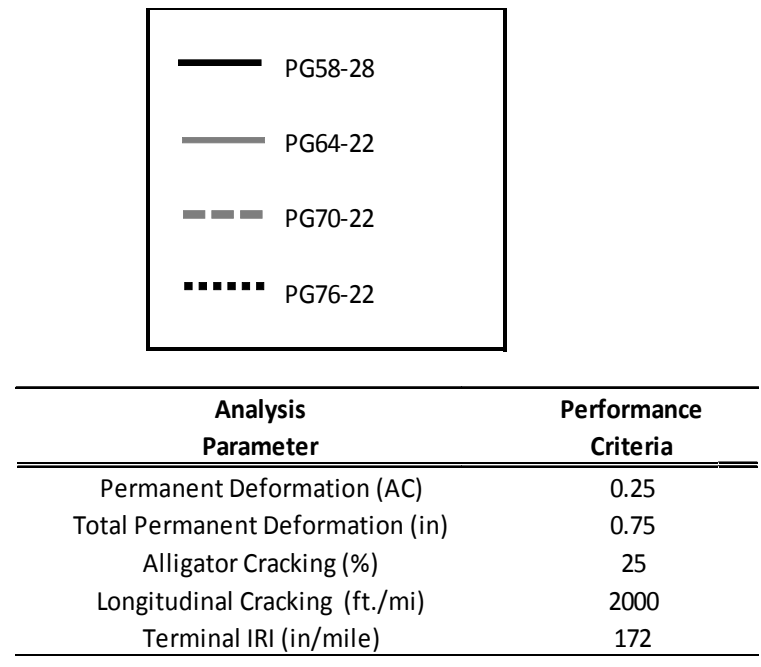




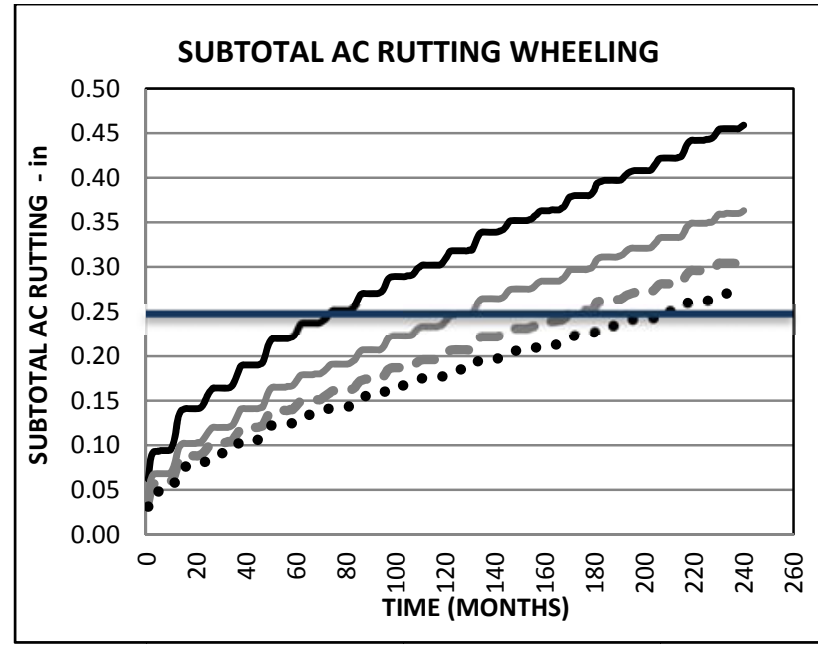

Figure 147: AC Rutting as a function of $P G$ Binder type Structure \#2

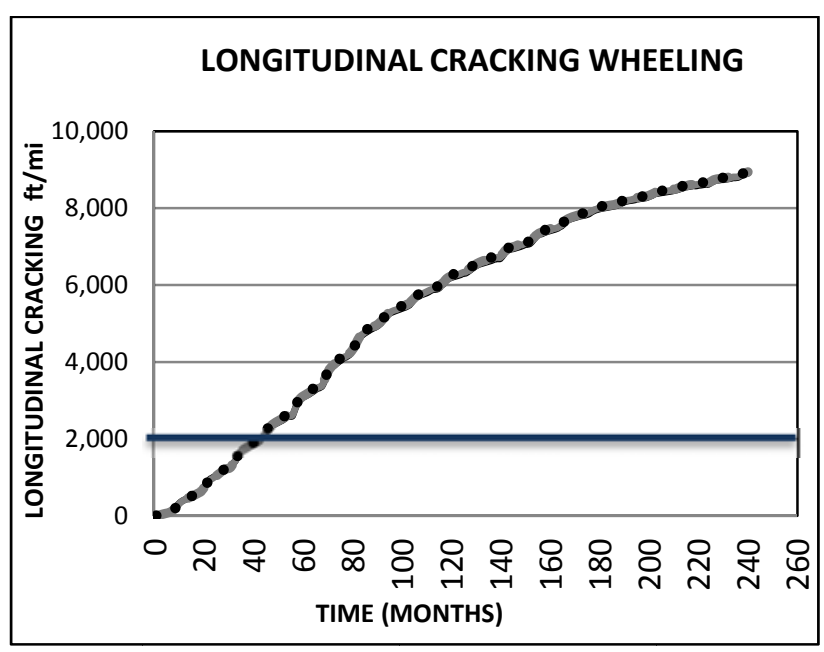

Figure 148: Longitudinal cracking as a function of PG Binder type Structure \#2

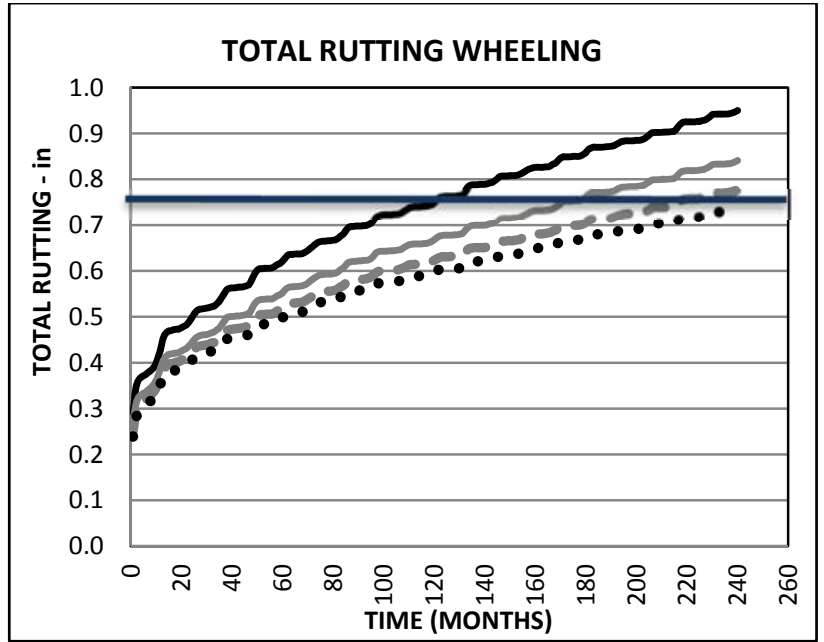

Figure 149: Total Rutting as a function of $P G$ Binder type Structure \#2

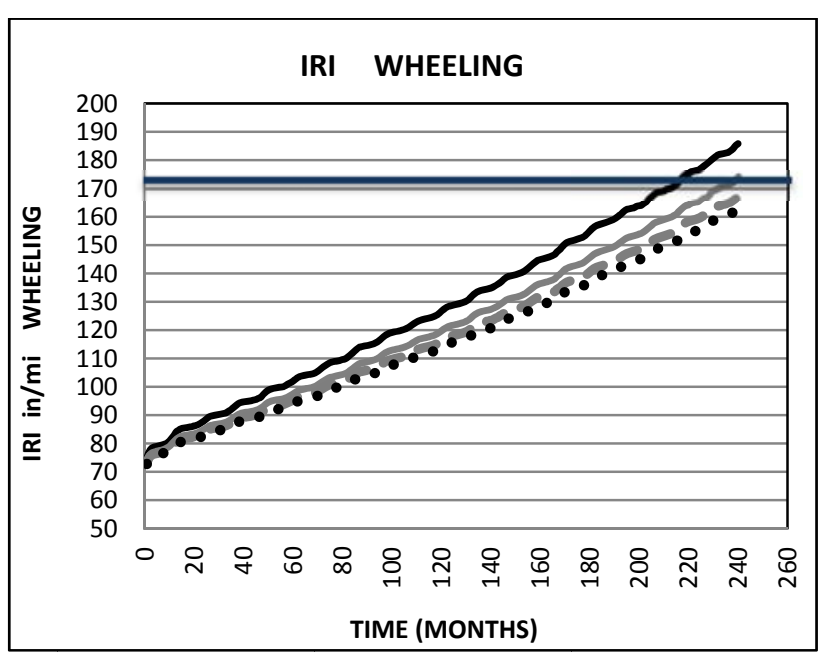

Figure 150: IRI as a function of $P G$ Binder type Structure \#2

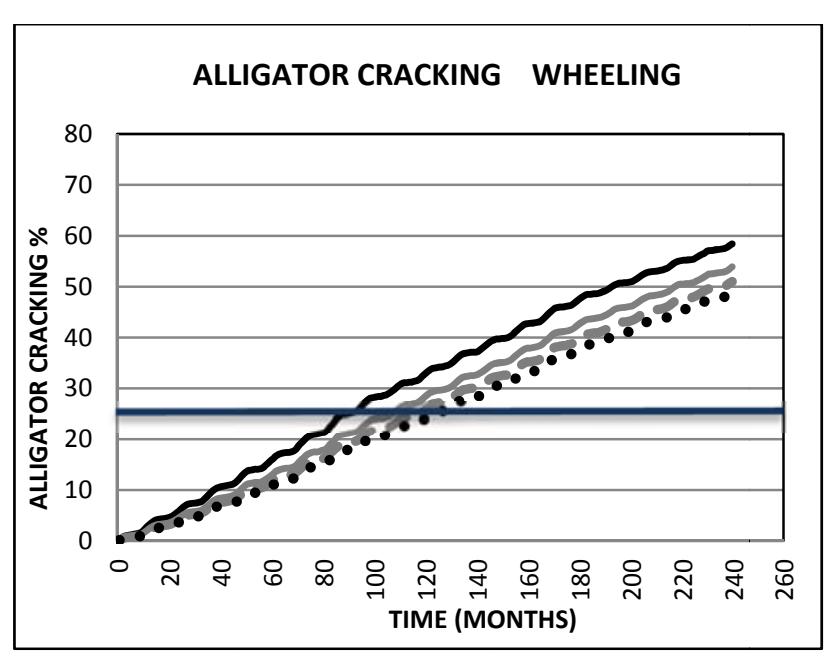

Figure 151: Alligator cracking as a function of $P G$ Binder type Structure \#2

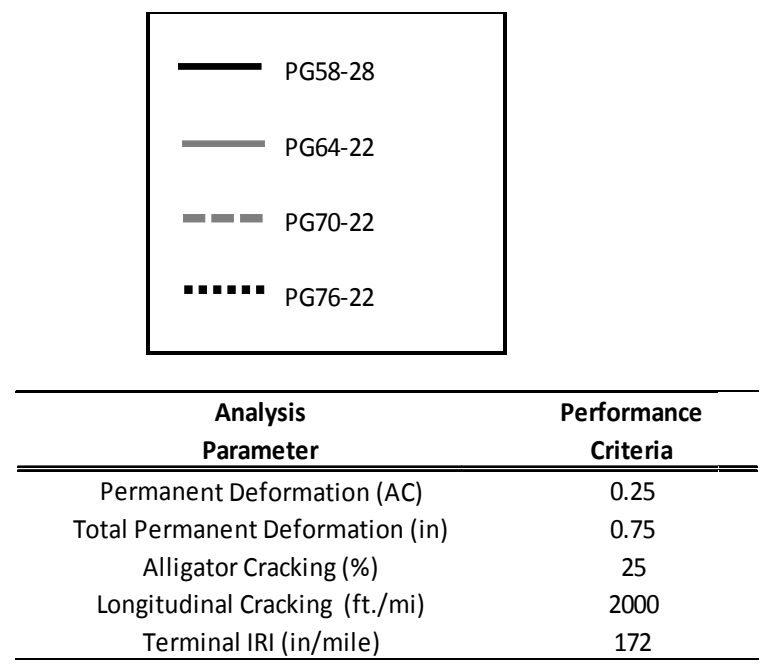




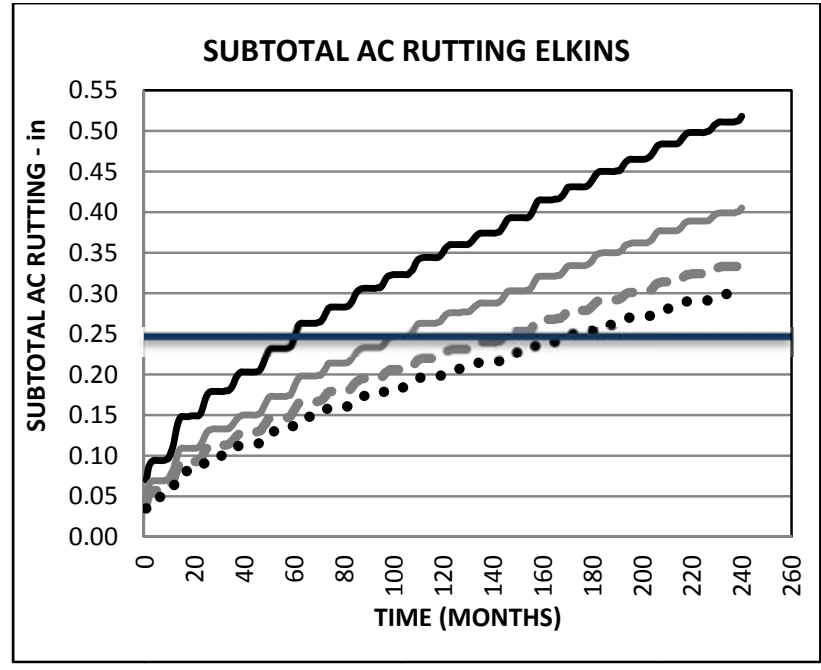

Figure 152: AC Rutting as a function of $\mathrm{PG}$ Binder type Structure \#2

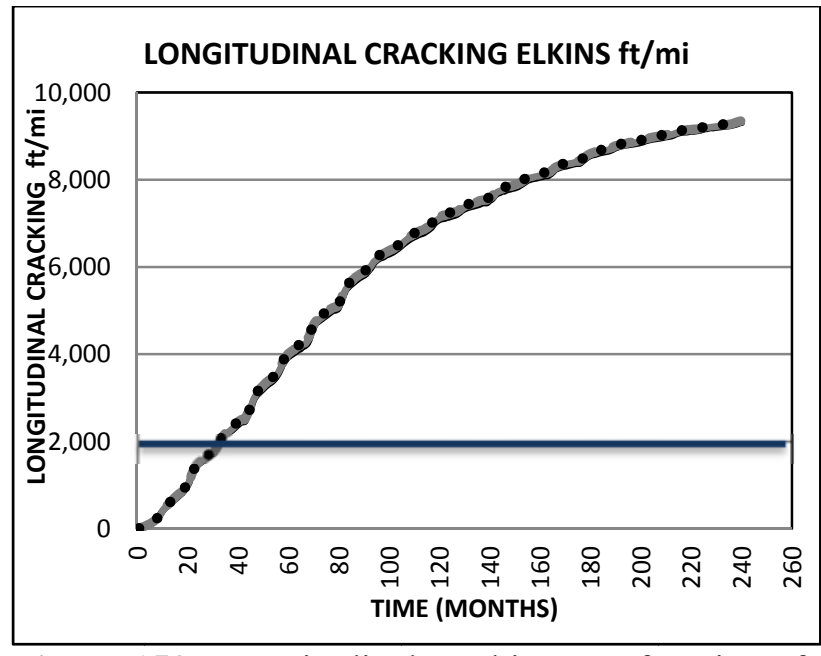

Figure 153: Longitudinal cracking as a function of PG Binder type Structure \#2

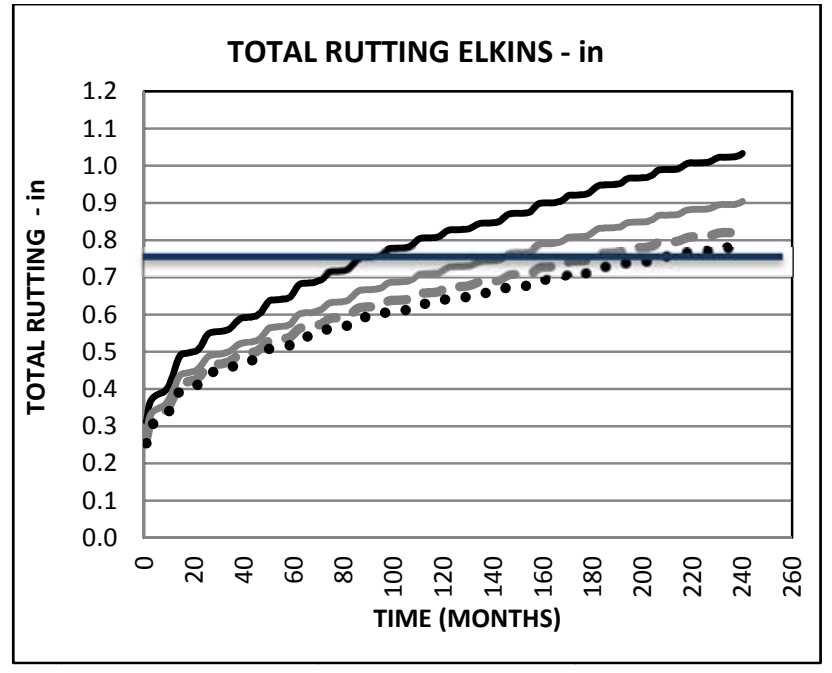

Figure 154: Total Rutting as a function of $P G$ Binder type Structure \#2

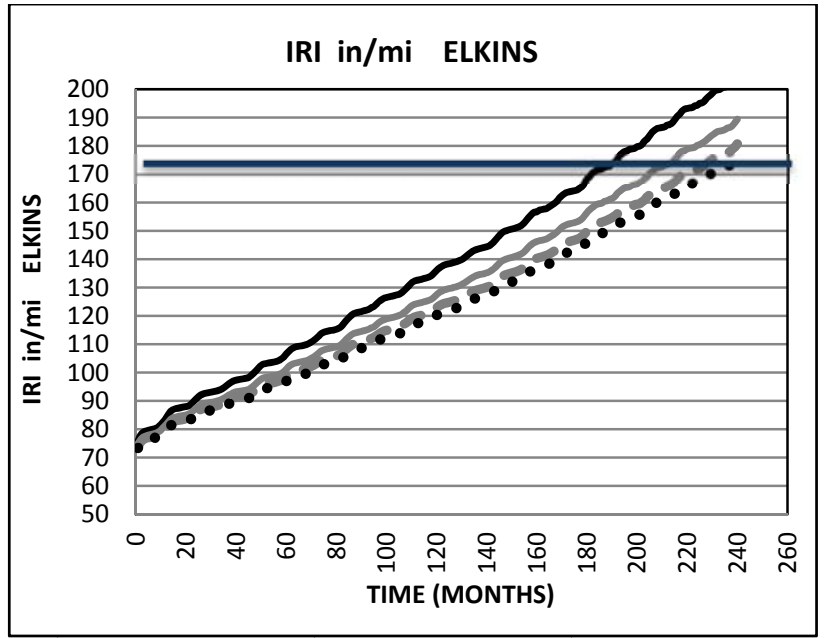

Figure 155: IRI as a function of $P G$ Binder type Structure \#2

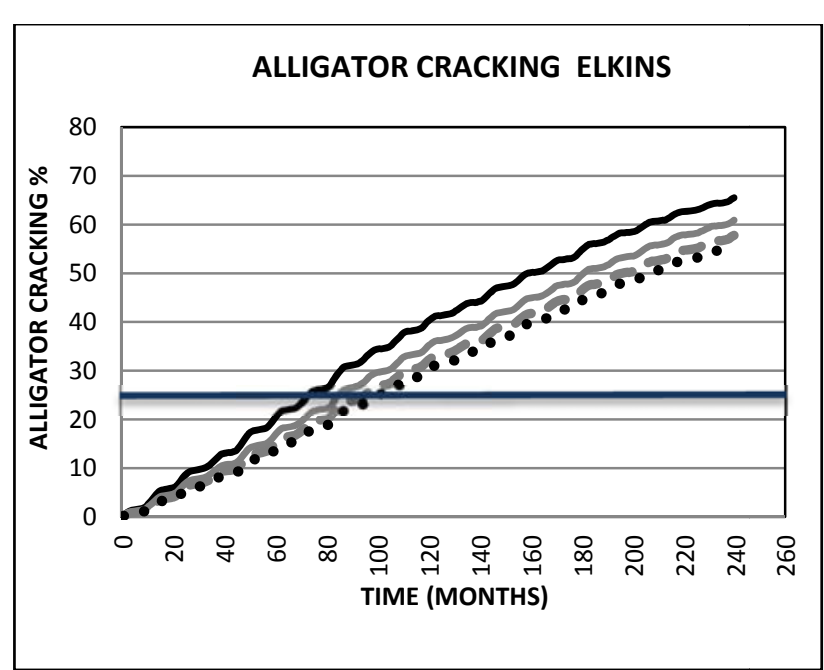

Figure 156: Alligator cracking as a function of $\mathrm{PG}$ Binder type Structure \#2

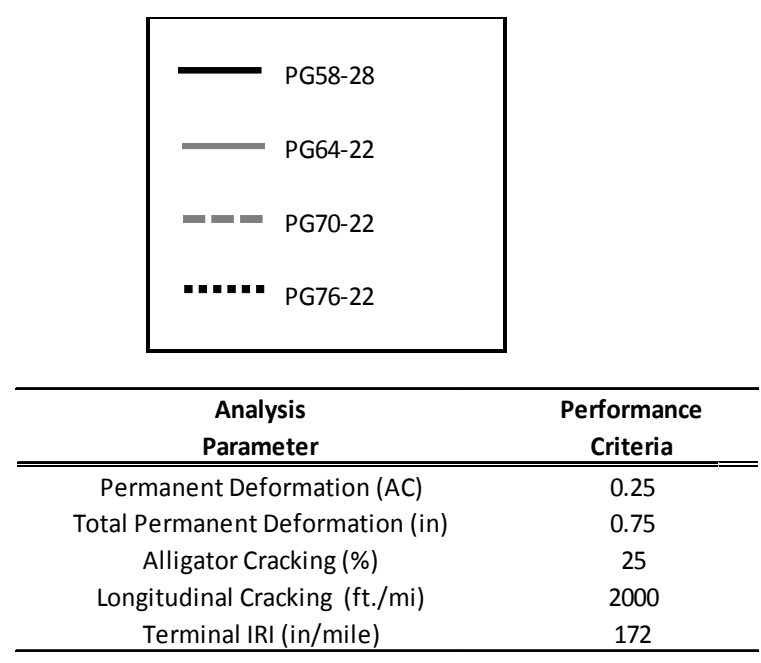




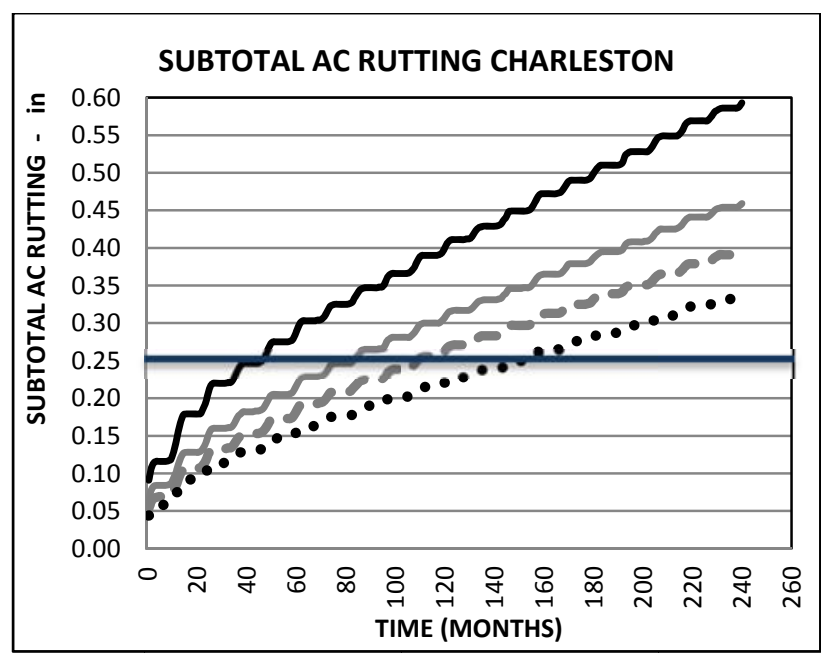

Figure 157: AC Rutting as a function of $P G$ Binder type Structure \#2

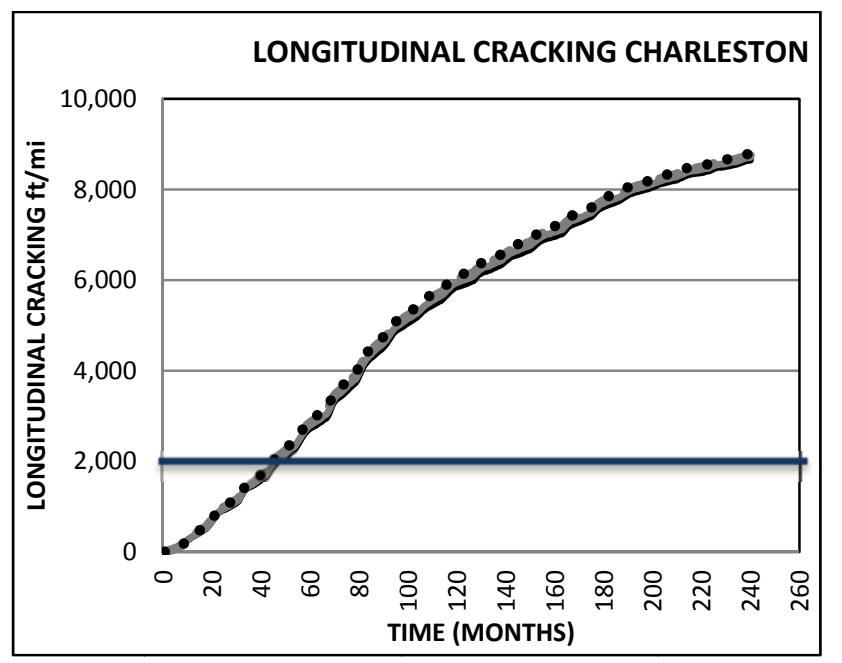

Figure 158: Longitudinal cracking as a function of

PG Binder type Structure \#2

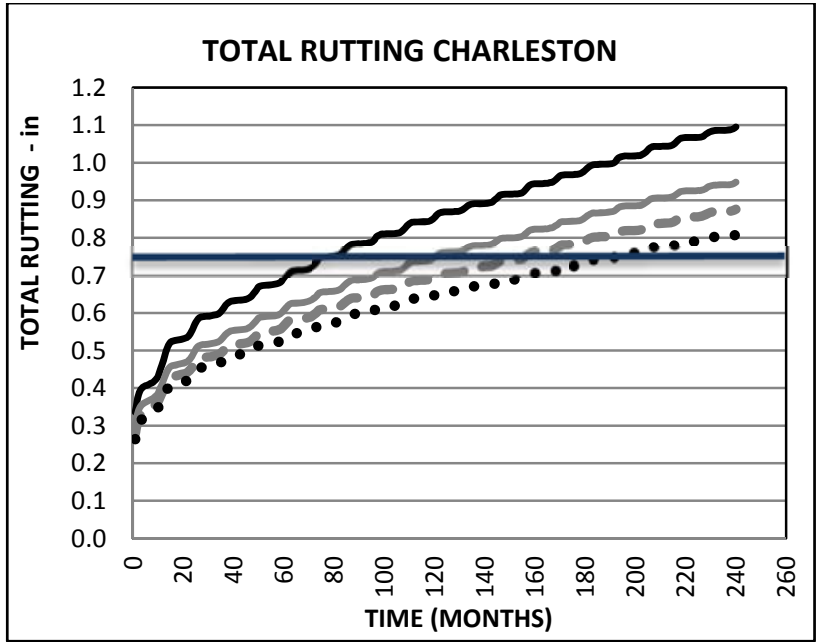

Figure 159: Total Rutting as a function of $P G$ Binder type Structure \#2

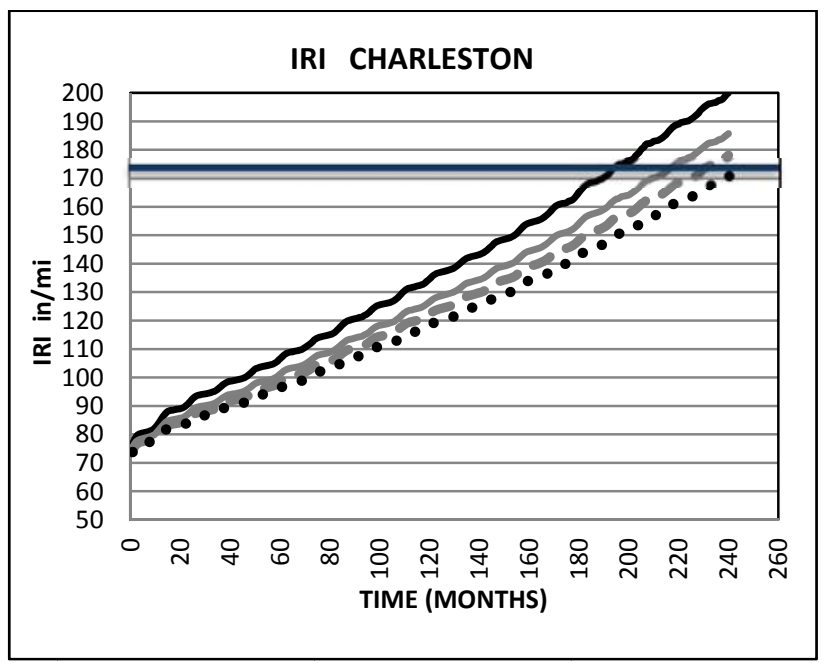

Figure 160: IRI as a function of $P G$ Binder type Structure \#2

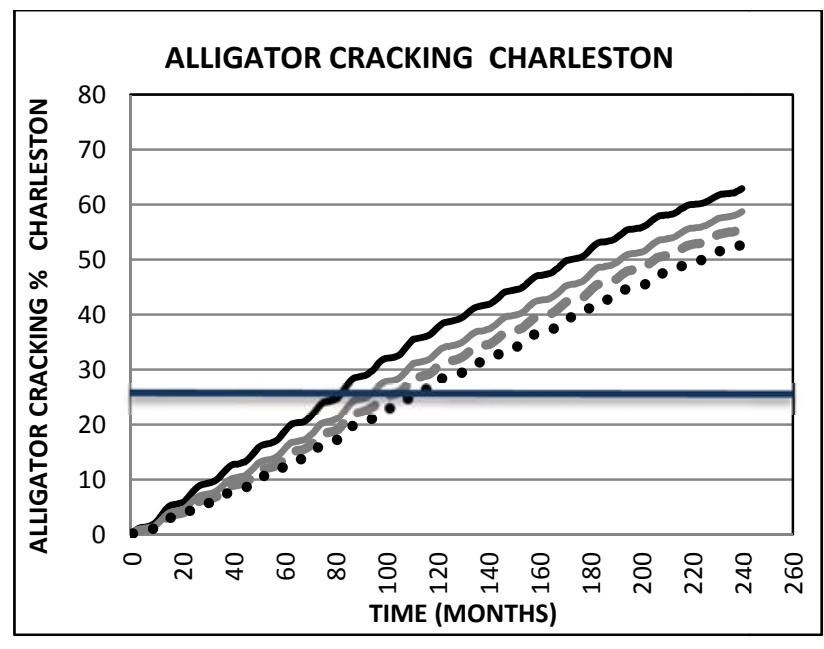

Figure 161: Alligator cracking as a function of $P G$ Binder type Structure \#2

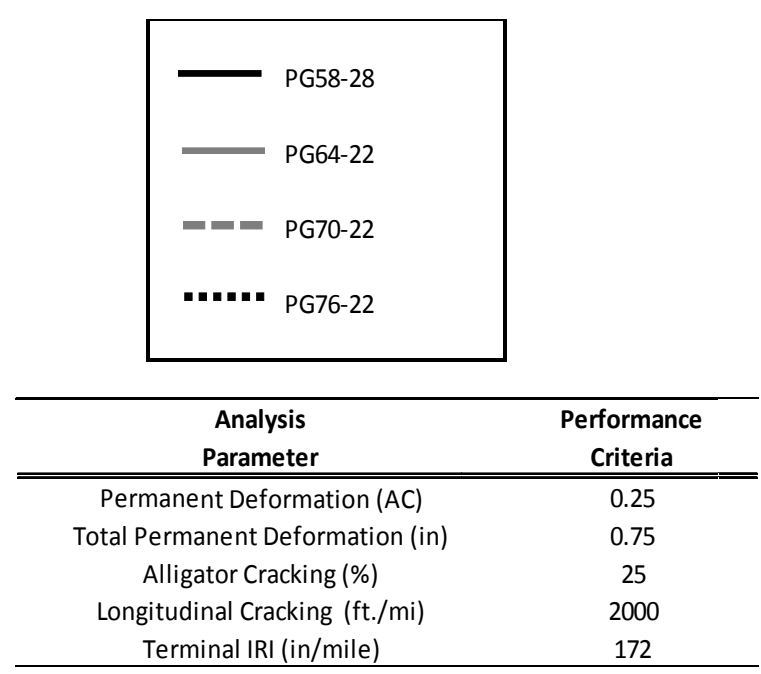


Appendix C Analysis of Viscosity 
Table 18: Viscosity in Bluefield

\begin{tabular}{|c|c|c|c|c|c|c|c|c|c|c|c|c|c|c|c|c|c|c|c|c|c|}
\hline \multicolumn{22}{|c|}{ Log Viscosity Bluefield (cP) } \\
\hline \multirow{2}{*}{$\begin{array}{c}\text { Depth } \\
\text { in }\end{array}$} & \multirow{2}{*}{$\begin{array}{c}\text { Time } \\
\text { Months }\end{array}$} & \multicolumn{5}{|c|}{ PG58-28 } & \multicolumn{5}{|c|}{ PG64-22 } & \multicolumn{5}{|c|}{ PG70-22 } & \multicolumn{5}{|c|}{ PG76-22 } \\
\hline & & 16 & 40 & 70 & 100 & 130 & 16 & 40 & 70 & 100 & 130 & 16 & 40 & 70 & 100 & 130 & 16 & 40 & 70 & 100 & 130 \\
\hline \multirow{5}{*}{0.5} & 1 & 14.77 & 11.53 & 9.11 & 7.44 & 6.18 & 15.60 & 12.20 & 9.66 & 7.91 & 6.57 & 15.57 & 12.32 & 9.89 & 8.21 & 6.91 & 15.56 & 12.43 & 10.10 & 8.48 & 7.22 \\
\hline & 12 & 25.22 & 13.66 & 9.43 & 7.54 & 6.33 & 26.08 & 14.23 & 9.88 & 7.94 & 6.69 & 26.05 & 14.32 & 10.07 & 8.20 & 6.99 & 26.03 & 14.42 & 10.24 & 8.43 & 7.27 \\
\hline & 60 & 36.44 & 15.46 & 9.69 & 7.64 & 6.49 & 37.10 & 15.91 & 10.06 & 7.97 & 6.81 & 37.08 & 15.99 & 10.21 & 8.19 & 7.08 & 37.07 & 16.06 & 10.35 & 8.38 & 7.32 \\
\hline & 180 & 40.47 & 16.04 & 9.77 & 7.67 & 6.56 & 41.02 & 16.45 & 10.11 & 7.99 & 6.86 & 41.00 & 16.52 & 10.26 & 8.19 & 7.11 & 40.99 & 16.59 & 10.38 & 8.37 & 7.34 \\
\hline & 240 & 41.06 & 16.13 & 9.79 & 7.68 & 6.57 & 41.60 & 16.53 & 10.12 & 7.99 & 6.86 & 41.58 & 16.59 & 10.26 & 8.18 & 7.12 & 41.57 & 16.66 & 10.39 & 8.37 & 7.34 \\
\hline \multirow{5}{*}{1.0} & 1 & 14.17 & 11.38 & 9.09 & 7.44 & 6.17 & 14.99 & 12.06 & 9.64 & 7.90 & 6.57 & 14.96 & 12.18 & 9.88 & 8.21 & 6.90 & 14.95 & 12.29 & 10.09 & 8.48 & 7.22 \\
\hline & 12 & 20.26 & 12.62 & 9.27 & 7.49 & 6.26 & 21.10 & 13.24 & 9.77 & 7.92 & 6.63 & 21.06 & 13.34 & 9.98 & 8.20 & 6.95 & 21.05 & 13.45 & 10.17 & 8.45 & 7.25 \\
\hline & 60 & 26.80 & 13.67 & 9.42 & 7.55 & 6.35 & 27.52 & 14.22 & 9.88 & 7.94 & 6.70 & 27.50 & 14.31 & 10.06 & 8.20 & 7.00 & 27.49 & 14.40 & 10.24 & 8.43 & 7.28 \\
\hline & 180 & 29.15 & 14.01 & 9.47 & 7.57 & 6.39 & 29.81 & 14.53 & 9.91 & 7.95 & 6.73 & 29.78 & 14.62 & 10.09 & 8.19 & 7.02 & 29.77 & 14.71 & 10.26 & 8.42 & 7.29 \\
\hline & 240 & 29.49 & 14.06 & 9.48 & 7.57 & 6.39 & 30.14 & 14.58 & 9.91 & 7.95 & 6.73 & 30.12 & 14.67 & 10.09 & 8.19 & 7.02 & 30.11 & 14.75 & 10.26 & 8.42 & 7.29 \\
\hline \multirow{5}{*}{3.0} & 1 & 13.64 & 11.25 & 9.07 & 7.43 & 6.16 & 14.46 & 11.93 & 9.63 & 7.90 & 6.56 & 14.43 & 12.05 & 9.87 & 8.21 & 6.90 & 14.41 & 12.16 & 10.08 & 8.49 & 7.21 \\
\hline & 12 & 15.93 & 11.71 & 9.13 & 7.45 & 6.19 & 16.74 & 12.37 & 9.68 & 7.91 & 6.58 & 16.71 & 12.49 & 9.90 & 8.20 & 6.92 & 16.70 & 12.60 & 10.11 & 8.48 & 7.23 \\
\hline & 60 & 18.38 & 12.10 & 9.19 & 7.47 & 6.23 & 19.15 & 12.74 & 9.72 & 7.92 & 6.61 & 19.12 & 12.85 & 9.94 & 8.20 & 6.94 & 19.11 & 12.96 & 10.14 & 8.47 & 7.24 \\
\hline & 180 & 19.26 & 12.23 & 9.21 & 7.48 & 6.24 & 20.01 & 12.86 & 9.73 & 7.92 & 6.62 & 19.98 & 12.97 & 9.95 & 8.20 & 6.94 & 19.97 & 13.07 & 10.15 & 8.46 & 7.24 \\
\hline & 240 & 19.39 & 12.25 & 9.21 & 7.48 & 6.24 & 20.13 & 12.87 & 9.73 & 7.92 & 6.62 & 20.11 & 12.98 & 9.95 & 8.20 & 6.94 & 20.10 & 13.09 & 10.15 & 8.46 & 7.24 \\
\hline \multirow{5}{*}{5.0} & 1 & 13.52 & 11.22 & 9.06 & 7.43 & 6.16 & 14.33 & 11.90 & 9.63 & 7.90 & 6.56 & 14.30 & 12.02 & 9.86 & 8.21 & 6.90 & 14.29 & 12.13 & 10.08 & 8.49 & 7.21 \\
\hline & 12 & 14.93 & 11.50 & 9.10 & 7.44 & 6.18 & 15.74 & 12.17 & 9.66 & 7.91 & 6.57 & 15.71 & 12.29 & 9.89 & 8.21 & 6.91 & 15.70 & 12.40 & 10.10 & 8.48 & 7.22 \\
\hline & 60 & 16.44 & 11.74 & 9.14 & 7.45 & 6.20 & 17.22 & 12.40 & 9.68 & 7.91 & 6.59 & 17.19 & 12.51 & 9.91 & 8.20 & 6.92 & 17.18 & 12.62 & 10.12 & 8.47 & 7.23 \\
\hline & 180 & 16.98 & 11.82 & 9.15 & 7.46 & 6.21 & 17.75 & 12.47 & 9.69 & 7.91 & 6.60 & 17.72 & 12.58 & 9.91 & 8.20 & 6.93 & 17.71 & 12.69 & 10.12 & 8.47 & 7.23 \\
\hline & 240 & 17.06 & 11.83 & 9.15 & 7.46 & 6.21 & 17.83 & 12.48 & 9.69 & 7.91 & 6.60 & 17.80 & 12.59 & 9.91 & 8.20 & 6.93 & 17.79 & 12.70 & 10.12 & 8.47 & 7.23 \\
\hline \multirow{5}{*}{15.0} & 1 & 13.40 & 11.18 & 9.06 & 7.43 & 6.16 & 14.20 & 11.87 & 9.62 & 7.90 & 6.56 & 14.17 & 11.99 & 9.86 & 8.21 & 6.90 & 14.16 & 12.10 & 10.08 & 8.49 & 7.21 \\
\hline & 12 & 13.88 & 11.28 & 9.07 & 7.43 & 6.16 & 14.68 & 11.96 & 9.63 & 7.90 & 6.56 & 14.65 & 12.08 & 9.87 & 8.21 & 6.90 & 14.64 & 12.20 & 10.09 & 8.49 & 7.22 \\
\hline & 60 & 14.39 & 11.36 & 9.08 & 7.44 & 6.17 & 15.19 & 12.04 & 9.64 & 7.90 & 6.57 & 15.16 & 12.16 & 9.88 & 8.21 & 6.91 & 15.15 & 12.27 & 10.09 & 8.48 & 7.22 \\
\hline & 180 & 14.58 & 11.39 & 9.09 & 7.44 & 6.17 & 15.37 & 12.06 & 9.64 & 7.90 & 6.57 & 15.34 & 12.18 & 9.88 & 8.21 & 6.91 & 15.33 & 12.30 & 10.09 & 8.48 & 7.22 \\
\hline & 240 & 14.60 & 11.39 & 9.09 & 7.44 & 6.17 & 15.40 & 12.07 & 9.64 & 7.90 & 6.57 & 15.37 & 12.18 & 9.88 & 8.21 & 6.91 & 15.36 & 12.30 & 10.09 & 8.48 & 7.22 \\
\hline \multirow{5}{*}{18.0} & 1 & 13.38 & 11.18 & 9.06 & 7.43 & 6.15 & 14.19 & 11.87 & 9.62 & 7.90 & 6.56 & 14.16 & 11.99 & 9.86 & 8.21 & 6.90 & 14.15 & 12.10 & 10.08 & 8.49 & 7.21 \\
\hline & 12 & 13.79 & 11.26 & 9.07 & 7.43 & 6.16 & 14.59 & 11.94 & 9.63 & 7.90 & 6.56 & 14.56 & 12.06 & 9.87 & 8.21 & 6.90 & 14.55 & 12.18 & 10.09 & 8.49 & 7.21 \\
\hline & 60 & 14.22 & 11.33 & 9.08 & 7.43 & 6.17 & 15.02 & 12.01 & 9.64 & 7.90 & 6.56 & 14.99 & 12.13 & 9.87 & 8.21 & 6.90 & 14.98 & 12.24 & 10.09 & 8.48 & 7.22 \\
\hline & 180 & 14.37 & 11.35 & 9.08 & 7.44 & 6.17 & 15.17 & 12.03 & 9.64 & 7.90 & 6.57 & 15.14 & 12.15 & 9.87 & 8.21 & 6.91 & 15.13 & 12.26 & 10.09 & 8.48 & 7.22 \\
\hline & 240 & 14.39 & 11.36 & 9.08 & 7.44 & 6.17 & 15.19 & 12.03 & 9.64 & 7.90 & 6.57 & 15.16 & 12.15 & 9.87 & 8.21 & 6.91 & 15.15 & 12.26 & 10.09 & 8.48 & 7.22 \\
\hline
\end{tabular}


Table 19: Viscosity in Morgantown

\begin{tabular}{|c|c|c|c|c|c|c|c|c|c|c|c|c|c|c|c|c|c|c|c|c|c|}
\hline \multicolumn{22}{|c|}{ Log Viscosity Morgantown (cP) } \\
\hline \multirow{2}{*}{$\begin{array}{c}\text { Depth } \\
\text { in } \\
\end{array}$} & \multirow{2}{*}{$\begin{array}{c}\text { Time } \\
\text { Months } \\
\end{array}$} & \multicolumn{5}{|c|}{ PG58-28 } & \multicolumn{5}{|c|}{ PG64-22 } & \multicolumn{5}{|c|}{ PG70-22 } & \multicolumn{5}{|c|}{ PG76-22 } \\
\hline & & 16 & 40 & 70 & 100 & 130 & 16 & 40 & 70 & 100 & 130 & 16 & 40 & 70 & 100 & 130 & 16 & 40 & 70 & 100 & 130 \\
\hline \multirow{5}{*}{0.5} & 1 & 14.82 & 11.55 & 9.12 & 7.45 & 6.18 & 15.65 & 12.22 & 9.67 & 7.91 & 6.57 & 15.62 & 12.34 & 9.90 & 8.21 & 6.91 & 15.61 & 12.45 & 10.11 & 8.48 & 7.22 \\
\hline & 12 & 25.72 & 13.79 & 9.47 & 7.57 & 6.35 & 26.59 & 14.36 & 9.92 & 7.97 & 6.71 & 26.56 & 14.46 & 10.11 & 8.22 & 7.01 & 26.54 & 14.55 & 10.28 & 8.45 & 7.29 \\
\hline & 60 & 37.55 & 15.71 & 9.77 & 7.68 & 6.53 & 38.22 & 16.15 & 10.14 & 8.02 & 6.84 & 38.20 & 16.23 & 10.29 & 8.23 & 7.11 & 38.19 & 16.31 & 10.43 & 8.42 & 7.35 \\
\hline & 180 & 41.81 & 16.33 & 9.86 & 7.72 & 6.59 & 42.37 & 16.73 & 10.20 & 8.03 & 6.89 & 42.35 & 16.80 & 10.34 & 8.23 & 7.15 & 42.34 & 16.87 & 10.47 & 8.41 & 7.38 \\
\hline & 240 & 42.44 & 16.42 & 9.88 & 7.73 & 6.60 & 42.98 & 16.81 & 10.21 & 8.04 & 6.90 & 42.96 & 16.88 & 10.35 & 8.23 & 7.15 & 42.96 & 16.95 & 10.48 & 8.41 & 7.38 \\
\hline \multirow{5}{*}{1.0} & 1 & 14.21 & 11.39 & 9.09 & 7.44 & 6.17 & 15.03 & 12.07 & 9.65 & 7.91 & 6.57 & 15.00 & 12.19 & 9.88 & 8.21 & 6.91 & 14.99 & 12.30 & 10.10 & 8.49 & 7.22 \\
\hline & 12 & 20.62 & 12.71 & 9.30 & 7.51 & 6.27 & 21.47 & 13.33 & 9.80 & 7.94 & 6.64 & 21.43 & 13.44 & 10.01 & 8.21 & 6.96 & 21.42 & 13.54 & 10.20 & 8.47 & 7.26 \\
\hline & 60 & 27.59 & 13.84 & 9.47 & 7.58 & 6.37 & 28.31 & 14.39 & 9.92 & 7.97 & 6.72 & 28.29 & 14.48 & 10.11 & 8.22 & 7.02 & 28.28 & 14.57 & 10.28 & 8.45 & 7.30 \\
\hline & 180 & 30.10 & 14.21 & 9.53 & 7.60 & 6.41 & 30.76 & 14.73 & 9.96 & 7.98 & 6.76 & 30.73 & 14.81 & 10.14 & 8.22 & 7.04 & 30.72 & 14.90 & 10.31 & 8.44 & 7.31 \\
\hline & 240 & 30.47 & 14.26 & 9.54 & 7.60 & 6.42 & 31.12 & 14.77 & 9.97 & 7.98 & 6.76 & 31.09 & 14.86 & 10.15 & 8.22 & 7.05 & 31.09 & 14.95 & 10.31 & 8.44 & 7.31 \\
\hline \multirow{5}{*}{3.0} & 1 & 13.66 & 11.25 & 9.07 & 7.43 & 6.16 & 14.47 & 11.94 & 9.63 & 7.90 & 6.56 & 14.44 & 12.05 & 9.87 & 8.21 & 6.90 & 14.43 & 12.17 & 10.09 & 8.49 & 7.21 \\
\hline & 12 & 16.09 & 11.75 & 9.15 & 7.46 & 6.20 & 16.91 & 12.41 & 9.69 & 7.92 & 6.59 & 16.88 & 12.53 & 9.92 & 8.21 & 6.92 & 16.86 & 12.64 & 10.12 & 8.48 & 7.23 \\
\hline & 60 & 18.72 & 12.18 & 9.21 & 7.48 & 6.24 & 19.50 & 12.81 & 9.74 & 7.93 & 6.62 & 19.47 & 12.92 & 9.95 & 8.21 & 6.94 & 19.46 & 13.03 & 10.16 & 8.47 & 7.24 \\
\hline & 180 & 19.67 & 12.31 & 9.23 & 7.49 & 6.25 & 20.42 & 12.94 & 9.75 & 7.93 & 6.63 & 20.39 & 13.05 & 9.97 & 8.21 & 6.95 & 20.38 & 13.15 & 10.17 & 8.47 & 7.25 \\
\hline & 240 & 19.81 & 12.33 & 9.24 & 7.49 & 6.25 & 20.56 & 12.96 & 9.75 & 7.93 & 6.63 & 20.53 & 13.07 & 9.97 & 8.21 & 6.95 & 20.52 & 13.17 & 10.17 & 8.47 & 7.25 \\
\hline \multirow{5}{*}{5.0} & 1 & 13.53 & 11.22 & 9.06 & 7.43 & 6.16 & 14.34 & 11.90 & 9.63 & 7.90 & 6.56 & 14.31 & 12.02 & 9.86 & 8.21 & 6.90 & 14.30 & 12.14 & 10.08 & 8.49 & 7.21 \\
\hline & 12 & 15.03 & 11.53 & 9.11 & 7.45 & 6.18 & 15.84 & 12.20 & 9.66 & 7.91 & 6.58 & 15.81 & 12.31 & 9.89 & 8.21 & 6.91 & 15.80 & 12.43 & 10.11 & 8.48 & 7.22 \\
\hline & 60 & 16.65 & 11.79 & 9.15 & 7.46 & 6.21 & 17.44 & 12.44 & 9.69 & 7.92 & 6.59 & 17.41 & 12.56 & 9.92 & 8.21 & 6.93 & 17.40 & 12.67 & 10.13 & 8.48 & 7.23 \\
\hline & 180 & 17.24 & 11.87 & 9.16 & 7.47 & 6.21 & 18.01 & 12.52 & 9.70 & 7.92 & 6.60 & 17.98 & 12.63 & 9.93 & 8.21 & 6.93 & 17.97 & 12.74 & 10.13 & 8.48 & 7.24 \\
\hline & 240 & 17.32 & 11.89 & 9.17 & 7.47 & 6.22 & 18.09 & 12.53 & 9.70 & 7.92 & 6.60 & 18.06 & 12.65 & 9.93 & 8.21 & 6.93 & 18.05 & 12.76 & 10.13 & 8.48 & 7.24 \\
\hline \multirow{5}{*}{15.0} & 1 & 13.40 & 11.18 & 9.06 & 7.43 & 6.16 & 14.21 & 11.87 & 9.62 & 7.90 & 6.56 & 14.18 & 11.99 & 9.86 & 8.21 & 6.90 & 14.17 & 12.11 & 10.08 & 8.49 & 7.21 \\
\hline & 12 & 13.91 & 11.29 & 9.07 & 7.43 & 6.16 & 14.72 & 11.97 & 9.64 & 7.90 & 6.56 & 14.69 & 12.09 & 9.87 & 8.21 & 6.90 & 14.68 & 12.20 & 10.09 & 8.49 & 7.22 \\
\hline & 60 & 14.47 & 11.38 & 9.09 & 7.44 & 6.17 & 15.27 & 12.06 & 9.65 & 7.91 & 6.57 & 15.24 & 12.17 & 9.88 & 8.21 & 6.91 & 15.23 & 12.29 & 10.10 & 8.49 & 7.22 \\
\hline & 180 & 14.67 & 11.41 & 9.09 & 7.44 & 6.17 & 15.46 & 12.08 & 9.65 & 7.91 & 6.57 & 15.43 & 12.20 & 9.88 & 8.21 & 6.91 & 15.42 & 12.31 & 10.10 & 8.48 & 7.22 \\
\hline & 240 & 14.70 & 11.41 & 9.09 & 7.44 & 6.18 & 15.49 & 12.09 & 9.65 & 7.91 & 6.57 & 15.46 & 12.20 & 9.88 & 8.21 & 6.91 & 15.45 & 12.32 & 10.10 & 8.48 & 7.22 \\
\hline \multirow{5}{*}{18.0} & 1 & 13.39 & 11.18 & 9.06 & 7.43 & 6.16 & 14.19 & 11.87 & 9.62 & 7.90 & 6.56 & 14.16 & 11.99 & 9.86 & 8.21 & 6.90 & 14.15 & 12.10 & 10.08 & 8.49 & 7.21 \\
\hline & 12 & 13.82 & 11.27 & 9.07 & 7.43 & 6.16 & 14.62 & 11.95 & 9.63 & 7.90 & 6.56 & 14.59 & 12.07 & 9.87 & 8.21 & 6.90 & 14.58 & 12.19 & 10.09 & 8.49 & 7.22 \\
\hline & 60 & 14.28 & 11.34 & 9.08 & 7.44 & 6.17 & 15.08 & 12.02 & 9.64 & 7.91 & 6.57 & 15.05 & 12.14 & 9.88 & 8.21 & 6.91 & 15.04 & 12.25 & 10.09 & 8.49 & 7.22 \\
\hline & 180 & 14.45 & 11.37 & 9.09 & 7.44 & 6.17 & 15.24 & 12.04 & 9.64 & 7.91 & 6.57 & 15.21 & 12.16 & 9.88 & 8.21 & 6.91 & 15.20 & 12.28 & 10.09 & 8.49 & 7.22 \\
\hline & 240 & 14.47 & 11.37 & 9.09 & 7.44 & 6.17 & 15.27 & 12.05 & 9.64 & 7.91 & 6.57 & 15.24 & 12.17 & 9.88 & 8.21 & 6.91 & 15.23 & 12.28 & 10.09 & 8.49 & 7.22 \\
\hline
\end{tabular}


Table 20: Viscosity in Wheeling

\begin{tabular}{|c|c|c|c|c|c|c|c|c|c|c|c|c|c|c|c|c|c|c|c|c|c|}
\hline \multicolumn{22}{|c|}{ Log Viscosity Wheeling (CP) } \\
\hline \multirow{2}{*}{$\begin{array}{c}\text { Depth } \\
\text { in }\end{array}$} & \multirow{2}{*}{$\begin{array}{c}\text { Time } \\
\text { Months }\end{array}$} & \multicolumn{5}{|c|}{ PG58-28 } & \multicolumn{5}{|c|}{ PG64-22 } & \multicolumn{5}{|c|}{ PG70-22 } & \multicolumn{5}{|c|}{ PG76-22 } \\
\hline & & 16 & 40 & 70 & 100 & 130 & 16 & 40 & 70 & 100 & 130 & 16 & 40 & 70 & 100 & 130 & 16 & 40 & 70 & 100 & 130 \\
\hline \multirow{5}{*}{0.5} & 1 & 14.80 & 11.54 & 9.11 & 7.44 & 6.18 & 15.63 & 12.21 & 9.66 & 7.91 & 6.57 & 15.60 & 12.33 & 9.89 & 8.21 & 6.91 & 15.59 & 12.44 & 10.11 & 8.48 & 7.22 \\
\hline & 12 & 25.50 & 13.73 & 9.45 & 7.56 & 6.34 & 26.36 & 14.30 & 9.90 & 7.95 & 6.70 & 26.33 & 14.40 & 10.09 & 8.21 & 7.00 & 26.31 & 14.49 & 10.26 & 8.44 & 7.28 \\
\hline & 60 & 37.05 & 15.59 & 9.73 & 7.66 & 6.51 & 37.72 & 16.04 & 10.10 & 8.00 & 6.83 & 37.69 & 16.12 & 10.25 & 8.21 & 7.10 & 37.68 & 16.20 & 10.39 & 8.41 & 7.34 \\
\hline & 180 & 41.20 & 16.20 & 9.82 & 7.70 & 6.58 & 41.76 & 16.60 & 10.16 & 8.01 & 6.88 & 41.74 & 16.67 & 10.30 & 8.21 & 7.13 & 41.73 & 16.74 & 10.43 & 8.39 & 7.36 \\
\hline & 240 & 41.82 & 16.29 & 9.84 & 7.70 & 6.59 & 42.35 & 16.68 & 10.17 & 8.01 & 6.89 & 42.33 & 16.75 & 10.31 & 8.21 & 7.14 & 42.33 & 16.82 & 10.44 & 8.39 & 7.37 \\
\hline \multirow{5}{*}{1.0} & 1 & 14.21 & 11.39 & 9.09 & 7.44 & 6.17 & 15.03 & 12.07 & 9.65 & 7.91 & 6.57 & 15.00 & 12.19 & 9.88 & 8.21 & 6.91 & 14.99 & 12.30 & 10.10 & 8.49 & 7.22 \\
\hline & 12 & 20.62 & 12.71 & 9.30 & 7.51 & 6.27 & 21.47 & 13.33 & 9.80 & 7.94 & 6.64 & 21.43 & 13.44 & 10.01 & 8.21 & 6.96 & 21.42 & 13.54 & 10.20 & 8.47 & 7.26 \\
\hline & 60 & 27.59 & 13.84 & 9.47 & 7.58 & 6.37 & 28.31 & 14.39 & 9.92 & 7.97 & 6.72 & 28.29 & 14.48 & 10.11 & 8.22 & 7.02 & 28.28 & 14.57 & 10.28 & 8.45 & 7.30 \\
\hline & 180 & 30.10 & 14.21 & 9.53 & 7.60 & 6.41 & 30.76 & 14.73 & 9.96 & 7.98 & 6.76 & 30.73 & 14.81 & 10.14 & 8.22 & 7.04 & 30.72 & 14.90 & 10.31 & 8.44 & 7.31 \\
\hline & 240 & 30.47 & 14.26 & 9.54 & 7.60 & 6.42 & 31.12 & 14.77 & 9.97 & 7.98 & 6.76 & 31.09 & 14.86 & 10.15 & 8.22 & 7.05 & 31.09 & 14.95 & 10.31 & 8.44 & 7.31 \\
\hline \multirow{5}{*}{3.0} & 1 & 13.66 & 11.25 & 9.07 & 7.43 & 6.16 & 14.47 & 11.94 & 9.63 & 7.90 & 6.56 & 14.44 & 12.05 & 9.87 & 8.21 & 6.90 & 14.43 & 12.17 & 10.09 & 8.49 & 7.21 \\
\hline & 12 & 16.09 & 11.75 & 9.15 & 7.46 & 6.20 & 16.91 & 12.41 & 9.69 & 7.92 & 6.59 & 16.88 & 12.53 & 9.92 & 8.21 & 6.92 & 16.86 & 12.64 & 10.12 & 8.48 & 7.23 \\
\hline & 60 & 18.72 & 12.18 & 9.21 & 7.48 & 6.24 & 19.50 & 12.81 & 9.74 & 7.93 & 6.62 & 19.47 & 12.92 & 9.95 & 8.21 & 6.94 & 19.46 & 13.03 & 10.16 & 8.47 & 7.24 \\
\hline & 180 & 19.67 & 12.31 & 9.23 & 7.49 & 6.25 & 20.42 & 12.94 & 9.75 & 7.93 & 6.63 & 20.39 & 13.05 & 9.97 & 8.21 & 6.95 & 20.38 & 13.15 & 10.17 & 8.47 & 7.25 \\
\hline & 240 & 19.81 & 12.33 & 9.24 & 7.49 & 6.25 & 20.56 & 12.96 & 9.75 & 7.93 & 6.63 & 20.53 & 13.07 & 9.97 & 8.21 & 6.95 & 20.52 & 13.17 & 10.17 & 8.47 & 7.25 \\
\hline \multirow{5}{*}{5.0} & 1 & 13.53 & 11.22 & 9.06 & 7.43 & 6.16 & 14.34 & 11.90 & 9.63 & 7.90 & 6.56 & 14.31 & 12.02 & 9.86 & 8.21 & 6.90 & 14.30 & 12.14 & 10.08 & 8.49 & 7.21 \\
\hline & 12 & 15.03 & 11.53 & 9.11 & 7.45 & 6.18 & 15.84 & 12.20 & 9.66 & 7.91 & 6.58 & 15.81 & 12.31 & 9.89 & 8.21 & 6.91 & 15.80 & 12.43 & 10.11 & 8.48 & 7.22 \\
\hline & 60 & 16.65 & 11.79 & 9.15 & 7.46 & 6.21 & 17.44 & 12.44 & 9.69 & 7.92 & 6.59 & 17.41 & 12.56 & 9.92 & 8.21 & 6.93 & 17.40 & 12.67 & 10.13 & 8.48 & 7.23 \\
\hline & 180 & 17.24 & 11.87 & 9.16 & 7.47 & 6.21 & 18.01 & 12.52 & 9.70 & 7.92 & 6.60 & 17.98 & 12.63 & 9.93 & 8.21 & 6.93 & 17.97 & 12.74 & 10.13 & 8.48 & 7.24 \\
\hline & 240 & 17.32 & 11.89 & 9.17 & 7.47 & 6.22 & 18.09 & 12.53 & 9.70 & 7.92 & 6.60 & 18.06 & 12.65 & 9.93 & 8.21 & 6.93 & 18.05 & 12.76 & 10.13 & 8.48 & 7.24 \\
\hline \multirow{5}{*}{15.0} & 1 & 13.40 & 11.18 & 9.06 & 7.43 & 6.16 & 14.21 & 11.87 & 9.62 & 7.90 & 6.56 & 14.18 & 11.99 & 9.86 & 8.21 & 6.90 & 14.17 & 12.11 & 10.08 & 8.49 & 7.21 \\
\hline & 12 & 13.91 & 11.29 & 9.07 & 7.43 & 6.16 & 14.72 & 11.97 & 9.64 & 7.90 & 6.56 & 14.69 & 12.09 & 9.87 & 8.21 & 6.90 & 14.68 & 12.20 & 10.09 & 8.49 & 7.22 \\
\hline & 60 & 14.47 & 11.38 & 9.09 & 7.44 & 6.17 & 15.27 & 12.06 & 9.65 & 7.91 & 6.57 & 15.24 & 12.17 & 9.88 & 8.21 & 6.91 & 15.23 & 12.29 & 10.10 & 8.49 & 7.22 \\
\hline & 180 & 14.67 & 11.41 & 9.09 & 7.44 & 6.17 & 15.46 & 12.08 & 9.65 & 7.91 & 6.57 & 15.43 & 12.20 & 9.88 & 8.21 & 6.91 & 15.42 & 12.31 & 10.10 & 8.48 & 7.22 \\
\hline & 240 & 14.70 & 11.41 & 9.09 & 7.44 & 6.18 & 15.49 & 12.09 & 9.65 & 7.91 & 6.57 & 15.46 & 12.20 & 9.88 & 8.21 & 6.91 & 15.45 & 12.32 & 10.10 & 8.48 & 7.22 \\
\hline \multirow{5}{*}{18.0} & 1 & 13.39 & 11.18 & 9.06 & 7.43 & 6.16 & 14.19 & 11.87 & 9.62 & 7.90 & 6.56 & 14.16 & 11.99 & 9.86 & 8.21 & 6.90 & 14.15 & 12.10 & 10.08 & 8.49 & 7.21 \\
\hline & 12 & 13.82 & 11.27 & 9.07 & 7.43 & 6.16 & 14.62 & 11.95 & 9.63 & 7.90 & 6.56 & 14.59 & 12.07 & 9.87 & 8.21 & 6.90 & 14.58 & 12.19 & 10.09 & 8.49 & 7.22 \\
\hline & 60 & 14.28 & 11.34 & 9.08 & 7.44 & 6.17 & 15.08 & 12.02 & 9.64 & 7.91 & 6.57 & 15.05 & 12.14 & 9.88 & 8.21 & 6.91 & 15.04 & 12.25 & 10.09 & 8.49 & 7.22 \\
\hline & 180 & 14.45 & 11.37 & 9.09 & 7.44 & 6.17 & 15.24 & 12.04 & 9.64 & 7.91 & 6.57 & 15.21 & 12.16 & 9.88 & 8.21 & 6.91 & 15.20 & 12.28 & 10.09 & 8.49 & 7.22 \\
\hline & 240 & 14.47 & 11.37 & 9.09 & 7.44 & 6.17 & 15.27 & 12.05 & 9.64 & 7.91 & 6.57 & 15.24 & 12.17 & 9.88 & 8.21 & 6.91 & 15.23 & 12.28 & 10.09 & 8.49 & 7.22 \\
\hline
\end{tabular}


Table 21: Viscosity in Elkins

\begin{tabular}{|c|c|c|c|c|c|c|c|c|c|c|c|c|c|c|c|c|c|c|c|c|c|}
\hline \multicolumn{22}{|c|}{ Log Viscosity Elkins (cP) } \\
\hline \multirow{2}{*}{$\begin{array}{c}\text { Depth } \\
\text { in }\end{array}$} & \multirow{2}{*}{$\begin{array}{c}\text { Time } \\
\text { Months }\end{array}$} & \multicolumn{5}{|c|}{ PG58-28 } & \multicolumn{5}{|c|}{ PG64-22 } & \multicolumn{5}{|c|}{ PG70-22 } & \multicolumn{5}{|c|}{ PG76-22 } \\
\hline & & 16 & 40 & 70 & 100 & 130 & 16 & 40 & 70 & 100 & 130 & 16 & 40 & 70 & 100 & 130 & 16 & 40 & 70 & 100 & 130 \\
\hline \multirow{5}{*}{0.5} & 1 & 14.76 & 11.53 & 9.11 & 7.44 & 6.18 & 15.60 & 12.20 & 9.66 & 7.91 & 6.57 & 15.56 & 12.32 & 9.89 & 8.20 & 6.91 & 15.55 & 12.43 & 10.10 & 8.48 & 7.22 \\
\hline & 12 & 25.14 & 13.63 & 9.42 & 7.54 & 6.33 & 25.99 & 14.20 & 9.87 & 7.94 & 6.69 & 25.96 & 14.30 & 10.06 & 8.19 & 6.99 & 25.95 & 14.40 & 10.23 & 8.42 & 7.27 \\
\hline & 60 & 36.27 & 15.42 & 9.68 & 7.63 & 6.49 & 36.92 & 15.87 & 10.04 & 7.97 & 6.81 & 36.90 & 15.95 & 10.20 & 8.18 & 7.07 & 36.89 & 16.02 & 10.34 & 8.38 & 7.32 \\
\hline & 180 & 40.25 & 16.00 & 9.76 & 7.66 & 6.55 & 40.80 & 16.40 & 10.10 & 7.98 & 6.85 & 40.78 & 16.47 & 10.24 & 8.18 & 7.10 & 40.77 & 16.54 & 10.37 & 8.36 & 7.34 \\
\hline & 240 & 40.84 & 16.08 & 9.77 & 7.67 & 6.56 & 41.37 & 16.48 & 10.11 & 7.98 & 6.86 & 41.35 & 16.55 & 10.25 & 8.18 & 7.11 & 41.35 & 16.61 & 10.37 & 8.36 & 7.34 \\
\hline \multirow{5}{*}{1.0} & 1 & 14.16 & 11.38 & 9.09 & 7.44 & 6.17 & 14.99 & 12.06 & 9.64 & 7.90 & 6.56 & 14.95 & 12.17 & 9.88 & 8.21 & 6.90 & 14.94 & 12.29 & 10.09 & 8.48 & 7.22 \\
\hline & 12 & 20.20 & 12.60 & 9.27 & 7.49 & 6.26 & 21.04 & 13.22 & 9.77 & 7.92 & 6.63 & 21.01 & 13.33 & 9.98 & 8.20 & 6.95 & 20.99 & 13.43 & 10.17 & 8.45 & 7.24 \\
\hline & 60 & 26.68 & 13.64 & 9.42 & 7.55 & 6.35 & 27.40 & 14.19 & 9.87 & 7.94 & 6.70 & 27.37 & 14.28 & 10.06 & 8.19 & 7.00 & 27.36 & 14.38 & 10.23 & 8.42 & 7.27 \\
\hline & 180 & 29.00 & 13.98 & 9.46 & 7.56 & 6.38 & 29.65 & 14.50 & 9.90 & 7.95 & 6.73 & 29.63 & 14.59 & 10.08 & 8.19 & 7.02 & 29.62 & 14.68 & 10.25 & 8.41 & 7.28 \\
\hline & 240 & 29.34 & 14.03 & 9.47 & 7.57 & 6.39 & 29.99 & 14.55 & 9.90 & 7.95 & 6.73 & 29.96 & 14.63 & 10.09 & 8.19 & 7.02 & 29.95 & 14.72 & 10.25 & 8.41 & 7.29 \\
\hline \multirow{5}{*}{3.0} & 1 & 13.64 & 11.24 & 9.07 & 7.43 & 6.16 & 14.45 & 11.93 & 9.63 & 7.90 & 6.56 & 14.42 & 12.05 & 9.87 & 8.21 & 6.90 & 14.41 & 12.16 & 10.08 & 8.49 & 7.21 \\
\hline & 12 & 15.90 & 11.70 & 9.13 & 7.45 & 6.19 & 16.72 & 12.36 & 9.68 & 7.91 & 6.58 & 16.69 & 12.48 & 9.90 & 8.20 & 6.92 & 16.68 & 12.59 & 10.11 & 8.47 & 7.22 \\
\hline & 60 & 18.32 & 12.09 & 9.19 & 7.47 & 6.23 & 19.10 & 12.73 & 9.71 & 7.92 & 6.61 & 19.07 & 12.84 & 9.93 & 8.20 & 6.94 & 19.06 & 12.94 & 10.14 & 8.46 & 7.24 \\
\hline & 180 & 19.19 & 12.22 & 9.21 & 7.48 & 6.24 & 19.94 & 12.84 & 9.73 & 7.92 & 6.62 & 19.91 & 12.95 & 9.94 & 8.20 & 6.94 & 19.90 & 13.06 & 10.14 & 8.46 & 7.24 \\
\hline & 240 & 19.32 & 12.24 & 9.21 & 7.48 & 6.24 & 20.07 & 12.86 & 9.73 & 7.92 & 6.62 & 20.04 & 12.97 & 9.94 & 8.20 & 6.94 & 20.03 & 13.07 & 10.14 & 8.46 & 7.24 \\
\hline \multirow{5}{*}{5.0} & 1 & 13.52 & 11.21 & 9.06 & 7.43 & 6.16 & 14.33 & 11.90 & 9.63 & 7.90 & 6.56 & 14.30 & 12.02 & 9.86 & 8.21 & 6.90 & 14.29 & 12.13 & 10.08 & 8.49 & 7.21 \\
\hline & 12 & 14.91 & 11.50 & 9.10 & 7.44 & 6.18 & 15.72 & 12.17 & 9.66 & 7.91 & 6.57 & 15.69 & 12.28 & 9.89 & 8.20 & 6.91 & 15.68 & 12.40 & 10.10 & 8.48 & 7.22 \\
\hline & 60 & 16.40 & 11.74 & 9.14 & 7.45 & 6.20 & 17.19 & 12.39 & 9.68 & 7.91 & 6.59 & 17.16 & 12.50 & 9.90 & 8.20 & 6.92 & 17.15 & 12.62 & 10.11 & 8.47 & 7.23 \\
\hline & 180 & 16.94 & 11.81 & 9.15 & 7.46 & 6.21 & 17.71 & 12.46 & 9.69 & 7.91 & 6.59 & 17.68 & 12.57 & 9.91 & 8.20 & 6.92 & 17.67 & 12.68 & 10.12 & 8.47 & 7.23 \\
\hline & 240 & 17.01 & 11.82 & 9.15 & 7.46 & 6.21 & 17.78 & 12.47 & 9.69 & 7.91 & 6.60 & 17.75 & 12.59 & 9.91 & 8.20 & 6.93 & 17.74 & 12.69 & 10.12 & 8.47 & 7.23 \\
\hline \multirow{5}{*}{15.0} & 1 & 13.39 & 11.18 & 9.06 & 7.43 & 6.16 & 14.20 & 11.87 & 9.62 & 7.90 & 6.56 & 14.17 & 11.99 & 9.86 & 8.21 & 6.90 & 14.16 & 12.10 & 10.08 & 8.49 & 7.21 \\
\hline & 12 & 13.87 & 11.28 & 9.07 & 7.43 & 6.16 & 14.68 & 11.96 & 9.63 & 7.90 & 6.56 & 14.65 & 12.08 & 9.87 & 8.21 & 6.90 & 14.64 & 12.19 & 10.09 & 8.49 & 7.22 \\
\hline & 60 & 14.38 & 11.36 & 9.08 & 7.44 & 6.17 & 15.18 & 12.04 & 9.64 & 7.90 & 6.57 & 15.15 & 12.15 & 9.87 & 8.21 & 6.91 & 15.14 & 12.27 & 10.09 & 8.48 & 7.22 \\
\hline & 180 & 14.56 & 11.39 & 9.09 & 7.44 & 6.17 & 15.36 & 12.06 & 9.64 & 7.90 & 6.57 & 15.33 & 12.18 & 9.88 & 8.21 & 6.91 & 15.32 & 12.29 & 10.09 & 8.48 & 7.22 \\
\hline & 240 & 14.59 & 11.39 & 9.09 & 7.44 & 6.17 & 15.38 & 12.06 & 9.64 & 7.90 & 6.57 & 15.35 & 12.18 & 9.88 & 8.21 & 6.91 & 15.34 & 12.30 & 10.09 & 8.48 & 7.22 \\
\hline \multirow{5}{*}{18.0} & 1 & 13.38 & 11.18 & 9.06 & 7.43 & 6.15 & 14.19 & 11.87 & 9.62 & 7.90 & 6.56 & 14.16 & 11.99 & 9.86 & 8.21 & 6.90 & 14.15 & 12.10 & 10.08 & 8.49 & 7.21 \\
\hline & 12 & 13.78 & 11.26 & 9.07 & 7.43 & 6.16 & 14.59 & 11.94 & 9.63 & 7.90 & 6.56 & 14.56 & 12.06 & 9.87 & 8.21 & 6.90 & 14.55 & 12.18 & 10.08 & 8.49 & 7.21 \\
\hline & 60 & 14.21 & 11.33 & 9.08 & 7.43 & 6.17 & 15.01 & 12.01 & 9.64 & 7.90 & 6.56 & 14.98 & 12.12 & 9.87 & 8.21 & 6.90 & 14.97 & 12.24 & 10.09 & 8.48 & 7.22 \\
\hline & 180 & 14.36 & 11.35 & 9.08 & 7.43 & 6.17 & 15.15 & 12.03 & 9.64 & 7.90 & 6.57 & 15.13 & 12.14 & 9.87 & 8.21 & 6.90 & 15.11 & 12.26 & 10.09 & 8.48 & 7.22 \\
\hline & 240 & 14.38 & 11.35 & 9.08 & 7.43 & 6.17 & 15.18 & 12.03 & 9.64 & 7.90 & 6.57 & 15.15 & 12.15 & 9.87 & 8.21 & 6.91 & 15.14 & 12.26 & 10.09 & 8.48 & 7.22 \\
\hline
\end{tabular}


Table 22: Viscosity in Charleston

\begin{tabular}{|c|c|c|c|c|c|c|c|c|c|c|c|c|c|c|c|c|c|c|c|c|c|}
\hline \multicolumn{22}{|c|}{ Log Viscosity Charleston (cP) } \\
\hline \multirow{2}{*}{$\begin{array}{c}\text { Depth } \\
\text { in }\end{array}$} & \multirow{2}{*}{$\begin{array}{c}\text { Time } \\
\text { Months }\end{array}$} & \multicolumn{5}{|c|}{ PG58-28 } & \multicolumn{5}{|c|}{ PG64-22 } & \multicolumn{5}{|c|}{ PG70-22 } & \multicolumn{5}{|c|}{ PG76-22 } \\
\hline & & 16 & 40 & 70 & 100 & 130 & 16 & 40 & 70 & 100 & 130 & 16 & 40 & 70 & 100 & 130 & 16 & 40 & 70 & 100 & 130 \\
\hline \multirow{5}{*}{0.5} & 1 & 14.86 & 11.56 & 9.12 & 7.45 & 6.18 & 15.69 & 12.24 & 9.67 & 7.91 & 6.58 & 15.66 & 12.35 & 9.90 & 8.21 & 6.91 & 15.65 & 12.47 & 10.12 & 8.49 & 7.22 \\
\hline & 12 & 26.10 & 13.89 & 9.50 & 7.59 & 6.36 & 26.98 & 14.46 & 9.96 & 7.98 & 6.72 & 26.94 & 14.56 & 10.15 & 8.24 & 7.02 & 26.93 & 14.66 & 10.32 & 8.47 & 7.30 \\
\hline & 60 & 38.40 & 15.89 & 9.83 & 7.71 & 6.55 & 39.07 & 16.34 & 10.19 & 8.05 & 6.87 & 39.05 & 16.42 & 10.34 & 8.26 & 7.13 & 39.04 & 16.49 & 10.48 & 8.46 & 7.38 \\
\hline & 180 & 42.84 & 16.54 & 9.93 & 7.76 & 6.62 & 43.40 & 16.95 & 10.27 & 8.07 & 6.92 & 43.38 & 17.02 & 10.41 & 8.27 & 7.18 & 43.37 & 17.08 & 10.54 & 8.45 & 7.41 \\
\hline & 240 & 43.50 & 16.64 & 9.95 & 7.76 & 6.63 & 44.04 & 17.03 & 10.28 & 8.07 & 6.93 & 44.02 & 17.10 & 10.42 & 8.27 & 7.18 & 44.01 & 17.17 & 10.54 & 8.45 & 7.41 \\
\hline \multirow{5}{*}{1.0} & 1 & 14.24 & 11.40 & 9.09 & 7.44 & 6.17 & 15.06 & 12.08 & 9.65 & 7.91 & 6.57 & 15.03 & 12.20 & 9.88 & 8.21 & 6.91 & 15.02 & 12.31 & 10.10 & 8.49 & 7.22 \\
\hline & 12 & 20.91 & 12.78 & 9.32 & 7.52 & 6.28 & 21.75 & 13.40 & 9.82 & 7.95 & 6.65 & 21.72 & 13.51 & 10.03 & 8.22 & 6.97 & 21.71 & 13.61 & 10.22 & 8.48 & 7.26 \\
\hline & 60 & 28.20 & 13.97 & 9.51 & 7.60 & 6.39 & 28.93 & 14.52 & 9.96 & 7.99 & 6.74 & 28.90 & 14.61 & 10.15 & 8.24 & 7.04 & 28.89 & 14.70 & 10.32 & 8.47 & 7.31 \\
\hline & 180 & 30.84 & 14.36 & 9.57 & 7.62 & 6.43 & 31.50 & 14.88 & 10.01 & 8.00 & 6.77 & 31.48 & 14.96 & 10.19 & 8.24 & 7.06 & 31.47 & 15.05 & 10.35 & 8.47 & 7.33 \\
\hline & 240 & 31.23 & 14.41 & 9.58 & 7.63 & 6.44 & 31.88 & 14.93 & 10.01 & 8.00 & 6.78 & 31.85 & 15.02 & 10.19 & 8.24 & 7.07 & 31.85 & 15.10 & 10.36 & 8.47 & 7.33 \\
\hline \multirow{5}{*}{3.0} & 1 & 13.67 & 11.26 & 9.07 & 7.43 & 6.16 & 14.49 & 11.94 & 9.63 & 7.90 & 6.56 & 14.46 & 12.06 & 9.87 & 8.21 & 6.90 & 14.45 & 12.17 & 10.09 & 8.49 & 7.22 \\
\hline & 12 & 16.21 & 11.78 & 9.16 & 7.46 & 6.20 & 17.04 & 12.44 & 9.70 & 7.92 & 6.59 & 17.00 & 12.56 & 9.92 & 8.21 & 6.93 & 16.99 & 12.67 & 10.13 & 8.48 & 7.23 \\
\hline & 60 & 18.99 & 12.23 & 9.23 & 7.49 & 6.24 & 19.77 & 12.87 & 9.75 & 7.93 & 6.63 & 19.74 & 12.98 & 9.97 & 8.22 & 6.95 & 19.73 & 13.08 & 10.17 & 8.48 & 7.25 \\
\hline & 180 & 20.00 & 12.38 & 9.25 & 7.50 & 6.26 & 20.75 & 13.00 & 9.77 & 7.94 & 6.64 & 20.72 & 13.11 & 9.98 & 8.22 & 6.96 & 20.71 & 13.22 & 10.18 & 8.48 & 7.26 \\
\hline & 240 & 20.14 & 12.40 & 9.26 & 7.50 & 6.26 & 20.89 & 13.02 & 9.77 & 7.94 & 6.64 & 20.86 & 13.13 & 9.99 & 8.22 & 6.96 & 20.85 & 13.24 & 10.18 & 8.48 & 7.26 \\
\hline \multirow{5}{*}{5.0} & 1 & 13.54 & 11.22 & 9.06 & 7.43 & 6.16 & 14.35 & 11.91 & 9.63 & 7.90 & 6.56 & 14.32 & 12.03 & 9.87 & 8.21 & 6.90 & 14.31 & 12.14 & 10.08 & 8.49 & 7.21 \\
\hline & 12 & 15.11 & 11.55 & 9.12 & 7.45 & 6.18 & 15.93 & 12.22 & 9.67 & 7.91 & 6.58 & 15.90 & 12.33 & 9.90 & 8.21 & 6.91 & 15.88 & 12.45 & 10.11 & 8.49 & 7.22 \\
\hline & 60 & 16.83 & 11.83 & 9.16 & 7.47 & 6.21 & 17.61 & 12.48 & 9.70 & 7.92 & 6.60 & 17.58 & 12.59 & 9.93 & 8.21 & 6.93 & 17.57 & 12.70 & 10.14 & 8.48 & 7.24 \\
\hline & 180 & 17.45 & 11.92 & 9.18 & 7.47 & 6.22 & 18.22 & 12.56 & 9.71 & 7.92 & 6.61 & 18.19 & 12.68 & 9.94 & 8.22 & 6.94 & 18.18 & 12.79 & 10.14 & 8.48 & 7.24 \\
\hline & 240 & 17.54 & 11.93 & 9.18 & 7.47 & 6.22 & 18.31 & 12.58 & 9.71 & 7.92 & 6.61 & 18.28 & 12.69 & 9.94 & 8.22 & 6.94 & 18.27 & 12.80 & 10.14 & 8.48 & 7.24 \\
\hline \multirow{5}{*}{15.0} & 1 & 13.40 & 11.18 & 9.06 & 7.43 & 6.16 & 14.21 & 11.87 & 9.62 & 7.90 & 6.56 & 14.18 & 11.99 & 9.86 & 8.21 & 6.90 & 14.17 & 12.11 & 10.08 & 8.49 & 7.21 \\
\hline & 12 & 13.94 & 11.30 & 9.07 & 7.43 & 6.16 & 14.75 & 11.98 & 9.64 & 7.90 & 6.56 & 14.72 & 12.10 & 9.87 & 8.21 & 6.90 & 14.71 & 12.21 & 10.09 & 8.49 & 7.22 \\
\hline & 60 & 14.53 & 11.39 & 9.09 & 7.44 & 6.17 & 15.33 & 12.07 & 9.65 & 7.91 & 6.57 & 15.30 & 12.19 & 9.88 & 8.21 & 6.91 & 15.29 & 12.30 & 10.10 & 8.49 & 7.22 \\
\hline & 180 & 14.74 & 11.42 & 9.10 & 7.44 & 6.18 & 15.54 & 12.10 & 9.65 & 7.91 & 6.57 & 15.51 & 12.21 & 9.89 & 8.21 & 6.91 & 15.50 & 12.33 & 10.10 & 8.49 & 7.22 \\
\hline & 240 & 14.77 & 11.43 & 9.10 & 7.44 & 6.18 & 15.57 & 12.10 & 9.65 & 7.91 & 6.57 & 15.54 & 12.22 & 9.89 & 8.21 & 6.91 & 15.53 & 12.33 & 10.10 & 8.49 & 7.22 \\
\hline \multirow{5}{*}{18.0} & 1 & 13.39 & 11.18 & 9.06 & 7.43 & 6.16 & 14.20 & 11.87 & 9.62 & 7.90 & 6.56 & 14.17 & 11.99 & 9.86 & 8.21 & 6.90 & 14.16 & 12.10 & 10.08 & 8.49 & 7.21 \\
\hline & 12 & 13.84 & 11.28 & 9.07 & 7.43 & 6.16 & 14.65 & 11.96 & 9.64 & 7.90 & 6.56 & 14.62 & 12.08 & 9.87 & 8.21 & 6.90 & 14.61 & 12.19 & 10.09 & 8.49 & 7.22 \\
\hline & 60 & 14.33 & 11.36 & 9.08 & 7.44 & 6.17 & 15.13 & 12.03 & 9.64 & 7.91 & 6.57 & 15.10 & 12.15 & 9.88 & 8.21 & 6.91 & 15.09 & 12.26 & 10.10 & 8.49 & 7.22 \\
\hline & 180 & 14.51 & 11.38 & 9.09 & 7.44 & 6.17 & 15.31 & 12.06 & 9.65 & 7.91 & 6.57 & 15.28 & 12.17 & 9.88 & 8.21 & 6.91 & 15.27 & 12.29 & 10.10 & 8.49 & 7.22 \\
\hline & 240 & 14.54 & 11.39 & 9.09 & 7.44 & 6.17 & 15.33 & 12.06 & 9.65 & 7.91 & 6.57 & 15.30 & 12.18 & 9.88 & 8.21 & 6.91 & 15.29 & 12.29 & 10.10 & 8.49 & 7.22 \\
\hline
\end{tabular}




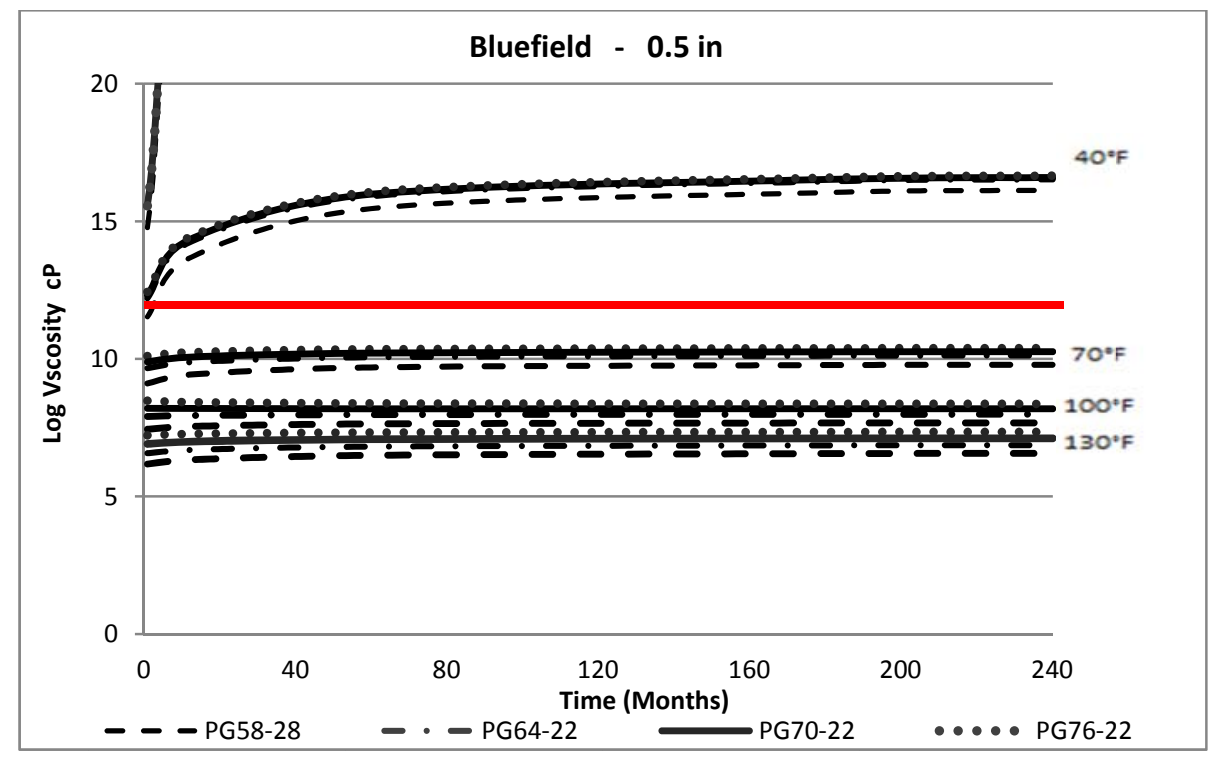

Figure 162: Aging effect on viscosity Bluefield at 0.5 in

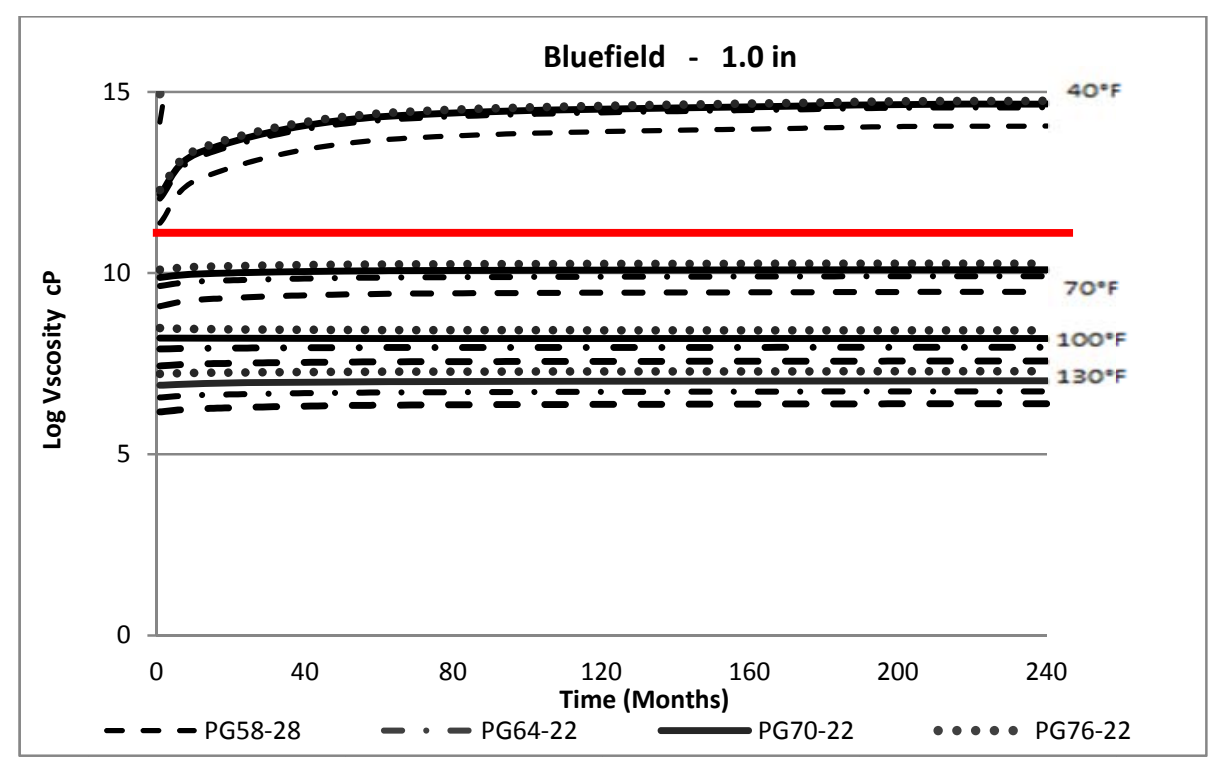

Figure 163: Aging effect on viscosity Bluefield at 1.0in

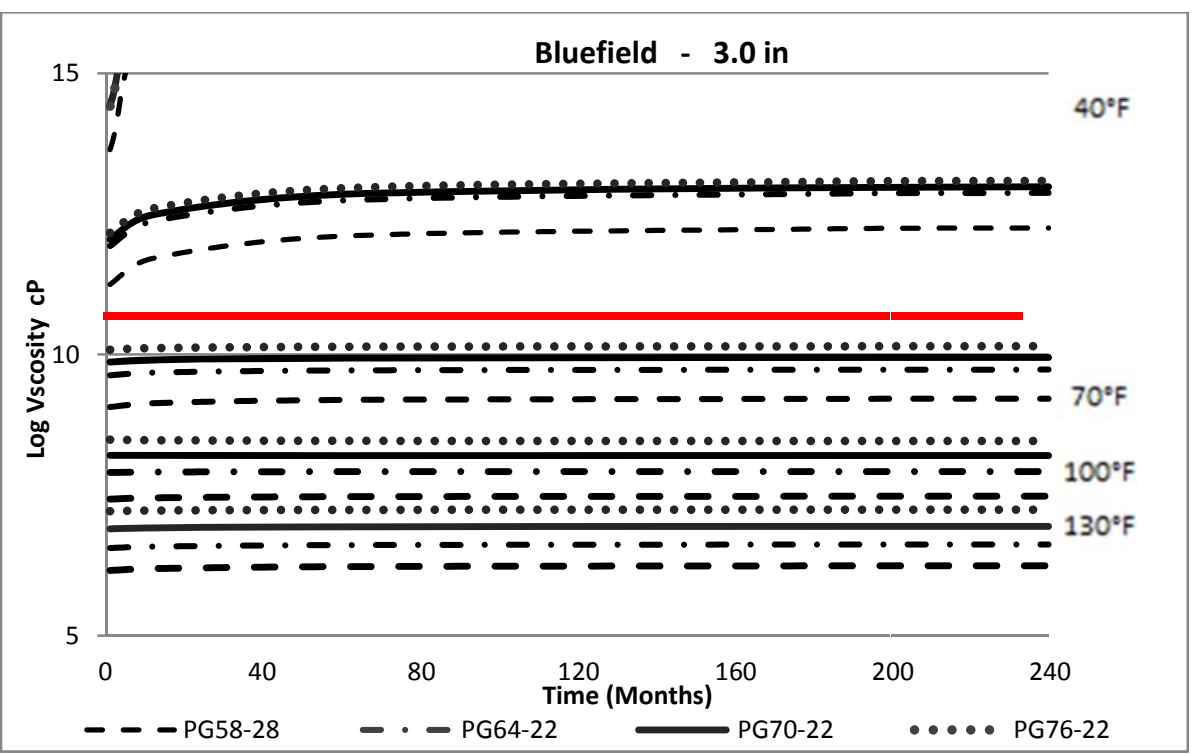

Figure 164: Aging effect on viscosity Bluefield at 3.0in

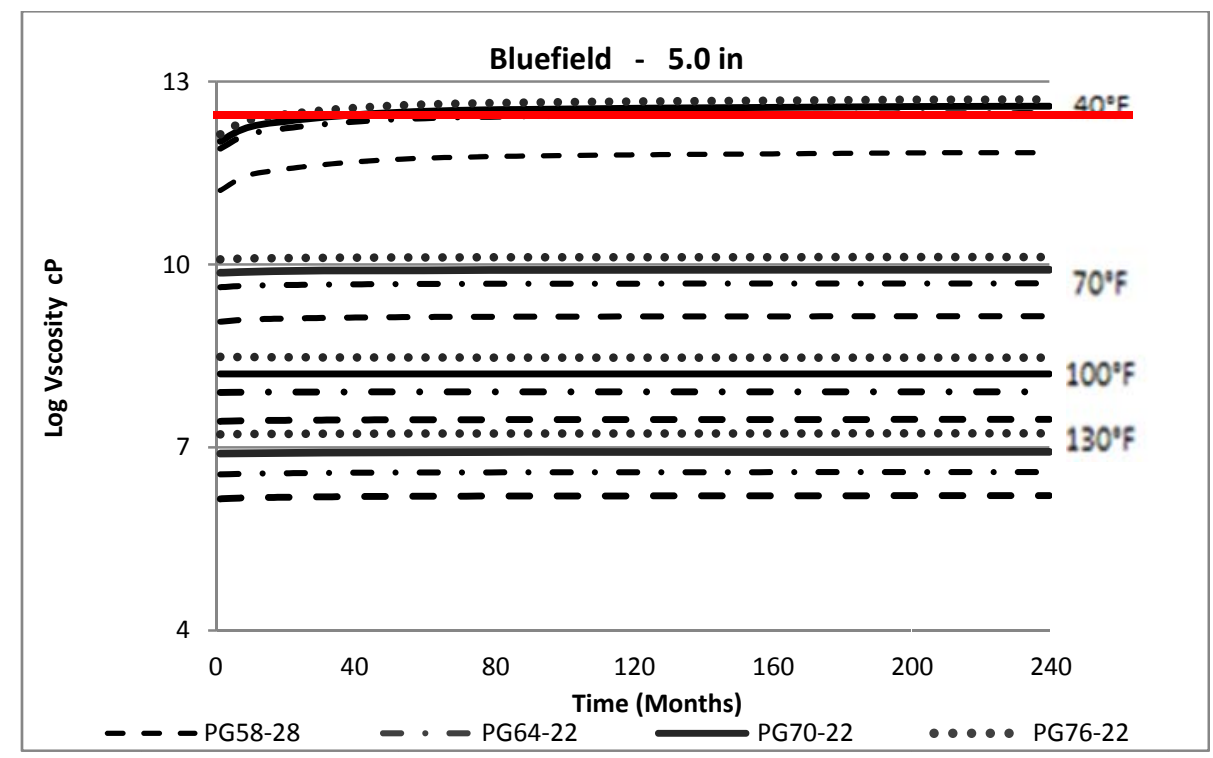

Figure 165: Aging effect on viscosity Bluefield at 5.0in 


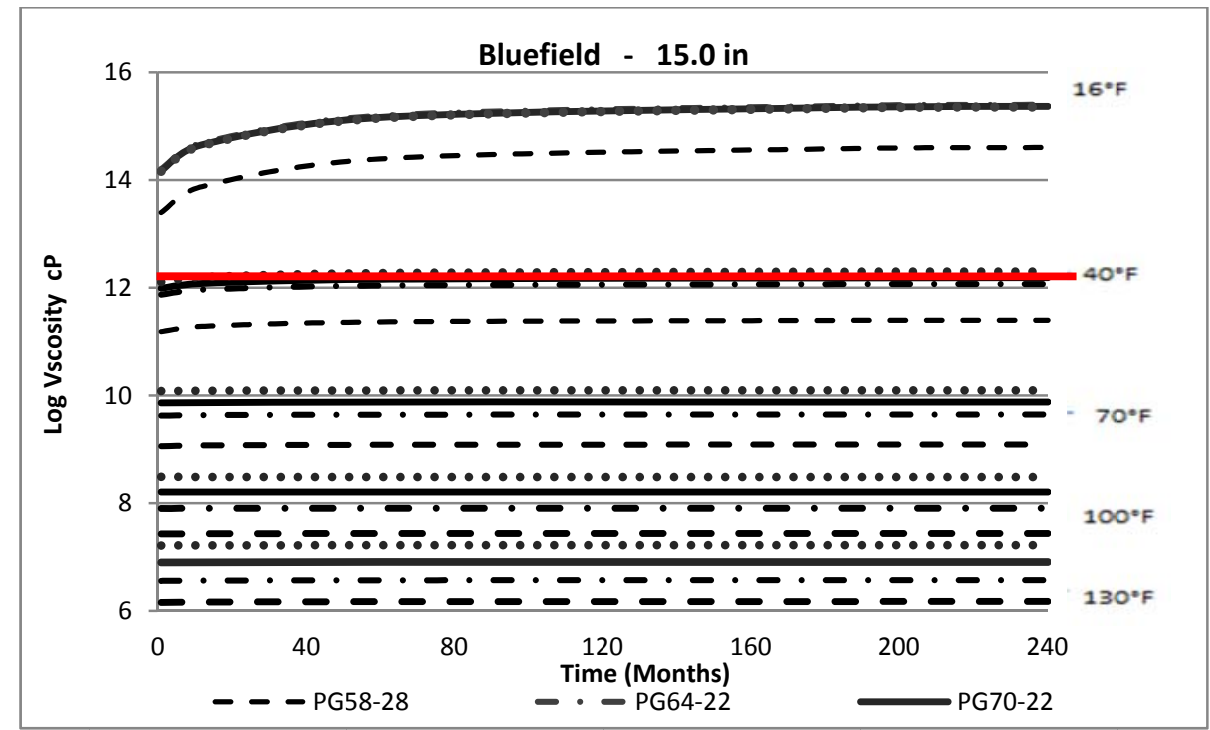

Figure 166: Aging effect on viscosity Bluefield at 15.0in

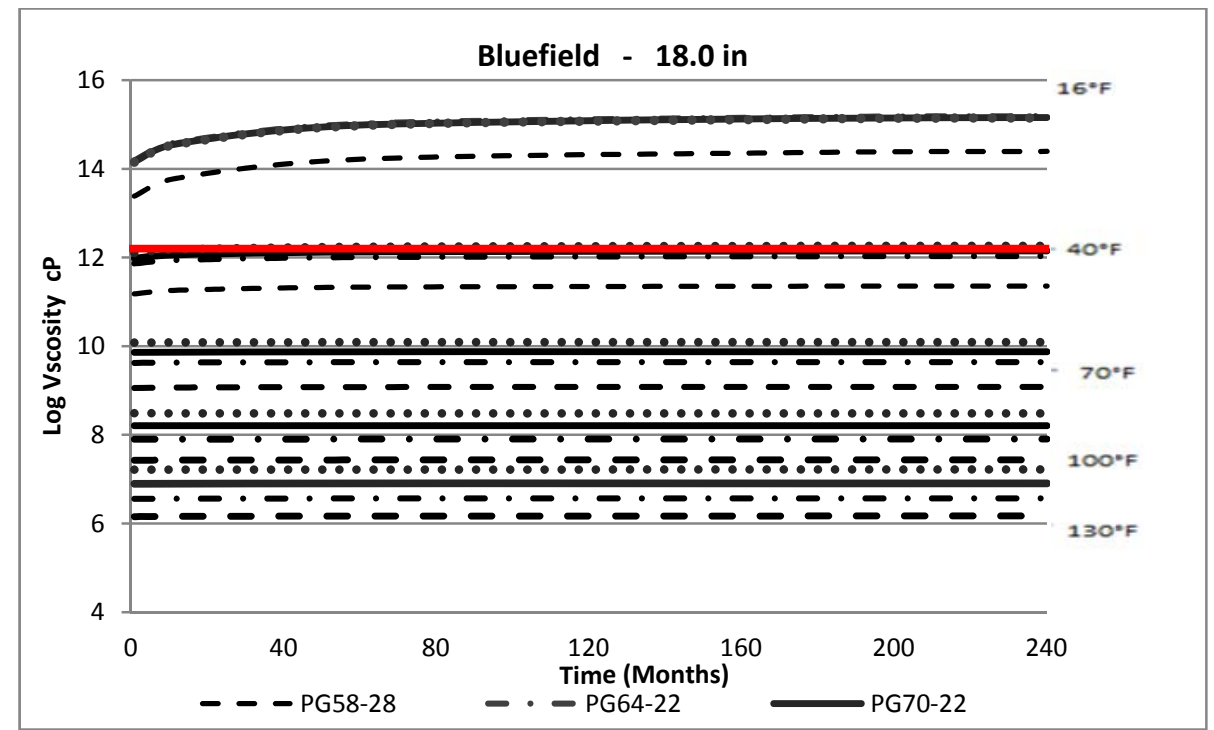

Figure 167: Aging effect on viscosity Bluefield at 18.0in

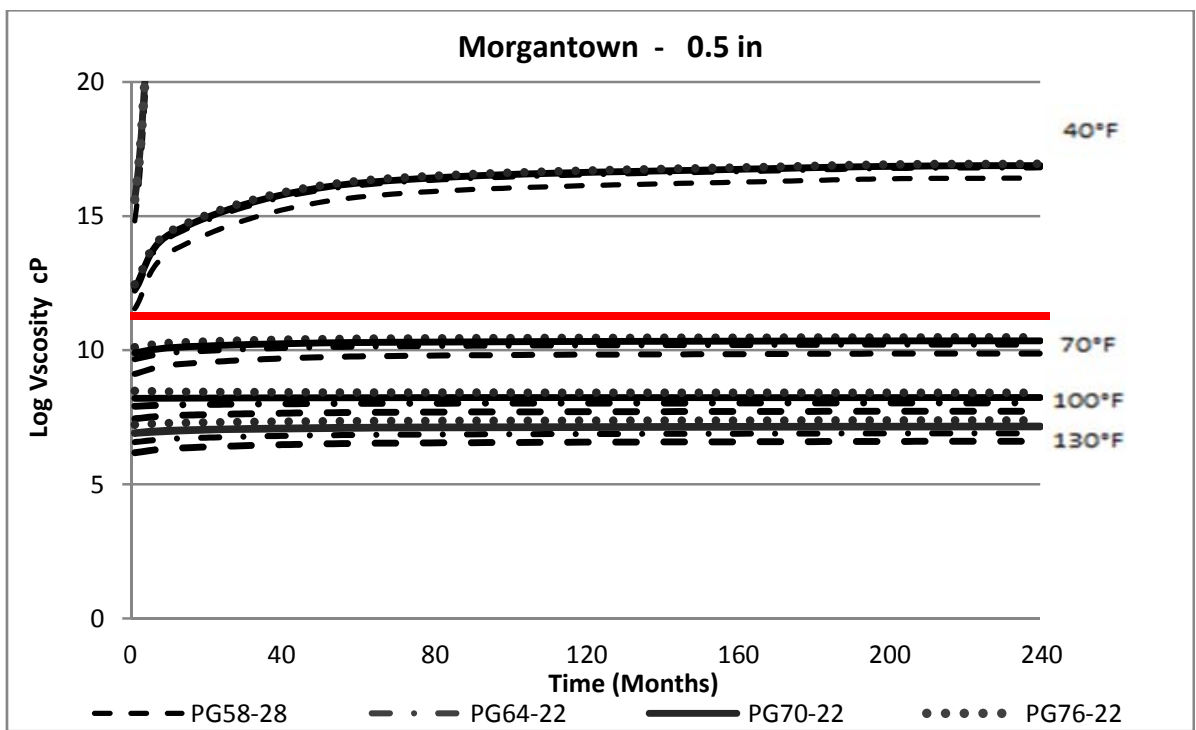

Figure 168: Aging effect on viscosity Morgantown at 0.5 in

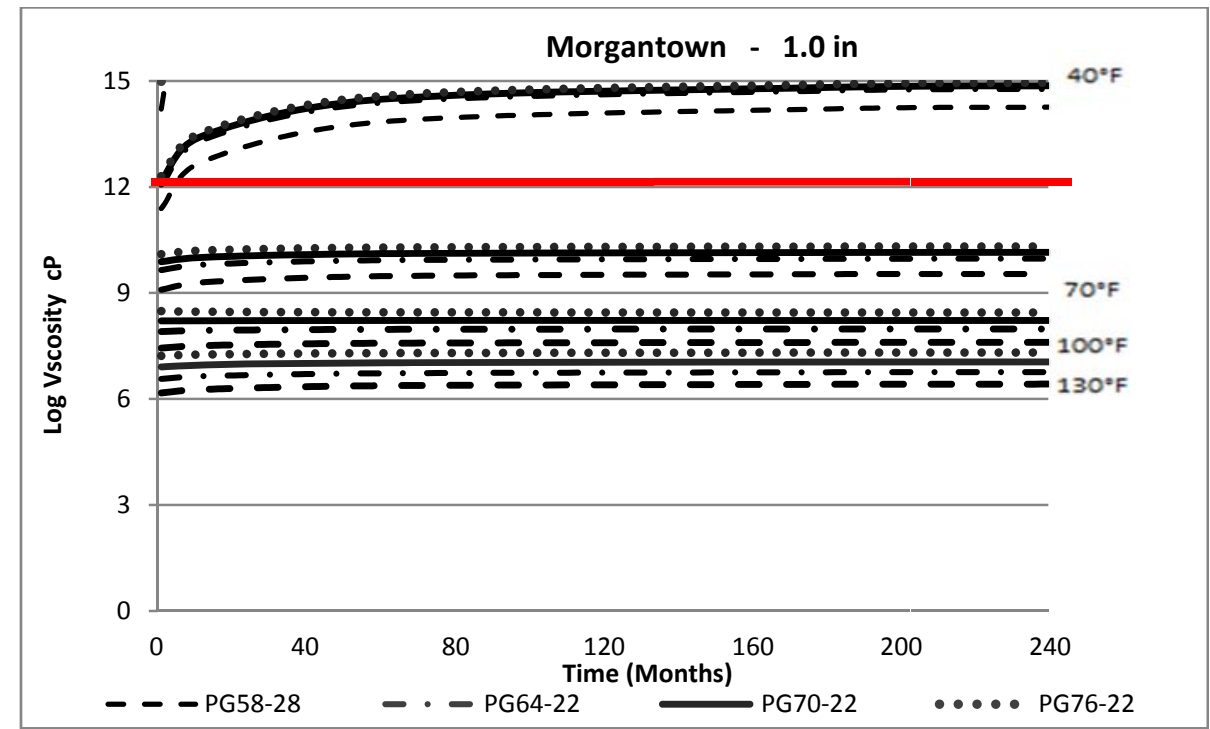

Figure 169: Aging effect on viscosity Morgantown at 1.0in 


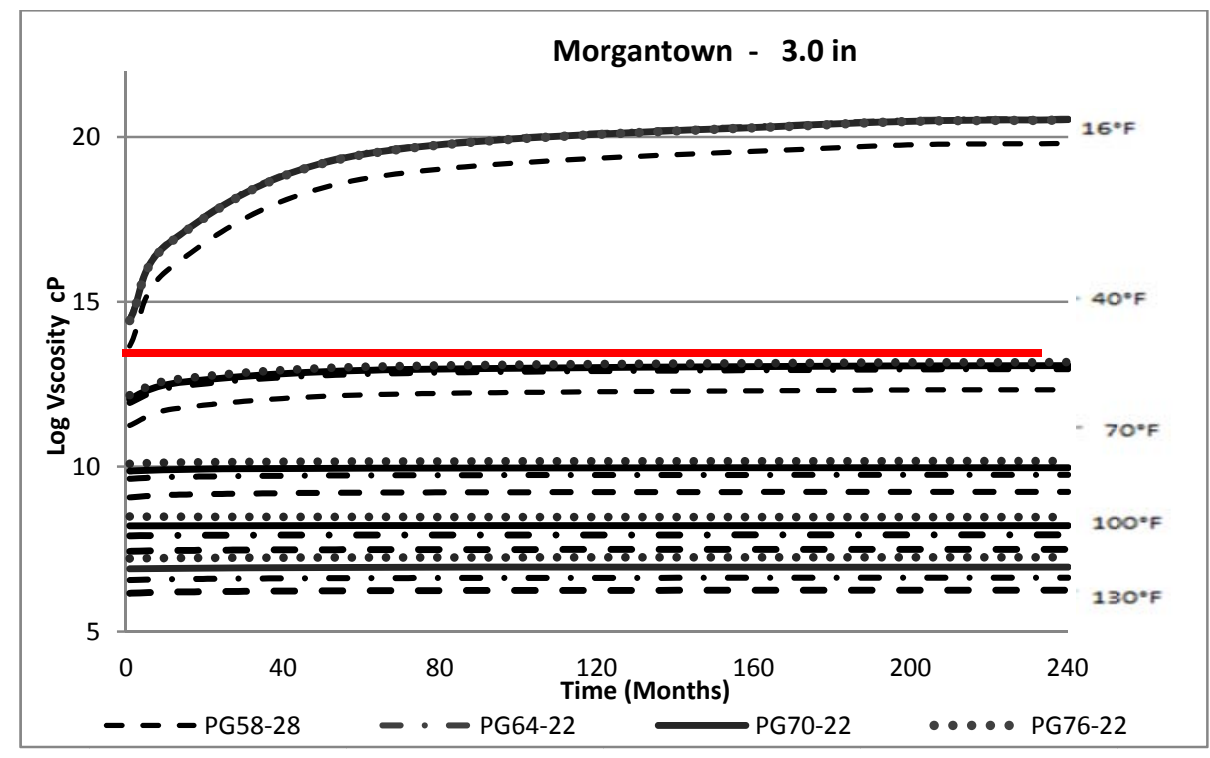

Figure 170: Aging effect on viscosity Morgantown at 3.0in

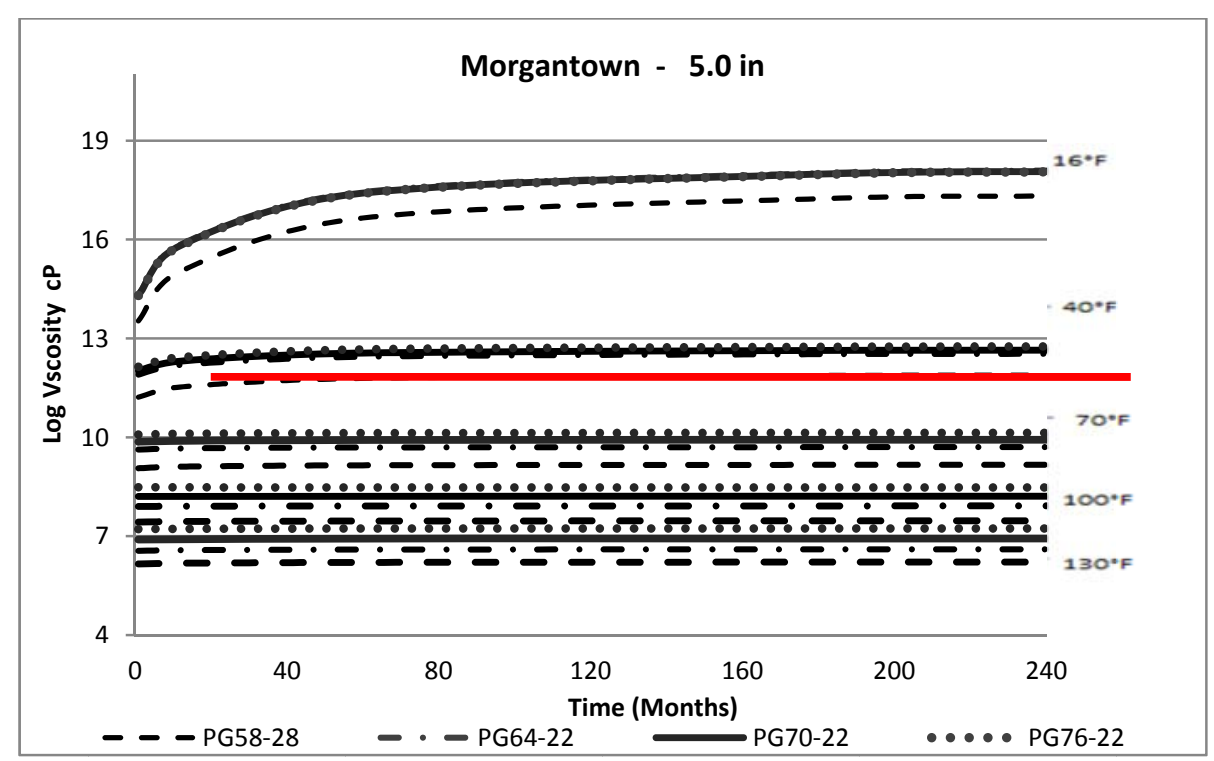

Figure 171: Aging effect on viscosity Morgantown at 5.0in

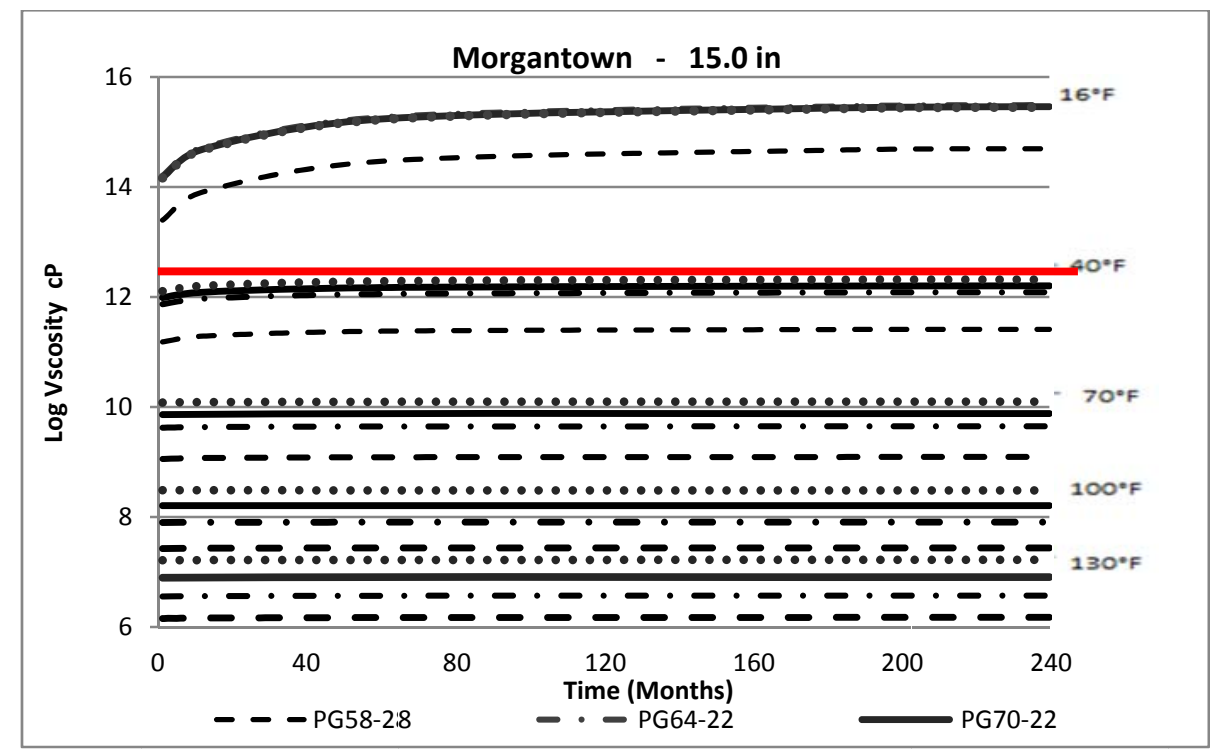

Figure 172: Aging effect on viscosity Morgantown at 15.0in

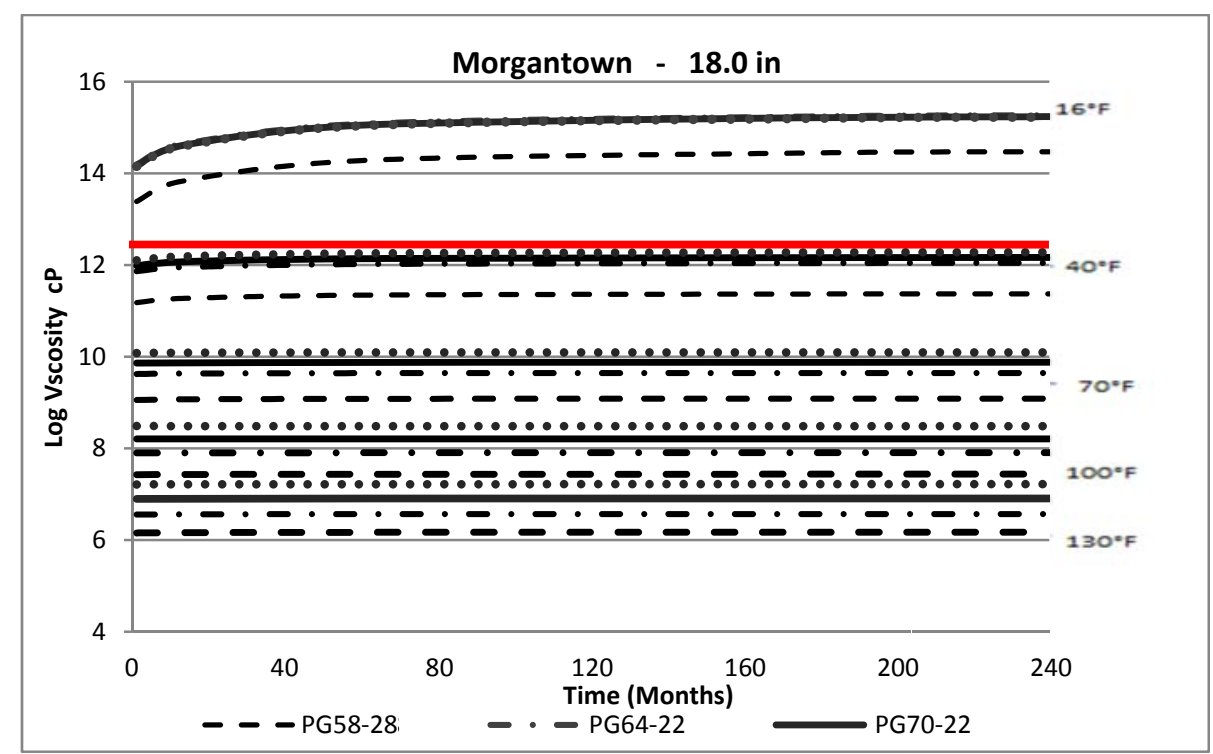

Figure 173: Aging effect on viscosity Morgantown at 18.0in 


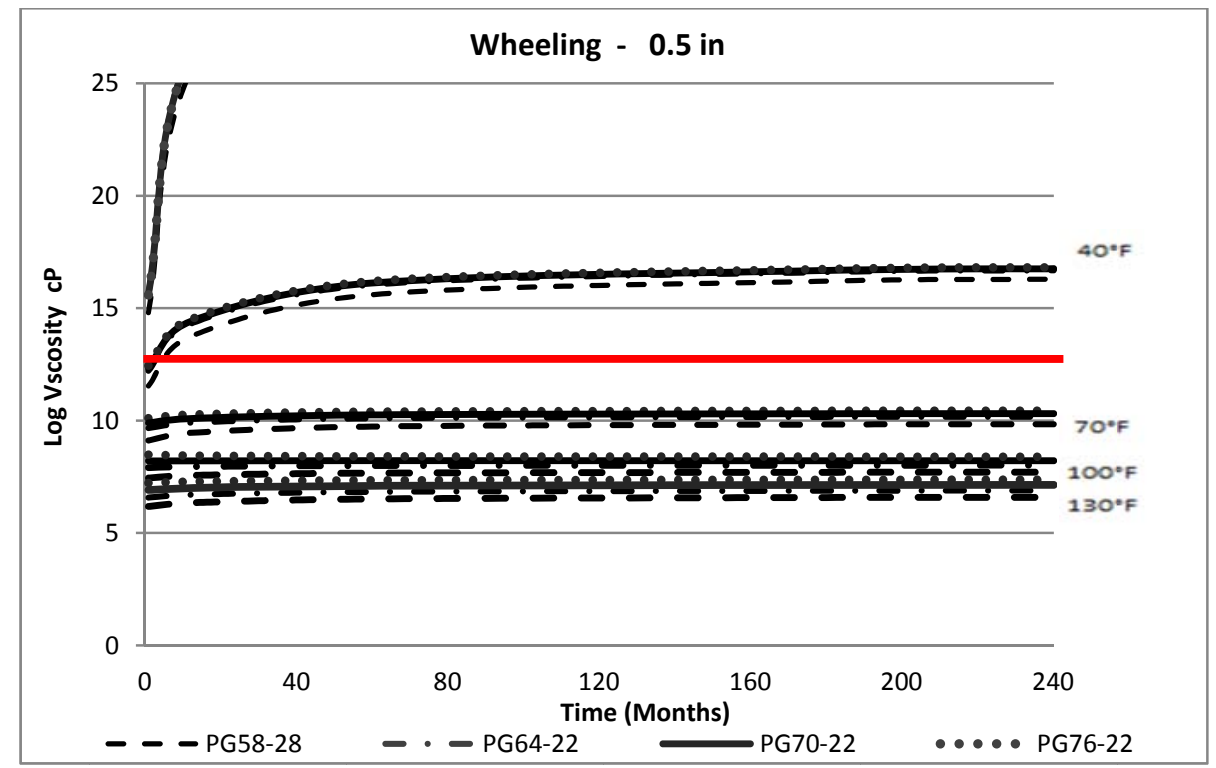

Figure 174: Aging effect on viscosity Wheeling at $0.5 \mathrm{in}$

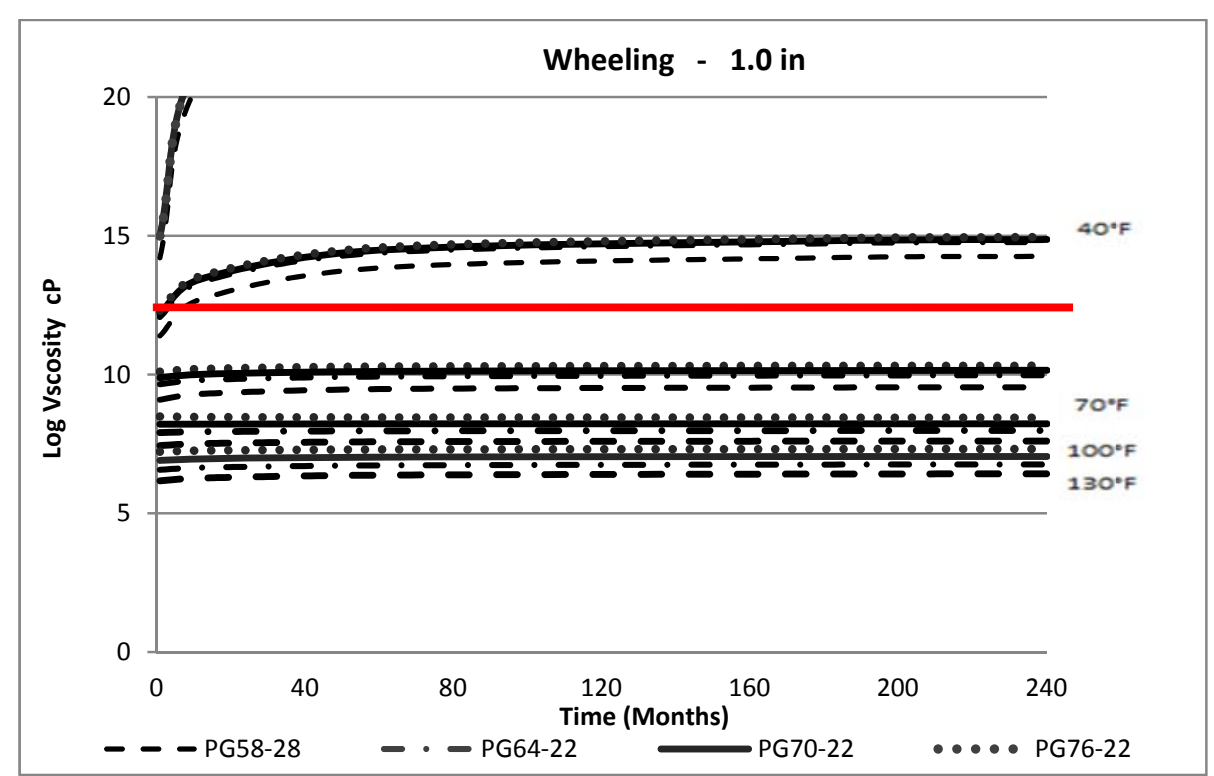

Figure 175: Aging effect on viscosity Wheeling at 1.0in

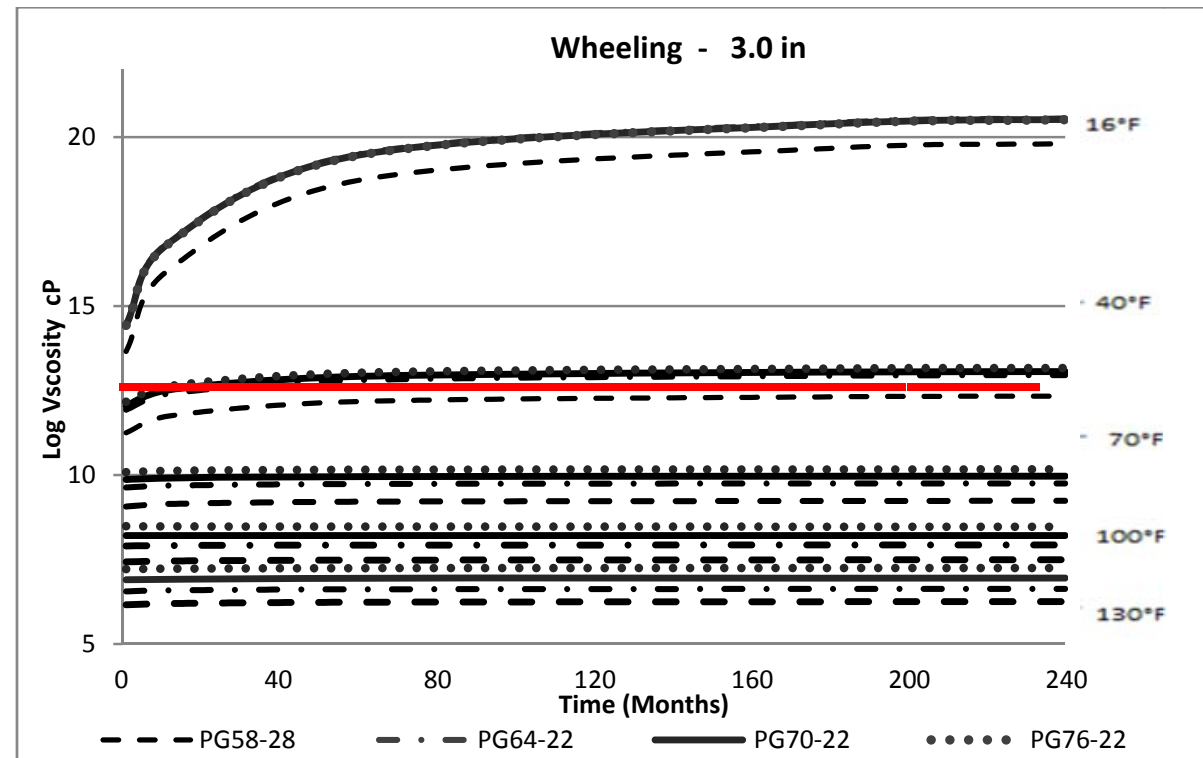

Figure 176: Aging effect on viscosity Wheeling at 3.0in

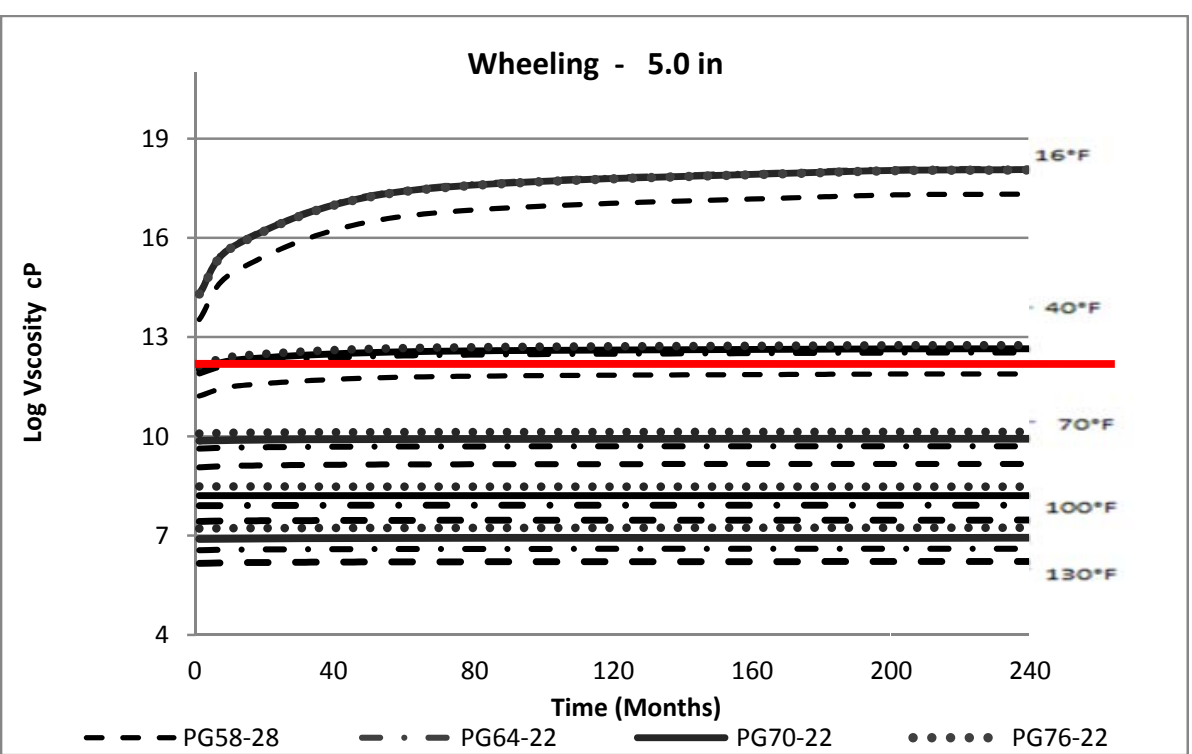

Figure 177: Aging effect on viscosity Wheeling at 5.0in 


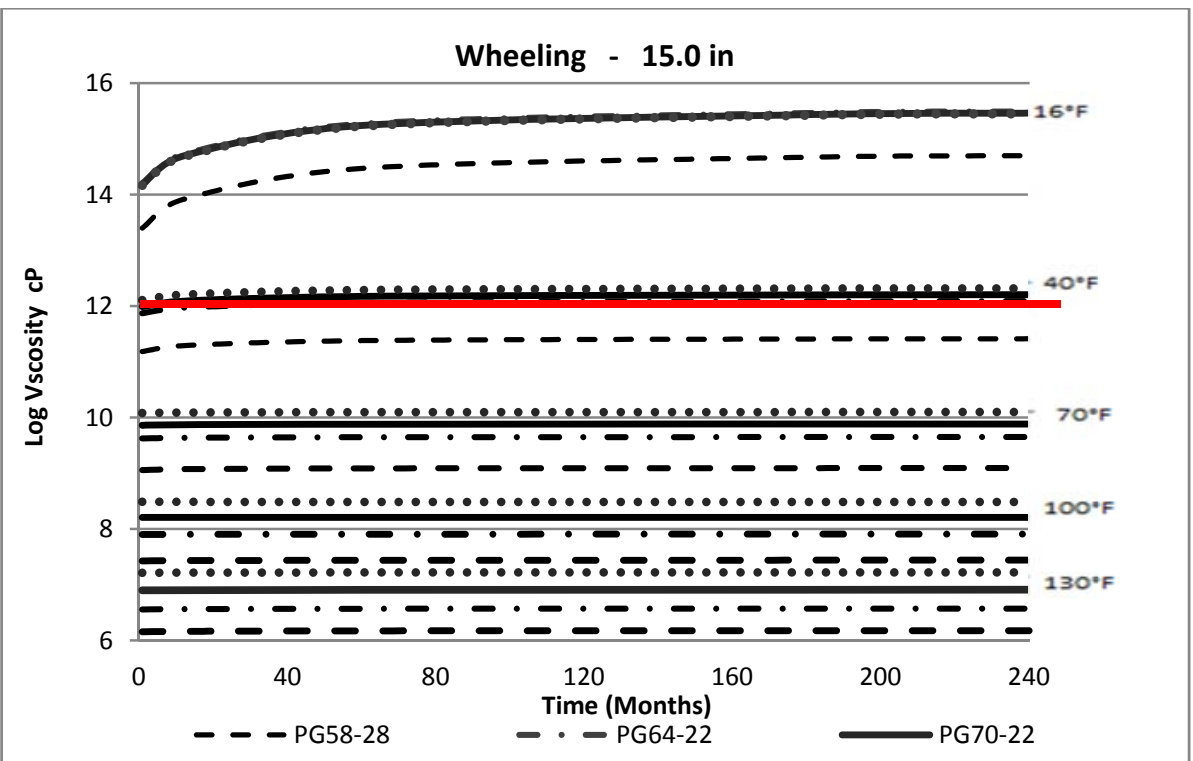

Figure 178: Aging effect on viscosity Wheeling at 15.0in

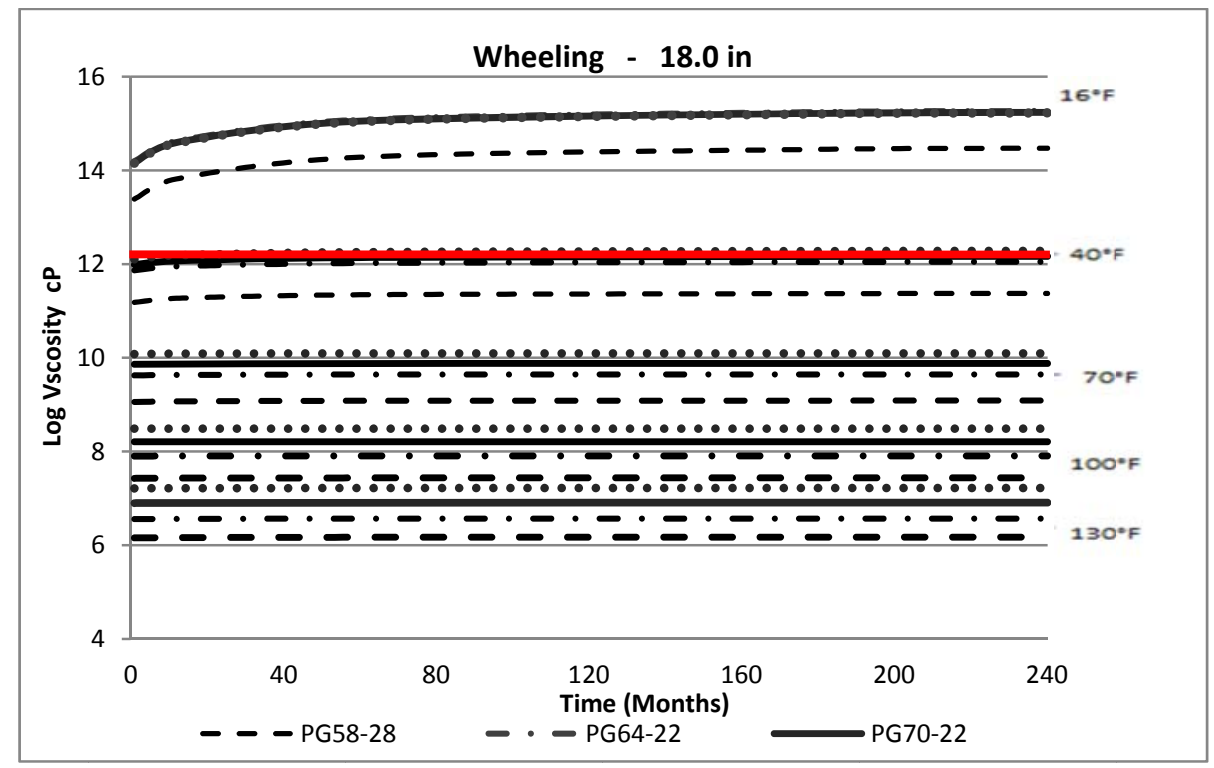

Figure 179: Aging effect on viscosity Wheeling at 18.0in

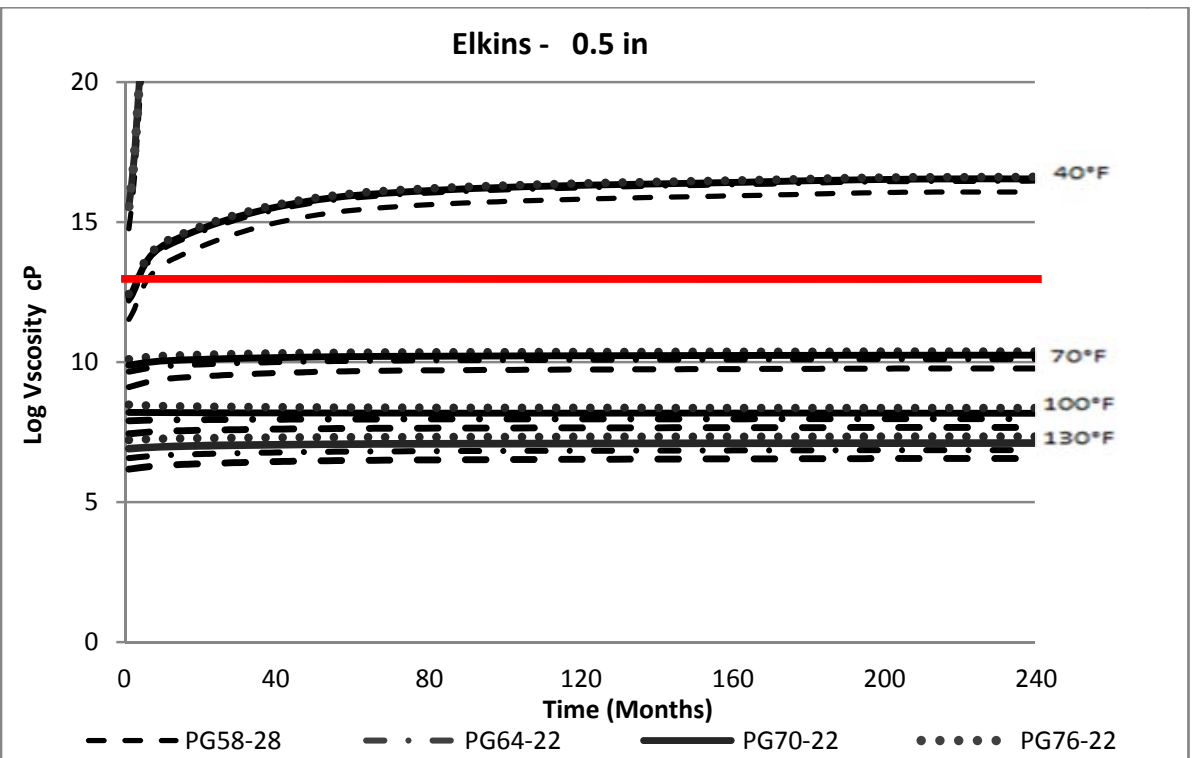

Figure 180: Aging effect on viscosity Elkins at 0.5 in

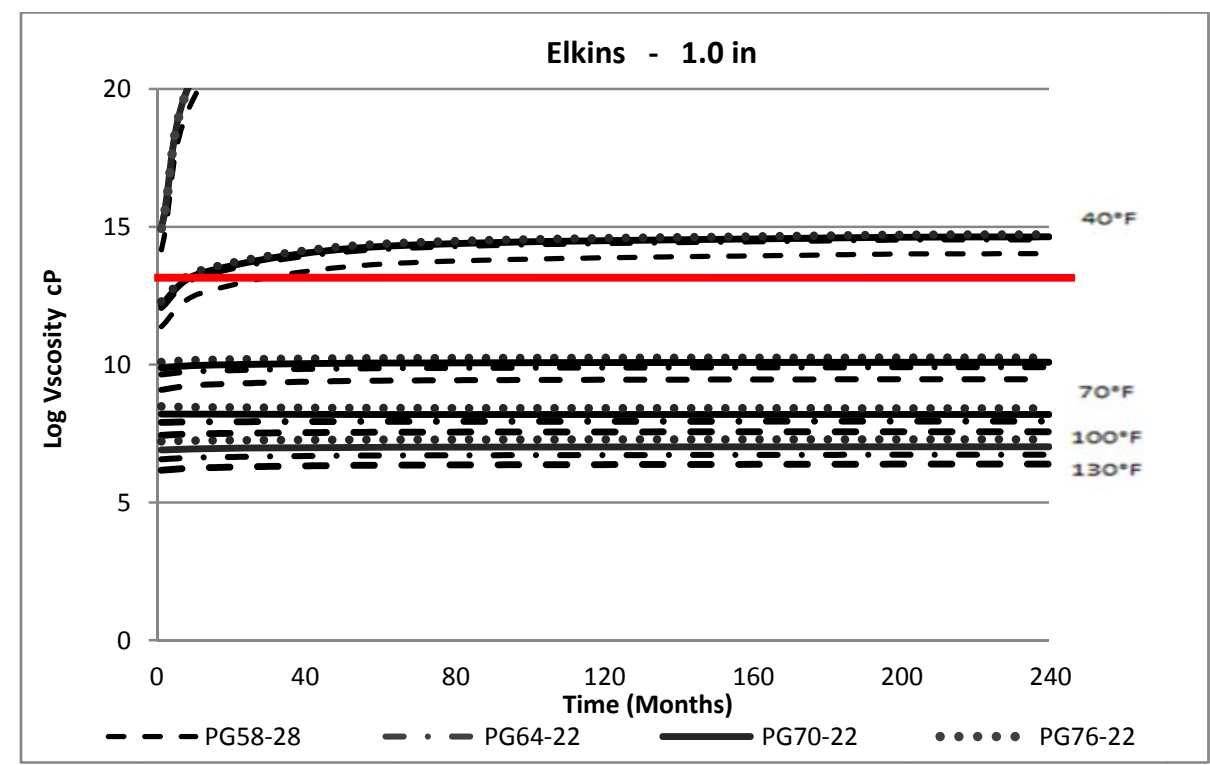

Figure 181: Aging effect on viscosity Elkins at 1.0in 

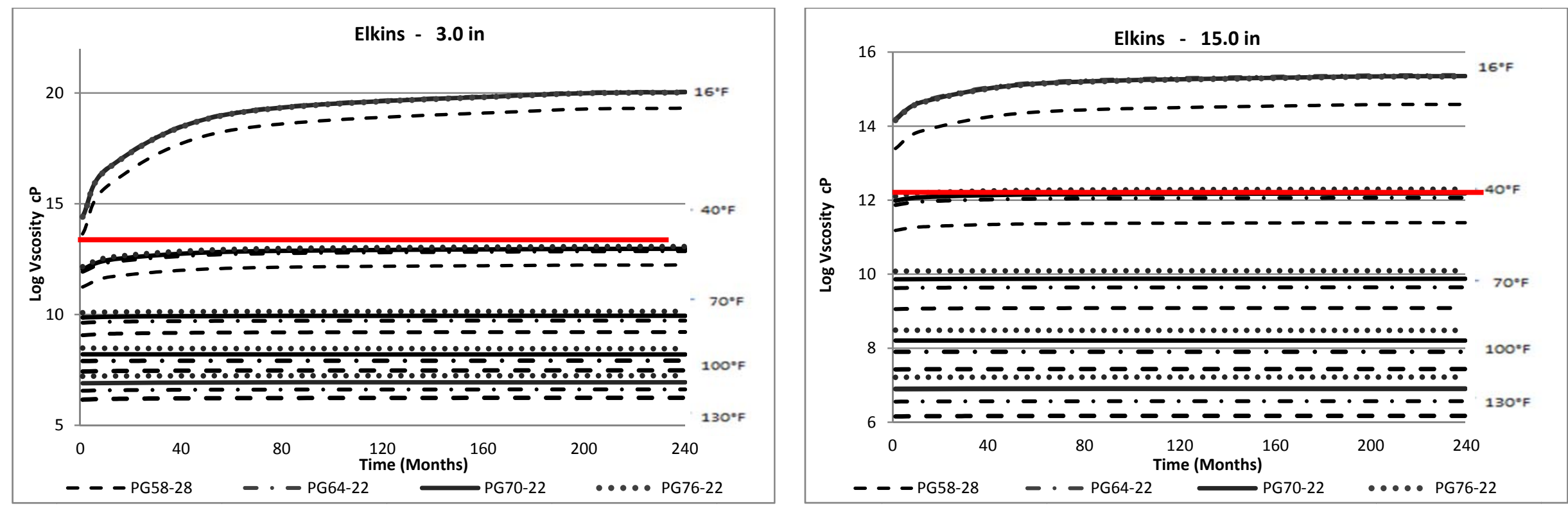

Figure 182: Aging effect on viscosity Elkins at 3.0in

Figure 184: Aging effect on viscosity Elkins at 15.0in
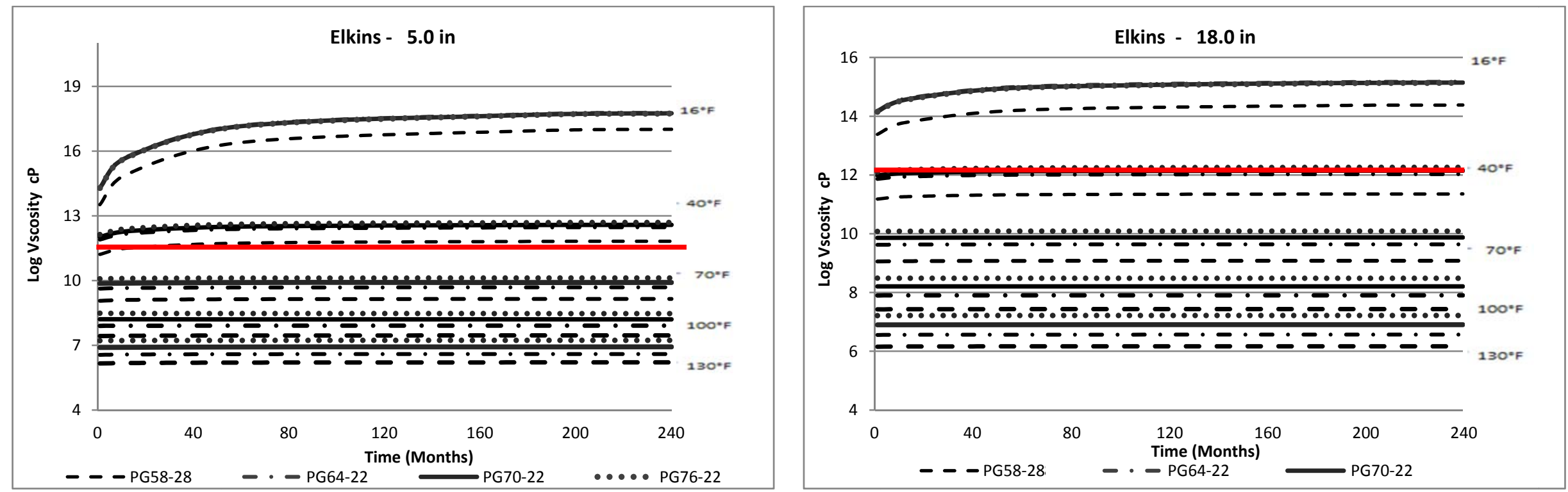

Figure 183: Aging effect on viscosity Elkins at 5.0in

Figure 185: Aging effect on viscosity Elkins at 18.0in 


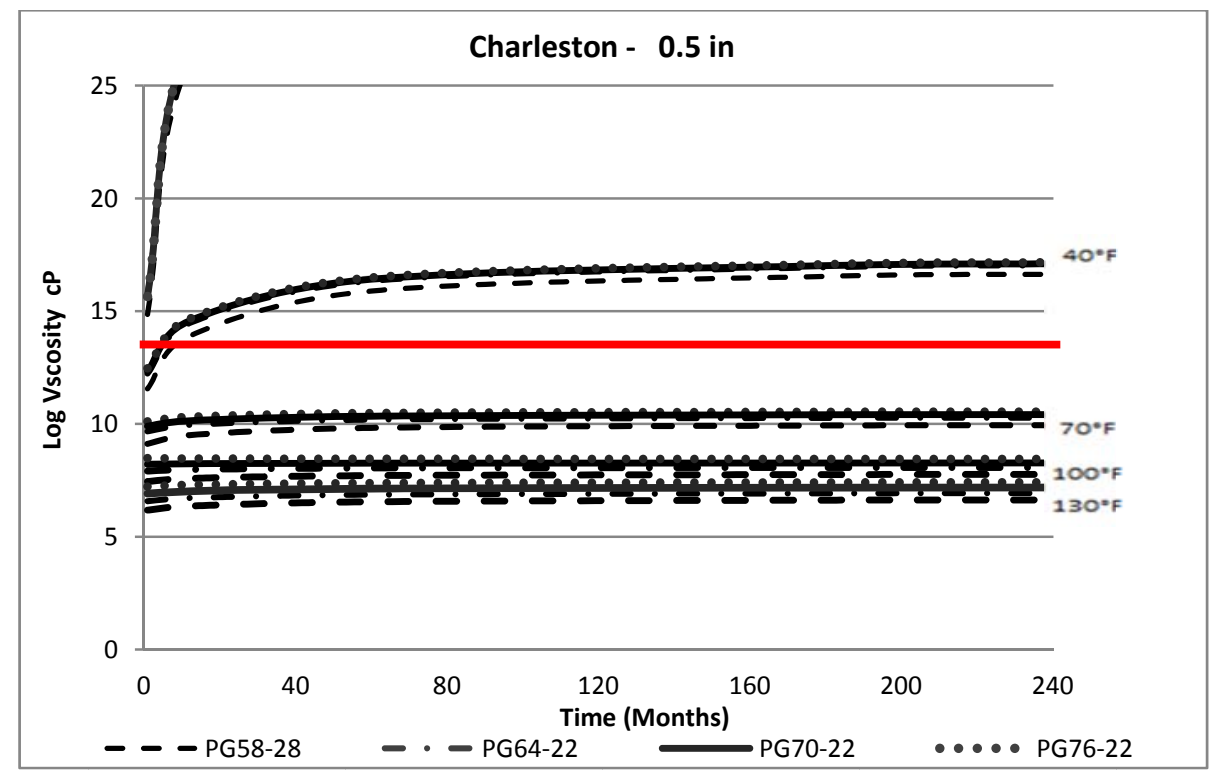

Figure 186: Aging effect on viscosity Charleston at 0.5 in

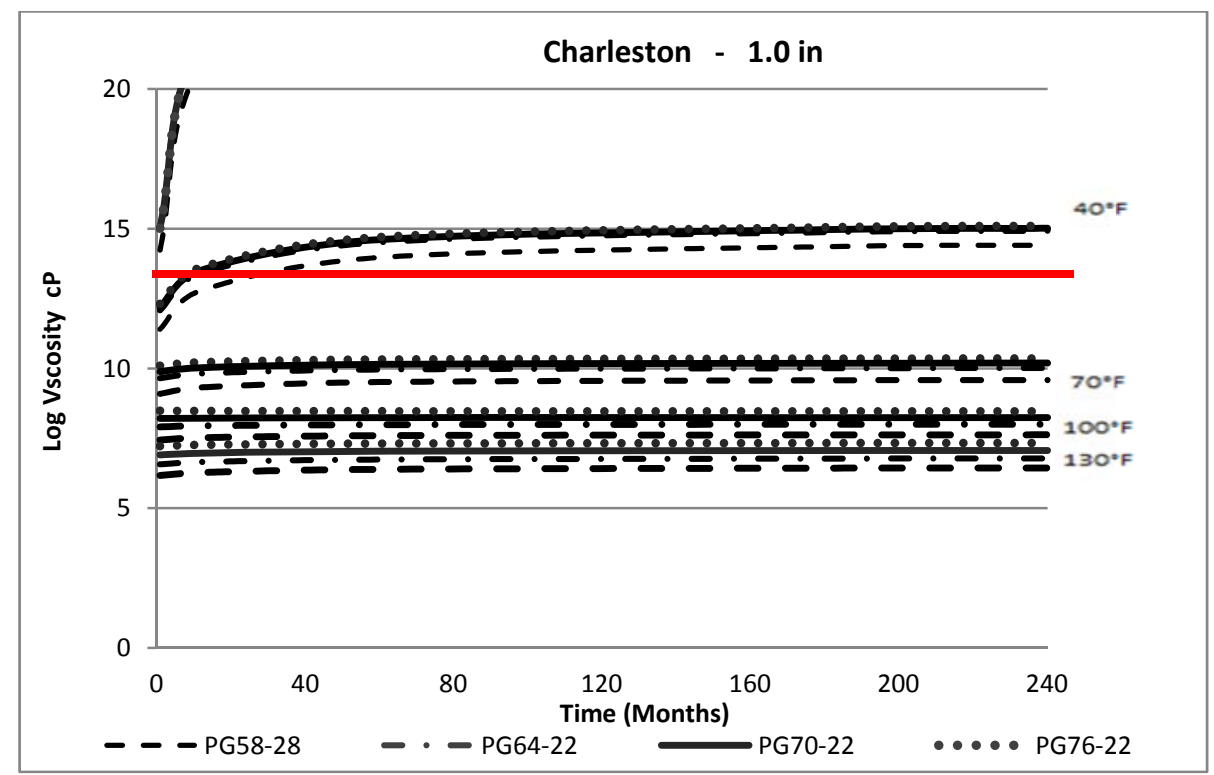

Figure 187: Aging effect on viscosity Charleston at 1.0in

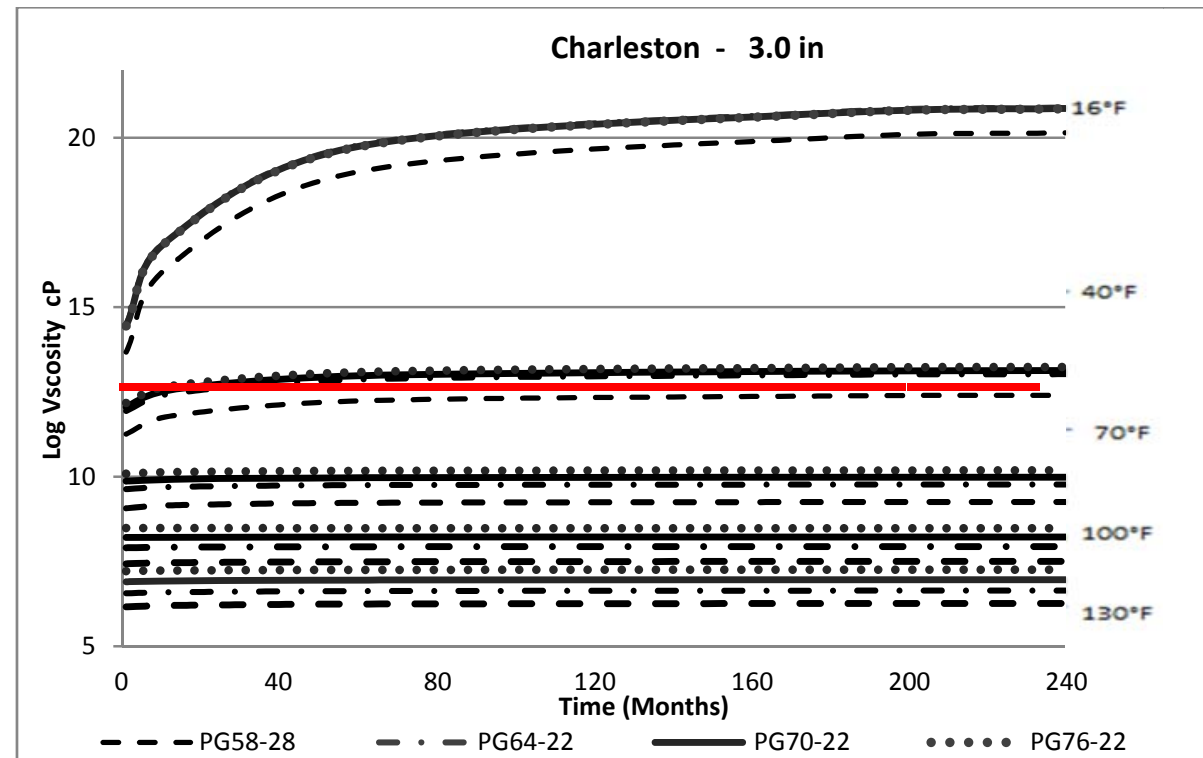

Figure 188: Aging effect on viscosity Charleston at 3.0in

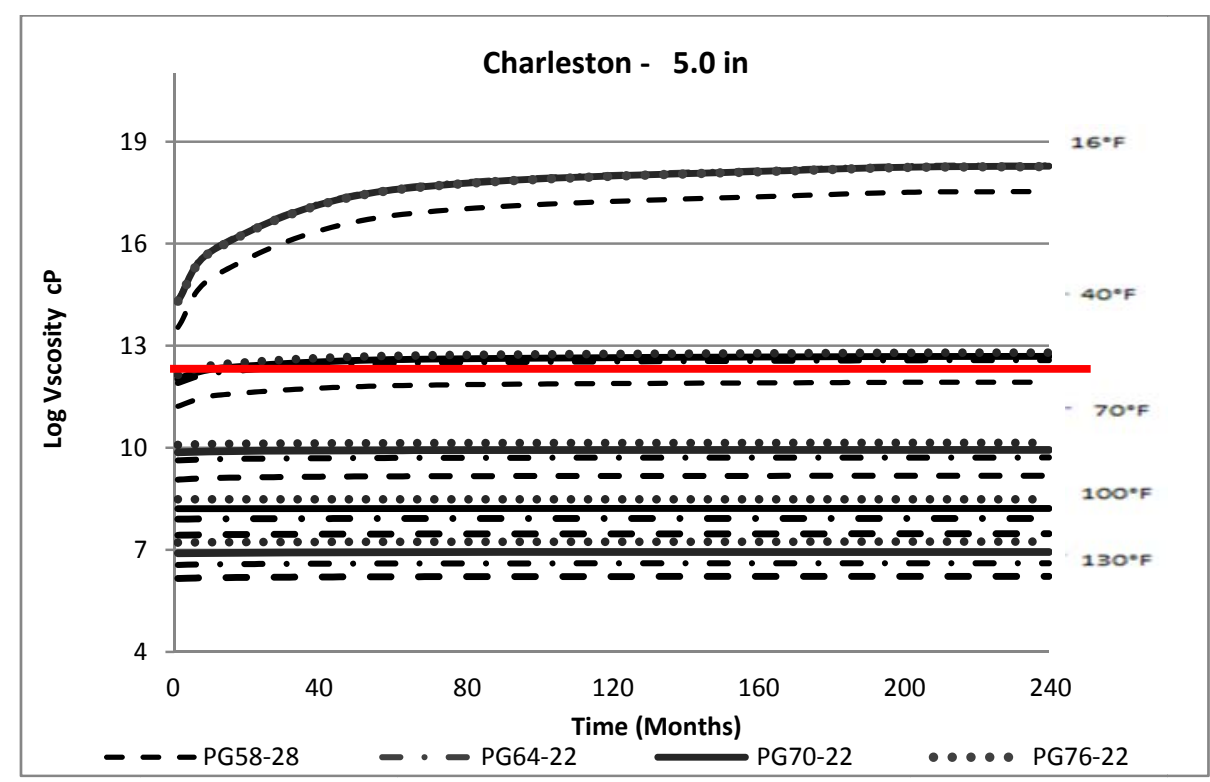

Figure 189: Aging effect on viscosity Charleston at 5.0in 


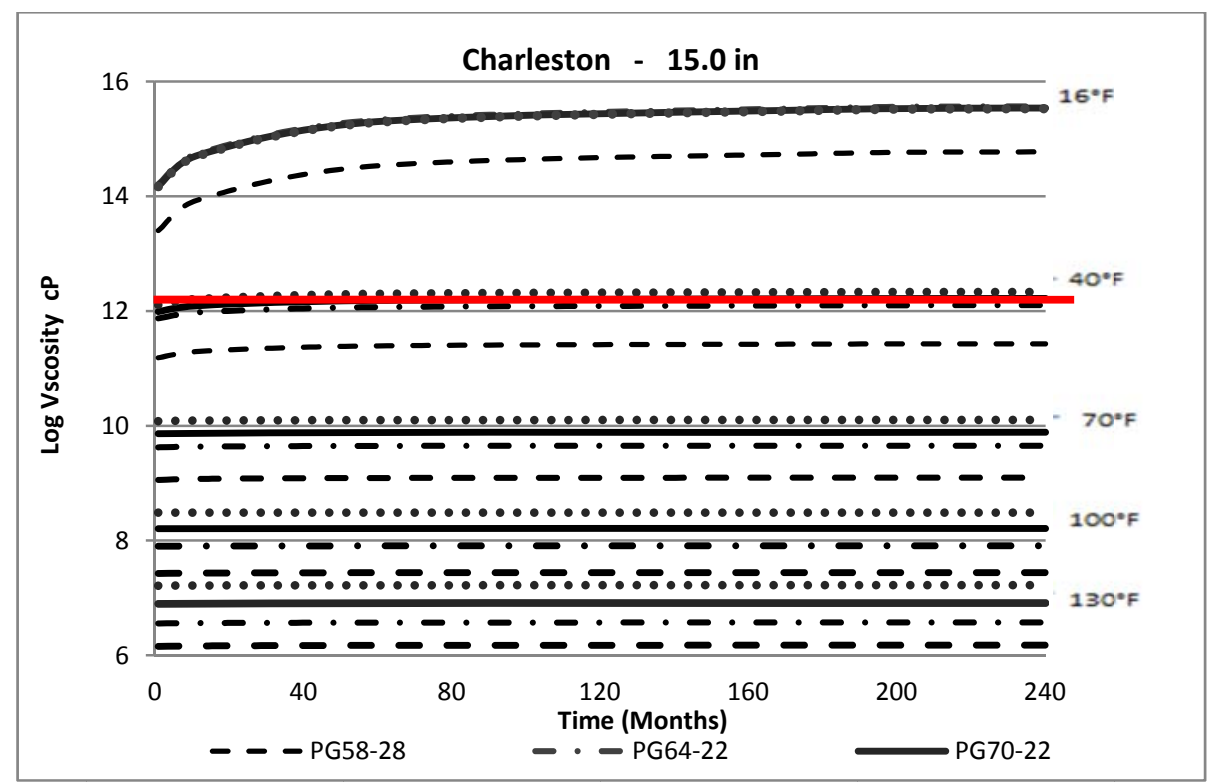

Figure 190: Aging effect on viscosity Charleston at 15.0in

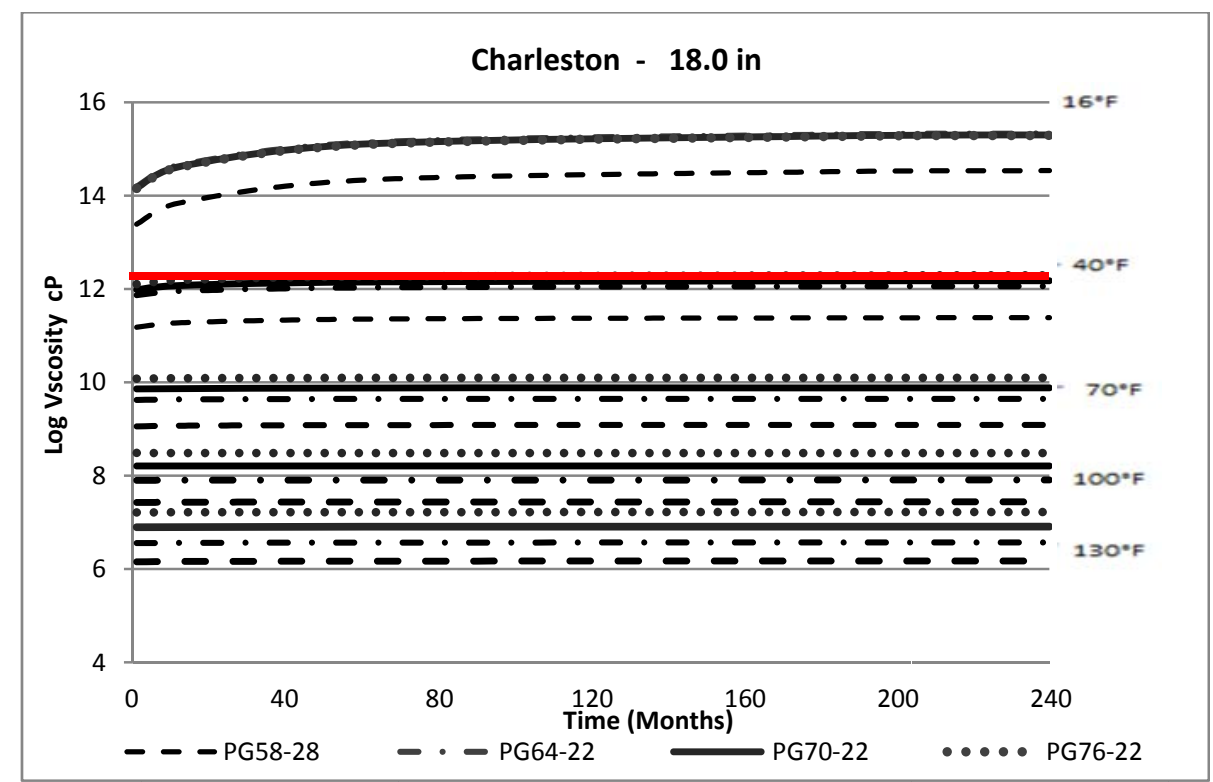

Figure 191: Aging effect on viscosity Charleston at 18.0in 